


\title{
EVERYTHING IS CONNECTED: AN INTERPRETIVE STUDY OF LOCAL ECONOMIC DEVELOPMENT IN SOUTH AFRICA
}

\author{
DISSERTATION
}

\author{
to obtain \\ the degree of doctor at the University of Twente, \\ on the authority of the rector magnificus, \\ prof.dr. H. Brinksma, \\ on account of the decision of the graduation committee, \\ to be publicly defended \\ on Wednesday $4^{\text {th }}$ of April 2012 at 16.45 hours
}

by

Hazel Mutsa Kwaramba

born on the 4th of December 1980

in Harare, Zimbabwe 
This thesis was approved by Prof. dr. Jon C. Lovett, promotor 
In de reeks Schone technologie en Milieubeleid worden milieuvraagstukken belicht vanuit wetenschappelijke visies op overheidsbeleid, technologie en management.

Deel 1 De effectiviteit van gemeentelijke milieubeleidsplanning F.H.J.M. Coenen

Deel 2 Bevordering van milieumanagement in organisaties T.J.N.M. de Bruijn en K.R.D. Lulofs

Deel 3 The feasibility of Dutch environmental policy instruments Josee J. Ligteringen

Deel 425 jaar milieubeleid in Nederland: instrumenten, incidenten en effecten R.A. van de Peppel, P-J. Klok en D. Hoek

Deel 5 The endurance of Mexican Amate Paper R. Citlalli López Binnquist

Deel 6 Sustained Diffusion of Renewable Energy Valentina Dinica

Deel 7 Water Governance and Institutional Change Stefan M.M. Kuks

Deel 8 Innovation and Institutional Change Peter S. Hofman

Deel 9 Transparancy in the Food Chain Agni Kalfagianni

Deel 10 Land Markets and Public Policy Wilbert Grevers

Deel 11 Corporate social Responsibility and Public Policy-Making Arno Mathis

Deel 12 Private Equity; Public Principle David Regeczi

Deel 13 Understanding how actors influence policy implementation Katharine A. Owens

Deel 14 Geruisloos Beleid Derek Jan Fikkers

Deel 15 The Power to Produce Annemarije Kooijman-Van Dijk

Deel 16 Join the Club! Johannes Boshuizen

Deel 17 Environmental Policy Integration and Energy Jørgen Knudsen

Deel 18 Werk in Uitvoering Jaap Evers

Deel 19 Supply Chain management for sustainable development Tanapat Sangaroon 
Colofon

(c) Hazel M. Kwaramba

University of Twente/School of Management and Governance/CSTM ISBN : 978-90-365-3355-3 


\section{Content}

List of tables, figures, pictures and maps vii

Acronyms ix

Xhosa $x$

Acknowledgements $\quad$ xi

Chapter One

Introduction $\quad 1$

$\begin{array}{lll}1.1 & \text { Background } & 1\end{array}$

1.2 Transformation in South Africa 2

1.3 The Role of Tourism in Transformation 2

1.4 Is the Past of South Africa Relevant? 4

1.5 The Problem Statement 7

$\begin{array}{ll}\text { 1.5.1 The academic challenge } & 7\end{array}$

1.5.2 The practical challenge 8

1.6 Theoretical Underpinning 8

1.7 Objectives 11

1.8 Research Questions 11

1.9 Methodology 12

1.10 Study Site - Case Study Description 12

1.11 Contributions to Knowledge 13

1.12 Thesis Outline 13

Chapter Two

Does the Past have a Place in Today and Tomorrow? 17

$\begin{array}{lll}2.1 & \text { Background } & 17\end{array}$

2.2 Development and 'Local Economic Development' 19

2.3 Tourism and Poverty Reduction in South Africa 21

2.4 Apartheid Socio-spatial Organization and Tourism Development 23

2.4.1 Commoditisation of Apartheid heritage for tourism 25

2.5 Theoretical Underpinning of the Study 28

2.5.1 Space 29

2.5.2 Network and culture 31

2.5.3 Conscientisation 33

2.6 The Study Setting 34 
2.6.1 The Knysna township tour 36

2.6.1.1 The tourist gaze $\quad 37$

2.6.1.2 The 'Lobola' episode 39

2.6.2 The Port Elizabeth township tour 40

2.6.2.1 Primary school visit $\quad 43$

2.6.2.2 Afternoon tea 44

2.6.2.3 Interview with tour company founder $\quad 44$

2.7 Discussion 45

2.7.1 Space and development 46

2.7.2 Discourses 47

2.7.3 Cultural hegemony 49

2.8 Reflections 53

$2.9 \quad$ Emerging Issues for Research 54

Chapter Three

Methodology $\quad 57$

3.1. Introduction $\quad 57$

3.2. Phenomenological Approach 57

3.3. Hermeneutics 58

3.3.1 Hermeneutic phenomenology 59

3.3.1.1 Pre-understanding $\quad 60$

3.3.1.2 Interpretive process 60

3.4 Research Model $\quad 62$

3.4.1 Relationship between economic empowerment and progressive human values $\quad 64$

3.4.2 Diffusion of entrepreneurship 66

$\begin{array}{lll}\text { 3.4.3 Significant qualities of a successful entrepreneur } & 67\end{array}$

3.4.4 Cultural commoditisation 68

3.5. Explication of the Data 70

3.5.1 Questionnaire evaluation 70

3.5.2 Interviews, discussions and transcription 71

3.5.3 Explication of observations 72

$\begin{array}{lll}\text { 3.6. Positionality } & 73\end{array}$

$\begin{array}{ll}\text { 3.6.1 Descriptions of experiences } & 74\end{array}$

3.6.1.1 My identity $\quad 74$

3.6.1.2 Belonging 76 
$\begin{array}{ll}\text { 3.6.1.3 Questions about purpose and research } & 78\end{array}$

$\begin{array}{lll}3.6 .2 & \text { Reflections } & 80\end{array}$

$\begin{array}{lll}3.7 & \text { Conclusion } & 82\end{array}$

Chapter 4

Challenges for Entrepreneurial Steering through Black Economic Wmpowerment Initiatives in South Africa

4.1. Introduction 85

4.2. Black Economic Empowerment 86

4.2.1 Black Economic Empowerment and tourism 88

4.2.2 Entrepreneurship and tourism 90

4.2.3 Women entrepreneurship 93

4.3. Data Collection 94

$\begin{array}{lll}\text { 4.3.1 Study context } & 94\end{array}$

4.3.1.1 Government funded home-stays $\quad 94$

4.3.1.2 Independent home-stays 95

4.3.2 Methodology 95

4.3.3 Data analysis 97

$\begin{array}{lll}\text { 4.4. } & \text { Results } & 97\end{array}$

4.4.1 Interview data $\quad 97$

4.4.1.1 Lack of skills and experience $\quad 97$

4.4.1.2 Black Economic Empowerment and prejudice 98

4.4.1.3 Dependency 99

4.4.2 Comparison of home-stays - Observations 100

4.4.2.1 Summary of home-stay experiences 100

4.4.2.2 Institutional arrangements 103

4.5. Discussion of Results 103

4.5.1 Women entrepreneurship in tourism home-stays 103

$\begin{array}{ll}\text { 4.5.2 Institutional arrangements } & 104\end{array}$

$\begin{array}{lll}\text { 4.5.3 Dependency } & 105\end{array}$

4.5.4 Constraints to Black Economic Empowerment 105

$\begin{array}{lll}\text { 4.5.5 Power and access } & 107\end{array}$

$\begin{array}{lll}4.6 & \text { Conclusions } & 108\end{array}$ 
Chapter Five

Evaluation of Local Tourism Development as a Tool for Women Economic Entrepreneurial

5.1 Background

5.2 Local Economic Development in South Africa

5.3 Tourism and Local Economic Development

5.4 Social Interdependence

5.5 Kwam eMakana Case Study

5.5.1 Methods

5.5.2 Results

5.5.2.1 Formulation

5.5.2.2 Household economic contribution from the home-stays

5.5.2.3 Implementation and operation

5.5.2.4 Monitoring and evaluation

5.5.2.5 Decision making process and ownership of the project 125

$\begin{array}{lll}5.6 & \text { Discussion of results } & 125\end{array}$

5.7 Conclusion 131

Chapter Six

Emotional Confidence Levels and Success of Tourism Development for Poverty Reduction: the South African Kwam eMakana Home-stay Project

6.1 Introduction

6.2 Tourism Development and South Africa 134

6.2.1 Tourism home-stay 135

6.2.2 Case description - Kwam eMakana 136

$\begin{array}{lll}6.3 & \text { Emotional Confidence } & 138\end{array}$

6.3.1 Emotional confidence and tourism development 139

$\begin{array}{ll}\text { 6.3.2 Emotional intelligence approach } & 139\end{array}$

$\begin{array}{lll}6.4 & \text { Methodology } & 140\end{array}$

$\begin{array}{lll}6.4 .1 & \text { Observations } & 141\end{array}$

6.4.2 Semi-structured Interviews 141

6.4.3 Questionnaire survey 142

6.4.3.1 Group discussion 142

6.4.4 Explication of the data 143

6.5 Results 143

$\begin{array}{lll}6.5 .1 & \text { Interviews } & 144\end{array}$ 
6.5.2 Observations 146

$\begin{array}{ll}\text { 6.5.3 Questionnaire } & 147\end{array}$

$\begin{array}{lll}\text { 6.5.3.1 Levels of education } & 147\end{array}$

$\begin{array}{ll}\text { 6.5.3.2 Distribution channels of Kwam } & 147\end{array}$

6.5.3.3 Emotional intelligence and discussion responses 147

$\begin{array}{ll}\text { 6.5.3.3.1 Self-awareness } & 148\end{array}$

$\begin{array}{ll}\text { 6.5.3.3.2 Social-awareness } & 149\end{array}$

$\begin{array}{ll}\text { 6.5.3.3.3 Self-management } & 149\end{array}$

6.5.3.3.4 Social-skills 150

$\begin{array}{lll}6.6 & \text { Discussion } & 151\end{array}$

6.7 Conclusion 154

Chapter Seven

Beyond Hosts and Guests: The Role of Indigenous Knowledge and Emancipative Beliefs in Negotiating Cultural Commoditization in Township Tourism 155

$\begin{array}{lll}7.1 & \text { Background } & 155\end{array}$

7.2 Cultural Tourism as a Means of Economic Diversification 157

7.2.1 The commodification process of culture in tourism 158

$\begin{array}{lll}7.2 .1 .1 & \text { Tourism as industry } & 158\end{array}$

$\begin{array}{lll}\text { 7.2.1.2 Significance of cultural resources } & 159\end{array}$

7.2.1.3 Tourism: Africa's culture industry 161

7.2.2 The role of food in cultural tourism 163

$\begin{array}{lll}7.3 & \text { Theoretical Underpinning } & 165\end{array}$

7.3.1 Indigenous knowledge approach 165

$\begin{array}{lll}\text { 7.3.2 Emancipative beliefs } & 167\end{array}$

$\begin{array}{lll}\text { 7.3.3 Study context } & 168\end{array}$

$\begin{array}{lll}7.4 & \text { Methodology } & 169\end{array}$

$\begin{array}{ll}\text { 7.4.1 The student overnight home-stay experience } & 169\end{array}$

$\begin{array}{lll}7.5 & \text { Results } & 171\end{array}$

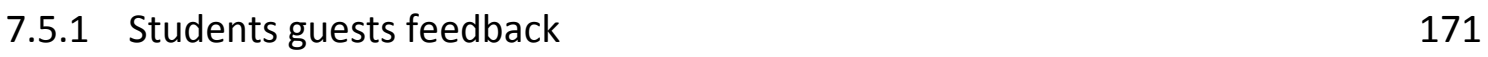

7.5.1.1 Interpretation of Table KL 171

$\begin{array}{lll}\text { 7.5.1.2 Interpretation of Table KK } & 173\end{array}$

$\begin{array}{lll}\text { 7.5.1.3 Interpretation of table KE } & 175\end{array}$

7.5.1.4 Integrated summary of tables $\quad 175$

7.5.2 Kwam eMakana hosts' feedback - Informal discussions 176

$\begin{array}{lll}\text { 7.5.3 Post home-stay visit workshop } & 177\end{array}$ 
$\begin{array}{lll}7.6 & \text { Discussion } & 178\end{array}$

$\begin{array}{lll}\text { 7.6.1 Staged authenticity } & 178\end{array}$

$\begin{array}{ll}\text { 7.6.2 Culture as a product } & 181\end{array}$

$\begin{array}{lll}7.7 & \text { Conclusions } & 184\end{array}$

Chapter Eight

Conclusions and Recommendations $\quad 185$

$\begin{array}{lll}8.1 & 185\end{array}$

8.2 Methodology 186

$\begin{array}{lll}\text { 8.3 Problem Statement } & 187\end{array}$

$\begin{array}{lll}8.4 & \text { Key Findings } & 188\end{array}$

$\begin{array}{lll}8.5 & \text { Recommendations } & 194\end{array}$

8.5.1 Institutional arrangements that promote synergy 195

8.5.2 Emotional intelligence and conscientisation 197

8.5.3 Contributions to Academic Knowledge 198

8.5.4 Areas for future research 201

References $\quad 203$

$\begin{array}{ll}\text { Summary } & 227\end{array}$

Summary in Dutch 233

Appendices:

Appendix 1: Home-stay facilities $\quad 239$

Appendix 2: Economic Theory $\quad 242$

Appendix 3: Summary of the differences between traditional and modern Xhosa food 247

Appendix 4: Research Instrument A $\quad 249$

Appendix 5: Research Instrument - Observations 12256

Appendix 6: Research Instrument - Observations $2 \quad 257$

Appendix 7: Research Instrument 258

Appendix 8: Research Instrument - Discussion Session 259

About the author $\quad 260$ 


\section{List of tables, figures, pictures and maps}

\section{List of tables}

Table 2.1 The National Guidelines for Responsible Tourism 22

Table 2.2 Guiding Principles for Economic Responsibility 22

Table 2.3 Knysna reality tour participants 36

Table 2.4 Port Elizabeth reality participants $\quad 41$

Table 3.1 Summary of differences between research assumptions 61

Table 3.2 Data Collection Methods 62

Table 3.3 Data Collection Strategy 63

Table 4.1 Objectives of Broad-based Black Economic Empowerment Act and Principles Of BEE Model $\quad 87$

Table 4.2 Research Methods 96

Table 4.3 Comparison of home-stay visits 100

Table 4.4 Home-stays'Characteristics 102

Table 4.5 Home-stays entrepreneurial performance 103

Table 5.1 aims of the Kwam eMakana project, Makana LED goals and Makana $\begin{array}{ll}\text { Tourism Vision } & 119\end{array}$

Table 5.2 Kwam eMakana 2009 Festival Period Revenue Statement 122

Table 5.3 Household Economic benefits of Kwam eMakana 122

Table 5.4 Kwam eMakana 2009 budget 124

Table 6.1 Emotional Intelligence Competency scores of Kwam eMakana women tourism Homestay operators 148

$\begin{array}{lll}\text { Table 7.1 Composition of Student Groups } & 170\end{array}$

Table 7.2 Group KL - Student perceptions of home-stay overnight experience 172

Table 7.3 Group KK - Student perceptions of home-stay overnight experience 174

Table 7.4 Group C - Student perceptions of home-stay overnight experience 174

Table 8.1 The process of conscientisation in Kwam eMakana 198

\section{List of figures}

Figure 1.1 Theoretical Map 9

Figure 2.1 Transformative praxis 33

Figure 2.2 Conscientisation in South Africa township tour participants 53

Figure 3.1 Research Model 64 
Figure 5.1 Social interdependency as foundation for other theories

\section{List of pictures}

Picture 2.1 Informal settlement in Knysna Township

Picture 2.2 Showing a Reconstruction and Development Programme housing

Picture 2.3 Luxury housing in South Africa

Picture 7.1 Dinner at Kwa Lulu's

\section{List of maps}

Map 2.1 South Africa showing positions of study areas; Knysna, Port Elizabeth and Grahamstown

Map 4.1 Map of South Africa showing positions of Grahamstown and Port Elizabeth 


\section{Acronyms}

$\begin{array}{ll}\text { BEE } & \text { Black Economic Empowerment } \\ \text { BBBEE } & \text { Broad-based Black Economic Empowerment } \\ \text { DEAT } & \text { Department of Environment and Tourism } \\ \text { DPLG } & \text { Department of Provincial and Local Government } \\ \text { DSRAC } & \text { Department for Sports Recreation and Culture } \\ \text { DTI } & \text { Department for Trade and Investment } \\ \text { EI } & \text { Emotional Intelligence } \\ \text { GDP } & \text { Gross Domestic Product } \\ \text { IMF } & \text { International Monetary Fund } \\ \text { IT } & \text { Information Technology } \\ \text { LED } & \text { Local Economic Development } \\ \text { MDG } & \text { Millennium Development Goals } \\ \text { NGO } & \text { Non-Governmental Organization } \\ \text { PARIS } & \text { Pan African Research and Innovation Services } \\ \text { PDI } & \text { Previously Disadvantaged Individuals } \\ \text { PPT } & \text { Pro-poor Tourism } \\ \text { RDP } & \text { Reconstruction Development Programme } \\ \text { SMME } & \text { Small Medium Micro Enterprises } \\ \text { ST-EP } & \text { Sustainable Tourism for Eliminating Poverty } \\ \text { TALC } & \text { Tourism Area Life Cycle } \\ \text { UN } & \text { United Nations } \\ \text { UNCTAD } & \text { United Nations Conference on Trade and Development } \\ \text { UNESCO } & \text { United Nations Educational, Scientific and Cultural Organization } \\ \text { UNWTO } & \text { United Nations World Tourism Organization } \\ \text { USP } & \text { Unique Selling Point } \\ & \end{array}$




\section{Xhosa/ South African Translations}

$\begin{array}{ll}\text { Amagwinya } & \text { Fat Cakes } \\ \text { Chisa Nyama } & \text { Barbeque } \\ \text { Kunjani sisi? } & \text { How are you sister? } \\ \text { Mna sikhonile } & \text { I am fine } \\ \text { Sangoma } & \text { Herbalist/Traditional Healer } \\ \text { Shabeen } & \text { Tavern } \\ \text { Sisi } & \text { Sister }\end{array}$


"I searched around the world and I found myself"

Beyonce

DEDICATION

I dedicate this work to my whole family. To my maternal grandmother a woman of amazing strength, a remarkable woman who raised my mother and me. To my mother an achiever beyond remarkable odds through your achievements you gave me permission to be me. My paternal grandmother a quiet woman with a heart so warm and filled with love. To my amazing father for the gift of confidence and unconditional love and showing me the value of hard work. To my grandfathers the men who taught me the value of truth in all things. To the rest of the family thank you for showing me the true value and worth of family and to always start from a place of love. I know truly understand that "the apple does not fall far from the tree".

"All that I am is who I have always been"

-Mukunda wekwa Kwaramba, Muzukuru wa VaDzuda na VaMusesengwa, muera Maposanungu; Vamambo, akazvarwa nemukunda wekwa Musesengwa, muera Moyo Chirandu.- 
"Success is not measured by what you accomplish but by the opposition you have encountered, and the courage with which you have maintained the struggle against overwhelming odds."

-Orison Swett Marden-

I offer my sincere gratitude to my promoter and supervisor Prof. Dr. Jon Lovett, who supported me throughout my thesis with his patience and knowledge whilst allowing me the room and total freedom to work on my own. I attribute my completion to his encouragement without it this thesis, would not have been completed or written. As my supervisor, he provided the necessary criticism and advice and this actually encouraged me to continue even when I was close to abandoning everything.

The development of the ideas in this thesis were greatly influenced by interviews and conversations, both formal and informal, with government officials, private-sector representatives, independent researchers, friends and family in South Africa and Zimbabwe, and I am grateful for their willingness to discuss their views on Southern African local economic development strategies and African identity with me. Many of the formal interviews would have probably not taken place without the help of the Stenden Community Development office who assisted in establishing the right contacts and therewith greatly contributed to the successful completion of two rounds of fieldwork in the Eastern Cape Province. My gratitude is also extended to Dr. Wouter for accepting me as visiting fellow at Stenden South Africa. Alroi Taai and Juliet Chipumuro I acknowledge your assistance in introducing me to the academic and local economic development world in South Africa and for providing research support by granting unconditional access to the sources of Kwam eMakana. Without the cooperation of the Kwam eMakana women this study would not have seen the light of day. I will also like to especially acknowledge Lelethu Ngoma for allowing me access into all areas of the home-stay project and taking time out of her busy schedule to drive me around and to answer all my questions. Additionally, all her efforts to introduce me to officers involved in the project and local economic development practitioners; Zukiswa, Nebha and Gwen in the province are gratefully acknowledged. I am also thankful for the friendship that we developed over the years since my first field visit - this will last a lifetime. I am thankful for the help received from the ten student translators who translated the questionnaire and discussion session into impeccable Xhosa for the Kwam eMakana women. The staff and students of Stenden South Africa created such a supportive and inspiring environment.

Thank you to Prof. Dr. Larry O'Toole, Dr. Van Amerom and Dr. Skutch for the critical comments at different stages of the study your reviews truly opened up my way of thinking. Dr. Coenen I am grateful for all the support and smoothing over of numerous issues that arose. Talks over lunch or in offices with friends and colleagues were also very helpful, thanks are due to Joy, Irna, Thomas and Magi. Over the years I met so many people at CSTM that have become great friends and provided numerous moments for laughter, in my early years I would like to thank Annick, Vivek, Lucy, Grace, Tanapat, Libasse and Bhaskar. Thank you to Gul for the readings that provided lighter moments during some very turbulent times. Vicky for always sharing funny stories and encouraging me to push on no matter what. Thank you to Maya for allowing me to talk about everything that I wanted to say (which we all know is a lot!) and laughing and 
seeing the lighter side of things always. In the very final days of my writing I met Nthabi thank you for the discussions, poems and laughter, without knowing you gave me permission to write on my experiences in your country. Thanks are also due to Barbera for all the chats at the coffee machine, every time we would bump into each other we would laugh about all the girly things I love so much. Ada, Monique and Anniemiek always made sure that all my comings, stays and goings were arranged smoothly, I am very grateful for all the behind the scenes support.

A great number of people deserve special mention for their help and support over several years, which came in many different forms and guises, and without which this research project could neither have been started nor completed. I am eternally grateful to my parents for their faith in my abilities and endless patience and financial support over the years - I am so grateful for your commitment to giving the best education from a very young age. Kudzai, simply put thank you for being the best little sister and a true friend, your outlook to life inspires me and you gave me strength to continue when I was really tired. I also want to thank my brothers. I am thankful for all the encouragement and assistance that I received from my all of my family (all of you cousins, aunts, grandparents and uncles - far too many to mention by name) throughout the years. Thanks are due to Prof. Dr. Hughes, Dr. Knowles and Dr. Roberts for communicating your confidence in my abilities and encouraging me to pursue doctoral studies. Professor/Diplomat Mutunhu has been not only a source of support and advice during the year I was working from Southern Africa but also (and probably unknowingly) always knew the right thing to say at the right time to keep me going at this thesis. My sincerest appreciation is extended to his wife Judy Mutunhu for welcoming me into her gallery, home and kitchen our non-scientific discussions on food and art during my visits provided just the right balance. Waleed thank you for all your efforts in my participation in the ARSCP-6 in Cairo, you are a good friend, through you I also met Omnia and Sarah who have become very great friends with whom much laughter is always shared when we meet - I fondly remember our most recent meeting in Amsterdam earlier this year.

My good friend Anthony who took care of me especially after my return from Zimbabwe and provided scientific support that culminated in a co-authored paper. Your positive outlook to life sustained me during this very challenging time and thank you for always welcoming me to your home - my African haven in Enschede. I am so grateful for all your support and advice and I am truly humbled by your loyalty - I truly treasure our friendship. I would like to express my appreciation to our circle of friends - Maja, Eze, Ekpo, Chris, Tiblet and Firew - for providing a homely community and always looking out for me and ensuring that all my needs were met including throwing parties in my honour when I was travelling. Omy and Kinxli I met you at the end but I laughed so much in your company, thank you (mhenn its 10 over 10 for real, Correct!). Tawanda I remember you fondly and how we used to dance, your insistence on there is no problem that good music and dancing cannot solve remains with me today Sahwira makakora, your belief in me and never die outlook was so pivotal to my completion. Nadine has been a source of inspiration through some of the darkest moments of this study, always available to listen to my concerns with the most sound of advice, always swiftly followed by a good glass of beverage. Thank you for always welcoming me into your home be it in Enschede, Groningen or most recently Berlin. You provided a haven for me a place where I 
could escape scientific worries - you are so dear to me. I would like to extend my thanks to Michael and Evelyn Gyampo who welcomed me into their home and provided a transit home in Johannesburg during my trips to conferences and Zimbabwe. Shelton and Nyarie thank you for being good and understanding friends always seeing the lighter side of things, and never growing tired of my thesis related complaints. Michelle you need a medal for enduring all my 'venting' almost on a daily basis about all my PhD blues for we met during them and you managed to stay through all of them. You made Capetown a home for me always opening your door, there are many memories there especially my favourite spots Mzoli's and the Biriyani Warehouse - I cherish our friendship. My Port Alfred girls; Thando, Shika, Mawue and Ntlalo thank you so much for the validation you put everything in perspective, you girls also brought out my free spirit, I found my love for music and dance again - you made fieldwork so much fun (Gudzengad!). Irene thank you for your love and support and teaching me that asking for help does not show weakness - I do not have to do everything by myself because I have good friends to lean on. Mary a remarkable woman of strength I am honored to have you for a friend, I gain strength from you. Sanja and Margot Gohre I remain indebted to you for your assistance so long ago that opened so many opportunities for me. I also want to extend thanks to my friends from Geneva - Grace and Gwinyai thank you for all the support through this arduous process that started so many years ago, always cheering me on. Nana thank you for always telling me the truth, you encouraged me to finish and now you have Hazel back! Nankhonde thank you for showing me what I could become if only I dared to believe it. From my time in Manchester I am grateful to Funmi, Sola, Mel, George, Maxim, Suman and Bibi for sharing the most enjoyable of university years with me. Candice, Lepang, Melissa, Chido and Laureen my childhood friends thank you for always encouraging me to follow my dreams and your constant support throughout this $\mathrm{PhD}$ journey.

I know I have left out a lot of people, names could not come to me at this moment but in my heart I am eternally grateful for all your support. Thank you all.

Funding for the research was provided by ASPC through the award of a research grant commencing in January 2008. Financial support for the fieldwork conducted in South Africa was provided by Stenden South Africa and CSTM. 


\section{Chapter One}

\section{Introduction}

\subsection{Background}

The purpose of this introductory chapter is to present the aim and general context of the study. This encompasses an interdisciplinary framework and the interrelationship of tourism and local economic development (LED) for poverty reduction. This research is much wider than tourism and LED; it includes issues about poverty and its alleviation; and explores some of the intricacies of poverty of South Africa - a contentious debate without a doubt. The adoption of a historical perspective is intended to provide an understanding of how former structures still influence developmental goals. This study is about the tourism-LED nexus in South Africa with a special focus on 'broad-based black economic empowerment' (BBEE) or as it is commonly referred to Black Economic Empowerment (BEE). BEE is an example of national development policy targeted at empowering marginalized communities, while the Kwam eMakana pilot project is the operationalized form of BEE within the national LED framework and study setting for this thesis. The study seeks to understand the dynamics of local government and project level realities that enable or hinder the realization of $\mathrm{BEE}$. It is an interdisciplinary attempt to analyze the role of tourism in South Africa's post-apartheid transformation process and to engage in current discourses on tourism and LED by applying a conscientisation approach.

The chapter introduces background information concerning tourism and the transformation agenda in South Africa. The government's commitment to 'developmental local government' (Rogerson 2002) through LED is particularly relevant for understanding the current tourism-LED nexus in South Africa thus it is introduced in this chapter but covered in more detail in Chapters 4 and 5 presenting the empirical results. Then it discusses the underpinning notion of analysis grounded in the viewpoint that the psychological trauma of the individual is also a central factor in the attainment of BEE through LED initiatives. In this view conscientisation in the tourism development process forms the conceptual context for the study and different theories within the South African tourism-LED nexus are discussed. Finally, the structure of the entire thesis and the major arguments in each chapter are provided. 


\subsection{Transformation in South Africa}

South Africa forms a country where fundamental socio-political transformations continue to take place (Rogerson 2004; Southall 2007; Jauch et al. 2009). The concept of transformation in South Africa refers to the process of transforming a society by demolishing the socio-economic structures established by apartheid policy (Andreasson 2010). Redressing the apartheid legacy of the domination of business ownership by the white minority and the exclusion of the black majority from economic activity was one of the key visions articulated by the Reconstruction and Development Programme (RDP) - the blueprint for the country's democratic transformation (Rogerson 2002; Kaplan 2004). It is based on the notion that reconstruction and development are parts of an integrated process, incorporating growth, development, reconstruction, redistribution and reconciliation into a unified programme (Department of Environmental Affairs and Tourism [DEAT] 1996). Therefore, as described by Janis (2010) transformation is explicitly linked to unequal power relations as the colonial legacy in post-apartheid societies. Transformation is a process that takes place in the entire society (DEAT 1996; 1998) over a prolonged period because of embedded institutional arrangements and the effects of childhood education that last through adulthood, and concerns all economic sectors (Benell 1999).

\subsection{The Role of Tourism in Transformation}

The critical question is what does tourism have to do with poverty and LED in South Africa? (Chapter 5). The promotion of tourism has been identified as a key strategy that can lead to economic growth, community development and poverty alleviation in developing countries (Scheyvens 2002; Buhalis and Costa 2006; Dredge and Jenkins 2007; Hall 2008; Jensen 2010). Before going further it is necessary to define the concepts tourism and LED. According to Sharpley (2009: 149), "tourism is an inherent part of the processes of production and consumption aiming at economic profits inherent in modern capitalism". Therefore, tourism can be conceptualised as "a global process of commodification and consumption involving flows of people, capital, images and cultures" (Meethan 2001: 4). The World Bank (2011) describes LED as "the purpose of LED is to build up the economic capacity of a local area to improve its economic future and the quality of life for all. It is a process by which public, business and nongovernmental sector partners work collectively to create better conditions for economic growth and employment generation". In 2006 Mufumandi minister of 
Provincial and Local Government in his foreword of The National Framework for Local Economic Development (2006 - 2011), he emphasised that "all economic development takes place at the local level and Local Government must influence the shape and direction of local economies if the national economy is to attain the goals set for it and if it is to grow and create a better life for all its residents". In the South African context, the government in its national development goals, views the notion of long-term process of structural transformation as an integral part of its democratic ideals where emphasis is placed on evolving from a nation characterized by high inequity levels to one where all citizens are economically empowered with a high level of human welfare (Mbeki 2004). Hence the government particularly supports those previously disadvantaged by apartheid.

In view of these challenges tourism emerged as a significant development option in post-apartheid South Africa (Binns and Nel 2002). The White Paper on the Development and Promotion of Tourism (1996; hereinafter referred to as White Paper) described the political transformation from the apartheid era as having in effect 'opened' the country's tourism potential to the world. In 2002 The South African DEAT concluded that tourism still played a relatively small role in the South African economy. It explained that a lot had to be done in order to fulfil the potential; to significantly contribute to national income and poverty alleviation (DEAT 2002). DEAT (2002) also argued that traditionally, the main focus of the government had been on the growth of international arrivals and total foreign exchange earnings. Not on fostering entrepreneurial opportunities for the historically, disadvantaged, poverty relief, employment and LED. On a global scale tourism has risen to one of the world's most powerful socio-economic forces, with 924 million international tourists in 2008 and an expected 1.6 billion by 2020 (United Nations World Tourism Organisation [UNWTO] 2009).

Telfer and Sharpley (2008) introduced a concept 'tourism-development dilemma', which refers to cases in which tourism is attractive as a means of stimulating social and economic development, but development often fails to materialise and comes with significant costs to local communities (Chapter 5 and Chapter 7). Nevertheless, tourism as a tool towards poverty reduction is increasingly gaining popularity (Hall 2008; Jensen 2009; Magi 2010). It is argued that it increases the economic viability of marginalised areas, therefore stimulating social regeneration and improving living conditions of whole communities (Janis 2010). At the same time, there has been much criticism about how tourism as an industry prioritises the commercial virtues of an international business, (Jensen 2009) yet rarely addressing local development needs 
such as entrepreneurial economic empowerment (Chapter 4) through the proliferation of small micro medium enterprises (SMME). Case studies of tourism provide few credible answers to the fundamental policy question; how can developing countries harness tourism as a tool to promote entrepreneurial economic empowerment? This puts the tourism LED debate in South Africa in a rather interesting place. Tourism is already important for the country. Its contribution to growth and exports is not contested. Its contribution to the lives of the poor however, is more disputed and variable (Binns and Nel 2002; Briedenhann and Wickens 2004; Karamata and Gwari 2007; Magi 2010).

In its Global Report on Women in Tourism 2010, the UNWTO continues to urge governments to maximise the potential of tourism for eradicating poverty by developing appropriate strategies in co-operation with all major groups, including indigenous and local communities especially women. In South Africa the Tourism Growth Strategy 2008-2010 economic growth, employment creation, poverty reduction, $\mathrm{BEE}$, ecological and environmental sustainability, and reduction of regional development inequities are mentioned as central to realizing long term national development objectives. Tourism in South Africa has been (Ferrario 1986; Mosola 2003) and continues to be (Magi 2010), faced with a number of impediments to further its growth and development. One of the critical challenges in tourism remains the limited involvement of the historically neglected groups and their inadequate training and education presents a further challenge (Magi and Nzama 2009). The emphasis of this study is on establishing how the previously disadvantaged can attain entrepreneurial economic empowerment through LED tourism. Many studies (Briedenhann and Wickens 2007; Rogerson 2007; Telfer and Sharpley 2008; Jensen 2009; Boonabana 2010; Janis 2010) show that in developing countries tourism is regarded as an important, but controversial, development and poverty reduction strategy and therefore it deserves full attention in the field of development studies. This study highlights some of the issues that require more research within tourism and LED research.

\subsection{Is the Past of South Africa Relevant?}

According to Jaffe et al. (2005) psychological and emotional trauma emanate from a humiliating or deeply disappointing experience, regardless of its source, emotional trauma contains three common elements; 1) it was unexpected the person was unprepared there was nothing the person could do to prevent it from happening; 2 ) It 
is not the event that determines whether something is traumatic to someone, but the individual's experience of the event and 3 ) it is not predictable how a given person will react to a particular event. By adopting an underpinning notion of analysis grounded in the viewpoint that the psychological trauma of the individual is a central focus in the South African transformation agenda. The study takes into consideration claims that apartheid created circumstances for feelings of incompleteness and inferiority among blacks South Africans and contends that apartheid oppressed and psychologically impacted the mental health of black South Africans (Kagee and Price 1994; Ka Sigogo 2004). The social impacts of apartheid had far-reaching effects that are still visible today.

For instance the emergence of township tourism as LED and poverty reduction initiatives under the aegis of BEE cannot be accurately analyzed without accounting for the historical context of how these residential areas came into being. According to Goudie et al. (1999) huge sprawling townships were designed to make labour accessible to the white cities and towns. The townships were neglected; often with no running water; no sanitation, or roads. Some were situated near unhygienic landfill sites or industries. Industry operated without environmental regulation; the mines polluted the land, water and air; there was poor disposal of toxic wastes (McDonald 2002). The trauma of living in such degraded surroundings is certainly relevant in assessing how the residents take up government tourism initiatives designed for their economic empowerment, which requires showcasing conditions that largely still persist today, for tourism to a predominantly white market.

Most black South Africans are unable to take advantage of economic empowerment opportunities on offer because they do not have basic literacy, business skills, education. Ngalwana (2011) describes this as the effect of apartheid and goes on to state "... also bred an inferiority complex in black people ...". Maathai (2006: 69) substantiates this thinking when she states "the trauma of the colonized is rarely examined, and steps are rarely taken to understand and redress it. Instead, the psychological damage passes from one generation to the next, until its victims recognize their dilemma and work to liberate themselves from the trauma" (see Chapter 2). Ngalwana refers to the work by Chang (2007) who writes that South Africa will remain a 'cappuccino society' (a mass of black at the bottom, a thin layer of white froth above it and a sprinkling of cocoa at the top) if a certain degree of 'equalization of outcomes' is not pursued with a view to creating a substantively and genuinely fair society. He warns that failure to do this will breed economic resentment among black youths. Economic resentment breeds criminality which in turn breeds a nation that is 
frightened of itself. That depletes productivity levels as people are scared to venture out and the economy stalls. In efforts to reverse this situation the South African government has designed policies such as The Preferential Procurement Policy Framework Act, Employment Equity Act and the entrenching affirmative action in section 9 (2) of the Constitution specifically targeted at uplifting the black population. In view of trauma, and how it still impacts development consciousness, this study contends that it is important to review how these policies are implemented through a government aid/donor model of financing to achieve the overarching national goal of BEE.

Current literature (Briedenhann and Wickens 2007; Rogerson 2009; Magi and Nzama 2009 ; Magi 2010; Olutola and Mofokeng 2010) on the role of tourism in achieving poverty reduction in South Africa does not give due academic attention to the possible role apartheid played and continues to play in shaping the development consciousness of previously disadvantaged communities. The question has to be asked as to why the black community in South Africa appear to need so much leverage from other people and stakeholders? Given the prolific literature that seems always to treat them as a people needing assistance, such an interrogation is necessary. Ramutsindela (2007) in his analysis of the position of grassroots communities does not locate the reasons for the less than enthusiastic community response to a productive engagement with the land, in the feelings of insecurity planted and nurtured by the long history of community engagement with apartheid, which was officially abolished in 1990 . The stance taken in this study is that apartheid, although it has been replaced by democratic rule, is still a force that may have to be analysed to determine its possible impact on the attitudes and capabilities of the communities towards participating in entrepreneurial township tourism.

Literature (e.g. Roe et al. 2004; Ramutsindela 2007; Rogerson 2009; Magi 2010; Mazibuko 2010) does not assess the viability of empowerment from public participation programmes put in place to upgrade the local peoples' lives through involving them in planning and management of tourism LED initiatives, an academic gap this study intends to fill. When applied to tourism, conscientisation theory dictates that attention be given to the level of participation readiness of affected communities. Literature in tourism development (Jensen 2010; Janis 2010; Mazibuko 2010; Boonabana 2010) skirts this concern as it does not question the power structures and the social and economic relationships in place, in so far as do they aid/empower or deter/derail meaningful involvement of locals, and this presents yet another academic gap. 


\subsection{The Problem Statement}

A close examination of South Africa reveals the country is facing a crisis of rampant poverty, this has its roots in the apartheid policies and can also be attributed to postapartheid government policies. The irony is that South Africa is rated as the richest and most developed state in Africa. The big question is: what is the role of a vibrant tourism sector within a nation that is a young democracy facing challenges of deprivation? Poverty is a point of concern, because it affects over half of the population. This dilemma should be a concern of all citizens; it is not just a theoretical difficulty.

\subsubsection{The academic challenge}

Research has largely failed to bridge the chasm between poverty practitioners, who do not know about tourism and secretly doubt whether anything that pampers the elite can really help the poor; and tourism industry players who are too busy watching their tight margins or arrival statistics to worry much about poverty. Between these two camps, much of the 'tourism and development' academic literature has dedicated itself to cataloguing the 'perils' of inappropriate exploitation of the environment, the local economy, culture and the people (Ashley and Mitchell 2005; Telfer and Sharpley 2008; Hall 2009; Janis 2010). Tourism seems best avoided unless it is so small-scale, indigenously owned, environmentally sensitive and 'authentic' that it disappears from mainstream view (Ashley and Mitchell 2005). The key point is that the LED impacts of tourism can be enhanced through changes in government and project participants' practices. The main focus of the research is therefore not on merely acquiring new data to simply add to the existing works on the subject but rather the collection of new data and its use in a coherent structure with existing information. The intention is to give both the existing and new works a theoretical perspective. The hope is that by putting them together it will help direct the path of future implementation of LED tourism initiatives geared for women entrepreneurial economic empowerment in South Africa. Understanding both the potential and pitfalls of tourism is a necessary first step towards making LED tourism more entrepreneurial. What is absent from most micro-level analyses, however, is a comparison of the various positive and negative impacts that tourism may have in a particular location and how they relate to the specific livelihood objectives of the local population. It is one thing to identify 'positive impacts'; it is another to consider how they fit with the livelihoods and capabilities of a community. 


\subsubsection{The practical challenge}

Tourism as an economic powerhouse in South Africa is not disputed. Its contribution to the marginalised communities is however questionable. Tourism has the capacity to address numerous current inequality challenges. How the industry incorporates the poor either as partners with entrepreneurial possibilities, as menial labourers or people that receive hand outs/donations without any true sense of ownership in the industry is key. The following are real challenges to achieving the aforementioned:

- Inadequate education, training and awareness (capabilities) of the benefits the industry can afford the poor as real partners and stakeholders;

- Weak institutional structures and capacities at all levels to promote real LED tourism For poverty reduction;

- Currently local communities are seen as tourism products rather than inputs in the product development.

These factors lead to limited integration of local communities and previously neglected groups into the tourism economy

\subsection{Theoretical Underpinning}

The argument advanced in this study follows the reasoning that communities may have to reach a certain level of consciousness before they can perceive their space differently and be called to make decisions about the nature of their involvement let alone participation in government LED initiatives. In line with this objective, the study adopts Freire's (1970) ideas on consciousness to support the theoretical framework (Figure 1.1) and methodology. Conscientisation's (Chapter 2) major strength as a notion of analysis is that it brings into focus other important concepts like social identity, power relationships and identity construction, which may be important in shaping a collective mentality that may be critical to a collective approach to community participation in LED by promoting entrepreneurship (Chapter 4 ) to achieve the overarching goal of BEE. According to (Freire 1970: 19) conscientisation is the process of "learning to perceive social, political, and economic contradictions developing a critical awareness - so that individuals can take action against the oppressive elements of reality". Smith (1996: 190) argues that "good concepts are flexible, ambiguous, suitable to any occasion" and with this in mind, the study exploits the concept of socio-spatial socialization (Chapter 2) to inform an inquiry directed at understanding the perceptions of tourism development by its multi-stakeholders. 
Figure 1.1: Theoretical Map

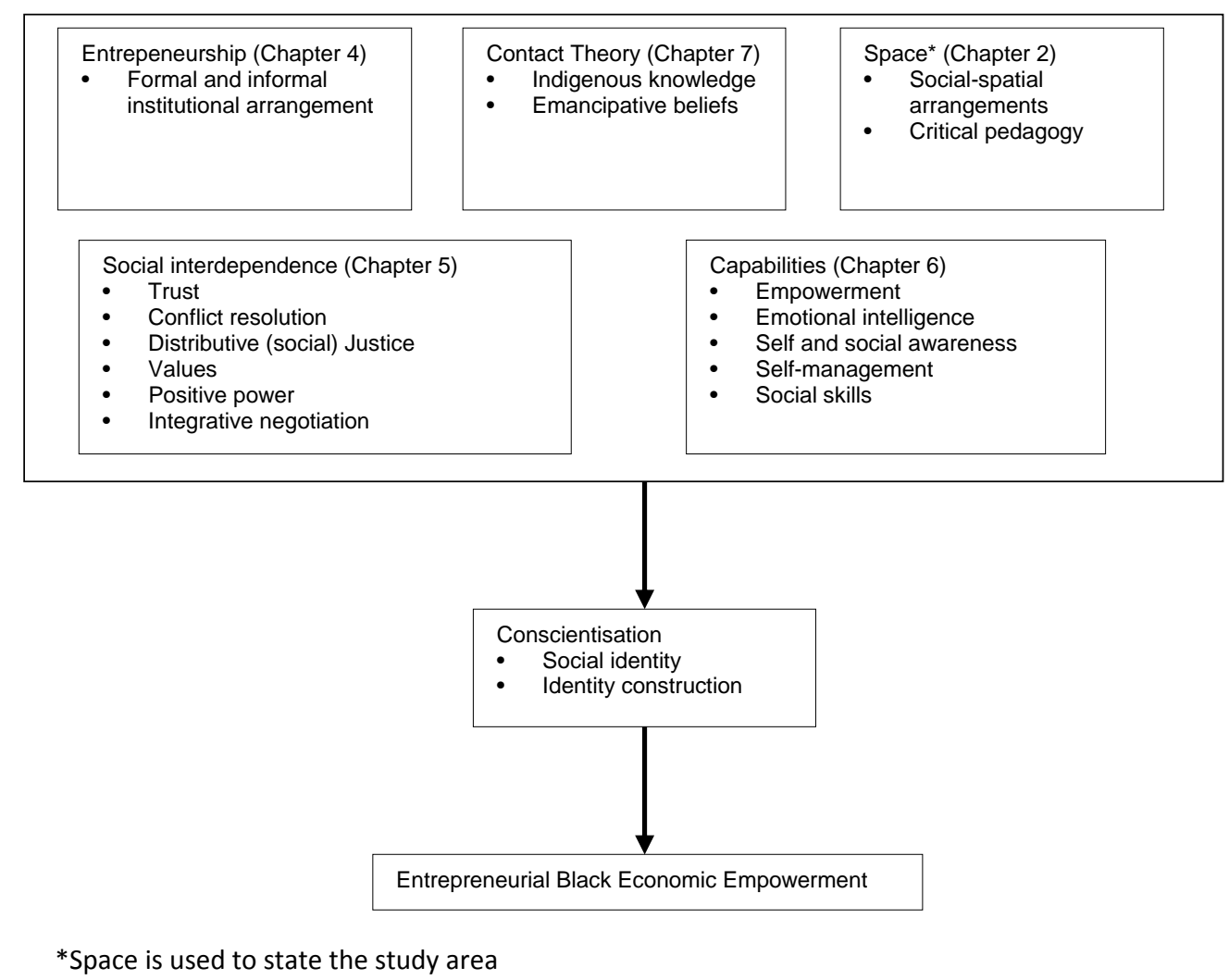

To explain how these perceptions shape and inform the kinds of interactions, and the impact these interactions have on the socio-economic development of the poor communities, the study applies social interdependence theory (Chapter 5). This approach is an affirmation of Soja's, (1985: 90) argument that "spatiality situates social life in an active arena where purposeful human agency jostles problematically with tangential social determinations to shape everyday activity, particularize social change, and etch into place the course of time and the making of history". Soja's assertion can be applied to tourism as a tool for poverty reduction and in that way Chapter 6 examines how empowerment and capabilities are important attributes in LED participants. To gain an understanding of how tourism development can then be contextualised as an economic product (Chapter 7) the concepts of indigenous knowledge and emancipative beliefs are adopted and placed in the political and social arena in which different stakeholders jostle for equitable space to meet their development, empowerment and conservation needs; and even their hidden political agenda. 
This study is informed by the theory of social space in its attempts to broach the subject of leveraging women economic empowerment through the promotion of LED tourism entrepreneurial initiatives. The theory of social space is concerned with analyses of the perceptions and relationships within and across the various groups that make up the LED community, as a way of locating the obstacles to enhancing women capabilities (Sen 1984) in the operationalization of township tourism home-stays (Chapter 7). The poverty reduction thrust of this study echoes the views popularized by Sen (1984) which are centered on providing opportunities for enhanced well-being (Sen 1985, 1993; Gasper 2007). Well-being has many facets (Gasper 2007), with an individual's well-being depending not only on material endowments, but also (and especially) on the capabilities (Chapter 6) of the individual (Sen 1984, 1993, 1999). Policy initiatives were the basis for tourism change in South Africa (Chapter 4), and Wahab and Pigram (2000: 28) have argued that "change is a powerful and positive force which, when harnessed constructively, challenges individuals and groups to perform at their optimum capability". In his work Sen $(1985,1993)$ advanced the notion that capabilities imply interconnectedness within a relational conception of society. In this light the study also considers social interdependence (Chapter 5) as a relative notion (Dworkin 1988). They are interpreted in the context of the township environment that is made up of events, objects, and other agents. To evaluate the degree of an agent's autonomy or interdependence the study puts the agent in touch with objects, events, and other agents (Hexmoor 2000; Hexmoor and Kortenkamp 2000). By working in the presence of other agents, no assumptions about explicit cooperation, coordination or about psychological influences among agents are made (Brainov and Hexmoor 2001). This introduces contact theory (Amir 1969; Pettigrew 1998), as an explanation of attitudes of tourists towards cultural groups at a destination (Chapter 7). Contact theory, stems from the field of social psychology and implies that contact between people, generally of different ethnicity, will lead to a change in, or a reaffirmation of, intercultural attitudes towards the other ethnic groups (Allport 1954; Amir 1969; Cook 1978; Pettigrew 1986, 1998; Pettigrew and Tropp 2005). Contact theory (Chapter 7) can be regarded as the 'science' behind attitude change, and if it is assumed that positive attitude change is a precursor to successful township tourism (Pizam 1996; Tomljenovic and Faulkner 2000) its importance becomes obvious. 


\subsection{Objectives}

Based on the gaps identified above, the main aim of this study is to understand the dynamics of local government and project-level realities that will enable or inhibit the realization of entrepreneurial BEE with the view to inform future project design and contribute to academic knowledge. The study is informed by the following objectives:

1. To identify knowledge gaps on BEE and LED on both levels and to understand why these gaps exist;

2. To identify how national policies impact LED tourism initiatives which are being used to enhance economic impacts on marginalized communities in South Africa;

3. To define and assess the responsibilities of all stakeholders in promoting progressive human values through an assessment of tourism LED in the country;

4. To critically analyze the positive and negative impacts on women of these policies and initiatives.

\subsection{Research Questions}

In order to address the objectives outlined above, this research is guided by the following research questions:

1. What is the relationship between economic empowerment and progressive human values for the previously disadvantaged in South Africa?

2. Can entrepreneurship be taught, inspired and diffused through a society to achieve BEE?

2.1 How do women home-stay operators negotiate formal and informal institutional arrangements to derive economic entrepreneurial empowerment through government LED cultural tourism home-stays?

3. What are the most significant qualities of a successful entrepreneur, especially in the uncertain environment of a developing country context?

4. To what extent does cultural commoditization drive the economics of government LED tourism home-stays? 


\subsection{Methodology}

The methodological context of this study is only briefly introduced here it is treated in detail in Chapter 3. There is considerable discussion among tourism academics about appropriate methodologies and research orientations for studying tourism (Riley and Love 2000; Aitchison 2001; Ritchie et al. 2004). It is encouraging that more and more, multiple mixed method research strategies are gaining increased acceptance in this field. Due to the high behavioural content and diverse nature of tourism, integrated approaches are beneficial for tourism research, especially for investigations into tourism production (Farrell and Twining-Ward 2004). This thesis uses an interpretive approach to give the participants a voice and to stress the methodological importance of reflexivity where the researcher has multiple positionalities in the study. Triangulation of data sources and methods, combining qualitative and quantitative techniques enables a richer understanding of roles and responsibilities and of women in their experiences with LED tourism for entrepreneurship. The use of multiple mixed method research strategies in an interpretive approach challenges traditions of voices framed within the positivist approach in tourism research where women's voices have remained largely unheard (e.g. Decrop 1999; de Bruin and Lewis 2004; Dupuis and de Bruin 2004). The methods of the research include a questionnaire survey, in-depth interviews, observations, discussion sessions LED women home-stay operations.

\subsection{Study Site - Case Study Description}

\footnotetext{
Kwam eMakana Tourism Home-stays, Eastern Cape Province, South Africa

Kwam eMakana is a home-stay pilot project developed as part of the Local Economic Development (LED) strategy for poverty reduction (PR) in 2004 by the South African Department of Sport, Recreation, Arts, and Culture (DSRAC). The initiative was built around the annual Grahamstown Arts and Culture festival. Its aim is to assist women over 40 years old from Jozi Township to enter the tourism economy. All the women involved were either previously unemployed or earned a household income of less than R 1,500 per month.
}

DSRAC, the National Development Agency, a local NGO, and a tourism institute provided training for the women. Participants received "starter packs" and an annual R 500 grant. During the festival, the homestays, which function as informal guesthouses, receive guaranteed occupancy from DSRAC officers. Bookings were made through the Grahamstown Tourism Office. Women involved in the programme make between $R$ 8,000 and R 28,000 a year. To date, 60 women have been trained. These women are changing the future of their children. The owner of KwaKwesela said, "because of my home-stay, my daughter is reading Economics at university." These women are role models, showing their community that they too can run businesses and provide for their families.

The project has not been without its problems, however. 55 homes were initially designated for the project with the intention that the most successful would graduate to become bed and breakfasts. Today, 46 remain but most have not graduated from the start-up phase. The majority of the home-stays only have 
occupancy for two weeks during the festival. This situation is of concern to all involved as the intention was for home-stays to graduate from "assistance receiving" to "entrepreneurially driven."

In the neighboring Township of Port Elizabeth, a different type of home-stay project provides a point of comparison. Port Elizabeth's home-stays were started by women on the premise of $100 \%$ entrepreneurial capital and drive. Instead of being focused on a particular event, these homestays were designed to cater to year-round cultural tourists. The women believed their culture to be unique and interesting enough for people to want to experience it without an event. The home-stays have formed business partnerships and linkages with other tourism businesses and are relatively successful.

Factors influencing success

- High level of entrepreneurial spirit and self-confidence

- Ownership and decision-making resting with the women

Lessons learned

Kwam eMakana has had some positive economic impact, but the comparison with the Port Elizabeth homestays shows that no amount of training and aid can replace entrepreneurial drive. Top-down donordriven projects can make women dependent and reduce the empowerment outcomes of the work.

\subsection{Contributions to Knowledge}

Ultimately this study aims to contribute to the existing body of knowledge of LED and tourism development centered on the inclusion of previously disadvantaged communities. Some of the knowledge contributions that are essential to sustain the above mentioned aim are listed below:

- A fuller understanding of why most of the poor in South Africa continue to remain poor and in some cases become even poorer in the face of government LED initiatives;

- Insight into the degree to which these initiatives are more than just economic means and contribute to constructive autonomy and interdependence in other aspects of life (social and political) and;

- A more balanced understanding of current power structures and the social and economic relationships in place and how these impact the attainment of entrepreneurial economic empowerment.

\subsection{Thesis Outline}

The thesis presents a multi-dimensional analysis of how the local realities shape and impact on the attainment of government goals through an aid/donor funding model to tourism LED. Each chapter presents a unique angle to view the effects of this approach to LED, corresponding to the four research questions. 


\section{Chapter 1}

This initial chapter essentially lays out the conceptual foundations of this research in terms of problem formulation and structuring, research questions and methods, and the country and site-specific context of the analysis.

\section{Chapter 2}

Presents the possible contribution of a critical pedagogic approach to black South African women's inclusion in the township tourism economy. The reader is informed of the author's connection to the study area; and following that descriptions of important episodes are detailed. The chapter then links the ideas of Freire (1978) to the concept of discourse, and uses the approach to interpret township tourism as a conscientisation agent. The potential contribution of critical pedagogy in the study and practice of township tourism development in the South Africa is carefully examined.

\section{Chapter 3}

Provides the philosophical and methodological foundations of the study, this necessitates an overview of the wider philosophy of social science research. This leads to acceptance of the interpretive approach with hermeneutical considerations and a discussion of its validity ensues. Discussion of tourism as a discipline and research orientation provides a conceptual framework. The importance of reflexivity is raised and the relevant significance of positionality (situating myself) as researcher is presented.

\section{Chapter 4}

Challenges the classic structure of funding for top-down projects applying governmentled conceptual frameworks. It begins the presentation of empirical findings of this study. The chapter proposes an approach to women economic empowerment anchored in developing and encouraging a truly entrepreneurial approach to wealth creation as an avenue to achieving BEE. It concludes that to achieve BEE, more emphasis must be placed on an agenda that promotes prosperity and progressive human values.

\section{Chapter 5}

The chapter focuses on the economic contributions of tourism at local and project levels. It analyses how formal and informal institutional arrangements of LED impact the women assuming ownership of the government LED project. The chapter refers to a model derived from economic theory with game theory reasoning to inform the 
argument that social interdependence can enhance the sustainability of LED women tourism home-stay initiatives.

\section{Chapter 6}

Identifies and addresses some problematic aspects of research on the role of tourism for poverty reduction. The chapter reviews some of the discourses on SMMEs that combine tourism, development and poverty reduction. It employs empowerment and Sen's capabilities approach to poverty reduction and presents empirical evidence to explain how the women operators' competencies impact their performance in the LED initiative.

\section{Chapter 7}

Shows that the assessment of cultural commoditization also highlights the consequences of cultural misconception, and reveals the role of culture in township tourism. The concepts of indigenous knowledge and emancipative beliefs are used to explain the relational link between hosts and guests. It challenges more traditional ways of perceiving the workings of cultural tourism, and on a more general level, social action and cultural expressions. This opens new possibilities and offers potential for new understandings.

\section{Chapter 8}

Provides answers to the main research questions. It presents a synthesis of the research, highlights and discusses the salient issues that emerge. It also points to interesting and necessary future research ideas.

The chapters in this thesis were written for publication as stand-alone articles, hence some of the material in this chapter is introductory and will be developed in the ensuing chapters as relevant. 


\section{Chapter Two}

\section{Does the Past have a Place in Today and Tomorrow?}

\subsection{Background}

Apartheid affected every aspect of the daily lives of black South Africans (Ngalwana 2011). Racial segregation, job reservation, restrictions on mobility, and the provision of inferior education and health care were just some of the more obvious aspects of that system (Dube 1985; Moultrie 2001). According to Dubauw (1995), by steadily eroding the legal rights of black people and endowing the white population with greater rights, the apartheid regime succeeded in creating one of the most unequal societies in the world. The seed of apartheid was planted long before the regime became institutionalized and was given a name. In 1913 the Land Act limited black people to ownership of just $13 \%$ of the total land. The land that was reserved for black people was marginal and unproductive (Kagee and Price 1994). Later, the creation of 'homelands' by the Nationalist government in 1948 separated black people further from the land (Moultrie 2001). The spatial arrangement of town planning resulted in townships designed to make labour accessible to the white cities and towns (Goudie et al. 1999). The townships and most rural communities were neglected; often with very limited to no essential services such as sanitation, roads, running water waste disposal or electricity (Harries 1989), which many still do not have (Matinga 2010). Education was unequal; for whites it was compulsory and free; blacks had to pay for it and it was not compulsory. Schools for blacks were understaffed; teachers were under-qualified; class sizes too large for meaningful learning (Dube 1985). Dlamini (1997) described South Africa's literacy levels as among the lowest in the world; a legacy that is still prevalent (Ngalwana 2011; Vavu 2011). The migrant system of labour disrupted marital life and family life, husbands and fathers were forced to leave their villages to seek work in the towns, where they often became alienated from their families (Moultrie 2001). Women had to do the work of the men as well and began to head the households de facto, while their husbands made the real decisions from a distance. The extended family - which had always been a source of strength and unity in adversity - began to break down.

In an effort to reverse the previous positions in society, the democratic South African Constitution promotes equal opportunity for all through various policies and programmes in education, tourism, agriculture, mining, construction to name only five. 
However, most black South Africans are unable to take advantage of these opportunities because they do not meet the set criteria: education, skills, and basic literacy, to access these programs (Magi 2010; Vavi 2011; Ngalwana 2011). This is one "of the effects of apartheid which has also bred an inferiority complex in black people" Ngalwana 2011:1). It is very difficult to find employment or qualify for most BEE schemes when one is illiterate. The effects of apartheid are more than just political and economic. According to Ngalwana (2011: 1) "an even greater damage caused by apartheid manifests itself in the perception that both races have of themselves and each other". He writes that many black South Africans "are generally not convinced that a black person can do a job just as well as, if not better than, a white person of similar qualification". He adds that even professional black people have fallen victim to this subtle sense of self-hatred (Ngalwana 2011: 1). Barack Obama (2004) in his book Dreams from my father: $A$ story of race and inheritance identifies the same self-hatred in Chicago when he worked as a community organizer, in poor black neighbourhoods, especially when he tried to pin down the idea of self-esteem. The perverse effects of apartheid and all forms racial discrimination (slavery and colonialism) is the inferiority complex it has engenders in the oppressed over long periods (Obama 2004; Maathai 2006). This, Ngwalwana (2011: 1) writes, "is not an affliction ravaging only the lower classes; it eats up black professionals equally the same".

There has been opposition to development policies focusing on the apartheid past. One such expression of opposition came from the African National Congress (ANC) political opponent Zille (2011) who stated that "not entrenching race as the sole marker of identity is the antidote to addressing the past without entrenching apartheid". Ngalwana (2011: 1) responded by saying this was oxymoronic, contending that "Zille seeks effectively to equate the redress of the inequalities of apartheid with entrenching apartheid". He maintains Zille "does so by asserting that redress focuses on race, focussing on race entrenches it and therefore entrenches apartheid". Ngalwana (2011) vehemently labels this "an intellectually and, as it turns out, constitutionally vacuous proposition". Ngalwana (2011: 1) posits that "one cannot make an omelette without first breaking an egg, in his analogy the constitutional redress is the omelette and race is the egg". According to Ngalwana (2011: 1) the inequalities of apartheid cannot be addressed without focussing on race". Hence the government of South Africa through its BEE legislation is making resources available to black South Africans, especially the youth, with a view to redressing the effects of apartheid. 
In the context of this study, home-stay tourism is a particularly good 'lens' through which to view the effects of apartheid, so that effective solutions can be created and implemented because home-stays are situated in Townships - essentially the birthplace of apartheid. The effects discussed above will be visible, making the study site an experimental laboratory of sorts. This chapter will introduce a discussion of how a pedagogic approach can be applied to the South African context of township tourism as well as discussing its potential contribution to contemporary tourism research. Pedagogy refers to the process of teaching. The term generally refers to a style of instruction, it is also occasionally referred to as the correct use of instructive approaches. For example, Paulo Freire (1978) referred to his method of teaching adult humans as 'critical pedagogy'. In connection with those instructive approaches the teacher's own philosophical beliefs of instruction are embraced and directed by the student's background knowledge and experience, situation, and environment, as well as learning goals of both the student and the teacher. By adopting a pedagogic approach the study evaluates if conscientisation as a progressive human value is a factor in how the women of Kwam eMakana negotiate entrepreneurial economic empowerment through the government LED project. Borrowing from critical pedagogy as it is applied in education the study positions the government in the instructor's role and the project participants are assigned the student role, each with their learning roles governed by the background knowledge, experience, situation, and environment of both parties.

The underpinning notion of analysis here is grounded in the viewpoint that psychological trauma, emanating from historical structures and experiences of the individual, is a determining factor in empowerment and poverty reduction. The thesis advanced is that conscientisation in South Africa is both relevant and possible due to the entrance of the equality discourse in this case via the township tourism development scene.

\subsection{Development and 'Local Economic Development'}

The discourse on development is complex terrain. For Trainer (2002), the main problem with 'development' arises when it is simply equated to growth - which assumes trickle-down benefits to the poor (to achieve 'development' through growth). In a book edited by Turok (2008), it is argued that the trickle-down effect assumed by orthodox market economists does not work. Benefits received by poor and marginalised people are often few and inadequate unless the structural dynamics of 
exclusion are addressed. The United Nations Millennium Development Goals (UNMDG) include specific commitments to reduce by half the proportion of people living in extreme poverty by 2015. According to Sen (1984) poverty is a multi-faceted concept which embraces not only insufficient levels of income but a lack of access to essential services such as education, water and sanitation, health care and housing.

In South Africa, within the National Framework for Sustainable Development, development is seen as "a process that results in the qualitative improvement in human well-being, which, in turn, is achieved via access to infrastructure and services, education and enhanced skills, empowerment via secure livelihoods and cultural development, decent health care and welfare support" (DEAT 2006: 64). In contrast, material economic growth is defined as "the quantitative material expansion of physical infrastructure, capital assets of various kinds, economic resources, intellectual and institutional capital" (DEAT 2006). It is argued that material growth is a necessary condition for development up to a certain point, beyond which development can occur at a rate that is faster than material economic growth. They posit that non-material growth and development is achieved by reducing the 'total material requirements of the economy' - more commonly known as 'dematerialization'. This recognizes that we live on a biophysical planet, where certain environmental limits exist, and where certain natural capital cannot be substituted by financial capital or technological innovations (Department Provincial and Local Government [DPLG] 2006: i).

In order to achieve development, a number of theorists have proposed alternative ways of living (see Max-Neef 1991; Korten 1995; Henderson 1999;Trainer 2002). What they have in common is a focus on people meeting their own needs through contributing and controlling their own productive efforts - which allows for a measure of self-reliance. This involves practicing community-based decision-making and participation (Scheyvens 2002; Chapter 5); applying local resources and technologies in an ecologically sound manner (Minang 2007; Chapter 7); building local economies (Easterly 2006; see Chapter 4); rejecting one-dimensional and simplistic views and solutions to the challenges of poverty and development; and striving for satisfactory and sufficient but materially simple living standards as distinct from the Western consumer lifestyle (Trainer 2002; Rivett-Carnac 2009). Within the 'development debate' outlined above, the Bertlesmann Foundation and World Bank see LED as the process by which public, business and non-governmental sector partners collaborate to create better conditions for economic growth and employment generation in pursuit of a better life for all (Turok 2008). Nel (2001) in reviewing the status of LED in South Africa, quotes Escobar as saying that "LED is one response to the so-called 
development impasse ... and has parallels with the antidevelopment argument about the need to focus on innovative grassroots movements". For Rogerson (2003: 1004) "LED in South Africa has not been based on this 'innovative grassroots movement' approach, but has had a distinct neo-liberal flavor." He believes that the traditional practice of LED has been historically characterized by four key components: competitiveness of localities, the enhancement of growth (here he talks about property-led development), supporting job creation (through business retention and SMME development), as well as community development (such as community enterprises and cooperatives).

\subsection{Tourism and Poverty Reduction in South Africa}

Poverty is arguably the biggest development challenge facing South Africa (RivettCarnac 2009). In the drive to achieve the government's 'Vision 2014' targets - of achieving a $6 \%$ growth rate, and halving unemployment and poverty - tourism was identified as key economic contributor (The Presidency 2007). It is highly promoted, amongst other reasons, because of its labour intensity, ability to attract foreign exchange earnings, and creation of opportunities for small business participation. Inevitably there are also a variety of challenges that come with the relentless promotion of tourism as a development option. How these challenges are met will certainly influence the sector in the long-term, and it is clear that positive initiatives by the industry will enable regional and LED, including poverty alleviation, to take place in parallel with the needs of a viable economic business. In fact, it was argued by Goodwin and Robinson (2004) that these two components of tourism should not be separated. Rivett-Carnac (2009) notes that tourism's many supporters, including the UNWTO, view tourism as a massive contributor to sustainable development. Whereas tourism per definition "comprises the activities of persons travelling to, and staying in places outside, their usual environment for not more than one consecutive year for leisure, business and other purposes" (UNWTO I Rivett-Carac 2009: 4). Ecotourism is a particular form of tourism occurring in natural areas that includes benefits for communities and the conservation of ecosystems. Responsible tourism is a broader concept that describes tourism operations that take a triple-bottom line view (which includes economic, social and environmental considerations), and that can also occur outside natural areas. The National Guidelines for Responsible Tourism (see Table 2.1) developed in South Africa were published by the DEAT in 2002 and they were adopted as the national sector planning guidelines for tourism. 
Table 2.1: The National Guidelines for Responsible Tourism

\section{Responsible Tourism:}

1. Minimizes negative economic, environmental, and social impacts;

2. Generates greater economic benefits for local people and enhances the well-being of host communities, improves working conditions and access to the industry;

3. Involves local people in decisions that affect their lives and life chances;

4. Makes positive contributions to the conservation of natural and cultural heritage, to the maintenance of the world's diversity;

5. Provides more enjoyable experiences for tourists through more meaningful connections with local people, and a greater understanding of local cultural, social and environmental issues;

6. Provides access for physically challenged people; and

7. Is culturally sensitive, engenders respect between tourists and hosts, and builds local pride and confidence.

Source: http://www.icrtourism.org/capetown.shtml

\section{Table 2.2: Guiding Principles for Economic Responsibility}

\section{Guiding Principles for Economic Responsibility:}

1. Assess economic impacts before developing tourism and exercise preference for those forms of development that benefit local communities and minimize negative impacts on local livelihoods (for example through loss of access to resources), recognizing that tourism may not always be the most appropriate form of local economic development;

2. Maximize local economic benefits by increasing linkages and reducing leakages, by ensuring that communities are involved in, and benefit from, tourism. Wherever possible use tourism to assist in poverty reduction by adopting pro-poor strategies;

3. Develop quality products that reflect, complement, and enhance the destination;

4. Market tourism in ways which reflect the natural, cultural and social integrity of the destination, and which encourage appropriate forms of tourism;

5. Adopt equitable business practices, pay and charge fair prices, and build partnerships in ways in which risk is minimized and shared, and recruit and employ staff recognizing international labour standards;

6. Provide appropriate and sufficient support to small, medium and micro enterprises to ensure tourism-related enterprises thrive and are sustainable.

Source: http://www.icrtourism.org/capetown.shtml

The guidelines cover the economic, social and environmental agendas for responsible tourism. The section on Guiding Principles for Economic Responsibility (refer to Table 2.2) is a specific checklist of actions that people in the industry could take to increase the positive impact on LED. Both ecotourism and responsible tourism can be viewed as forms of sustainable tourism.

These guidelines were developed with and for the tourism industry in South Africa, tourism is a major economic sector in South Africa. Although estimates of its contribution to Gross Domestic Product (GDP) and employment are based on many assumptions, some of them unverified, it is certain that tourism can and does make a serious contribution to economic development (DEAT 2009). The UNWTO (2010) estimates that tourism accounts for up to $10 \%$ of GDP, making it the world's largest 
industry. The potential for tourism to contribute significantly to poverty alleviation is considerable. Work since 1998 by the Pro-Poor Tourism (PPT) Partnership (Ashley et al. 2001) has demonstrated that tourism can contribute to poverty reduction and that for many of the least developed countries, and in many rural areas, tourism is one of the few current viable strategies for economic development. One particular strategy that has drawn attention has been: "tourism that results in increased net benefits for poor people" (PPT Partnership 2005: section 1, Para 1). The UNWTO's report on Tourism and Poverty Alleviation published for the World Summit on Sustainable Development in Johannesburg in 2002 drew substantially on the work of the PPT partnership and there are now a range of initiatives taking place in South Africa like Southern Sun, Wilderness Safaris, Sun City and Spier Lodge (Goodwin 2003).

Furthermore, with particular reference to sustainable development, in comparison to most other industries, tourism can better protect biodiversity and conserve natural resources. If managed well it can also protect and promote local cultures (Chapter 7) in a responsible and sensitive manner (Rivett-Carnac 2009; Kelly 2006a). In 2007 tourism in South Africa was credited with directly accounting for about 8.1\% of GDP (direct and indirect contribution), approximately 400000 direct jobs and about R60 billion in foreign exchange earnings in 2007 (South African Tourism 2007), earning it the title 'the new gold' (Fontyn 2008). Olutola and Mofokeng (2010) remark that the successful hosting of the 2010 FIFA World Cup increased global awareness of the country and region, hopefully changing certain strongly-held negative perceptions (around crime in particular) which should lead to more foreign tourist arrivals in years to come. In terms of legal and regulatory 'governance', South Africa's relatively robust policies around land restitution, labour rights, BEE, amongst others, afford it a strong framework for equitable development of tourism, at least on paper (Magi 2010). Progress on the issues of inclusion and natural resource conservation in tourism is experienced as real and meaningful (although by no means adequately so) by South Africans. Increasing numbers of black South Africans are participating in the sector, as tourists, owners, operators, employees and service providers (Rivett-Carnac 2009).

\subsection{Apartheid Socio-spatial Organization and Tourism Development}

Tourism development in any given community is the result of complex interrelated social, economic and political factors (Peck and Lepie 1989). To participate in tourism, people should have reasonable incomes, leisure times, means of transport and freedom of movement (Peck ad Lepie 1989). The policy of apartheid deprived the 
majority of South Africans from such benefits (Mkhize 1994). The move toward democracy provided many challenges, the most enduring in the tourism sector is the need to cater for the emerging black tourist market and black tourism entrepreneur (Marahaj et al. 2008). The South African case of tourism small enterprise development is distinctive, in certain respects, within the developing world. It is distinguished by commitments made by the post-apartheid government to introduce new national policy frameworks and institutions designed to support the SMME economy for the inclusion of previously disadvantaged communities towards meeting the objectives of post-apartheid reconstruction (Rogerson 2002). A high priority is attached by national government to achieving the objectives of transformation and of BEE in South African tourism (Magi 2010). In the past the tourism economy of South Africa has been estimated at $95 \%$ in the ownership of whites; with the Ministry of Tourism and Environmental Affairs on occasion in 2004 and 2009 drawing attention to the lilywhite complexion' of the ownership structure of South African tourism (in Rogerson 2002). There is still a strong perception among black South Africans that tourism is a 'white preserve'.

Post-apartheid South Africa faced the challenge of re-inventing its image as a tourist destination, hence, throughout the 1990s the government initiated different tourism promotion strategies, but the economic impacts of tourism have been highly variable (Marahaj et al. 2008). Whilst BEE was partly achieved through equity shares granted in existing large travel and tourism enterprises (Letsema Consulting 1999; The Cluster Consortium 1999), the promotion of black ownership of small tourism enterprises remains a fundamental component of national government initiatives for the wider transformation of the South African economy (Marahaj et al. 2008). Otherwise, the tourism industry in South Africa will continue to "simply perpetuate past divisions thus undermining efforts to establish a more inclusive and socially responsible tourism" as highlighted by Goudie et al. (1999: 22). The challenge for transformation has been recognised, but the tourism industry is yet to demonstrate whether it can progress beyond socio-spatial organisation of the apartheid era. The most challenging complexity lies in the simultaneous existence of extreme North and extreme South characteristics inherent in the country, for example, "Durban's beachfront is on the one hand the crown jewels of advanced industrial capitalism; and on the other hand the crude elements of a developing country city" (Grant and Butler-Adam, 1992: 210) are evident in the energy, housing, health care and water and sanitation sectors.

The common view of the tourism industry is that it employs a higher level of part-time and seasonal workers, and offers mainly unskilled and semi-skilled jobs (Gunn 1994; 
Scheyvens 2002). A major challenge facing the promotion of tourism as an LED option in South Africa is the need to get local people to buy into the idea of pursuing tourism as an economic and urban regeneration option (Magi 2010). In this view township tourism has emerged as a low cost entrepreneurial possibility for the black population and it has also received government support. Magi (2010) suggests that changing the mindset about tourism is crucial to the success of township tourism.

\subsubsection{Commoditisation of Apartheid heritage for tourism}

This section will discuss the historical significance of black South African women's inclusion in the township tourism economy from a critical pedagogic perspective. The reader is informed of the author's connection to the tourism study area, following which descriptions of important episodes are detailed and the historic importance of the country permeates in through these interactions. After that links are made to the ideas of Freire and the concept of discourse; with township tourism interpreted as a conscientisation agent. Finally, the potential contribution of critical pedagogy in the study and practice of township tourism development is highlighted.

Ashworth describes the past as being decorated with "acts of collective ... violence imposed on others by governments, ideologies and social groups, so it is possible to interpret not only every battlefield and war museum but also every castle, ruler's palace, cathedral, merchant's house, country house, plantation or factory as an atrocity site" (2004: 2) (Turnbridge and Ashworth 1996; also see work on Dark Tourism: Stone 2008; Sharpley 2009). Ashworth (2004) describes in detail how the possibility for successful commodification of this heritage in tourism can be limited by a requirement that the event itself has four main characteristics.

"First, there must be a human perpetrator and a human victim so that people, as tourists, can identify, or are identified by others, as perpetrators or victims. Secondly, the perpetrator must be engaged in a conscious, deliberate action and the victims must be innocent, thus not contributing significantly to their own condition, for it is the knowing consciousness of the perpetrator in an intentional act that renders it an atrocity. Thirdly, atrocity implies an extraordinary seriousness, whether of scale, however difficult that may be to quantify, or unusualness that is out of the ordinary for it is this bizarreness which draws the attention of the observer to the event that transforms routine cruelty into atrocity. Fourthly, an atrocity is an event that is known and remembered which requires knowledge and memorability. A secret, unknown or forgotten atrocity can only be potentially usable. This memorability stems not only from the inherent nature and circumstances of the event, but also from the way knowledge of it is promoted and subsequently used. There is a need for the event to capture the imagination of others at the time and later. This would seem to suggest that recentness is an advantage not only because of the surviving human memory of those directly involved, but also the efficiency of modern global information distribution techniques" (Ashworth 2004: 2). 
I draw from three episodes in modern history that seem to fulfill these requirements as discussed by Ashworth (2004); two of which have been studied in this way (Ashworth and Hartmann 2005) and thus can serve as precedents for a focus here upon the case of South Africa under study here. The Holocaust of Jews in Europe from 1933-1945 as a culmination of a much longer persecution, and the pursuit of the Atlantic Slave Trade between the sixteenth and the nineteenth centuries, have both the necessary scale and longevity (Ashworth 2004). Both are remembered through many specific sites, occurrences and individuals and both have powerful current implications for personal and group identity construction and for political nation and state building (Ashworth 2004).

"Both are currently used in part for tourism although tourism was not, and remains not, the main motive for heritage interpretations in either case. Finally both were world scale, long term, systematic, top-down impositions of injustice and oppression from one large group of perpetrators upon another equally large group of victims. Identification is thus so widespread in practice that it may be extended to include all humanity in one way or another. We are thus all involved whether as tourists or not." (Ashworth 2004)

Similar to Ashworth (2004) "the third such episode, which is [also under study] here; the imposition in South Africa of the ideology of racial separation, from 1948-1990 builds upon these two precedents, (also see Ashworth and Hartmann 2005) and the second which was comprehensively introduced by Dann and Seaton (2003 in Ashworth 2004: 2-3).

\begin{abstract}
"As in the other episodes [as highlighted by Ashworth in 2004] it was the culmination of a much longer period of racial discrimination which was not confined to the period or to that country. It is reflected in the memorialization of many specific sites, events and personalities; it has a contemporary significance for the construction of social identities (Freire 1978) and nation building; it involves a wider world as legatee of perpetration; and, finally and most relevant in this context, it is now used for tourism." (Ashworth 2004: 3).
\end{abstract}

Ashworth (2004: 3) also states that:

"The visible differences are in timing as the ending of the apartheid system is much more recent than the abolition of slavery or the ending of the Jewish Holocaust. Secondly, and most significantly, is the continuing presence of both victims and perpetrators in the same country."

Furthermore, according to Ashworth (2004: 3)

\footnotetext{
"this coexistence is not just a tolerated spatial coincidence, it has become a necessity to be maintained as economically and politically central to the creation of the new 'rainbow nation' of the explicitly multiracial South Africa. This adds a further dimension of complexity to an already inherently complex problem."
} 
Literature (Ramutsindela 2007; Visser 2009; Magi and Nzama 2009; Rogerson 2009, 2010) on tourism development in South Africa does not give due academic attention to the possible role apartheid played and continues to play in shaping the development consciousness of communities. The question has to be asked as to why black South Africans appear to need so much leverage from other people and stakeholders? Considering the prolific literature that seems always to treat them as a people needing asistance, this interrogation is necessary, this gap is addressed in Chapter 6.

The intention of this study is not to write about history and its injustices rather it is to take account of the past and assess how it impacts on the success of present development policies. Kelly (2006a) presents tourism as one of a range of therapies by which the likelihood of conflict can be reduced and Kelly (2006b) proposes that tourism can be used to encourage harmonious relationships among people of different cultures. Kelly (2006b) highlights that by using a case study approach, a number of authors have argued that tourism has the potential to aid peace and cab be a driving force towards healing the rift between divided nations (Poria 2001; Yu and Chung 2001; Henderson, 2002 in kelly 2006b). Yu and Chung (2001) discuss the notion in regards to a divided Korea while the latter also examines the theory with respect to Taiwan and China. Poria (2001) also suggests that tourism, in particular heritage tourism, could be a force for peace within the Middle East. The Kwam eMakana pilot project is distinctive in that it is a project offering accommodation to visitors attending South Africa's largest Arts and Culture festival in a township (a space that is important in the historical context of the country). The study asserts that the location of the Kwam eMakana home-stays in this way present an opportunity for therapy for the operators and the community at large from the trauma of the past in the way that they engage with their space and homes through the township tourism platform. This project allows the home-stay operators to host guests in their homes (space) of different racial backgrounds which was formerly discouraged by the socio-spatial organization of the era. The use of such heritage poses distinctive issues and requires careful management based upon an understanding of the phenomenon. Building on the claim by D'Amore (1988) recognition of tourism's potential to aid peace through economic development and poverty alleviation (UNWTO 2002, 2005) has increased. The majority of the pro-peace tourism literature focuses on the notion that tourism, through contact with other cultures, leads to greater understanding and affection between cultural groups (Khamouna and Zeiger 1995; Mclntosh et al. 1995; Askjellerud 2003, 2006; Kelly 2006a) inherent in this notion is the potential of tourism to heal past injustices and trauma (Ashworth 2004). According to Kelly (2006b) peace through tourism has attracted much critique, mainly that it is principally a utopian ideal. 


\subsection{Theoretical Underpinning of the Study}

In order to discuss the theoretical contribution of a critical pedagogic approach we will review three contemporary research approaches to township tourism development; space, network and culture. A critical pedagogic approach is used to illuminate the veiled assumptions and challenges in stimulating conscientisation (Berta Avila 2003) in view of the historical background and how it impacts the South African township tourism context. The people's sense of social space, is taken in this study as one that has the potential to determine to a large extent people's motivation levels to engage productively with opportunities and resources. The actual contact with other ethnic groups and hence cultures can influence the social space. Whilst the South African government policy in its written form may articulate clearly that communities have to be integrated into economic activities of LED, which on its own may not be enough to motivate communities to want to be part of LED initiatives. The sense of social space may actually be more crucial to a determination of a community response to a project (Chapter 7). Spatial-socialization of communities therefore, is explored as a possible method of empowering communities. Empowerment is taken to mean "the process of enabling persons to master their environment and achieve self-determination" (Simmons and Parsons 1983: 199), a definition similar to Sofield's (2003: 80) "a social process that is designed to facilitate people controlling their own lives ... (which) it achieves by recognizing, promoting, and enhancing people's abilities to meet their own needs, solve their own problems, and mobilize the necessary resources" (Chapter 6). Linked very closely to the concept of spatial socialization is the concept of consciousness.

The research views women community cohesion as integral to the process of creating environments in which communities may see the need to engage themselves voluntarily on their own, and with other stakeholders, in the productive space of township tourism (Chapter 5). They have to appreciate the need to reach out and form partnerships with other communities and tourism operations. In line with this thinking, the study adopts Freire's (1972) ideas on consciousness as a supporting theoretical framework, the concept of conscientisation will also inform the methodological approach of this study. Interestingly, the work of Freire was banned in South Africa during apartheid where it had been brought to prominence through Steve Biko's Black Consciousness Movement. Conscientisation's major strength as an underpinning notion of analysis is that it brings into focus other important concepts like social identity, capabilities, space, social interdependence and contact which may be important in shaping a collective mentality that may be critical to a collective approach 
to women entrepreneurial economic empowerment through township tourism. Additionally, the research evaluates the relevance of conditions identified in contact theory as explaining attitudes of home-stay operators (hosts) tourists (guests) and towards each other. Smith (1996: 190) argues that "good concepts are flexible, ambiguous, suitable to any occasion" and with this in mind, the study exploits the concept of social space to inform an inquiry directed at understanding the perceptions of township tourism by its multi-stakeholders, and how these perceptions shape and inform the kinds of interactions, and the impact these interactions have on the socioeconomic development of women LED township tourism home-stays.

\subsubsection{Space}

Research interest around concepts such as industrial districts, industrial parks and industrial clusters are examples (Greve 1995; Carbonara 2002; Pereira 2004) of visible space transformations making them lucrative for government support. A government can launch an industrial park programme or financially support clusters and receive high visibility in contrast to funding small scale projects aimed at economic entrepreneurial empowerment of the disadvantaged (Chapter 4). A spatial approach based on quantitative analysis does however not reveal much about what is behind spatial data or why regions/provinces that share a number of characteristics can differ considerably in terms of entrepreneurial activity. Absent in this approach is knowledge about the processes that have a potential to transform a region/province to become socially and economically empowered especially in South Africa. In the past spatial development and economic opportunities were clearly demarcated on racial lines. The segregation of leisure facilities such as beaches, hotels, restaurants, libraries, cinemas, to name but a few, was anything but insignificant, as the label 'petty' apartheid might imply. It was instead, an elaborate and humiliating system often entrenched with force (Goudie et al. 1999).

The study questions the modalities according to which tourist spaces are lived, analyzed and interpreted. In this direction, the research examines different tourist phenomena (and/or the viewpoints used to approach them) of Kwam eMakana cultural tourism home-stay project based on an anthropological conception of space. Interestingly the home-stay project was not designed to incorporate the heritage perspective of the space of the township but the study contends that this project does not operate in isolation of its physical space (Chapter 7). Besides being an abstract concept, in this study space constitutes an active element of cultural modeling; space is not a neutral container within which human actions are accomplished independently 
from its cultural shaping and heritage but a real and true meaningful feature contributing to structure human actions and give them purpose inside a society (Ashworth and Hartmann 2005). By following this reasoning, the reflection on tourist spaces takes on a particularly decisive role for the definition of cultural township tourism home-stays. This reasoning necessitates assessing township home-stay tourism with a historical view.

\begin{abstract}
"The location of apartheid heritage as having three characteristics. First, every 'homeland' and township is a monument to the apartheid system. Indeed the whole socio-spatial organization and relationships of areas and districts, of work, service and residential functions and of the transport systems that bound them together is a product of the attempt to establish racially separate development. Secondly, the recentness of the attempt to create a heritage of apartheid and its insertion into an already existing array of British and Afrikaner heritages has almost inevitably resulted in a scatter of sites and collections. Thirdly, much of the heritage does not easily lend itself to the architecturally impressive or the historically dramatic." (Ashworth 2004:6).
\end{abstract}

According to Ashworth (2004: 7):

\begin{abstract}
"much of the history of the anti-apartheid movement was acted out by poor people in the townships amongst the mundane and ordinary structures and environments of the poor. The homes (much like the Kwam eMakana home-stays) of its heroes and the sites of its events are by their nature unimpressive and commonplace compared to the imposing public buildings and grandiloquent monumental statuary of the previous regime. Events, such as the Sharpeville shootings of 1960 or the Soweto school uprising of 1976, may have been dramatic and memorable but the settings in which they took place are not."
\end{abstract}

The use of turbulent heritage poses distinctive issues and requires careful assessment based upon an understanding of the phenomenon from the viewpoint of the locals. Extant literature (Binns and Nel 2002; Nel and Rogerson 2005; Nel and Binns 2010) on LED pays little attention to the ability of government LED approach to address the needs of disadvantaged groups like women (Chapter 5). Research rarely goes on to assess the role space plays in determining the attitudes and behaviour patterns of the women tourism operators and the implications of their participation in relation to how they bargain with their heritage to navigate a sector they were previously excluded from as a source of entrepreneurial economic empowerment. This study posits that the goal of black economic inclusion in tourism is laudable, however, in order to attain progressive engagement of the black population as producers of township tourism demands an understanding of the heritage through a process of conscientisation. The argument is that black South Africans may have to reach a certain level of consciousness before they can perceive their space differently and be called to make 
decisions about the nature of their involvement let alone participation in tourism entrepreneurship.

\subsubsection{Network and culture}

Additionally the study adopts the network perspective which often seems to be oriented either towards structure (strong or weak ties, with the issue of trust emerging as a strong characteristic) or the individual as networker (Johannisson 1995; Burt 2000). To a certain extent network perspectives offer an alternative view which binds together the individual with the spatial socialization of a place. This presents a challenge with township tourism where people - within as well as outside its realm are thought of as the ones who are going to carry out the actions that could change the structure of the network. Individuals are intermeshed in networks and this process of change (Giddens 1984) and the closer one gets to these processes the more they become blurred and vaguely outlined. As Mønsted (1993: 219) concludes: "networks are hard to identify, apart from regular socio-metric patterns, which may not be very important in innovative contexts". Thus the network approach could provide insights into what processes of township tourism could look like, but still it does not illuminate what to look for in processes of transformation. Active networks may be established to make productive ground for the creation of an entrepreneurial culture (Chapter 4).

The creators, custodians, interpreters and managers of township tourism not only may have, but are very likely to have, quite different motives and objectives than the visitors. Similarly, McEarchern (2001) and Murphy (1997) proffer that the explicit intentions of many of the managers and interpreters of sites and museums of heritage tourism are frequently and openly expressed to be informative. Ashworth (2004: 5) describes it from the viewpoint of governments, "the principal function of heritage is the legitimation of dominant ideologies and jurisdictions and thus a revolutionary change in the ideology of the state will be reflected in a radical change in public heritage which is adjusted to concur with new power relations, popular aspirations and values". He goes on to explain that "a new past needs to be explicitly created to reflect and support the new present, whilst the old becomes at best irrelevant and at worst contradictory". However, Ashworth (2004: 5) maintains that

"the simple argument for change is modified in South Africa by two constraints. First, the realization of a new heritage agenda costs time and money and there is a shortage of both. Secondly, a simple and definitive shift from the old to the new would threaten the stability of the transition. The democratic government is publicly committed, to a multi-racial and multi-ethnic 
consensus. This raises the sensitive issues of establishing the trappings of the new state legitimacy while assuaging minorities, including those who were committed to the old".

The culture approach can explain less tangible limitations in the proliferation of entrepreneurship (Johannisson 1995; Davidsson 1995; Conklin Frederking 2004) and BEE in township tourism (Chapter 4). Other concepts that provide similar explanations are 'human capital' and 'social capital' (Moser 2009). These concepts give hints to 'soft' factors explaining challenges and variations, but say little about the processes that generate or prevent entrepreneurial activity. The study addresses this gap by assuming a connection between the individual and the space they inhabit, however, the culture concept may illuminate how it works (Chapter 7). Previous research on township tourism can to a substantial extent be characterized by these three approaches. All three harmonize with the approach to BEE as a discriminating attribution of individuals and the idea that disadvantaged individuals could be 'helped'. This presumes government intervention and the promotion of external assistance in the form of financial support towards the black population may be of benefit however this uncertainty reveals a possible oversight; are informal networks a more selfgenerating support mechanism (Chell and Baines 2000; Bisk 2002; Hjalmarsson and Johansson 2003; Greene and Storey 2004). As such the individual is also recognized as initiator of conscientisation beyond the institution (Chapter 4). Laukkanen and Niitykangas (2003) point to the strategies of local decision-makers as a key, Johannisson and Nilsson (1989) launch the concept of community entrepreneur as someone who works as a catalyst in helping others to pursue opportunities. While Johnstone and Lionais (2004) instigate the notion of community business entrepreneurship to refer to individuals who themselves perceive opportunities, activate networks and achieve entrepreneurial activity with implications far beyond what is involved in running their own firm. When Rampele (2008) discusses empowerment in South Africa he stresses that for success there must be involvement by inhabitants in the processes that could transform their space. In this study, focus is on processes that might have the potential to transform a locality, in economic as well as social measures (Chapter 7). Empowerment in this study is thus viewed as being about social change as much as it is about transformation within the context of the government RDP (Chapter 4). Given that “... change means to go from something stable and known to something less stable and more unknown [it is plausible that there is] ... - depending on the degree of stability - a lot of interaction among the people involved"(Berglund and Johansson 2007:5). Not surprisingly, there are bound to be agreements as well as disagreements of what, as well as how, things are to be 
done. As such the study presents an analysis of township tourism actors' dialogue (Freire, 1970) occurring in the Eastern Cape Province of South Africa.

\subsubsection{Conscientisation}

Conscientisation has been described as an ongoing process of reflection, interaction with others, and action that facilitates an authentic voice for the oppressed (Freire 1978). Arguments exist that state authenticity or authentic voice can never truly be reached because realities are socially constructed (Berta-Avila, 2003). Freire (1978) posits that individuals might experience an epiphany and see themselves in the context of a new reality, but in truth, that reality is constructed to manipulate the individuals (Chapter 4). It is envisaged that when the oppressed understand that manipulation and alienation exist, this realization becomes the stepping-stone to experiencing the process of conscientisation, however, the process in itself does not take place in a vacuum. Berta-Aliva (2003) points out that the process can be gradual or accelerated, depending on the conditions created for dialogue and reflection. In a study of Xicanos in the United States, Berta- Avila (2003) maintains that dialogue and reflection become essential to naming individual experience in the world and to conceptualize it within a historical context. For the South African perspective, authentic becomes the act of naming the reality in which one exists with the understanding that reality is never static, rather it is always changing. Darder (1995 in Berta-Avila 2003: 119) "stated it is a worldview or a historical outlook that puts into perspective the experiences that in this case black South Africans confront in their daily lives. 'Voice' becomes the political action that challenges the domination that wants to keep black South Africans nameless and voiceless (Hooks, 1989). Voice through dialogue becomes the means to rupture the silence to transform the reality".

Figure 2.1: Transformative Praxis

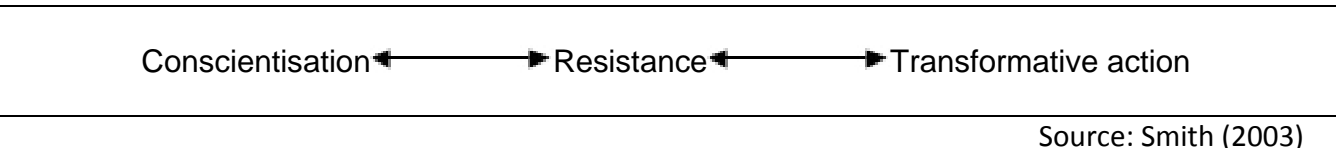

Source: Smith (2003)

'Authentic voice,' in its totality, becomes, as Hooks (1989 in Berta-Avila 2003:119) said, "a process of healing to help guide [black South Africans in this case] into transforming their world and to allow them to move from object to subject (see Figure 2.1). The challenge in the context of this study is that little attention has been paid to the need 
to build group cohesion or a women community consciousness that would enable the women to see the need to jointly solve their poverty problems (Chapter 5). Consciousness is a major theme in this study exemplified by the adoption of Freire's (1972) Pedagogy of the Oppressed's, ideas on consciousness function as a supporting theoretical framework informing both the literature review and methodological considerations.

\subsection{The Study Setting}

Next the chapter will describe the setting of the study area then it will turn to two episodes which the author considers important illustrations. These episodes, occurred during township reality tours in Kynsna and Port Elizabeth (as shown in Map 2.1) at first were confusing and something to which the author repeatedly visited during research. Quite simply, the episodes were so overwhelming that initially it was not clear what it was about these episodes that kept the author intrigued. Later viewing the events from multiple lenses it appeared to be a collision between conscientisation and the equality discourse. Higgins-Desbiolles (2006) describes reality tours as organized trips to developing communities that endeavour to show what real life is like in that community, including problems of violence, poverty and disempowerment. Admittedly, what ensues is the author's interpretation of the subject under analysis. Importantly, these episodes became paramount and their analysis highlighted other salient issues which influenced the shaping of the research design.

Two municipalities in the Eastern and Western Cape provinces of South Africa (see Map 2.1 ) provide the empirical setting. The Western Cape is one of the more affluent provinces with the distinction of having a well-established tourism sector (Visser 2009). While the Eastern Cape is characterized by some of the highest levels of poverty and unemployment in the country and has been described as one of the most vulnerable regions, with regard to the labour market, in South Africa (Pan African Research and Investment Services [PARIS], 2010). Not surprisingly much of the growth in international tourism has limited economic impact on the Makana region of the Eastern Cape, as most (approximately 5 million) tourism arrivals are accounted for by cross border visits from neighbouring Southern African Development Community (SADC) countries. Only 3\% of visitors to the Eastern Cape are from Africa and the Middle East making the Eastern Cape the 2nd least of the nine provinces visited by such tourists. This must be compared to $50 \%$ 
Map 2.1: South Africa showing positions of study areas; Knysna, Port Elizabeth and Grahamstown

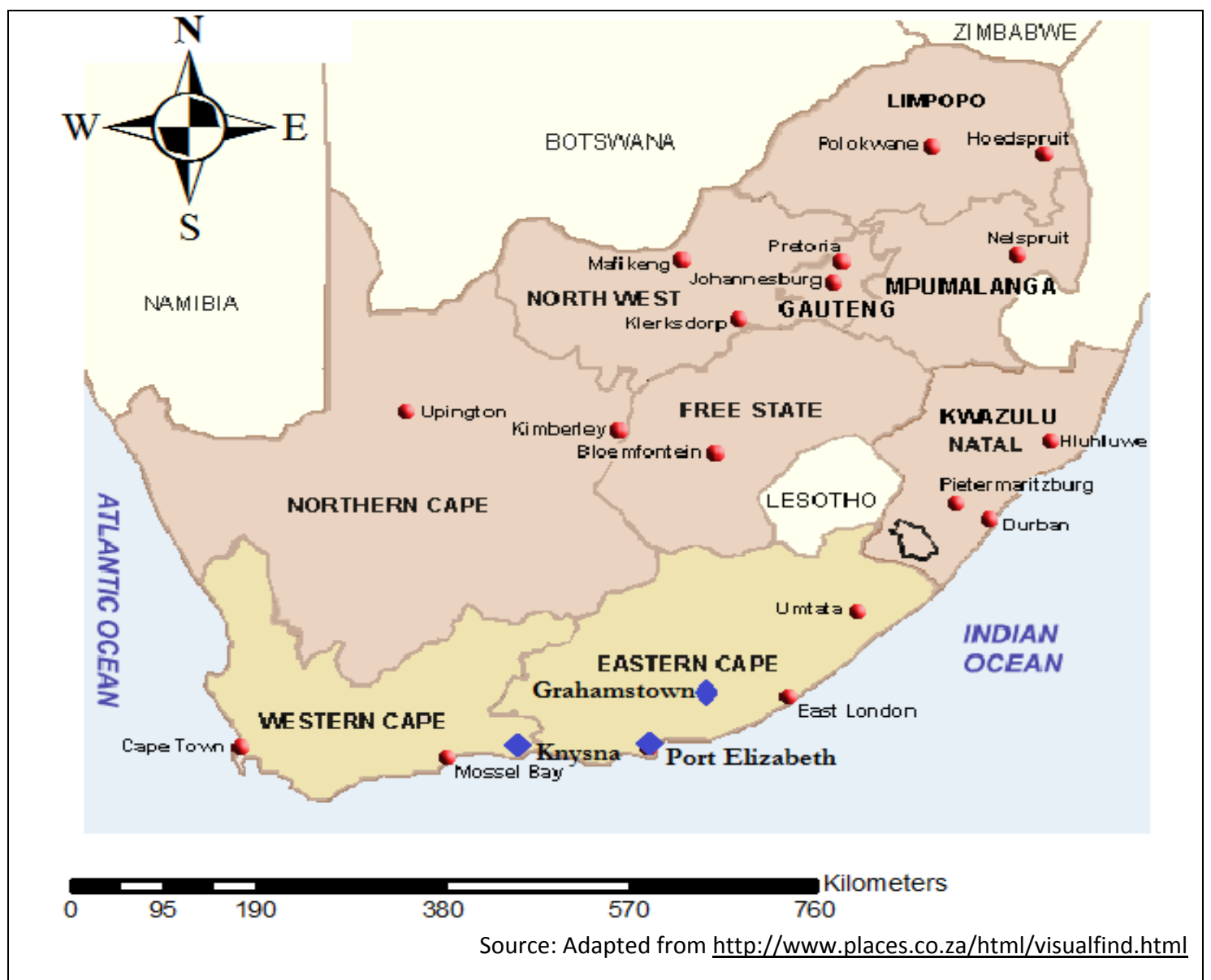

in Gauteng and $20 \%$ in KwaZulu-Natal. Approximately $16 \%$ of Eastern Cape visitors come from North America and 22\% come from Europe (South Africa Tourism, 2008). Understandably for policymakers such a situation is certainly a challenge, likewise for academics in the fields of tourism development and entrepreneurship.

Tourism growth represents a LED opportunity for the Eastern Cape, especially since tourism has been shown to generate more economic activity (through backward and forward linkages) than other forms of investment. Spending by tourists and the supply of goods and services demanded by tourists thus results in a much larger impact on the economy of the region than the initial spending. This is known as the multiplier effect. Using a rough set of analysis developed by Baaijens and Nijkamp (1997) calculations show that the tourism multiplier for the Makana Municipal area is less than, or equal to, 0.5 . This means that for every R1 of tourist expenditure in the municipality, an additional R0.5 is generated in indirect spending. 
The reader will now be presented with narratives of two guided township reality tours that the researcher participated in as part of field work. Significant episodes arising from the tours are highlighted.

\subsubsection{The Knysna township tour}

The purpose of the tour was defined in a meeting held with the Eastern Cape municipality directorate. Essentially the aim was for the team to see and learn from how Knysna incorporated its township as a tourism product through observing and experiencing a cultural township reality tour to inform the design of the proposed township tour in the Eastern Cape. The author was present at the said municipal meeting; this privileged attendance was facilitated through the author's affiliation with a home-stay pilot project (the doctoral study research site). The training partners of the home-stay project were in discussions with the municipality to roll out a similar project. The author had a visiting fellow position with the hospitality and tourism institute to investigate the economic and social contribution of the home-stay project. Against this background the author was invited by seniors at the training institute and the municipality to join the tour in the capacity of researcher. The purpose of the tour was communicated to the tour company by the organizing officer from the onset. A team of eight (see Table 2.3) including the author set off on a six hour drive in a minivan to Knysna.

Table 2.3: Knysna reality tour participants

\begin{tabular}{|l|l|l|l|}
\hline Position & Nationality & Sex & Reference \\
\hline Municipality Director & South African & Female & MDF \\
\hline Deputy Municipality Director & South African & Female & DMDF \\
\hline Program Manager & South African & Female & PMF \\
\hline Program Officer 2 & South African & Male & POM \\
\hline Driver & South African & Male & DM \\
\hline German Intern 1 & German & Female & GIF-1 \\
\hline German Intern 2 & German & Female & GIF-2 \\
\hline Researcher & Zimbabwean & Female & RF \\
\hline
\end{tabular}




\subsubsection{The tourist gaze}

This section will describe the author's experience of the Knysna tour. The discussion is derived from observations, conversations and discussions that the researcher held as part of research activities. The group arrived at the tour operator's office (start point and transferred to the company's tour bus. The tour guide, who was also the owner of the company, was a white British man who had settled in Knysna some 18 years earlier. His first remark was "oh my do I feel a fool today, giving a township tour to a group of black South Africans ... [chuckles]." On arrival in Knysna township we took a guided foot tour around an informal settlement. The settlement houses people while they wait to receive a government funded RDP house. At the time of the tour the government was said to have built over 2.3 million houses for disadvantaged South Africans. The foot tour did not include interaction the community; rather the group walked around, looking and listening to the descriptions of the surroundings as narrated by the tour guide. For instance comments like "these little shacks in some cases can house between 12 and 15 people, ..." and "when you walk in the township and see men or women holding hands they are not necessarily 'gay' they are just used to living in crammed spaces. They are not like Westerners we have 'personal space'...". The reality tour made a point to highlight the physical living conditions, such as the lack of adequate sanitation facilities or the few running water taps servicing the settlement (see Picture 2.1).

Picture 2.1: Informal settlement in Knysna Township

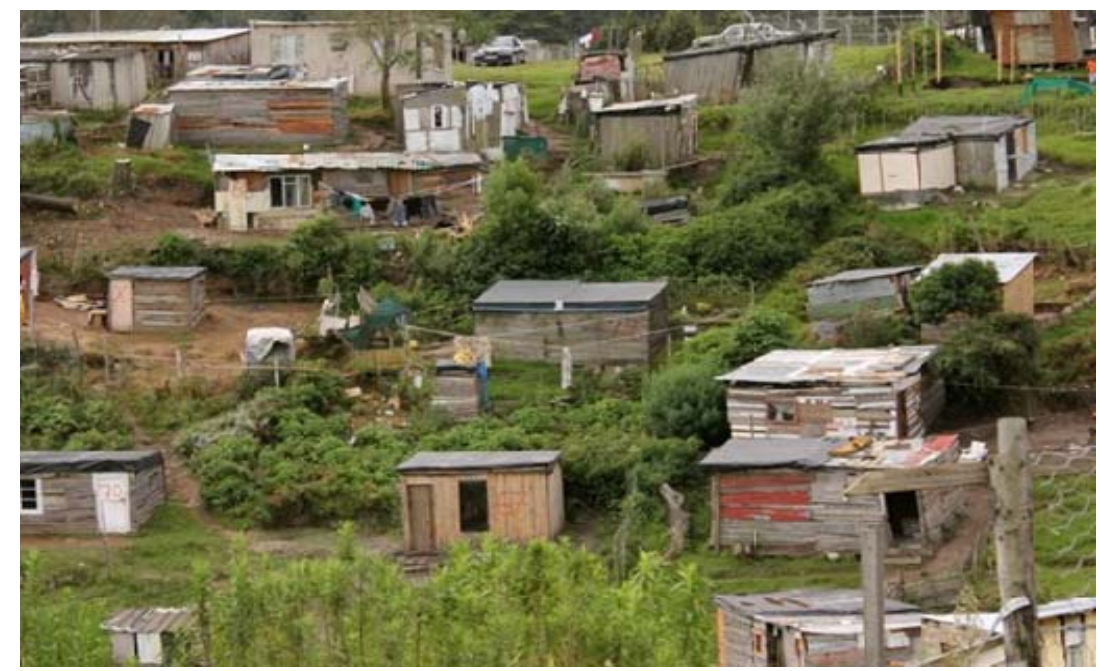

Knysna 2009 (The Author). 
The author (RF) was quiet and observant of the surroundings and the other group members. The group members were very quiet, interestingly the men in the group kept walking a few steps ahead, not really listening to the descriptions offered. The South African women kept shuffling their feet and occasionally whispering in Xhosa among themselves, while the German interns looked both shocked and interested. Interestingly, no one really asked the guide any questions. As we walked towards the tour bus, the programme manager (PMF) falls in step with RF. She then says "I am so sick of this portrayal of us as if we are animals ... [sighs]" and she went on to pronounce "my people have suffered [clicks her tongue - denotes frustration or anger]. Simultaneously, RF realized tears were streaming behind her sunglasses in that moment realizing that she was angered at this portrayal of township life. After the guided walk, as we approached the vehicle a small girl aged about five lingered around the tour guide and he playfully tugged at her arm. When we had settled in the car he told us "I normally bring the kids sweets, but today I forgot them, that's why she was hanging around ... she expected to get some sweets [chuckles] the little rascal ..." There was silence; it was as if everyone held their breath waiting for someone else to speak up. People were shuffling their feet and trying to catch the eye of other participants to see if someone dared to respond to this statement. RF who had a research position was repeatedly nudged by the person (PMF) sitting to the left. Obviously, she wanted her to say something. Initially, RF took great care not to intervene and to maintain a position of the 'neutral observing researcher' instead, so on this instance she bit her lip (admittedly, inside my emotions were raging! 'neutral'no chance!). We drove past numerous RDP residential areas (see Picture 2.2) where people had been resettled into; the guide explained how families live in the informal settlements in makeshift housing until they are allocated a house.

Picture 2.2: Showing a Reconstruction and Development Programme housing

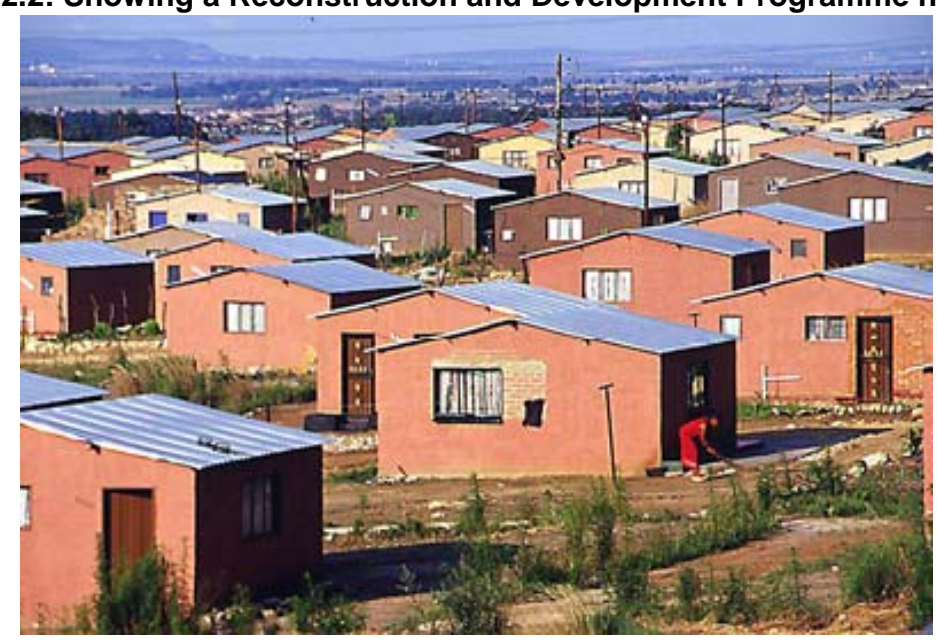

Knysna 2009, (Letsaolo, 2009). 


\subsubsection{The 'Lobola' episode}

The most significant incident came toward the end of the tour, the township in Knysna overlooks the 'white' residential areas which are either on or face the waterfront. As we approached the highest point of the hill in full view of the white suburbs as they were formerly known the guide pulled off the street and he turned round to face the group and said "I like to end my tours here, with the same story, in the West we marry for love, here it is different; when a man takes a wife he pays the woman's family it is called 'lobola' ... [laughs] ..." There was absolute silence; there was shock mixed with disbelief in the faces of passengers, RF was so amazed at this comment. After prolonged silence, RF decided to speak up. That decision meant stepping out of the neutral 'researcher role' (at this point I acknowledged to myself that since this reality tour had started I had been anything but neutral) and simultaneously reacting as an African whose marriage custom happens to be also 'lobola', as such the author voiced "but that is not accurate we are neither bought nor sold into marriage" [with a lot of emotion in her voice that it was shaking]. He responded after a moment of silence stating "well [pause] yes you are not sold, but you have to understand that this explanation is for the benefit of the Europeans in the group they have no idea about the culture here." (Admittedly, the tour guide had no explicit knowledge of the RF's role in the group; the tour had been arranged by the administration office. He also did not know that the RF lived in Europe and had done so for ten years). Given that response RF challenged him further unequivocally stating that "all the more reason why it is important for you to portray the culture accurately!" He was visibly startled by the vehemence of the protest, at that point he went on to quantify that "indeed it is not a sale of the daughters by the family, [pause, shuffles uncomfortably] but rather it is a way for the sons-in-law to show the girl's family that he will be able to take care of her" RF started to contest this explanation "that is not exactly ..." and at that point the MDF instructed RF "stop! Not here, we can talk about this later when we are on our own ..." out of respect for MDF and her position and in observing protocol RF was present by invitation, she was silenced.

Simultaneously, RF observed that the men (DM and POM) were quiet with very guarded taut expressions on their faces; it appeared to be a deliberate, calculated form of learned composure. For the remainder of the tour no one from the party spoke, the guide showed the white residential areas and explained that in the country Knysna's townships were the closest to the white residential areas. "In other towns they are very far apart, it is not dangerous here". On finishing the tour the guide asked if there were any suggestions or comments to improve the tour experience. No one spoke up, he probed again for opinions of the experience, and instead an uneasy 
silence befell the bus. After a considerable pause the guide turned to RF and asked "what are your thoughts?" Responding entailed setting aside the 'researcher role' again, RF spoke candidly about her observations "I am amazed at how the tour did not involve any interaction with the locals as equals on the basis of cultural exchange through dance, music or food. These are very vibrant aspects of township life; instead this was a tour that highlighted deprivation and suffering of a people, having lived till the age of eight in a township myself I found this ...". At that point MDF again asked the author to "leave it, we can discuss this later" interestingly this time DMDF, PMF, DM and POM (including the men) objected, with DMDF vocalizing "let her speak he asked for comments" and all the participants agreed. That said RF just summarized stating "I think there should be more cultural elements integrated in the tour" again this was done to be respectful for MDF. The tour guide defended their tour structure stating that "you have to appreciate that our primary market is backpackers, inclusion of these products will make it too expensive for our market". There was no big debate after the tour but at dinner that evening it became clear that this incident had obviously made some impact during the day, there was a heated discussion.

Admittedly, after the experience of the Knysna tour, I was depressed, I did not have motivation to carry out the research and for a while I struggled with this. In order to carry on I had to accept that there was no neutral point for me with this research. With that I started to look for a methodology that embraces the situation I found myself in (see Chapter 3). I asked in interviews and discussions with tourism stakeholders of township tours and repeatedly the name of an organization in Port Elizabeth came up. When I found out that this tour company was owned by a white couple I was less than enthusiastic. Nevertheless given the number of times the company was mentioned positively as a best case example I decided to go and see. I will not profess that I had a neutral mind before embarking on this tour, I actually had very strong reservations and I prepared myself for yet another harrowing day. What ensued was so different from my expectations that it alerted me of my own prejudices, I was ashamed at the assumptions I had made, simply I was so inspired by the Port Elizabeth Township tour. The following section will detail the experience.

\subsubsection{The Port Elizabeth township tour}

Two months after the Knysna township tour we went on another township tour in Port Elizabeth in the Eastern Cape. Again the tour was conducted in a team, this time of five including the author, (refer to Table 2.4). 
Table 2.4: Port Elizabeth reality participants

\begin{tabular}{|l|l|l|l|}
\hline Position & Nationality & Sex & Reference \\
\hline Program Manager & South African & Female & PMF \\
\hline Program Officer & South African & Male & POM \\
\hline Prospective Entrepreneur & South African & Female & PEF \\
\hline German Intern 1 & German & Female & GIF-1 \\
\hline Researcher & Zimbabwean & Female & RF \\
\hline
\end{tabular}

Similar to the first tour the group drove to Port Elizabeth to the pick-up point. On arrival our driver opted to stay at the pick-up point instead of going on the township tour with the group. The group was combined with a Canadian couple who were on holiday in the country. The aim was the same as that of Knysna tour, the intention of the tour was communicated to the tour company beforehand and this time the author set up an interview with the owner of the company to be held after the reality tour at their offices. The tour guide was a black South African, a man "born and raised in Kwazakhele Township, Port Elizabeth who was studying towards his law degree while working" with the tour company. The tour guide says "This is a wonderful company to be part of. Not only do we get to explain and expose our culture, we also assist the people from our townships." During an interview with the managing director of the company, the director described the tour guide as having been "instrumental in developing the tourist experience in the township".

The tour started at the waterfront moving towards the city centre, the guide narrated the history of the city, stopping at various historical monuments including the cell that Steve Biko was held in before he was transported to Pretoria, where he was pronounced dead on arrival. From there we headed to the township areas driving for long distances between the buffer zones, used in apartheid times to separate the racially divided residential areas. The most luxurious suburbs were often occupied by a mainly white population (see Picture 2.3), then there are predominantly Indian areas, followed by the colored (mixed race) areas and on the periphery are the black Townships (refer to Picture 2.2 and 2.3 ), largely the same socio-spatial organization that still persists throughout the country. 


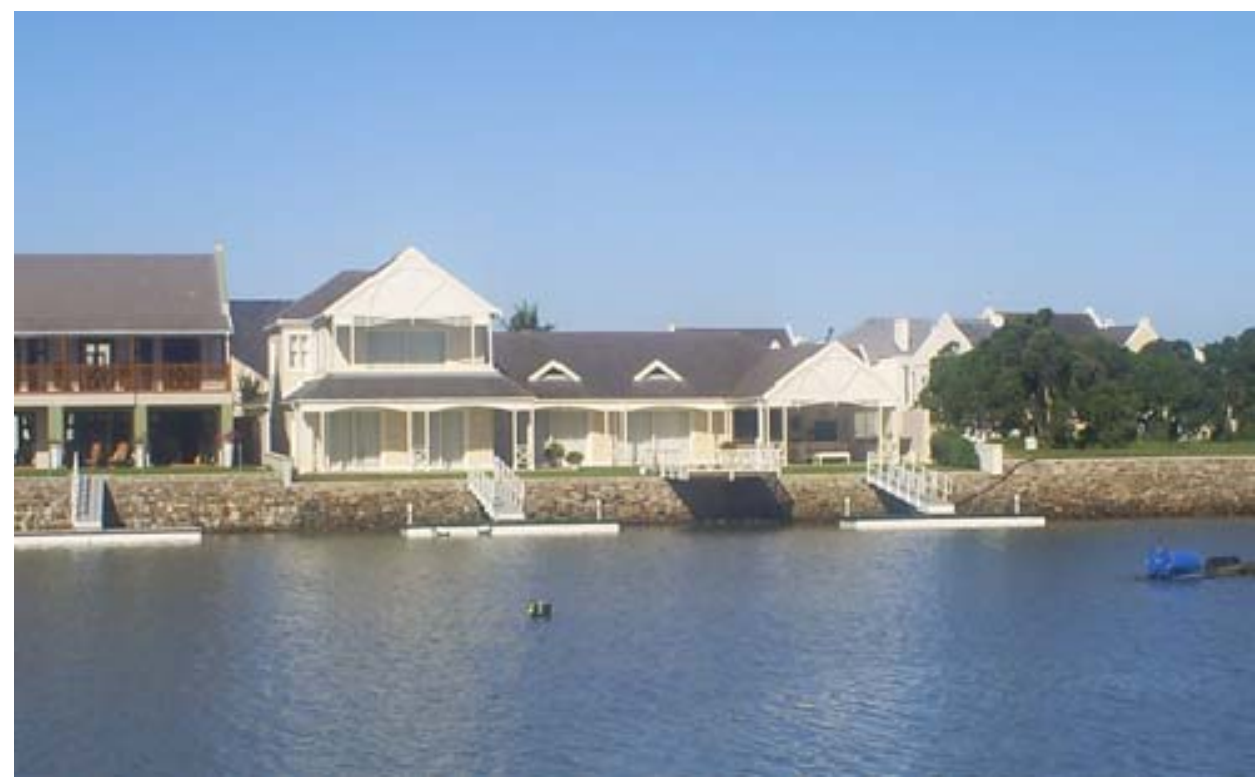

Port Alfred 2009, (The Author)

During the tour the guide talked about how the ideology of racial separation was implemented through a separate development policy that defined space and subsequently the services and resources available to inhabitants. He explained how black people were forcibly removed from their land without compensation resulting in the emergence of the present day informal settlements which still house a large proportion of blacks in the country. As we drove past a white residential area the tour guide told us that his parents were evicted from that area, they had owned property there. Remarkably, he spoke of this incident without any bitterness for what his parents had endured. He also informed the tour participants that the present government had reopened the cases of the people who were displaced by similar expulsions across the country. It occurred to RF that this might be the reason for the graceful way he spoke about his parents' misfortune - RF pondered; had the family at least received monetary compensation? Probing revealed that they had not received compensation he explained that "my father died during apartheid and my mother does not even want to hear the mention of the land ... [heaves a heavy sigh] ... so we have decided not to bring it up again, it upsets her so much she cannot even bear to think about what they went through, ... they lost all they had worked for". The bus was stunned into silence, a quick surveillance of the other passengers revealed a range of emotions, pain, shame, humiliation, controlled anger and perhaps pity. The tour guide however carried on talking about the townships without visibly altering his mood, stopping for local delicacies (the smiley face - sheep heads sold on street corners 
prepared by local women). He also talked about the vibrant dance and music culture of the Townships. We stopped at an arts and cultural village where residents sold various handmade curios, he also took us to the home of an elderly woman who is an herbalist (Sangoma) and she told us about her mixed racial heritage and life story.

\subsubsection{Primary school visit}

As part of the reality tour we also stopped at a local primary school; we arrived at the same time with another tour bus with a group of white South African women who were also taking the reality tour with the same company. Our guide informed us that we will be combined with the other group for the school tour. He mentioned that in the twelve years of the company's history they have never had white South Africans take a township tour with them, stating that "we have hosted many whites from other countries but never our own". He was visibly excited about this and he said "this is definitely a start ... we are making progress." Upon arrival at the school our group (Group-A) was ushered into the administration block, there we met the other group (Group-B) in a waiting hall. Greetings were exchanged; interaction between the groups was formal. After a few moments the headmistress of the school walked in and introduced herself, she was a black South African woman who had grown up in the Township and had attended the same primary school. Instantly one noticed her engaging gregarious and welcoming disposition.

After a brief introduction the headmistress took us on a guided foot tour of the school, first showing us the computer classrooms started without government funding. She spoke of how she acquires the computers "I ask for computers from companies that are discarding, remember 2000 - millennium bug? ... we have maintained a relationship ... some do not work we use those for spare parts". She spoke gratefully about three young German men working in Information Technology (IT), who visited the school through the township tour and how they volunteered two days of their holiday time to repair some computers. Stopping in front of a 40 foot shipping container painted in bright colours, she announced proudly "this is going to be our library, it will be open by next January". She explained how the opening had been delayed because one of the companies that had promised to donate books had a change in management and priorities were different. As she said this there was a chorus of "no's!" at the sound of this the headmistress turned to face the group and vehemently she stated "no pity here! We will get it open, we will find a way ... we have achieved so much!" With that she purposively moved on to show us an extensive vegetable garden. "We feed our children lunch, some of these children come from very poor homes that they can go without a meal, we ensure that they have at least one". 
The author was very quiet throughout the tour walking behind everyone, this was to allow for observation of the whole group. At one point as RF stood quietly looking into a classroom with pupils that the group had just been shown, the headmistress walked out of the classroom she walked towards the researcher and said in a quiet resolute voice while tugging at her hand "sisi [sister] you can do anything that you put your mind to!" I met her gaze and we smiled, she led us back to the administration block and there was tea and amagwinya (a type of doughnut) set out.

\subsubsection{Afternoon tea}

At tea seating was free interestingly the groups did not mix, opting to sit with tour group members. The author sat between the Canadian couple to the right and GIF to the left, small talk started across the table with members of different groups. RF remained quiet observing the interaction closely. The women from group-B were keen to establish a rapport with the Canandian couple and GIF in group-A (our group). Interestingly, no one from group-B attempted to speak to PMF, POM, PEF or RF from group-A. Some ten minutes later RF asked GIF to pass her the jam. As the three women from group-B sitting across from RF heard her speak for the first time they looked at RF with a lot of interest all of a sudden and one asked "oh are you American or Canadian?" to that RF answered "no" and offered no explanation. Immediately, GIF offered a brief but detailed profile of RF, as she expanded on her narrative RF watched as the women listened in what can most accurately be described as 'amazement'. There was suddenly a lot of attention directed at the RF; the fact that she was carrying out doctoral research and based in the Netherlands caused quite a stir. Numerous questions pertaining to RF's nationality, experiences of living and studying in the Netherlands and language proficiency were posed. To RF this change in behavior was preposterous the new feigned interest was distasteful, but RF maintained a tactful façade. Right then the driver came to announce that it was time to leave. On standing up the women wished RF well and one tugged at RF's arm, RF looked squarely at her and the woman said "you are a brave young lady, ... I wish you the best in your endeavours". With that RF said thank you and made her exit. On settling in the tour bus GIF turned and said to RF "now I understand everyone's reaction of during Knysna tour ... those women in there were absurd! ... How could they ignore you like that and then change when they found out what you do and where you live?" RF did not offer a verbal explanation instead she just laughed and shrugged.

\subsubsection{Interview with tour company founder}

During the interview with the managing director of the tour company held after the tour at the company's offices it was established that the idea to start a tourism 
venture centered on township culture started during university days. At this time the founder and some friends used to talk about the vibrancy of the township culture and its simultaneous camouflaged existence. Interestingly, the founder (white South African man) together with his black friends used to frequent entertainment spots such as Shabeens [local taverns] in the township. Information from the interview highlighted that the company was incepted as a profit generating business using entrepreneurial capital (Chapter 4). The aim was to create awareness about township culture that had been veiled from the world. Following the comment by the tour guide that they were giving their first tour to white South Africans that day, it was important to probe into what drove the founder to establish the tour operating company. The response was swift and precise "there was a gap in the market and the idea made sense so I invested my money. He also added that "our company is based on a business model, we are in it to make a profit, we partner with local businesses in the township, though we are engaged in various corporate social responsibility projects within the community". The founder spoke candidly of what he considered to be the true goal of apartheid "it aimed to break a people mentally, and in that regard apartheid was successful, the black population faces a lot of psychological trauma; definitely there are issues with confidence, self-worth and self-belief". He went on to elaborate that "government empowerment programmes seem to always omit this issue - the root of black poverty in the country; this is the key to unlocking wealth for the black population". When asked what he thought the government role was in the diffusion on entrepreneurship his response was "can entrepreneurship be taught?" he went on to say "I believe people are born entrepreneurs, but I believe issues of confidence, selfworth and self-belief are important for RDP".

\subsection{Discussion}

The study will apply a discourse approach to analysis that will be supplemented with critical pedagogy to make sense of the issues illuminated during the two reality tours. The intention is to make clear how critical pedagogy can be related to township tourism in order to deepen understanding of how dominating discourses could act as obstacles to processes of empowerment. With critical pedagogy the study connects to the ideas of Paolo Freire $(1970,1998)$, and in respect to discourse the study draws from poststructuralist thoughts, and more specifically from Laclau and Mouffe (1985). According to Laclau and Mouffe (1985), dialogue, vocabulary, metaphors, stories and the framing of various phenomena through the use of language is vital for the constitution of reality (Berger and Luckmann 1991; Burr 1995; Gergen 1999 in 
Berglund and Johansson 2007: 509). Consequently, both approaches share the view of language as constitutive, although they do not agree on the extent to which this is the case. Both Freire (1970) and Laclau and Mouffe (1985) are also inspired by, yet deviate from, Marxism and have, therefore, in common a critical stance considering how particular dominating views suppress humans. Indeed, Freire's thoughts have been developed primarily within educational science, among educationalists and primarily within a developing country context in the empowering of the poor. In relating his thoughts to a discourse perspective the intention here is to develop an understanding of how dominating discourses can function as oppressive elements in processes of township tourism. So, instead of referring to humans as oppressors, as Freire did, here dominating discourses are seen as oppressing. Of course humans employ these discourses, but most often, the study argues, people are unaware of the oppressive effects they produce. The following section will present an analysis of the interrelated issues revealed during the township reality tours. An overview how these issues inform the study as markers of conscientisation processes as suggested by Freire (1978) will be introduced.

\subsubsection{Space and development}

The experience of the Knysna tour was for the most part rather awkward, the comment "oh my do I feel a fool today, giving a township tour to a group of black South Africans..." automatically separated the participants on the basis of race. This remark signaled to the guide's hesitation to tour with a group of black South Africans. Understandably, the task at hand must have been overwhelming, he had to literally take people to their 'backyard' and tell them what life is like in a socio-cultural space that he himself has never inhabited. The contention as it was raised during the discussion at dinner is although he identified a business opportunity - that is commendable, the issue as it was debated at dinner was centered on his decision to conduct the reality tours himself. It emerged that it would have been more palatable to employ a local, arguing it would have made the experience authentic. Ritcher (1995: 81) cogently observes that while tourism is often marketed as a 'politically neutral' domain of human activity, it is characterized by the same complex social fault lines of class, gender and in this case 'race', that run throughout society. "How we choose to remember and commemorate events," she writes "is a very political act". This is a very relevant commentary, especially when you consider the remarks by Ashworth (2004) that if the new South Africa wishes to continue to involve its white, coloured and Asian minorities in its economic, social and political life, which is its clearly stated policy, then it cannot either demonize them or write them out of the script of the country's 
founding mythology. It needs at least their passive consent if not active embracing of the official heritage narrative. The 'rainbow nation' therefore may well have to accommodate separate heritages within the public domain, however uncomfortable or even contradictory these may be (Ashworth 2004). This realization validates the assertion made by Mønsted (1993) that in recognizing the limitations of network perspectives reveals a potential for networking in the creation of culture. On the other hand, tour participants conveyed that the Port Elizabeth tour guide, who lived in townships all his life, appeared very knowledgeable and this translated into a confident and pleasant atmosphere. He showed how blacks in the township negotiate their livelihoods in confined spaces while forging a culture and identity with dignity. The participants in the Port Elizabeth tour concurred that the guide successfully provided insights into a longitudinal human development story detailing the efforts of people and their government to strategically accumulate assets, networks and structures to escape poverty and attain the overall goal of $B E E$, however fraught with numerous challenges. The tour guide covered such issues as housing, employment, family dynamics, violence, and peace. This is similar to the work of Moser (2009) in her book Ordinary Families, Extraordinary Lives, where she charts the lives of families in Guayaquil, between 1978 and 2004; the result is a deep and holistic insight into the lives of a community.

\subsubsection{Discourses}

An issue arising during Knysna tour as argued by Urry (2002) is the visual nature of tourist experiences which underlies his concept of the 'tourist gaze'. The concept refers to visual elements of landscape which distinguish it from what is conventionally encountered in everyday life (Urry 2002: 3). He also points out that there are different tourist gazes, which may vary according to social groups and historical periods. The events of Knysna tour highlighted a lack of understanding of township culture by the guide resulting in the tourists gazing in a way evocative of how humans look into animals in a zoo. In relation to the township tourism concept it can be argued that this 'zoo effect' dehumanizes a people's way of life - outsiders pay to come and stare without any interaction on the basis of a shared equal platform as humans, presents a challenge for conscientisation in the locals. Snowball and Hamer (2008) postulate that while this sort of reality tours tourism has certainly brought economic rewards, there is also a danger that the social impact of tourists in such culturally sensitive areas can do damage to the very everyday life experiences that they are trying to experience (Chapter 7). They suggest that there is need to understand that township people do not always like the tours that now pass regularly through this place, some of these give 
them the feeling that they are living in a zoo. It is probable this 'zoo effect' stems from racial segregation of socio-cultural spaces during the apartheid years resulting in the lack of experience and awareness among whites about black culture and socioeconomic diversity. Similar challenges have been documented in other former settler states for instance Namibia and Kenya (Mbaiwa 2005).

There is something to be said about the portrayal of townships as places of squalor and poverty by a white male who does not reside in a township. This portrayal solidifies the assertion advanced by the founder of the Port Elizabeth tour guide that "on the surface, townships seem merely to be muddled areas overflowing with marginalized people. This is to some extent true, but once you delve deeper you will recognize that they are also places of great strength, courage, song and dance, survival, love and yes, happiness". During the heated debate a dinner after the Knysna tour anger was expressed by the South Africans in the group about the issue of giving the children sweets. This was the first time that the man in the group openly voiced their dislike of the whole tour. This certainly illuminated to the issue of muting of voices (Freire 1978). This also revealed the sidelining of the viewpoints of the people that live in the township and have become in part tourism products and a source of income for the reality tour operator. This led the author to ponder on how this has a bearing to identity construction and social identity, both issues were identified by Freire (1973) as important in the conscientisation process. What does the white man in a bus full of tourists bringing sweets to the children symbolize to these children?

This begs the question: how do black South Africans bargain with an industry that they were excluded from except as suppliers of cheap labour given their very limited educational and business backgrounds? It is important to point out that during apartheid black culture was decimated and labeled inferior (Mutunhu 2011; personal communication), now the same culture is on show, this is conflicting and for many a difficult undertaking, undoubtedly something can be found lacking. Considering the observations highlighted by the owner of company that conducted the Port Elizabeth tour that "... the black population faces a lot of psychological trauma; definitely there are issues with confidence, self-worth and self-belief" (Chapter 6). Borrowing from the work of Freire $(1973,1978)$ the study observes that black South Africans are indigenous to the land on which they live; the land is the connection to their identity and understanding of life. This connection was the threat to the growth of racially based capitalism in South Africa during apartheid, thus making it necessary to impose on the natives a dehumanizing cultural hegemony. The issue in the post-apartheid era is when black South Africans enter the schooling, workforce and entrepreneurial 
systems; they do so with a sense of displacement. They are not sure how to view themselves or how to view their role. Even if in their roles as students, workers or entrepreneurs they do not view themselves as displaced, they are still in a "culturally subordinate position because they have been raised within the socio-cultural and class constraints dictated by the dominant culture" (Darder 1991: 59). A necessary interrogation for this study is how then do they use township tourism as a positive force to advance progressive human values and as a platform that influences positive identity construction and social identity (Chapter 4)?

As illustrated in the primary school episode during the Port Elizabeth tour, the enterprise discourse can sometimes be excluding when it comes to ideas and people barred from its conception. Conversely, if dominating - and perhaps also excluding discourses exist, it should also be possible to find empowering discourses. When the headmistress fervently announces "no pity here!" she rejects the notion of pity, suggesting that as a school they are empowered to attain their goals. She reinforces this by stating "we will find a way ... we have achieved so much!" Her defiance and refusal to succumb to hardship speaks volumes of her outlook and beliefs and by extension as noted by Freire her 'prise de conscience' - conscientisation is certainly at work here. Thus the equality discourse when introduced, in this context, is empowering as it per se criticizes and puts into question the truths which are advanced by the enterprise discourse. Progression is a core concept in both the enterprise and the equality discourses, which does not seem to be a problem to the former as it is well situated within its economic dimension (Berglund and Johansson 2007). However, the equality discourse is drawn from less familiar discursive resources as, for instance, adult education, gender studies, empowerment and not least the ideas of Freire. What does this talk have to do with poverty reduction through township tourism? This question indicates the difficulties which arise in communicating the 'equal' idea. When such a situation of incomprehensibility is reflected upon and followed by contact, interaction and dialogue, it can also be seen as an opening for intervention and transformation of life, so that people can start to be seen as progressive both in their own eyes as well as in other people's eyes (Berglund and Johansson 2007).

\subsubsection{Cultural hegemony}

To maintain economic and political power, the dominant culture must impose cultural hegemony based on the theory of a 'colonial legacy' (Macedo 1998 in Berta-Avila 2003: 119) in this case also the 'apartheid legacy' to convince, black South Africans of 
their second-class status. The interplay of colonial and apartheid legacies in conjunction with cultural hegemony can be damaging for the participation of black South Africans in township tourism because it facilitates, as McLaren (1989) suggests, "the consent of the oppressed while simultaneously letting the oppressed play an active role in their own oppression" (in Berta-Avila 2003: 120). The notion of cultural hegemony was evident in both tours, in the Knysna tour the way the guide narrated black culture at a subservient level in contrast to his 'Western' culture. While in the Port Elizabeth tour the white women showed pity over the challenges faced by the headmistress; this is interpreted as viewing the black headmistress as relying on goodwill - less capable. While, over tea, cultural hegemony was enacted by some women through the varied degrees of importance they attached to people of different races. In these instances we are given a more multifaceted view on how conditions of dominance are manifested, the 'race' concept becomes one of other social divisions such as gender, class, religion, sexuality, age, profession, and so forth. From a pedagogical perspective, Freire (1973) advocates education as ideological and concentrates on the creative capacity of humans and the actors' ability to resist oppression. As such the collective characteristics above point to a strong suppression of the equality discourse and to the presence of domination and prejudice discourses present in tours.

Simultaneously, the experiences provided by the tour guides signaled the proliferation of dialogue as a necessary step to empowerment. Dialogue is the means available for us to learn about the oppressive elements in everyday life (Berta-Avila 2003). According to Freire (1970: 73) "silencing does not promote dialogue, and dialogue cannot exist unless the dialoguers engage in critical thinking - thinking which discerns an indivisible solidarity between the world and the people and admits of no dichotomy between them - thinking which perceives reality as process, as transformation, rather than as a static entity - thinking which does not separate itself from action, but constantly immerses itself in temporality without fear of the risks involved". For Freire, reflection and action cannot be separated as they compose two dimensions of a 'word', which is the essence of dialogue. Thus, "there is no true word that is not at the same time a praxis", and "to speak a true word is to transform the world" (Freire 1998: 87). Dialogue is, therefore, a powerful 'tool' to transform township tourism through processes of conscientisation. The easier path to choose is one of silence, which does not force the discourses to change but instead allows them to continue on as usual (Paiva 1992). As witnessed during the Knysna tour when the researcher confronted the guide "... but that is not accurate we are not sold into marriage". Whatever the experiences may be, a choice is presented when the door is finally opened (Paiva 
1992), a decision of conscientization is a process of constant self-reflection. If black South Africans choose to claim their authentic voice, they make a conscious decision that will go against the grain and definitely be viewed by the dominant culture as divisive (Darder 1995). Here they remained silent and the researcher was the one to voice an objection. This going against the grain was evident when MDF told her to stop "... not here, we can talk about this later when we are on our own ..." To this Mutunhu (2011; personal communication) makes the observation that "by virtue of her age it is plausible that she suffered the most as a victim of apartheid and entrenched coping mechanisms ... it is reasonable to concede as a victim of apartheid now in a position of authority in 'rainbow nation' South Africa ... to set very high standards of fairness to all", this implies not 'rattling the cage' or as Mutunhu puts it "if I am benefiting in material possessions that I never had before then why rock the boat?" This reaction adds weight to the remark made by the founder of the Port Elizabeth township tour company when he highlighted that one of the major issues compounding BEE is the trauma of apartheid. The anger and disbelief by the South Africans over the events of the day of the Knysna tour surfaced at dinner where there was a heated discussion. In short, conscientisation was at work. Listening is also part of the dialogue because it recognizes the existence of others. It is important to remember, as Freire (1998) proposed, that the ideas and experiences of some individuals are not the only ones that exist. By listening, they are working toward fostering an environment where all who engage can begin to claim their authentic voice. In this way, the praxis that transpires from discussion, dialogue, and listening becomes a frame of mind. Reflection and dialogue become synonymous because reflection without dialogue or dialogue with no reflection undermines real transformation (Freire 1970). If dialogue and reflection are not looked at within the same spectrum, one risks killing the dialogue and unintentionally acting as the oppressor (Berta-Avila 2003).

When oppressed people realize they can be owners of their reality, they can experience both joy and pain. This moment becomes a point of relief because a weight carried for so many years is finally lifted. The imposed silent voice that lived in seclusion emerges and shouts to the world, "I am here, I exist, and I am not going anywhere" (Berta-Avila 2003). During this process, a legitimate sense of anger overwhelms the person and allows them to place into context the injustices experienced (Freire 1998). Freire's assertion was enacted by PMF when she said "I am so sick of this portrayal of us as if we are animals ... my people have suffered". For many, this anger becomes a fire of motivation that "fuels the desire to resist, create change, and continue the fight" (Berta-Avila 2003). From the limited interaction with the headmistress it is possible that she has gone through some of the above processes 
of conscientisation. Freire (1998) stated that it is understandable to have this anger, but one cannot let it get out of control. If the anger controls the situation, then the people are not allowing room for reflection, possibly demonstrating reactionary as opposed to critical attitudes (Freire 1998). Black South Africans cannot process the experiences if they do not reflect. When the anger is processed and let go, they can come to an understanding of who they are in this world. Paiva (1992) maintains that coming to terms with this new understanding helps them to open up their hearts, spirits, and minds to love. Loving one-self is a beginning step to finding justice.

The role of confidence building is integral to the raising of the self-esteem. Lack of confidence and self-belief could actually explain why township women home-stay operators are not so active in the management of resources at their disposal. Timothy (2001: 167) in a view he shares with D'Amore (1983) and Brohman (1996) posit the view that first, residents must be empowered to determine their own goals, needs, and desires for development. Second, they must be given opportunities to benefit from tourism economically and socially. However, these scholars don't give academic attention to the need to create an environment in which communities can reach a stage where they can make empowering decisions, especially in a township tourism context. Whilst these authors agree that communities have to be empowered, there is nowhere they specifically isolate the factors and issues that have to be looked at to allow disempowered individuals to voluntarily present themselves for empowerment (Chapter 5). Although the strengths of the empowerment model (see Scheyvens 2002) are undeniable, its applicability to a LED township tourism project scenario opens up a number of questions. The argument advanced is that one can only empower individuals that would have presented themselves for empowerment. Perhaps then the first stage in meaningfully project management, may have to do with creating an environment in which marginalized residents feel free and motivated to be part of the township tourism economic processes (Chapter 6).

A point to consider here from the events that transpired during the tours "is that individuals and groups enter the cycle from any position and do not necessarily" (Smith 2003: 5) have to start at the point of 'conscientisation'. "In other words, individuals have been caught up in transformative praxis unintentionally". This as suggested by Smith (2003: 5) poses a different viewpoint to "much of the writing that tends to portray a lineal progression through the stages of 'conscientisation, resistance and transformative action'". Experience from the tours seems to suggest that these elements may occur in any order and indeed may all occur simultaneously. It is important to note as well that the arrows in the diagram go in both directions, which 
reinforces the idea of simultaneous engagement with more than one element. It is also an inclusive representation of struggle and moves beyond the hierarchical representation implied in the lineal model. The reasoning adopted is in the cycle diagram (Figure 2.2). All black South Africans met during the tours can be plotted somewhere on the circle (some are standing still, some are going backwards, others are well advanced). The point is that every South African is in the struggle whether they like it or not, whether the know it or not. This standpoint led to the formulation of the main issue under investigation in this study - do the conscientisation levels of the women of Kwam eMakana affect their economic optimization of the government LED township tourism initiative?

Figure 2.2: Conscientisation in South African township tour participants

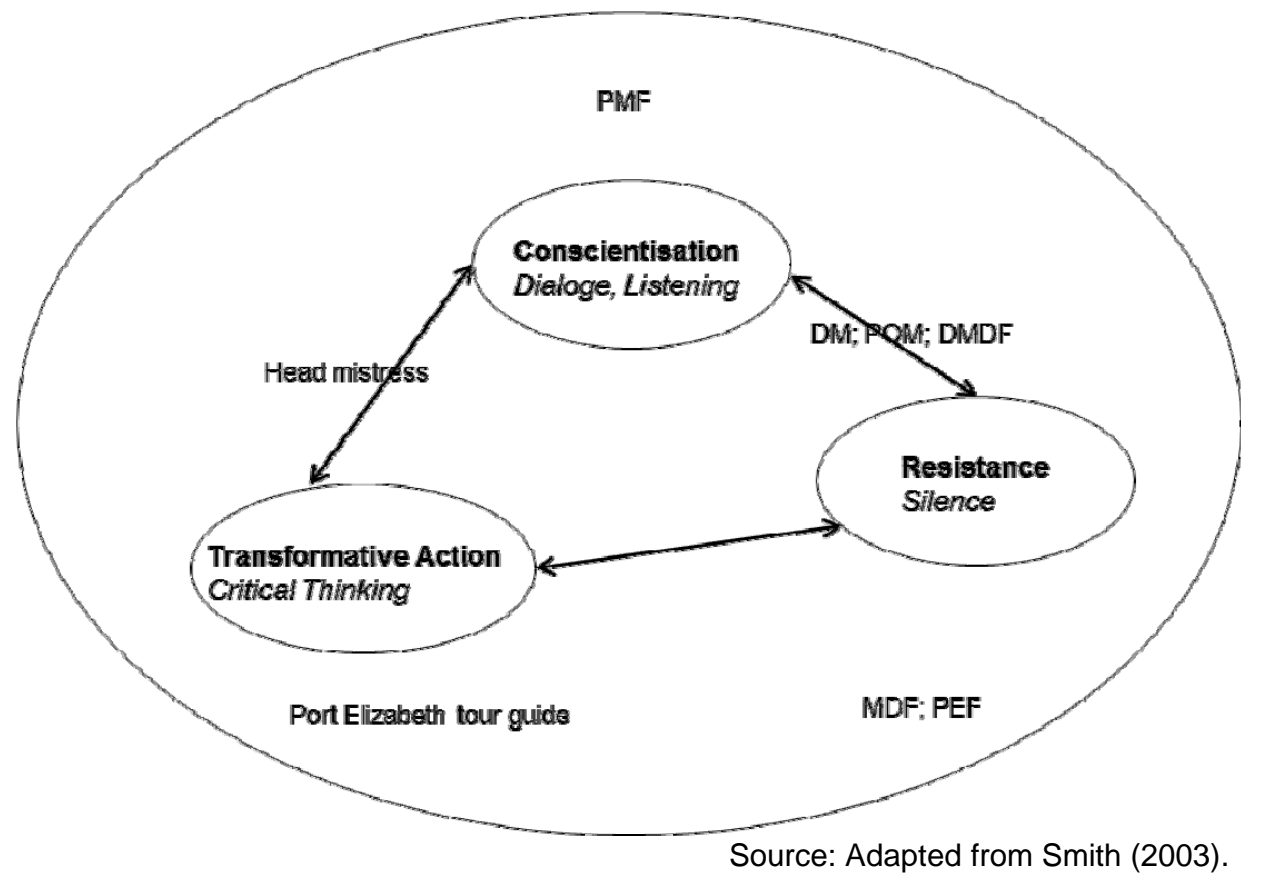

\subsection{Reflections}

With the benefit of hindsight the multiple roles of the researcher involved negotiating and functioning from 'insider' and 'outsider' perspectives. During field research it was important to remain nuanced of the effects that one's positionality can have on the research (Visser 2000), as demonstrated in the experiences described here. Coming to terms with the author's multiple privileged and underprivileged identities depending 
with the setting be it class, race, gender, nationality or educational background, in peripheral contexts, demanded a degree of introspection. The author often questioned her own legitimacy in the field and wondered what right she had to enter communities and write about lived realities that she often did not experience. As such it is acknowledged that the chosen actions might have influenced the outcome of the research. The view is that this allowed for the collection of a richer and more vigorous data set that allowed the author to connect seemingly unrelated issues to yield an extensive interconnected web of information (Chapter 3). Considering the number of silent signals which were made, such as frustrated and surprised facial expressions and looking wide-eyed and the nudging were probably one of many futile attempts to make someone raise a voice. It is probable that as a researcher, at that moment, to have influenced the silence by perhaps making it more obvious than it might have been if the researcher were absent. On the other hand, voicing concerns over the 'lobola' and 'tour design' issues during Knysna tour and in illuminating the underlying connotations over tea at the primary school during Port Elizabeth tour also had an impact. The uncomfortable comments, actions and insinuations did not just pass unnoticed, but instead invited other members of the tour to reflect upon and enter into dialogue amongst themselves about the conceptions and misconceptions of what their culture and traditions represent to the outside world.

\subsection{Emerging Issues for Research}

Black South Africans in the townships face challenges in attaining conscientisation through township tourism. From the above discussion it is clear that issues of culture, identity and equality remain significant in gaining BEE. The psychological damage on the black population brought about by apartheid will take time to correct (Chapter 6). Propagation of the benefits of the industry alone are not enough to attain the much sought after conscientisation; rather an account of the impacts of apartheid on the people and their socio-spatial organization as defined by apartheid is imperative. In their minds it is possible that township tourism as an economic empowerment strategy reinforces the stigma of the black South Africans being confined to a space that was deemed inferior (Chapter 7). Requiring they show case the cultural heritage of this space that they were forced into. Some might not be ready to do so, this situation presents a dichotomy, indeed the people want to preserve and nurture their heritage and at the same time they have a desire to be accepted by the economic system in order to escape poverty. Episodes from reality tours suggest that in part black South Africans are still affected by the socio-spatial organization of apartheid in how they live 
and the economic opportunities they engage in are influenced by the same dynamics (Chapter 4). To ascertain if conscientisation as progressive human value is a factor in how the women of Kwam eMakana negotiate entrepreneurial economic empowerment. Against this background the following are brought to the forefront:

1. For BEE through township tourism to be successful there is need for a candid assessment of the social impacts of the socio-spatial organization of apartheid.

2. There is need for greater sensitivity in the representation of culture and identity which attempts to achieve a balance between tourist expectations and dignity and respect for the local culture.

3. In light of the policy commitments in the sector it is suggested that the government should lead the way by applying the same sensitivity and incorporating into government initiated capacity building programmes amongst the historically disadvantaged.

The study adopts the view that a stronger focus on equality could help find ways to address the neglect and misrepresentation of black culture and spaces in the township tourism context. In the end as suggested by Ashworth (2004) the heritage of apartheid, its systematic imposition of suffering and of the ultimately successful resistance to it, is central to the founding narrative of the new state, the reconciliation of its 'rainbow' constituents, and the way that the state projects itself to nationals and visitors alike. It will be enhanced and expanded as the state develops and will play an increasingly significant role in extending the township tourism products on offer. However its very importance in all these fields adds to its complexity. The future, not only of a flourishing township tourism industry in an economic sense but of South Africa itself, and especially of its unique multi-racial and multi-ethnic experiment in nation building, may depend upon the successful management of this past. The gaps in knowledge identified in this chapter will be investigated in the four empirical chapters in the hope that they will provide answers that will help create a vibrant and sustainable township tourism in South Africa. 


\section{Chapter Three}

\section{Methodology}

\subsection{Introduction}

This chapter provides the philosophical and methodological foundations of this study. A brief overview of the wider philosophy of social science research is presented and leads into the acceptance of the hermeneutic phenomenological approach and discussion of its validity. Discussion of research orientations provides a conceptual framework and the importance of reflexivity is raised; and the relevant significance of situating myself as researcher is presented. Contextualizing the research within a postapartheid approach is also discussed and the women-centered focus of this study provides a pathway to understanding the lived experiences of others. To complement the historical perspective, and to avoid being stuck in a thematic groove, the study area in some sense became a laboratory in which a range of themes are explored: capabilities, social interdependence conscientisation, entrepreneurship, space, culture and contact. Such a multidimensional approach allowed for the inquiry of multiple interconnected issues permitting the place to remain albeit transformed - as such, the place became the cornerstone. Various issues emerged during the township reality tours (see Chapter 2 for a detailed discussion) and to a large extent determined the direction of this research. I constructed the research questions based on the gaps that were illuminated in the field (Chapter 2 ) by employing mixed methods that will be discussed in detail in this chapter.

\subsection{Phenomenological Approach}

In order to develop a clearer understanding of how the women of Kwam eMakana bargain with entrepreneurial economic empowerment through the government LED project, the study is phenomenologically inspired with an emphasis on hermeneutics, calling for naturalistic methods to develop an understanding of human experience in a specific context (Yanow and Schwartz-Shea 2006). This inspiration was based on the need for a suitable explorative research design. Phenomenology "accepts that researcher subjectivity is inevitably implicated in research, it is precisely the realization of the inter-subjective interconnectedness between the researcher and the researched that characterizes phenomenology. The important considerations are to what extent, 
and how, researcher subjectivity should be arranged in phenomenological research" (Finlay 2008: 6). As Giorgi (1994: 205) firmly stated, "nothing can be accomplished without subjectivity, so its elimination is not the solution. Rather how the subject is present is what matters and objectivity itself is an achievement of subjectivity". Phenomenologists (Groenewald 2004; Smith 2004; Yanow and Schwartz-Shea 2006) "also concur about the need for researchers to engage a 'phenomenological attitude" (Finlay 2008: 6). By using this attitude, "the researcher strives to be open to the 'other' and to attempt to see the world freshly, in a different way. The process has been described variously as disciplined naïveté, bridled dwelling, disinterested attentiveness, and/or the process of retaining an empathic wonderment in the face of the world" (Finlay 2008: 6). The aim of phenomenology in this study is as described by Moustakas (1994: 26) "the return to the concrete, captured by the slogan 'Back to the things themselves!"”.

The research methodology of this study also leans to "hermeneutic traditions which recognize the central role played by the researcher" (Finlay 2008: 2), and do not support the use of bracketing (Smith 2004 in Finlay 2008). Methodologically, the study draws on interpretive (hermeneutics), critical and the - post-structural traditions (Prasad 2005). According to Prasad (2005) post-structuralism recognizes the power of discourse to shape reality (both perceptions of reality and the concrete reality that is perceived). The theoretical views are entrenched in the adoption of a phenomenological attitude that privileges subjective meanings, multiple and changing truth (Fossey et al. 2002; Prasad 2005; Hawkesworth 2007; Altinay and Paraskevas 2008). It draws on the qualitative approach to inquiry (Phillimoore and Goodson 2004; Altinay and Paraskevas 2008) and utilizes qualitative methods (Pradhan 2003) of participant observation and semi-structured in-depth interviews complemented by questionnaire surveys. All research instruments were administered during two fieldwork visits between 2009 and 2010. Field notes were gathered and informal short conversations were held, tape recorded and later transcribed. While participatory observation activities included: township tours; social functions (for example, attending a Xhosa wedding); visits to local homes; and interaction with the community at large.

\subsection{Hermeneutics}

Hermeneutic sensibility refutes that it is conceivable to bracket researchers' experience and understandings. Instead the view is researchers need to come to 
cognizance with their preexisting beliefs, making it possible to examine and question these beliefs in light of new evidence (Halling et al. 2006). Finlay (2008: 17) maintains that researchers need to bring a "critical self-awareness of their own subjectivity, vested interests, predilections and assumptions and to be conscious of how these might impact on the research process and findings. Researcher's subjectivity should, therefore, be placed in the foreground so as to begin the process of separating out what belongs to the researcher rather than the researched". Thus, in terms of research, "the researcher should shift back and forth, focusing on personal assumptions" and then returning to looking at participants' experiences in a fresh way (Finlay 2008: 7). Wertz (2005) picks up on this point when accepting the value of a researcher's subjective experience when engaging the epoché of the natural attitude and during the analyses that follow from the phenomenological reduction. He suggests this process allows researchers to "recollect our sown experiences and to empathically enter and reflect on the lived world of other persons ... as they are given to the firstperson point of view. The psychologist can investigate his or her own original sphere of experience and also has an inter-subjective horizon of experience that allows access to the experiences of others" (Wertz 2005: 168).

\subsubsection{Hermeneutic phenomenology}

Hermeneutic phenomenology is concerned with the human experience as it is lived. The focus is toward illuminating details and seemingly trivial aspects within experience that may be taken for granted, with the objective of creating meaning and achieving a sense of understanding (Wilson and Hutchinson 1991). Heidegger focused on 'Dasein', which is translated as 'the mode of being human' or 'the situated meaning of a human in the world'. He viewed humans as being primarily concerned creatures with an emphasis on their fate in an alien world (Jones 1975; Annells 1996). Consciousness is not separate from the world, in Heidegger's (1927/1962) view, it is a formation of historically lived experience. He believed that understanding is a basic form of human existence in that understanding is not a way we know the world, but rather the way we are (Polkinghorne 1983). Koch (1995) outlined Heidegger's emphasis on the historicality of understanding as one's background or situatedness in the world. Historicality, refers to a person's history or background, it comprises what a culture gives a person from birth; it offers ways of understanding the world (Koch 1995). Through this understanding, one determines what is 'real'; yet Heidegger also believed that one's background cannot be made completely unambiguous. Munhall (1989) described Heidegger as having a view of people and the world as inextricably linked in cultural, social and historical contexts. 


\subsubsection{Pre-understanding}

Interpretive methods seek understanding of researchers entering a research setting with some pre-understanding and a general plan; the study is allowed to unfold with the assistance of informants. Emphasis is placed on investigating phenomena in their naturally occurring states, requiring the researcher to get close and acknowledge interaction between data and data collection methods (Geertz 1973). Cooperation between the researcher and the researched reduces researcher bias and encourages, in this case, women's voices. The importance of getting close to the participants in research is noted by Patton (1982), he states "the methodological mandate to be contextually sensitive, inductive, and naturalistic means that researchers must get close to the phenomenon under study. The institutional researcher who uses qualitative methods attempts to understand that setting under study through direct personal contact ... through physical proximity for a period of time and through the development of closeness." (Patton 1982: 10). This pre-understanding according to Heidegger (1927/1962) is the meaning or organization of a culture that are present before we understand and become part of our historicality of background. Laverty (2003: 8) describes pre-understanding as "something a person cannot put aside, as it is understood as already being with us in the world". Heidegger went as far as to claim that nothing can be encountered without reference to a person's background understanding. Koch (1995 in Laverty 2003: 8) "described this as a binding unity between a person and the world". According to Laverty meaning is found as we are constructed by the world while at the same time we are constructing this world from our own background and experiences" (2003: 8). There is a transaction between the individual and the world as they constitute and are constituted by each other (Munhall 1989 in Laverty 2003). Interpretation is seen as critical to this process of understanding. Claiming that to be human was to interpret, Heidegger (1927/1962) stressed that every encounter involves an interpretation influenced by an individual's background.

\subsubsection{Interpretive process}

Polkinghorne (1992) described this interpretive process as concentrating on historical meanings of experience and their development and collective effects on individual and social levels. Annells (1996) viewed hermeneutics as an interpretive process that seeks to bring understanding and disclosure of phenomena through language. Moreover, hermeneutics is the study of human cultural activity as texts with a view towards interpretation to find intended or expressed meanings (Kvale 1996). Gadamer (1975) viewed interpretation as a fusion of horizons, a dialectical interaction between the expectation of the interpreter and the meaning of the text (Polkinghorne 1992). " $\mathrm{A}$ 
'horizon' is a range of vision that includes everything seen from a particular vantage point. A person with no horizon, in Gadamer's view, does not see far enough and overvalues what is nearest at hand, whereas to have a horizon means being able to see beyond what is close at hand" (Laverty 2003: 10). "Questioning", he wrote, "is an essential aspect of the interpretive process as it helps make new horizons and understandings possible" (Laverty 2003: 10). Polkinghorne (1983: 375) cements this view by claiming that "understanding is always more than merely re-creating someone else's meaning. Questioning opens up possibilities of meaning, and thus what is meaningful passes into one's own thinking on the subject ... To reach an understanding in a dialogue is not merely a matter of putting oneself forward and successfully asserting one's own point of view, but being transformed into a communion in which we do not remain what we were". According to Crotty (1998), the theoretical perspective of interpretivism arose to conflict with positivism in its efforts to shed light on and explain human and social reality. Neuman (2000) effectively summarises the main differences of the approaches (Table 3.1). For the interpretivist, the primary goal of research is to understand. Emphasis is placed on gaining meanings and understanding, rather than just facts and generalisations. "Researchers cannot achieve the understanding; but rather an understanding of phenomenon at a point in time" (Polkinghorne 1983: 375).

Table 3.1: Summary of differences between research assumptions

\begin{tabular}{|c|c|c|}
\hline & Positivism & Interpretive Social Science \\
\hline Reason for research & $\begin{array}{l}\text { To discover natural laws so that } \\
\text { people can predict and control events }\end{array}$ & $\begin{array}{l}\text { To understand and describe } \\
\text { meaningful social interaction }\end{array}$ \\
\hline $\begin{array}{l}\text { Nature of social } \\
\text { reality }\end{array}$ & $\begin{array}{l}\text { Stable pre-existing patterns or order } \\
\text { that can be discovered }\end{array}$ & $\begin{array}{l}\text { Fluid definitions of a situation created } \\
\text { by human interaction }\end{array}$ \\
\hline $\begin{array}{l}\text { Nature of human } \\
\text { beings }\end{array}$ & $\begin{array}{l}\text { Self-interested and rational individuals } \\
\text { who are shaped by external forces }\end{array}$ & $\begin{array}{l}\text { Social beings who create meaning and } \\
\text { who constantly make sense of their } \\
\text { worlds }\end{array}$ \\
\hline $\begin{array}{l}\text { Role of common } \\
\text { sense }\end{array}$ & $\begin{array}{l}\text { Clearly distinct from and less valid } \\
\text { than science }\end{array}$ & $\begin{array}{l}\text { Powerful everyday theories used by } \\
\text { ordinary people }\end{array}$ \\
\hline Theory looks like & $\begin{array}{l}\text { A logical, deductive system of } \\
\text { interconnected definitions, axioms, } \\
\text { and laws }\end{array}$ & $\begin{array}{l}\text { A description of how a group's } \\
\text { meaning system is generated and } \\
\text { sustained }\end{array}$ \\
\hline $\begin{array}{l}\text { An explanation that is } \\
\text { true }\end{array}$ & $\begin{array}{l}\text { Is logically connected to laws and } \\
\text { based on facts }\end{array}$ & $\begin{array}{l}\text { Resonates or feels right to those who } \\
\text { are being studied }\end{array}$ \\
\hline Good evidence & $\begin{array}{l}\text { Is based on precise observations that } \\
\text { others can repeat }\end{array}$ & $\begin{array}{l}\text { Is embedded in the context of fluid } \\
\text { social interactions }\end{array}$ \\
\hline Place for values & $\begin{array}{l}\text { Science is value-free, and values have } \\
\text { no place except when choosing a } \\
\text { topic }\end{array}$ & $\begin{array}{l}\text { Values are an integral part of social } \\
\text { life: no group's values are wrong, only } \\
\text { different }\end{array}$ \\
\hline
\end{tabular}




\subsection{Research Model}

Several methods were used to gather primary data, according to Denscombe (2003) the choice of method/methods to use largely depends on the research purpose, resources available and to a greater extent, the skills possessed by the researcher. Neuman (2000) suggests that whatever data collection method is used, the researcher should make sure that respondents clearly understand the purpose and relevance of the study. To investigate the impacts of an aid/donor approach to BEE through tourism LED development initiatives the research combined participant observations, interviews, discussion sessions complemented by a questionnaire surveys (see Table 3.2). The data collection was carried out by the author during two field stays in 2009 and 2010 with a total duration of twelve months.

Table 3.2: Data Collection Methods

\begin{tabular}{|c|c|}
\hline $\begin{array}{c}\text { Observations } \\
\text { Municipality Directorate Meeting } \\
\text { Township Tours - Knysna and Port Elizabeth } \\
\text { Home-stay day visits } \\
\text { Home-stay overnight stays }\end{array}$ & $\begin{array}{c}\text { Interviews } \\
\text { Kwam eMakana Committee } \\
\text { Home-stay operators } \\
\text { Government project officers } \\
\text { Key Informants }\end{array}$ \\
\hline $\begin{array}{c}\text { Surveys } \\
\text { Home-stay operators questionnaire } \\
\text { Student Commentary }\end{array}$ & $\begin{array}{l}\text { Discussions } \\
\text { Home-stay operators during day visits (informal) } \\
\text { Home-stay operators and Committee (formal) } \\
\text { Students after overnight home-stay experience }\end{array}$ \\
\hline
\end{tabular}

Semi-structured interviews were also used to gain insights on the issues under study. In total the study interviewed 18 Kwam eMakana women home-stay operators and six independent home-stay operators (from Port Elizabeth and Ndlambe). Altogether, 33 interviews were conducted with tourism practitioners. This included a cross section of nine experts ( 2 consultants; 3 academics; 1 policy analyst; 1 project executive and 2 government officials).

The use of multiple methods was selected because a reliance solely on the researcher's construction would constrain the nature of the interactions. The diverse experiences, and perspectives, of the participants and researchers; and because of the need to probe multiple realities that are likely in a review of Kwam eMakana, a case study approach utilizing multiple data collection methods was selected. The methods employed are tabulated in Table 3.3 and explained. 
Table 3.3: Data Collection Strategy

\begin{tabular}{l|l}
\hline Research Question & Research Methods \\
\hline $\begin{array}{l}\text { 1. What is the relationship between economic } \\
\text { empowerment and progressive human values } \\
\text { for the previously disadvantaged in South } \\
\text { Africa? }\end{array}$ & $\begin{array}{l}\text { Observations; interviews; review policy documents; } \\
\text { literature review; township reality tours; attendance } \\
\text { at Municipal directorate meetings; pedagogic } \\
\text { approach; Conscientisation concept }\end{array}$ \\
\hline $\begin{array}{l}\text { 2. Can entrepreneurship be taught, inspired, and } \\
\text { diffused through a society to achieve BEE? }\end{array}$ & $\begin{array}{l}\text { Review of policy documents and reports; interviews, } \\
\text { discussion session; autonomy and interdependence } \\
\text { concepts }\end{array}$ \\
\hline $\begin{array}{l}\text { 3. What are the most significant qualities of a } \\
\text { successful entrepreneur, especially in the } \\
\text { uncertain environment of a developing country } \\
\text { context? }\end{array}$ & $\begin{array}{l}\text { Literature review; observations, home-stay day and } \\
\text { overnight visits; discussions; questionnaire survey } \\
\text { Emotional Intelligence approach; Capabilities } \\
\text { concept }\end{array}$ \\
\hline $\begin{array}{l}\text { 4. To what extent does cultural commoditization } \\
\text { drive the economics of government LED } \\
\text { tourism home-stays }\end{array}$ & $\begin{array}{l}\text { Overnight home-stay visits with student guests; } \\
\text { student guest commentaries; discussions with } \\
\text { home-stay operators; Contact theory }\end{array}$ \\
\hline
\end{tabular}

In Table 3.3 the reader is shown the research methods utilized to answer the four research questions under investigation in this study. The data collection strategy was used to design the enhanced research model (see Figure 3.1) applied in this study with the aim of developing a clearer understanding of how the women of Kwam eMakana bargain with entrepreneurial economic empowerment through the government LED project. The research model illustrates the interpretative interaction of the study at the two levels (local government and project) of analysis engaged in this study. At the local government level I supplemented the document analysis (policy and reports) with interviews with LED officials and tourism experts who had been involved in BEE legislative frameworks and initiatives. At the project level, I analyzed program objectives and how they had been implemented using secondary data. I also carried out interviews with persons responsible for the project implementation and the women home-stay operators and I observed the women during day and overnight visits to their home-stays. 
Figure 3.1: Research Model

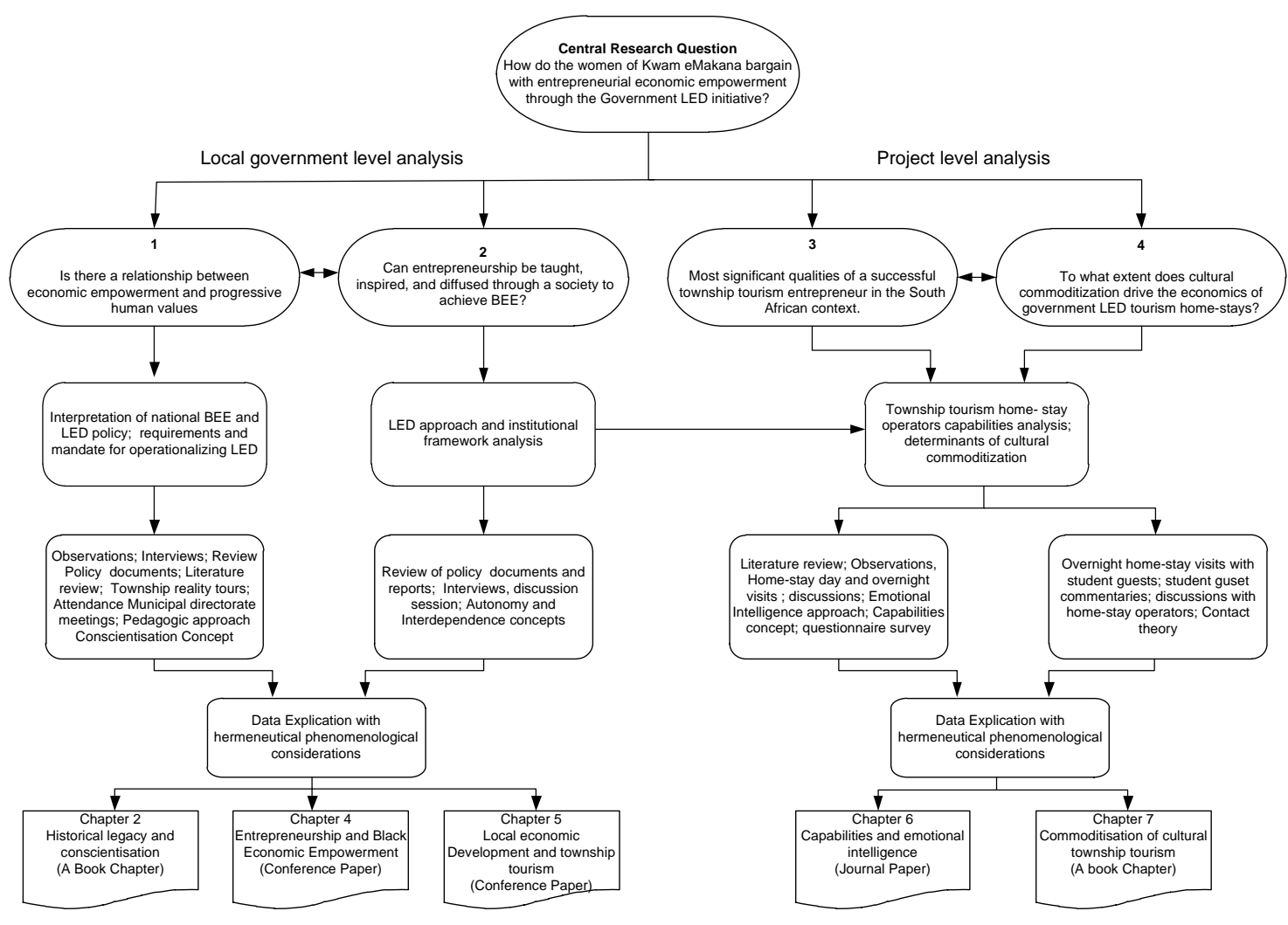

The ensuing sections discuss in detail the justification for the application of the research model.

\subsubsection{Relationship between economic empowerment and progressive human values}

In order to establish if there is a relationship between economic empowerment and progressive human values, observations were used to capture what the Kwam eMakana women home-stay operators actually do rather than what they say they do (Creswell 1994). Qualitative methods in the field, such as interviewing and participant observation, might be considered as obtrusive measures. I observed the surroundings of the women in their home-stays during day visits and engaged in discussions with the women. Various themes were illuminated giving rise to new lines of inquiry which were later incorporated in the questionnaire survey and the interview schedule, the discussions were of a conversational nature. The inquiries raised were directed at 
gaining clarification on an observed phenomenon or issue at hand. The observations were carried out at different times; early in the morning, mid-morning, at noon, and in the afternoon to mark any variations, but as there were no guests during this time no variations were noted. The purpose of the observations was to deepen the understanding of issues surrounding the relationship between economic empowerment and progressive human values in the women home-stay operators.

To be able to conceptualise the relationship between economic empowerment and progressive human values in the women home-stay operators, I elicited information through semi-structured interviews from a cross-section of stakeholders on the factors influencing economic empowerment through the LED home-stay project. The interview guide consisted of four issues 1) the women's role in Kwam eMakana; 2) the challenges at the leadership level of Kwam eMakana; 3) the respondents' interpretation of the future of Kwam eMakana; 4) the attunement of the government tourism development program to the principal goal of BEE. The semi-structured interviews allowed the home-stay operators and stakeholders to talk about their experiences and knowledge. While the interviews with the women home-stay operators focused on 1) the women's operational abilities in the running of their home-stays; 2) experiences and perspectives regarding the funding and structure of the project. In doing so, I explored topics that had not been considered relevant when designing the research trajectory, the semi-structured interview guide was also used to stimulate discussions about actual experiences the operators themselves identified as being significant for operating LED township tourism home-stays. This allowed me to not impose my preconceived notions of women entrepreneurial economic empowerment on the participants.

My invitation to participate in the municipal directorate meeting and the subsequent township reality tours afforded me the opportunity to observe the various considerations of local government authorities in operationalizing tourism for LED in the Eastern Cape. Salient issues emerged during the township reality tours (see Chapter 2 for a detailed discussion) and to a large extent determined the direction of this research. I constructed research questions based on the gaps that were illuminated in the field by employing the above-mentioned methods (refer to Table 3). With these gaps revealed, I reviewed literature on entrepreneurial economic empowerment, township tourism and LED policy documents and found the same gaps in literature. In this way, a hermeneutical phenomenology methodology helped me to reshape my research questions. This methodology permitted me to embrace my positionality and how it influences my interpretation of the results. Hermeneutical 
phenomenology accepts that researcher subjectivity is inevitably implicated in research, it allows the researcher to embrace their position with the research. The focus of this methodology is not on entering the field with pre-set theories which have to be verified or falsified. This allowed me to investigate any hunches I got; and themes and explanations I observed during my research activities. This led me to the discovery of the concept of conscientisation and how this has a bearing on development consciousness of marginalized communities (Chapter 6). To assess conscientisation a pedagogic approach (Chapter 2) was adopted.

\subsubsection{Diffusion of entrepreneurship}

Non-obtrusive qualitative methods, such as content analysis can be enlightening and enrich the emic understanding of effects of tourism (Babbie 1992; Holt 1997). Document analysis included a literature review on social interdependence. Evaluation of policy documents and reports proved useful in investigating matters concerning LED decision planning, implementation, decision making, monitoring and evaluation (Chapter 5). It provided valuable historical insights over time and how these influence present day policies in South Africa. However it could not provide insights on Kwam eMakana women home-stay operators opinions, needs or satisfaction with the LED project. The purpose of the interviews was to further explore women's experiences of operating LED home-stays by eliciting narratives from the women operators themselves in order to build on knowledge gained from the survey instrument. Additionally, in order to minimise issues of economic sensitivity, it was felt that the best method of gaining information from the participants was through individual semistructured interviews (as opposed to focus groups for example). The interviews in this research allow narratives to be developed as models of meaning to provide an important linkage between hermeneutic's abstract philosophical principles and the actual practice of hermeneutic interpretation (Laverty 2003). The interviews also ground this particular interpretive framework in a series of issues relevant to the phenomenological aspects of the person/culture relationship (see Merleau-Ponty 1962). That is, the personalised cultural meanings that constitute a person's sense of self-identity and the biographical significance of specific life events and experiences within this unfolding narrative of self (see Romanyshyn 1982). The cultural background provides the social categories, common sense beliefs, folk knowledge and interpretive frames of reference from which personalised meanings and conceptions of selfidentity are constructed (Faber and O'Guinn 1988; Holt 1997; Thompson 1997). 
In order to ascertain to what degree social interdependence influences the course of LED, the study was also interested in the interaction of the participants within the group as a means for eliciting information, rather than just collecting each individual's point of view (Creswell 1994). Therefore we carried out a discussion session with the women immediately after administering the questionnaire ensuring maximum participation. This was done to gain an appreciation of the women operators shared understandings of the LED project and the ways in which the women are influenced by others in a group situation. This allowed me to ascertain the group view from the individual view (semi-structured interviews). The discussion guide consisted of three issues 1 ) the experiences instrumental in the participants role in the government LED initiative; 2) the participants involvement in the development of their home-stays; and 3) the participants interpretation of their needs with regard to the future of the initiative. Questions regarding these issues were not developed prior to the observations and discussions, giving the freedom to word questions spontaneously and to establish a conversation style (Patton 1985) allowing the presentation of new questions while maintaining the flow of the discussion. The hermeneutic limitation however, is that the voice of the given subject will often express a nexus of personal meanings that are formed in a complex field of social and historical relationships. As such, a subject's self-perceptions can exhibit a considerable degree of situational variability depending on which personal meanings are salient in a given context (Thompson 1997, see also Belk 1975; Stayman and Deshpande 1989). This is particularly so in the case of exploring women's roles in their home-stays as their establishments have dual roles of home and enterprise; and undeniably this has embedded issues of capabilities and social interdependence.

\subsubsection{Significant qualities of a successful entrepreneur}

Addressing the main research issue posed by this question entailed the collection of objective data, so questionnaires were used. Their merit is they allowed for responses to be gathered in a standardized way, the speedy response rate was also an added benefit. As the questionnaire was administered in a session held at Joza Library where all the women home-stay operators were invited to participate through the Kwam executive committee. The information gathered was not as 'rich' as the themes established in the interviews and observations, however, information collected from the questionnaires enabled data to be gained on a broader spectrum of issues. This is important given the scarcity of scholarly research on the contribution of LED tourismhomestays to women entrepreneurial economic empowerment and women entrepreneurial capacities in South Africa. The aim of the questionnaire (Appendix 4) 
was to provide insights into respondents' characteristics, opinions and their home-stay features, and not to merely collect representative data to make mass generalisations (Chia and Yeo 1999) about township tourism or about home-stays. Themes used to develop the questionnaire were established from dependency and entitlement literature (Fitzgerald and Muske 2002). The questionnaire was designed together with an El expert, a co-author on the paper titled Emotional confidence levels and success of tourism development for poverty reduction: the South African Kwam eMakana homestay project published as a journal article in Tourism Management and included as Chapter 6 of the thesis. As part of its development, a draft of the questionnaire was given to a tourism consultant for comment on design. Following this, the questionnaire was pre-tested (pilot study) on six participants running tourism home-stays in Ndlambe (outside the sample area) to enable the pre-test respondents to provide feedback and suggestions for improvement. Results of pre-testing indicated that the questionnaire was easy to complete, with only minor amendments necessary.

Prior to disseminating the questionnaire at the session, we carried out a week long training workshop with 10 female native Xhosa/English speaking university students to assist with translating the questionnaire to the women. We decided on this to ensure that the women fully understood the questions, the women are not native English speakers and the researchers are not native Xhosa speakers. We deliberately chose to have female interpreters. It was agreed that bringing in male interpreters would most probably introduce other dynamics that were not part of this study (Yanow and Schwartz-Shea 2006). The translators were coached to avoid leading the women to a perceived desired response; and we monitored the session. Other methods that were used to elucidate pertinent issues for consideration in answering this research question, included observations during home-stay visits and a discussion session. Justification for these methods has been elaborated above. The study adopted an emotional intelligence methodology to assess how confidence levels impact the degree of economic empowerment of the women; and the relationship between capabilities of the women and attaining poverty reduction through entrepreneurship.

\subsubsection{Cultural commoditisation}

As a study investigating the role of culture in tourism home-stays for entrepreneurial economic empowerment, opinions and statements of guests' experiences formed a vital part of the methodology. Through interviews, observations and informal discussions the researcher went beyond the descriptive "whats" of cultural tourism to also afford answers or perspectives to more subjective and explorative "whys" and 
"hows". As part of the overnight visit analysis, working in collaboration with the project officer, prior to arrival at the home-stays the researcher managed to schedule interviews with the women home-stay operators after breakfast on the morning of departure. The interviews adopted a conversational style so that the women were comfortable in sharing their perception of the visit; and to also elaborate on the reasons why they hosted (choice of food and hospitality style) in the manner that they did.

This research question draws on data from 'before' and 'after' workshops where home-stay overnight visit evaluation surveys were conducted by three groups of students in November 2009. A total of 18 students across three groups participated in the study. The students participated on a voluntary basis and they were offered credit points at their study institution where the author has visiting fellow status. It was important to gather feedback from the student guests about their views of the cultural experience offered by the women home-stay operators during an overnight stay. This process began prior to leaving the academic tourism institute when the student guests were asked to briefly describe their expectations of home life in Joza Township. After returning from the overnight stay, the student guests were required to briefly describe their perceptions of the actual experience. This allowed for a before and after introspective look at the guests' opinions and possible insight into any variations between the 'perceived' and 'actual' experiences. In the 'after' workshop the student guests were required to provide open-ended commentaries on the same mini survey they filled out prior to the home-stay overnight visit. After the questionnaires were collected in the 'after' workshop the students engaged in an open-ended discussion on their home-stay experience in a group setting the researcher took notes and taped the discussion. The purpose was specifically to gain further data to assess the students' home-stay experiences. All of the 18 students participated in the requested discussion - providing an excellent response rate - though admittedly this was in part tied to the course credits to be awarded only on the completion of all required participatory steps.

In the context of cultural misconceptions, the aim was therefore to understand why and how these are created and how they can be conceptualized and hopefully avoided. The research does not aim to reject the fact that differences do cause misconceptions, but rather to provide a different and hopefully more analytical view on the phenomenon. The point is that seeking explanations in culture and human differences may very easily result in the halting of juxtapositions between individuals or groups already pointed out as incommensurable or imbalanced. Hence to account 
for this the study utilizes contact theory to provide illumination on the considerations for cultural commoditisation.

\subsection{Explication of the Data}

The heading 'data analysis' is deliberately avoided here because as Hycner (1999) cautions that 'analysis' has connotations for hermeneutic phenomenology. Emphasis was placed on how this affects me as researcher and to describes the researcher's experience and the idea that this is all research is or can ever be (Lofland and Lofland 1995). This allowed for an emergent design "because it is inconceivable that enough could be known ahead of time about the many multiple realities to devise the design adequately" (Lincoln and Guba 1985:41). Moreover, the diverse perspectives and value systems of researchers and participants "interact in unpredictable ways to influence the outcome" of the study (Lincoln and Guba 1985: 41). Thus to derive insight of how the women of Kwam eMakana bargain with entrepreneurial economic empowerment, thick descriptions are necessary. According to (Creswell 1994: 153) "data explication requires that the researcher be comfortable with developing categories and making comparisons and contrasts" (in Hycner 1999). It also entails that the researcher be open to other possibilities and see contrary or alternative explanations for the findings (Creswell 1994). Patton (1980) noted the data generated by qualitative methods are often voluminous. The employed data collection methods included several simultaneous activities that engaged the attention of the researcher; collecting information from the field, sorting information into categories according emerging themes, formatting the information into a story, and actually writing the qualitative text. The findings were explicated qualitatively; and the inductive data analysis technique was used to explicate the data. The explication started with the management of the data, followed by reading and noting; description, classification, interpretation and presentation of the analyzed findings. Major themes were identified and explicated in relation to the objectives of the study.

\subsubsection{Questionnaire evaluation}

As data was aggregated, the personal details of individual participants are not identified. Data from the questionnaires was coded and entered into SPSS v. 15.0 for analysis. Univariate data, presented as percentages, frequencies, tables and graphs is incorporated into the results and discussions of Chapter 6 of this thesis. Section D of the questionnaire (Appendix 4) adopted Goleman's El competencies measurement 
tool which uses Likert scaling questions with a 1-to-4 rating, this instrument had no centre or neutral point; the respondent had to declare whether she was in agreement or disagreement with the item.

\subsubsection{Interviews, discussions and transcription}

Even after maintaining extensive field notes and memoing (Creswell 1994) I still wrestled with my value systems and how they could contaminate the data. On several occasions I would question myself, perhaps, did I as the interviewer transcribe only what I wanted rather than what is actually there? In such instances it demanded 'stepping away' from data and then 'stepping back' into it, mentally revisiting the interview or discussion environment in an effort to capture the emotion and mood of the participants (Yanow and Schwartz-Shea 2006). In so doing it allowed the data to speak, issues that had been silenced because of the researcher's biases were given a voice. Even then frustration still occurred because the transcripts only contain the words (though one can state body language) these do not carry the emphasis or intonations that are used in speech. As a result the data to an extent is stripped of some of its meaning (Denscombe 2003). Transcribing and explication was a substantial part of the methods of interviewing and discussion sessions; and as such it was not treated as some insignificant routine to be tackledonce the real business of interviewing, discussions or observations had been completed (Denscombe 2003). This is true because the transcription of tapes is far more time consuming than the actual data collection.

Transcripts of interviews and discussions were compiled verbatim from the tapes as soon as possible after each event. As with all qualitative information, decisions were made about what to use, as multiple themes were established from the data. Thematic categories were established from interview and discussion data and editing of quotes was kept to a minimum to preserve their perspectives as precisely, yet clearly, as possible. For detailed analysis, a hermeneutic framework was used, from this perspective, the stories that the operators told about their experiences are a prime locus of discovery. The insights offered by this hermeneutic mode of interpretation is particularly useful in bridging the gap between the operators' overt awareness and stories of their life circumstances and the less overtly stated factors that shape their experiences and decisions about their cultural home-stays. Hermeneutic scholars emphasize that the process of textual interpretation cannot be reduced to the application of a 'method' (Gadamer 1975; Thompson 1997). Rather, the techniques used to formulate an interpretation are embedded within a framework of core 
assumptions and investigations, informed in this case, by literature and background research and also by the data gathered through observations.

The interpretation of interviews and discussions in this research follows the interpretation of the textual data and proceeds through a series of a part-to-whole iterations (see for example Arnold and Fischer 1994; Spiggle 1994). This iterative procedure actually entails two distinct stages (Thompson 1997) where the first is a cycle in which the interview transcript is read in its entirety to gain a sense of the whole. Further readings are then undertaken to develop an integrated understanding of the meanings conveyed by the text. The second part-to-whole movement is an intertextual one, whereby the researcher looks for patterns and differences across the interviews and discussions. There were, as is common in interpretive research (see Thompson 1997), interactive movements between the intratextual and interpretive cycles, where insights were gained from an interview or discussion text, interpreted later in the process and then reconsidered in light of developing understanding.

\subsubsection{Explication of observations}

I had to be disciplined to record each observation as comprehensively as possible, but without judgmental evaluation. I constantly engaged with the data from the different angles questioning what had happened. What was involved? Who was involved? This process allowed me to see why interpretive methodologies provide conceptual grounds for understanding why research, writing, and reading should be intertwined (Yanow and Schwartz-Shea 2006). This highlighted that the role of the researcher is important in this interpretive approach because it is the researcher interpreting the textual data. Hermeneutic research emphasises that an understanding of a text always reflects a fusion of horizons between the interpreter's frame of reference and the texts being interpreted (Arnold and Fischer 1994; Thompson 1997). The acknowledged implication is that the researcher's interpretive orientation (i.e. background knowledge, underlying assumptions, and questions of interest) enables one to become attuned to specific characteristics and patterns afforded by the textual data. Thus, again, the hermeneutic approach selected seeks to be open to possibilities afforded by the texts of the observations, rather than projecting a predetermined system of meanings on to the textual data. 


\subsection{Positionality}

Fieldwork by its nature is a messy and complicated process. For field research to be successful it is important to forge and maintain human relationships between researcher and participants across social boundaries. Notions of difference, perceived through interaction with others, can often complicate experiences in the 'field' (Bourke et al. nd). As such, it was important that I remained aware of the effects my own positionality can have on the research, as demonstrated in the experiences described below. Coming to terms with my own privileged and under-privileged identities, be it class, race, gender, nationality or educational background, in peripheral contexts, demanded a degree of introspection. I often questioned my own legitimacy in the field (Bourke et al. nd) and found myself wondering what right I had to enter a community and write about lived realities that I often do not experience. In shopping malls, coffee rooms, hallways, restaurants and even at a wedding I often interrogated my positionality as a young researcher in the field. This 'identity crisis' (Bourke et al. nd) is partly because I was conscious that, in the context of the field space, as the researcher I was continuously challenged with the implications of what my body represents difference, privilege and under-privilege. At first glance this discussion may be dismissible as guilt-ridden, self-involved and self-pitying nonsense (Bourke et al. nd). However; the topics addressed here continue to be unresolved in terms of how, as an up-and-coming researcher, I rationalized the "body politics" of my work.

Here, I reflect on and respond to this real and permeating challenge which continues to emerge in my experiences and life as an international resident and academic. The notes which I kept during my 'fieldwork', as a method to track and reflect on these issues in my research experiences, were key sources for this chapter. This is not a discussion that will necessarily bring new insights into the various themes I explored, but it does provide a critical forum in which I can highlight some of the internal tensions I grappled with in the field as I interacted with different and not so different communities. It might also provide ways of tackling how to transcend these challenges by moving towards a communicable purpose for those involved in the research process (Bourke et al. nd). This chapter threads together stories of language, nationality, gender, class, affiliation and race, exploring how they feed into my individual and collective research experiences. These reflections also make use of Davora Yanow's General Methodology course with the Netherlands Institute of Government (NIG) and its analytical 'toolbox' - a course in which I was a participant in May 2009. Moving from the narrated experiences of an obvious outsider to those included in some ways, and not in others, to an experience of doing research 'at 
home', the piece weaves together various experiences of difference and acceptance. Perhaps these experiences are linked to something more than just overt identity markers - that of simply being a researcher in the first place (Bourke et al. nd).

\subsubsection{Descriptions of experiences}

This section describes some selected events that happened during fieldwork that illustrate how my position changed during the field research period from time to time. I will show how my role was fluid in that sometimes I was treated as an insider, and at other times as an outsider. I consciously embraced these varied positions so as to remain nuanced to the methodological considerations of such multiple positions, some of which are described below.

\subsubsection{My identity}

I am a Zimbabwean national who investigated to what extent government LED initiatives promoted the goal of women entrepreneurial economic empowerment in Joza Township, Grahamstown, South Africa. This involved travelling to Port Alfred, South Africa to my partner research institute - a stakeholder in the tourism home-stay LED project. The partner institute facilitated my access to the local government directorate, the women home-stay operators in Joza Township and various drivers of tourism in the Eastern Cape. Numerous events were coordinated including two townships tours, home-stay overnight visits and visits to tourist attractions in the Grahamstown area. I was picked up on arrival by an intern (German - [GIS]) at the research institute and the Kwam project officer (black South African - [SAPO]). The ladies took me to my accommodation arranged for me by the research institute. The guesthouse was in the 'white' residential area of Port Alfred down the street from my partner research institute. What follows are my narratives of some events occurring during the time I spent in South Africa conducting field research for this study. These events were significant to me and how I consequently framed the research within phenomenological methodology considerations.

On arrival at the guesthouse, the owner (Mr. X) walked out to meet us. I was sitting in the back seat, as we got out of the car he looked at all of us and he walked towards GIS and cordially extended his arm announcing my name to her. She in turn replied "hello", and introduced herself and turned to point to me saying I was the guest. Mr. X was visibly surprised, after a brief moment he shuffled around; he stood in the same position and offered contrite greetings to SAPO and myself. Mr. X showed us into the house through the front door and the maid helped with my luggage, and his wife 
showed me to my room. She gave me the keys, informed me of all the facilities I could use and the house rules. As she gave me the keys she stated that "if you came in after $9 \mathrm{pm}$ the front door will be closed, this is the key for the back entrance, remember to lock the door". The next morning when I was leaving I went through the front room. As I reached the door I noticed Mr. X sitting at the desk in front of the door, I said "good morning" there was no response, so I repeated my greeting. This time I got a response, it came in a rather agitated tone and he said:

Mr. X: "listen, you should use the back entrance when you come and leave".

Me: [I was taken aback, caught off-guard, my tongue thick in my mouth and unable to reply for a moment, after a while I heard myself ask] "Why?"

Mr. X: [in an irritated tone], "because it makes a mess and Susan will have to sweep again".

Me: [I turned to look where I had walked and there was no dirt, so I looked at him] "but there is no dirt, I wiped my feet".

Mr. X: [He looked up at me for the first time that morning and said] "it will be easier", Me: "How come it was ok yesterday? Mrs. X did not mention that to me, she said only when I come in after 9pm when the front door is locked, I use the back entrance".

Mr. X: "Please don't read meanings into this it is not what you are making it out to be". Me: "Right ..."

My initial reaction to this scene was complete outrage; as I walked out of the gate that morning I thought I am going to ask for new accommodation - I will not be treated this way, I am paying to stay in his guesthouse! As I walked to the university, I was surprised at how calm I became. I caught myself in a thought process that amazed me; instantly, I decided I would stay on and use the back entrance as asked of me. I needed to experience what that meant and it would be important for my research. This incident occupied my thoughts for a long time; I discussed it over lunch with the two ladies who had picked me up the day before. They were both perturbed and interestingly their responses were varied; SAPO remarked that she had observed some rather stand offish behavior from the same gentleman and unequivocally stated "I am not shocked". While GIS said "he was strange, seemed disappointed that I was not his guest, but to say you should use the back entrance is just bizarre". As I rationalized this pre-breakfast encounter I realized my skin was a barrier that assumed a division between me and Mr. $X$. I found certain aspects of my external social construction mattered to varying degrees to different people. What emerged from the onset of my fieldwork was a potent consciousness of my race not my nationality on this occasion. My skin seemed to represent some kind of social standing - a maid perhaps, who serves and does not reside in the same space as those she serves. To him why else 
would I be here? My skin demands and incites disrespect, resentment, anger and dismissal and with those of same racial heritage it comes with acknowledgement expressed through nodding of the head and ever so brief smiles. The following extract details one such encounter.

\subsubsection{Belonging}

A few days later, while walking back to my room from the shopping centre - I saw two men in the street where I was living; they stopped me and introduced themselves in isiXhosa stating that they worked as gardeners in the same street. They went on to investigate who this unknown African woman to their community was.

Man A \& B: Kunjani sisi?

Me: mna sikhonile [from my accent and pronounciation they realized I was not a native Xhosa speaker, so they switched to English]

Man A: "Where are you working? We have not heard that anyone lost a job or are you replacing someone on leave? We do not know".

Me: I managed a reply in my rudimentary Xhosa, stating that "I am at the school"

Men B: He responded in English "oh, but you are not wearing the uniform, and you are not Xhosa".

Me: "I am a student and yes, I am not Xhosa".

Men B: "So where are you from?"

Me: "I am from Zimbabwe".

Man A: "But you don't look Zimbabwean, you look South African"

Me: [I smile] "What do Zimbabweans look like?

Man B: "She is Zimbabwean, she speaks a good English and Zimbabweans always go to school"

Man A: "Yes she is very intelligent, I can see it"

Man B: [addressing us both] "I would love to go to Zimbabwe"

Me: "You should come"

Man A \& B: "We will come, will you host us?"

Me: "Of course"

I turn this episode over and over in my head all the way back to my room. To the men, because I am black and female and on foot on the 'white side' I was definitely a maid first, and when that had been eliminated they had to establish what I was doing in that 'space'. It is important to mention that I took this field trip in 2009; and this was barely a year after the xenophobic attacks targeted at African foreigners. I will say when the men stopped me, I was conscious of my Nationality. I must also admit that I did not 
feel uncomfortable after I revealed my identity in this sense during this encounter or at any other time during my times in South Africa. I came to the understanding early on in my field research that the politics of this body I inhabit will be thrown open every day here; a body that stands for so much more than just me. Race, gender, class, nationality and affiliations are constant points of negotiation, justification and positioning. Positionality as they call it refers to the unique identity coordinates of your particular constellation of markers (Bourke et al. nd). Marked - that is an appropriate phrase. Skin marked visibly by under-privilege, minds marked less obviously by memories of prejudice, oppression and exploitation. There is no escaping the coordinates of positionality and people's responses to it. "Accept as I am" I ask. No such luck! The way in which I am perceived has an impact on the research and my experience (Matinga 2010), admittedly, this created conflicting emotions; what am I doing in this context, have I become one of those short-term outsiders 'experimenting' on South Africans? While in the above, 'difference' is read visibly and starkly (by race and nationality most obviously) as a researcher interrogating disadvantaged communities, a context I am familiar with, having lived in a township myself till the age of seven. I found I could negotiate the differences more subtly, through language, ethnicity and class dynamics. I must admit I was able to "code switch" (Matinga 2010) effectively proving my 'Africaness' (Matinga 2010) to my respondents, it is not always that simple. I used my nationality as an entry to discussions, and I found that this reduced the perceived 'difference' between the researcher and the researched and this was actually an aid to my research:

For example, at my first home-stay visit, I went with SAPO. Actually I went with her to all my research activities; she coordinated my questionnaire and discussion session, my interviews and observations. Upon arrival SAPO introduced me to the home-stay owner; she told her that I had come to conduct my doctoral research which I carried out in the Netherlands. From observing the respondent I noticed she was forming a perception that I felt was not in line with who I am. To counter that the first thing I said to her was "I am from Zimbabwe, and I grew up in a Township", and I told her how happy I was to be home (in the sense that I was in Africa). I described the difference in weather and told her how much I missed chisa nyama (barbequed meat), she smiled and said she understood. As she told me about her home-stay and she asked me what I thought about it and if it was up to standard for the overseas guests. I responded that "yes her home was up to standard to receive international guests for a cultural homestay experience". After this encounter I started to wonder do people from very different backgrounds have a right to research in contexts foreign to their own (Bourke et al. nd). However, through the workings of race, gender and class dynamics, I had 
managed to find my own 'insider' status to my study site. What then, does it mean to research one's own 'community'? Is a researcher ever a full 'insider' to any study site or is it more accurate to speak in terms of degrees. Whether situated in your 'home' country, or in a place one was not born in, our position as researchers automatically calls into question our authentic and personal knowledge of place.

\subsubsection{Questions about purpose and research}

Identity and difference not only affect access in the research process, but also inform questions around legitimacy, voice, validity and purpose (Yanow 2009). In the following section, I reflect on how I grappled with these questions of responsibility and positionality. In the context of a people centered study, where long hours were spent with research participants and intimate friendships forged, differences in identity and resources became powerfully salient. The ways in which people respond to traumatic events (here I refer to Apartheid) is varied through individualized experiences. Sometimes emotional responses to another's tragedy can make the situation more painful for respondents (Bourke et al nd). As in this sort of research, I remained largely on the outside of the communities I worked with, yet became parts of the daily community life in which relationships were formed. Bourke et al (nd) warn that the privileged, mobile researcher role also risks creating false expectations amongst participants who may believe that perhaps through the research, their own situations will improve. I realized first hand, working through these expectations and class differences, that the guilt and sometimes shame associated with this, is very potent. For instance, during the discussion session with the home-stay operators:

KMHS-CL/0037: "You are here for a reason; you are going to help us".

KMHS-CL/0012: "I know you are going to help me, go back overseas and tell them we need their help".

SAPO interjected (in isiXhosa) on my behalf explaining that I am a student who is researching the challenges with the project; the findings will be presented to the authorities for them to decide on future action. As I returned to my room I felt guilty and ashamed could I handle so much? I was raging inside of me enough already! Not least of all being a black African woman [...] a privileged black African woman. I had another life in suburbia - mobile lives, always in transit, both in South Africa and in Zimbabwe, or in my student housing in the Netherlands or any other base I would station for summer school (two months here; three months there or a week away for a conference): this was my world. That is so removed from the visible economic challenges of these women. The irony was the mechanized research code I had read so 
much about and I followed in the name of being courteous (Matinga 2010). I finished my research, I thanked my participants. I explained what happened next and that I would even come back to see them. The reality was I would write up my thesis and hopefully receive my doctorate degree. I started to wonder could I change these women's lives in any way given their expectations? Could my research change anything for these women in a meaningful way that they could immediately conceive? Instead, unequivocally, the research changed my own life, but that is not the issue here - at that thought the guilt and shame came back, am I using these women for my own selfdevelopment? Inevitably, the participants will continue to face the same challenges they did before I came. I started to think about who am I researching and writing for?

To address these concerns Finlay 2008: 8 cautions against the danger of engaging researcher reflexivity by "falling prey to navel gazing. The researcher needs to avoid preoccupation with their own emotions and experience if the research is not to be pulled in ... directions which privilege the researcher over the participant". Giorgi (1994 in Finlay 2008: 8) "offers a more specific argument against the dangers of researchers' overemphasizing their own self-awareness and attention to the research relationship. Giorgi also highlights the need to keep clear the intentional objects to which the researcher's acts are directed. It is important to guard against prioritizing the researcher's own growth and self-development over the explication of a phenomenon". Gadamer (1975: 268) describes self-reflection "in terms of being open to the other while recognizing biases". According to Gadamer (1975) knowledge in the human sciences always involves some self-knowledge and openness. According to him "this openness always includes our situating the other meaning in relation to the whole of our own meanings or ourselves in relation to it ... This kind of sensitivity involves neither 'neutrality' with respect to content nor the extinction of one's self, but the foregrounding and appropriation of one's own fore-meanings and prejudices. The important thing is to be aware of one's own bias, so that the text can present itself in all its otherness and thus assert its own truth against one's own fore-meanings" (Gadamer 1975: 268-269).

It has been mentioned (Finlay 2008) that in our spaces of research across various academic fields and identities, we are constantly negotiating our right to be in those spaces. Whether or not our negotiations and explanations are satisfactory to ourselves or members of the 'community', it is important to acknowledge these tensions, for the research, the researcher and the 'researched'. However, this acknowledgement can, and has often led to an impasse, or an abandonment of fieldwork altogether (Bourke et al nd). In attempts to move beyond the impasse, Nagar and Geiger, (2000; 2 in 
Nagar 2002: 183) suggest that asking the following critical questions; "1) How can researchers use fieldwork to produce knowledge across multiple divides (of power, geopolitical and institutional locations and axes of difference) in ways that do not reflect or reinforce the interests, agendas and priorities of the more privileged groups and places? 2)How can the production of such knowledge be tied more explicitly to the material politics of social change in favor of the less privileged communities and places?" They maintain that as academics it is not possible to simply abandon empirical work, we need to accountably work at these issues of power and purpose in our written products.

Wertz (2005) asserts one possible way of evading this trap is to embrace the intersubjective nature of researcher and researched relationships. According to MerleauPonty "there is a reciprocal insertion and intertwining of one in the other," (1968: 138). As researcher and co-researcher intermingle in "pre-analytic participation each touches and impacts on the other. If this more explicitly relational approach to phenomenological research is adopted, data is seen to emerge out of the researcher co-researcher relationship, and is understood to be co-created in the embodied dialogical encounter"( Merleau-Ponty 1968: 203). The notion that research is more beneficial to the researcher than the researched is a challenging and troubling notion I still struggle with. Despite the good intentions of research and scrutinizing how research may impinge on, or contribute to participants, it appears in order to contribute, we require a tradeoff (Laverty 2003). [You allow me to interview you and I will give you a shopping voucher or a gift as a thank you and so on]. For example, this research investigates to what extent the home-stay project promotes entrepreneurial economic empowerment among the women. Despite these indirect contributions, I asked myself how the research in itself directly assisted the women at a household level - the level that matters for them. Moreover, how do I openly and clearly communicate the direct purpose of such work? The episode during the discussion session illustrated to me that the impact of research is not always clear or relevant to the majority of the researched.

\subsubsection{Reflections}

The reflective narratives above have shared some of my individual experiences linked to 'insider' positionality, power and purpose in the research process. Of equal importance is what being an 'outsider' and 'insider' may mean for knowledge production, and its politics and purpose (Bourke et al. nd). In reflecting on my 'outsider' experiences, the socio-political history of South Africa drew strict racial 
divides into the geography of the cities, divides which have not been bridged in many places post-1994 (Vavi 2011). My presence as privileged 'outsider' in peripheral contexts was noticed, and questioned by the local members of the community (the men on the street near my accommodation); or was seen as the solution to a problem (the Kwam eMakana women). I agree with the suggestions made by Bourke et al. (nd) that the point is that my presence as researcher 'in the field' will always have an effect on the situation in which I find on the ground. The argument being that I am an outsider, and can never be a full insider. The situation changed as soon as I walked into that space; that space that will remain unknown to me in its totality - can one ever really know a place in its totality, even where one is born and lives. People have their self-constructed boundaries within the society they inhabit, be it they are informed by class, education, race and even gender. What was of importance to me was to realize and accept that I became part of that space for that fleeting moment of time. For those privileged moments of sharing, I was part of that space and to some extent influenced that space (Bourke et al. nd). This is what is pivotal for me and the methodology I selected in this research process. I came to understand and embrace that as researcher I cannot separate myself from the space. Who I am, how I am on that particular day and all that, helps mould me into the person that now sits 'within' the hermeneutical phenomenological space and will influence the outcome of whatever material I produce. Whatever difference I make, whatever story I write, I as a researcher needed to acknowledge my influence on the insider (Bourke et al. nd). From the other side of the 'insider-outsider' spectrum, I reflect:

"My research was guided by the desire to get at situated knowledge in an African context, in a place I identify with as home. It focused on multiple uses of the space of home-stays as both home and enterprise for economic empowerment through entrepreneurship. Haraway's (in Bhavnani 1994) writing, objectivity is about situated knowledge, not about perfection and splitting of subject and object. He describes it as allowing one to become answerable for what they learn to see. By adopting this view point, there was a responsibility of accepting that I could not separate who I am from the subject of the study. This meant acknowledging that who I am, what I think, who I believe I am, what I write and where I come from, affect the conclusion of my study, this is what Haraway (in Bhavnani 1994) called objectivity. As an 'insider' on some levels, I found being, an African, black woman and having lived in a Township until the age of seven made the research process easier. I also knew that the lack of a shared nationality and language would present significant challenges. By situating myself as an African who also lived in a township, I hoped to dispel any particular assumptions that would be constructed about my identity. However, I could not completely bridge the 
gap created by my educational status and perceived higher socio-economic level. A university education from abroad highlights the 'us' and 'them' - 'if she has university degrees, what can we say' (Bourke et al. nd). I found I had become an outsider in a place I call home. I also realized that I had the privilege of interpreting my informants' struggles and voices in a manner of my choosing. That meant that I held power to shape their voices based on the questions that I asked and the responses I got. This became serious because the reasons why these participants chose to speak, and spoke, were important in the study. Overall, this whole process placed me both at the centre and periphery of the research process (Bourke et al. nd). I was half insider as a Southern African black woman with real life experience of Township living. However, I was also half outsider because of my nationality, language (non Xhosa speaker) and any level of university education is held in high regard and represents a higher status. The fact that I was also from a European University meant my socioeconomic status was interpreted as even higher."

\subsection{Conclusion}

Ultimately, the tensions between insider/outsider, centre and periphery, positionality and representation, process and purpose are part and parcel of what it means to grapple with being a researcher. This is not to argue that other identity markers (of race, class, gender, nationality, etc.) do not shape these experiences and relationships in the 'field', but to add the marker of 'researcher' to the set of positionalities that powerfully shape knowledge. Whether 'foreigners' or 'at home', our very task as researchers moves us both to the center (in terms of the power to represent and write) and the periphery (in terms of belonging) of a community (Bourke et al. nd). In acknowledging these tensions which arise across identity and the body politics, we may reconsider the ways in which we offer an exchange in which the research purpose is understood and meaningful for all involved in the process and ask what can assist in bridging these gaps of partnership in the research process. As Nagar advises, "It is critical that such knowledge be produced and shared in theoretical languages that are simultaneously accessible and relevant to multiple audiences here and there" (Nagar 2002: 184), within the academic and the community.

The methodology employed was pivotal in capturing the local government and project level realities, hence it was able to address the research gaps illuminated in Chapter 2. The quantitative research reported on in this thesis provided information about descriptions of the women operators and the home-stays, and what happens within 
the project, while the qualitative part of this research offered insights into women's experiences of this - not what happens, but how it is experienced. While, the key informant interviews with a cross section of experts conducted in this research meant that the challenges of the project became concrete and vivid. 


\section{Chapter 4}

\section{Challenges for Entrepreneurial Steering through Black Economic Empowerment Initiatives in South Africa ${ }^{1}$}

\subsection{Introduction}

South Africa is a country where fundamental socio-political transformations continue to take place (Southall 2007; Andreasson 2010). The concept of transformation in South Africa refers to the process of transforming a society by demolishing the socioeconomic structures established by apartheid policy (Andreasson 2010). Therefore, as described by Janis (2010) transformation is explicitly linked to unequal power relations as the post-apartheid legacy. Transformation is a process that takes place in the entire society (DEAT 1996; 1998) over a prolonged period because of embedded institutional and socio-spatial arrangements (Anderson and Smith 2007) and the effects of social constructionism through childhood education that last through adulthood (Benell 1999).

Owing to tourism's potential the White Paper (DEAT 1996) identified tourism as a key development strategy that can lead to economic growth, community development and poverty alleviation (Magi and Nzama 2009). Tourism's ability to stimulate linkages with other sectors offers numerous entrepreneurial opportunities for the previously disadvantaged individuals (PDIs) especially women and the youth, and its importance to the national economy has contributed to its significance as a post-apartheid development option (Visser and Rogerson 2004; Rogerson 2007; Magi 2010). Thus various tourism initiatives specifically aimed at including the black population in tourism have been implemented to promote entrepreneurship and the transformation agenda - Kwam eMakana is one such initiative.

Using a comparative analysis of a government funded tourism home-stay project aimed at promoting entrepreneurship with privately owned home-stays, the study investigates the levels of entrepreneurial steering in the two initiatives. This chapter presents a nontraditional approach to women economic empowerment in South Africa; challenging the classic structure of government funded top-down projects which apply government-led conceptual frameworks. It borrows from Moser's (2009)

\footnotetext{
${ }^{1}$ Earlier version presented at International Tourism Conference Global Sustainable Tourism, 15-19 November 2010, Nelspruit, Mbombela, South Africa, ISBN: 978-0-620-46397-3
} 
work and proposes an approach to poverty reduction anchored in developing and encouraging an entrepreneurial approach to wealth creation as an avenue to achieving BEE. The chapter investigates to what extent BEE reverses the socio-economic arrangements established by the apartheid institution. The chapter recognizes that there are different ways to promote transformation; one approach is to train and equip more black South Africans to become skilled employees and entrepreneurs another is to support tourism BEE initiatives (Janis 2010). It concludes that to achieve BEE more emphasis must be placed on an agenda that promotes prosperity and progressive human values.

Before going in depth into these issues however, the background on the issue at hand will be provided below by presenting some highlights of the academic discussion surrounding transformation (BEE), tourism and women entrepreneurship. This is relevant for setting the context for the ensuing discussion by mapping out the evolution of the transformation debate in South Africa, its status quo as well as pinpointing where some of the difficult issues lie. In this chapter, women tourism entrepreneurship incorporates the social-cultural roles and behavioral characteristics of entrepreneurs while tourism home-stay enterprises are income generating initiatives that have elements of individual and collective benefits that link BEE to a broader process of economic, cultural and social change (Bennell 1999).

\subsection{Black Economic Empowerment}

South Africa introduced BEE as an intervention to engage the black majority in the mainstream economy (Jauch 2007). Redressing the apartheid legacy of the domination of business activities by the white minority and the exclusion of the black majority from the economic mainstream was one of the key visions articulated by the RDP - the blueprint for the country's democratic transformation (Rogerson 2002; Kaplan 2004). RDP is based on the idea that reconstruction and development are parts of an integrated process, incorporating growth, development, reconstruction, redistribution and reconciliation into a unified programme (DEAT 1996). Rogerson (2004) acknowledges that under apartheid, there occurred a process of systematic disempowerment of the masses whereby "the accumulation process was one of restricted wealth creation and imposed underdevelopment on black communities to ensure that they were, in the main, suppliers of cheap labour" (Esterhizen et al. 2008: 1). In its current form BEE aims to

"promote the achievement of the constitutional right to equality, increase broad-based and effective participation of black people in the economy and promote a higher growth rate, 
increased employment and more equitable income distribution; and establish a national policy on broad-based black economic empowerment so as to promote the economic unity of the nation, protect the common market, and promote equal opportunity and equal access to government service" (Extract from the Broad-BEE Bill; [BEEComm] 2001).

Table 4.1: Objectives of Broad-based Black Economic Empowerment Act and Principles of BEE Model

\begin{tabular}{|c|c|}
\hline $\begin{array}{l}\text { Objectives of Broad-based Black Economic Empowerment } \\
\text { Act No.53, } 2003\end{array}$ & Principles of BEE Model \\
\hline $\begin{array}{l}\text { The objectives of this Act are to facilitate BBEE by promoting; } \\
\text { 1. Economic transformation in order to enable meaningful } \\
\text { participation of black people in the economy; } \\
\text { 2. Achieving a substantial change in the racial composition } \\
\text { of ownership and management structures and in the } \\
\text { skilled occupations of existing and new enterprises: } \\
\text { 3. Increasing the extent to which communities, workers. } \\
\text { cooperatives and other collective enterprises own and } \\
\text { manage existing and new enterprises and increasing their } \\
\text { access to economic activities, infrastructure and skills } \\
\text { training } \\
\text { 4. Increasing the extent to which black women own and } \\
\text { manage existing and new enterprises, and increasing } \\
\text { their access to economic activities, infrastructure and } \\
\text { skills training; } \\
\text { 5. Promoting investment programmes that lead to broad- } \\
\text { based and meaningful participation in the economy by } \\
\text { black people in order to achieve sustainable development } \\
\text { and general prosperity; } \\
\text { 6. Empowering rural and local communities by enabling } \\
\text { access to economic activities, land, infrastructure, } \\
\text { ownership and skills; and } \\
\text { 7. Promoting access to finance for black economic } \\
\text { empowerment. }\end{array}$ & $\begin{array}{l}\text { The BEE model as it exists has } \\
\text { evolved to include the following } \\
\text { principles; } \\
\text { 1. Enterprise development, which } \\
\text { highlights the need to increase } \\
\text { black SMME development or } \\
\text { entrepreneurship, } \\
\text { 2. The need for white-owned } \\
\text { companies to collaborate with } \\
\text { emerging black companies thus } \\
\text { ensuring the transfer of skills. } \\
\text { Skills development with the } \\
\text { purpose to develop capabilities } \\
\text { and to empower people to be } \\
\text { able to make decisions and } \\
\text { build confidence. } \\
\text { Preferential procurement, which } \\
\text { ensures that there is more money } \\
\text { available for BEE procurement } \\
\text { while preventing the problem of } \\
\text { fronting. }\end{array}$ \\
\hline $\begin{array}{l}\text { Source: (No. } 53 \text { of 2003: Broad-Based Black Economic } \\
\text { Empowerment Act, 2003). }\end{array}$ & $\begin{array}{l}\text { Source: (Department of Trade } \\
\text { Investment[DTI] 2004a; b in Magi 2010) }\end{array}$ \\
\hline
\end{tabular}

Andreasson (2010) writes that BEE has been historically necessary in South Africa to overcome the legacy of internal colonization and apartheid. Hangala (2007: 7) maintains that "BEE is not the only means to empower previously disadvantaged people", the extension of basic infrastructure, improvements in educational and health system and efficient delivery of basic services are equally important interventions in redressing inequality (DTI 2004a; 2003). Ramphele (2008) explains that BEE is about broadening the base of participation in growing the economy to enlarge the economic cake that can be shared more equitably. BEE is meant to give PDIs room to participate in wealth creation. Notwithstanding, he mentions that it is not meant as a reward for being black, a woman or disabled, entitled to benefit without adding any value. 
Ramphele (2008: 267) warns "we dare not confuse ends and means". BEE has been criticized, (Magi 2010) the view point by some is that transformation has come to represent a way of compensating PDIs, rather than creating opportunities for all citizens to contribute their talents and energies to the process of developing the country (Ramphele 2008; Mbeki 2009).

This chapter analyses how the fourth aim of the BEE Act No.53 2003 and its subsequent translation in the first and third principles of BEE (refer to Table 4.1) are the basis of initiatives designed to attain BEE. It investigates how they are operationalized and how in that form they impact on the attainment of the said BEE aim. In South Africa, the moral authority of empowerment is welded, culturally, to a social process of rectification of social justice, so that voices previously silenced should have due influence in national, regional and local politics (Lalu 2004; Rogerson 2007; Andreasson 2010). This process of empowerment is context specific, defined within the local, historical, political, economic and social context (Allen and Brennan 2004; Rogerson 2007). Jauch (2007: 10) points out that the key question in BEE should be; "who is supposed to benefit from it and to what extent are socio-economic structures supposed to be transformed?" According to Moeletsi Mbeki (2009) the origins of BEE are somewhat dubious. He maintains that as a direct result of the origins of BEE for the PDIs it is critical that they remain perceived as victims and as weak. He goes onto to state that the payment of reparations central to BEE thus achieves the opposite of what it is claimed it was designed to do, that is to make PDIs leading players in the economy. Moeletsi Mbeki (2009) maintains that in reality, it makes PDIs perpetual junior support players to white controlled corporations. Notwithstanding, the critique by Moeletsi Mbeki (2009) on the origins of BEE it has definitely evolved since its inception and has emerged as a key part of restructuring and transformation of the post-apartheid South African economy to address the inequity and exclusion created by apartheid (Rogerson 2004; 2007; Andreasson 2010).

\subsubsection{Black Economic Empowerment and tourism}

The chapter approaches the challenges related to transformation of the tourism sector both from the political economy point of view and from the view of sustainable tourism development. As Bianchi (2002: 297) remarks, "the core question on the political economy of tourism is to what extent different modalities of [...] tourism are leading to a reduction or increase in the inequality of access to power and resources". In the South African context the effort to include the PDIs especially women in the tourism sector is of major importance, as sustainable development and sustainable 
tourism are explicit goals of the government (DEAT 1998; Ramphele 2008) but they cannot be achieved without transforming the sector to be more inclusive (Andreasson 2010). BEE implies economic sustainability in order to achieve a higher standard of living (Jauch et al. 2009) this assumes meeting the economic needs of the PDIs. Ndubano (2000 In Mbaiwa 2004: 3) writes that Kenya has shown that it is possible to have a booming tourist industry while the majority of the local people live in poverty. Similarly black people, especially in townships and rural areas, have been excluded from tourism development opportunities in South Africa.

According to literature (Lubbe 2003; Lalu 2004; Hangala 2007; Southall 2007; Jauch et al. 2009; Andreasson 2010) the support of the PDIs in the identification and development of viable tourism initiatives together with social responsibility programmes are necessary steps in the transformation process. The country's tourism sector has undergone a process of realignment and refocusing post-1994, influenced by national government's focus on meeting the country's considerable growth, development and transformation goals (Kaplan 2004; Visser and Rogerson 2004). As part of the BEE process a number of development policies have been drafted towards transforming all spheres of tourism (Magi 2010) these include:

1. The White Paper on the Development and Promotion of Tourism in South Africa (DEAT 1996);

2. Tourism in GEAR [Growth, Employment and Redistribution Strategy] (DEAT 1998);

3. The Transformation Strategy for South African Tourism (DEAT 2000);

4. Tourism Growth Strategy [South Africa] 2008-2010

According to Spykes (2002) BEE can improve participation of the PDIs in tourism enterprises. An important inquiry for tourism transformation raised by Hangala (2007) refers to the access of PDIs to opportunities, skills and facilities to ensure viable tourism participation. Southall (2007: 89) remarks that "a government programme which is so centered on race involves a philosophical dilemma in post-apartheid countries which are devoted to the pursuit of non-racialism and the abolition of all forms of discrimination based on race". Mbeki (2009) maintains that race is the central issue in the transformation agenda; race is the starting point of black economic disempowerment hence race has a pivotal role to play in the attainment of BEE. This supposition adds weight to Biko's (1978: 92) proposition that "to get the right answers, we must ask the right questions, we have to find out what went wrong - where and when". Maathai (2006: 69) substantiates this thinking when she states "the trauma of the colonized is rarely examined, and steps are rarely taken to understand and redress 
it. Instead, the psychological damage passes from one generation to the next, until its victims recognize their dilemma and work to liberate themselves from the trauma" (see Chapter 2). By applying this reasoning to the current BEE processes reveals an inquiry that can provide insight into issues surrounding the transformation agenda. There is a general consensus (Baskin 1995; DEAT 1996; DTI 2004b Visser and Rogerson 2004; Ramphele 2008; Andreasson 2010) that traditional tourism structure has to a large extent seen to the exclusion of participation by most PDIs. Interestingly, the dominance of white ownership in the tourism sector is in fact common throughout Southern Africa (Southall 2007). This has made some regard tourism as reinforcing neo-colonialist patterns (Ringer 1998; Gosovic 2000; Manyara and Jones 2007).

Transformation and development of South Africa's tourism industry, it is argued, entails both opening up the existing industry to PDIs and developing new forms of tourism in areas of the country formally excluded from the tourism economy - the rural areas, small towns and metropolitan townships (Rogerson 2002; DTI 2004a; Jauch et al. 2009; Janis 2010). Hence issues of entrepreneurship in tourism have received considerable attention both through government inclusionary development plans with the view of extending tourism benefits to the PDIs and from the academic and consultancy community in the country (DEAT 1998; 2000; Visser and Rogerson 2004; De Villiers 2005; Magi and Nzama 2009; Andreasson 2010). According to Rogerson (2004) South Africa is uniquely at the juncture of being able to use tourism as a main engine of economic regeneration, income and wealth redistribution. A central question for assessing the success of BEE through tourism development is how far it leads to real growth in PDIs well-being, how it has been and how it is (Allen and Brennan 2004). These arguments in the literature go some way to show how the aftermath of apartheid has created an institution focused on transformation by affording economic advancement opportunities to those denied the same by the previous institution. Thus this study investigates how BEE fairs in overcoming the challenge at hand.

\subsubsection{Entrepreneurship and tourism}

Entrepreneurship is commonly referred to as the action of starting a business which encompasses formulating the identity of the product or service to be sold, the forecast of the demand for the product or service, the design of the production methods to be used, the acquisition of financing, and the operation of the business (Wood 2005). Indeed, there are functions - beginning with the process of alertly noticing the presence of the opportunity before anyone else has and acting on it. He admits that starting a business is entrepreneurship, but he views entrepreneurship as more than the processes of writing a business plan, securing financing, and operating the business 
"entrepreneurship is the creation of a vision of the future which will follow the course of action identified by the entrepreneur-actor" (Wood 2005: 9). According to him all action involves entrepreneurship as an integral part, as entrepreneurship creates the future in a form different from what it would have been if the entrepreneur had acted differently. Given the prominence of entrepreneurship in the BEE legislation and model (Table 4.1) their roles in the creation of a black SMME sector, the section looks at the entrepreneurship discourse in South African tourism.

Entrepreneurship research in general is a field studied within a variety of disciplines; traditionally studies of entrepreneurship have focused on the individual characteristics of successful entrepreneurs. Owing to the multidisciplinary nature of entrepreneurship research the conceptualization and definition of entrepreneurship remains contested (Roomi and Parrot 2008). The possibility of providing a consistent definition of entrepreneurship is complicated by the notion that human behavior is supported by a range of attributes (Tata and Prasad 2008; Okpukpara 2009). It has been alleged (Manyara and Jones 2007; Magi and Nzama 2009) that BEE implies reclamation of the wider space in both social and economic dimensions for the PDIs; hence the proposition by Steyaert and Katz (2004) is befitting for South African entrepreneurship within the transformation agenda:

\footnotetext{
"If life as a daily creative formation is enacted through entrepreneurship, chances are created for and by people to make a difference towards their own situation. It is here that the many new variations of entrepreneurship - social, cultural, civic, ecological, etc. - can make a difference as the entrepreneurial endeavours are about reconnecting and repositioning certain groups of citizens (many times to so-called underprivileged ones) in a society that becomes simultaneously transformed. It becomes obvious then that entrepreneurship is far less a private activity than an everyday tactic on the public scene" (Steyaert and Katz 2004: 192).
}

In the context of tourism, entrepreneurship is complex and includes many interlinked forms of innovation undertaken by different actors - individually and collectively (Moser 2009). Traditionally, studies of entrepreneurship have focused on the individual characteristics of successful entrepreneurs. The individual is also recognized as an initiator of BEE beyond the single enterprise, Laukken and Niitykangas (2003) point to the strategies of local decision-makers as key. According to Storey (1994) these studies focus on the role of factors such as personality, human capital and ethnic origin. Human capital studies have found that entrepreneurship is related to educational attainment and work experience (Evans and Leighton 1990). Research by Evans and Leighton (1990) showed that people with higher educational attainment tend to found new business more often than those with less. A study by Malecki and Poehling (1999) revealed that the most important characteristic of innovators is the personality of the entrepreneur; extroverts had larger networks, sought out information from a larger number of sources, and looked to customers, suppliers and 
competitors for ideas. Other concepts that can explain less tangible aspects of entrepreneurship include 'social capital' and innovative milieu (Dakhli and de Clercq 2004). These concepts give hints to 'soft' factors explaining regional differences, but have hereto not much to say about processes that generate or prevent entrepreneurial activity.

Studies also noted the importance of the role of network in entrepreneurship. Saxenian (1999) found that widespread networks of Chinese and Indian business communities help people start new firms by providing contacts, linkages and financial support in the Silicon Valley. Personality studies have found that entrepreneurship is associated with characteristics like entrepreneurial vision, alertness to business opportunities, proactivity and family tradition (Blanchflower and Oswald 1990). Other studies have found entrepreneurship to be associated with ethnic origin. Lee (2001) found that Jews and Koreans are more successful entrepreneurs than AfricanAmericans because they had better access to capital and financing through family or ethnic networks than others. This observation is particularly important in this study as black South Africans are the racial group with the least number of entrepreneurs and are officially targeted for government support through BEE to promote entrepreneurship. This throws light on the issue of the histories of certain groups and how the past can curb entrepreneurial spirit for example in African-Americans, Aborigines and in this study black South Africans. Johannisson and Nilsson (1989) launch the concept of community entrepreneur as someone who works as a catalyst in helping others to pursue opportunities. Stuart and Sorenson (2003: 229) argue that businesses cluster because geographical proximity enables them to use "social ties necessary to mobilize essential resources". Their findings suggest that an entrepreneur's social relationship is crucial in using critical business - resources critical to start up a new enterprise.

This chapter assumes the theoretical context associated with the psychological perspective concerned with entrepreneurial personality and behavioral characteristics, (Chapter 2) arguing that entrepreneurs are risk-takers and have a high need for achievement, control and autonomy (Berglund and Johansson 2007; Roomi and Parrot 2008). As proposed by Knight (1985) it is impossible to assess the rationality of individual action without taking account of the institutional and cultural context in which everyday decisions are made. One challenge is that entrepreneurs act within society and that their entrepreneurial process is shaped by that society (Anderson and Miller 2003; Anderson and Smith 2007). In doing so, it also addresses the need for the theory that explains how institutional arrangements affect the overall heterogeneity of 
entrepreneurs in post- apartheid South Africa (see Chapter 5). Small business development has emerged as a dominant area in hospitality entrepreneurship research (Telfer and Sharpley 2008; Aitchnson 2009; Tong 2009). Within this area researchers have concentrated on topics such as the importance of small businesses in regional economic development. Okpukpara (2009) argues that small business is often mixed up with entrepreneurship, but that the two, however, are not synonymous.

\subsubsection{Women entrepreneurship}

Women entrepreneurship in tourism has become even more important nowadays as it has gained political importance since being acknowledged by UNWTO (2002). Women entrepreneurship in tourism in South Africa is emphasized as a means of battling discrimination and exclusion (Boonabaana 2010). The idea of egalitarianism is central to women entrepreneurship in tourism development, which gives prominence to the notion that 'many little things' count (Berglund and Johansson 2007). In connecting women entrepreneurship in tourism and empowerment, this study approaches the issue of women empowerment in a positive way instead of the usual 'a priori victimizing' approach (Moser 2009). Literature (Hamilton 2007; Tucker 2007; Tuyezere 2007; Tong 2009) on empowerment discusses empowerment from a priori idea that someone is a victim, a marginalized, poor person not having choices. However, by looking at empowerment and human possibilities positively (Moser 2009), and connecting them to entrepreneurship (Roomi and Parrot 2008), reveals there is a 'hidden' social entrepreneurship in tourism development, social change and preservation of cultural and natural heritage (Chapter 7). Extending this argument will enhance understanding of "how the different realms of gender and tourism interact over time" thus providing "more opportunities to positively guide tourism development and its concurrent social transformation" Tucker (2007: 102). Connecting women entrepreneurship in tourism and women empowerment expands the understanding of entrepreneurship as a business in the traditional sense to include the promotion of progressive human values (Berglund and Johansson 2007). This outlook also contributes to gender and entrepreneurship studies in tourism by paying attention to women empowerment, entrepreneurship and creativity as opposed to the dominant tendency in literature to describe constraints, inhibiting factors and marginalization, from the female point of view, in the area of women as hosts (Kinnaird and Hall 1996; Tuyezere 2007; Aitchson 2009). 


\subsection{Data Collection}

\subsubsection{Study context}

The intention of this chapter was to establish if the BEE framework for transforming the tourism sector by introducing entrepreneurship, to benefit in this case previously disadvantaged women, is being achieved. This section will present a comparative analysis of two study areas consisting of township tourism home-stay operations - the units under analysis. The first a government entrepreneurship project in the Grahamstown area and the second a group of women operating on $100 \%$ entrepreneurial steering in the Port Elizabeth area.

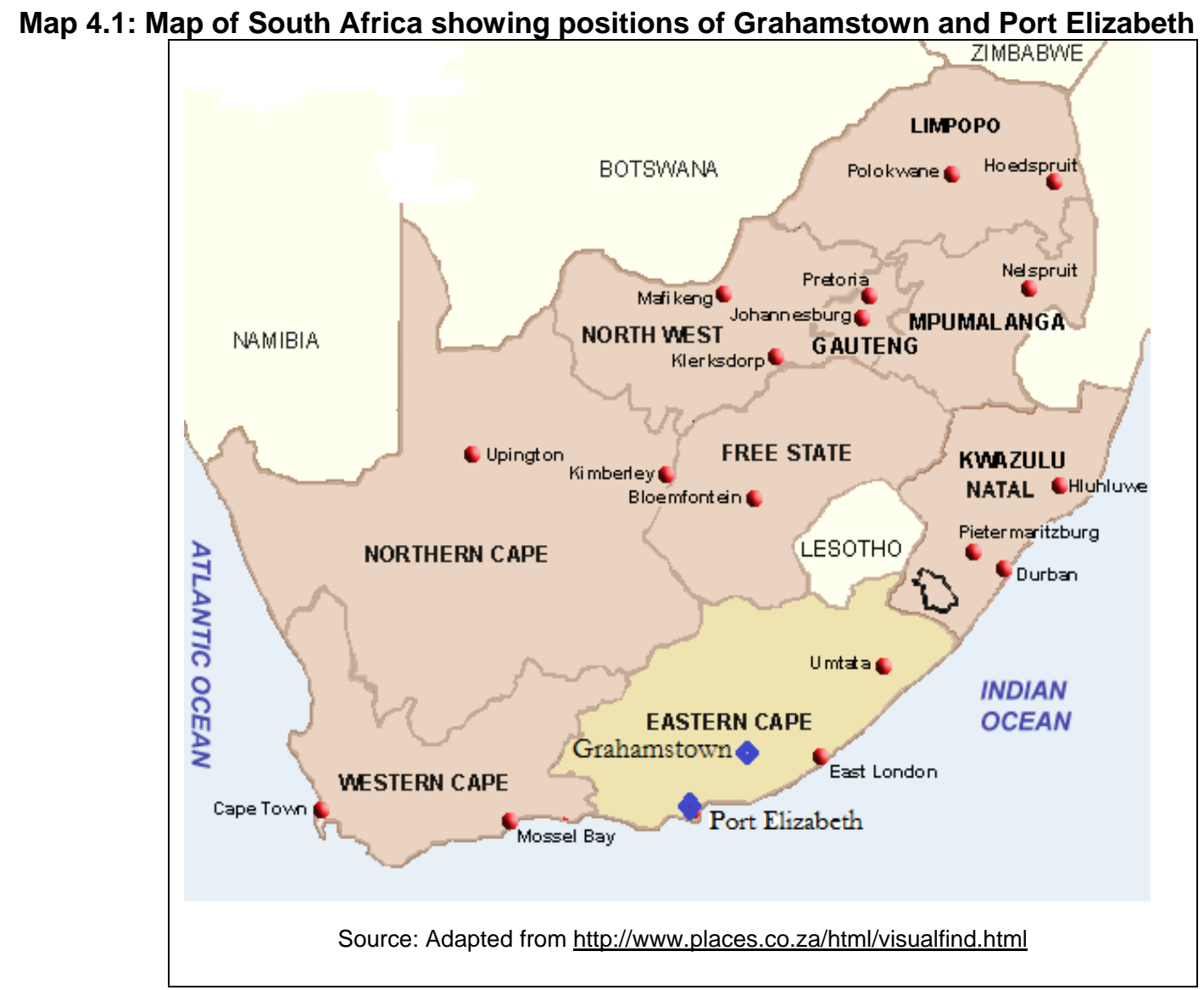

\subsubsection{Government funded home-stays}

In 2004 the South African Department of Sport, Recreation, Arts, and Culture (DSRAC) established a home-stay pilot project to promote the diffusion of entrepreneurship. The initiative was built around the annual Grahamstown Arts and Culture festival. It 
aimed to incorporate women aged above 40 from Joza Township into the tourism economy. The women were either previously unemployed or earned a household income of less than R1500 per month. The women received hospitality training to enhance their operational skills. Participants also received "starter packs" (bed linen and towels) and continue to receive an annual R500 inputs grant two weeks before the start of the festival. During the festival the home-stays receive guaranteed occupancy from DSRAC officers, the bookings are made through the Grahamstown Tourism Office. Most of the home-stays only have occupancy for two weeks annually during the festival, the home-stays can house anywhere from one and eight depending on the number of extra bedrooms at the home. The intention at inception was for the homestays to graduate from the initial phase of 'assistance receiving' to 'entrepreneurially steered' with the broad aim of contributing to BEE.

\subsubsection{Independent home-stays}

In 2004 a total of six women independently set up their homes to operate as tourism home-stays in Red Location (Township) in Port Elizabeth. The women use spare bedrooms in their homes to accommodate paying guests. The guests receive meals (breakfast and dinner) and are welcome to interact in all host family activities for the duration of their stay. The home-stays can accommodate a minimum of one and a maximum of four guests depending on the number of extra bedrooms in the home. According to the women entrepreneurs the setting up of the home-stays did not require much capital outlay as they use amenities in their homes for the business. All the women entrepreneurs are also employed full time (four primary school teachers and two administrators). The reasons cited for starting the home-stays were 1) additional income and 2 ) the cultural exchange. The women receive independent guests from various sources with some guests staying as long as three months in the case of interns. The home-stays were started on and continue to run on $100 \%$ entrepreneurial capital and steering.

\subsubsection{Methodology}

As a way of demonstrating how a government tourism home-stay initiative attempts to diffuse entrepreneurship through the BEE framework this study assesses to what extent government tourism home-stays promote the attainment of women entrepreneurial economic empowerment in view of the overarching BEE goal. The empirical material consists of semi-structured interviews held during fieldwork in 2009 (6 months) and 2010 (3 months), with a cross section of nine tourism experts (2 consultants; 3 academics; 1 policy analyst; 1 project executive and 2 government 
officials). The key informants were purposively selected on the basis of insider knowledge with the BEE framework and implementation. The study draws from interpretive thought informed by hermeneutical considerations that privilege subjective meanings and multiple truth (Altinay and Paraskevas 2008; Prasad 2005).

The study investigates: 1 ) the attunement of the tourism home-stays to the principal goal of BEE and 2) comparison of the BEE initiative's ability to stimulate self-reliance and entrepreneurial capabilities among previously disadvantaged women against the women entrepreneurially run home-stays. The research methods employed to ascertain to what extent BEE reverses the socio-economic arrangements established by the apartheid institution are presented in Table 4.2 .

Table 4.2: Research Methods

\begin{tabular}{|l|l|}
\hline Government funded home-stays & Entrepreneurially run home-stays \\
\hline $\begin{array}{l}\text { Document and Policy analysis; } \\
\text { Expert semi- structured interviews }\end{array}$ & Entrepreneurship model and theory \\
\hline \multicolumn{2}{|c|}{ Day visits; Observation, discussions } \\
Overnight stays; Observations, discussions \\
Institutional framework literature
\end{tabular}

To establish to what extent the BEE tourism home-stay project promotes the diffusion of entrepreneurial empowerment, a comparison is made of government tourism home-stays and entrepreneurially run home-stays and used as a basis for discussion of the outcomes of empirical findings. This involved visits to 39 home-stays of the total 44 home-stays in the government initiative and to all six entrepreneurially run tourism home-stays. Efforts to reach all 44 home-stays in the government initiative were made, however five of the women were unable to receive the author at the scheduled times owing to various commitments. The visits comprised day visits to all the home-stays with an average stay of two hours; and six overnight stays as a paying guest within the two categories, determined by budgetary limitations. Firstly, the home-stays were stratified on the basis of size (number of bedrooms), and then a home-stay was randomly selected from each subgroup. This meant four home-stays from the government initiative and two from the entrepreneurially run home-stays. During the visits the researcher engaged with the women operators through observations and short informal conversations; here some themes that had previously not been identified through literature emerged, allowing for new lines of inquiry. The author took field notes of the observations and tape recorded the short informal conversations and interviews. During the visits to the BEE tourism home-stays the project officer of the initiative accompanied the author, where she interpreted when 
necessary to both parties. The data was later transcribed and analyzed according to emerging themes.

\subsubsection{Data analysis}

The data collection methods employed included several simultaneous activities; collecting information from the field, sorting information into categories according emerging themes, formatting the information into a story, and actually writing the qualitative text. Transcripts of interviews and discussions were compiled verbatim from the tapes as soon as possible after each event. As with all qualitative information, decisions were made about what to use, as multiple themes were established from the data. Thematic categories were established from interview and discussion data and editing of quotes was kept to a minimum to preserve their perspectives as precisely, yet clearly, as possible. For detailed analysis, a hermeneutic framework was used. From this perspective, the stories that the operators told about their experiences are a prime locus of discovery, these were then juxtaposed with literature and BEE policy and frameworks to provide insight on the practical aspects of BEE and the promotion of entrepreneurship.

\subsection{Results}

The results of this study report on the challenges for the transformation agenda, these include: prevailing prejudices and unequal division of power and resources, lack of skills and experience and a dependency culture. These challenges are linked to the apartheid legacy but also to the independent government's inability to provide adequate efforts in skills development, BEE tourism development and entrepreneurship.

\subsubsection{Interview data}

\subsubsection{Lack of skills and experience}

The need for improved access to tourism education and training in tourism, which would increase skills levels, formed a common thread among respondents in the academic sector. Interviewee AR-1 explained that "as a result of diminished access to basic education under apartheid for the black majority, there is a shortage of qualified trained manpower among the previously disadvantaged". It also emerged from the interviews that the government's BEE efforts in general are viewed to be somewhat artificial in terms of how they place black persons in key driving posts in most cases 
without any merit such that BEE has come to be associated with a mere appeasement scheme for PDIs. In the words of respondent AR-2, "the government should first and foremost provide the education that ensures self-reliance and sustainability instead of giving handouts in the name of BEE". Moreover, informants acknowledged and concurred that sound business vision and experience are equally important requirements for establishing successful women tourism enterprises. Interviewee CR-1 unequivocally stated that "the aid approach to BEE initiatives that the government has adopted curtails the potential for poverty reduction because it diminishes the excitement and meaning of entrepreneurship ... there is no mechanism for aligning skills sets and experience with initiative". Respondent AR-3 adds weight to these concerns when he highlighted a lack of access by the women operators of government financed project to the tourism sector in both professional and touristic contexts "do not forget that these women have neither business management skills, nor experience with tourism either as tourists or professionals ... to expect them to take up ownership of the initiative, given the implementation is near impossible".

\subsubsection{Black Economic Empowerment and prejudice}

It emerged from research that the tourism transformation agenda has met with some challenges. Informants reported on how BEE legislation and initiatives have not entirely encouraged economic progression through tourism development in a way that promotes entrepreneurship. Respondent PAR-1 spoke of the ills of applying "top-down funded programmes with government-led conceptual frameworks". While GOR -1 remarked that "... the issue is that these programmes are steeped in bureaucracy that neither serves nor solves problems ..." Most of the informants shared a profound critique of BEE; a recurrent theme was that BEE in a broad sense was being used as an indirect mechanism to increase wealth and ownership among [in the main] already wealthy blacks who have thereafter become a new elite class. While CR-1 cautioned on the lack of awareness and coverage of BEE tourism opportunities, he describes how "those in need of BEE are in most cases not meaningfully exposed to BEE-related opportunities". Respondent CR-2 spoke of misplaced emphasis from the onset; he describes the structure of BEE as "not encouraging truly entrepreneurial approaches to wealth creation and poverty reduction ... black people are simply not ready to be managers in tourism".

The second objective sought to establish how stakeholders perceive PDIs participation in BEE tourism initiatives in the study areas. Respondent PER-1 observed that "BEE has become more about race than anything, the challenges and shortcomings open a can of worms ... [lowers his voice and sternly says] this is a learning curve, the real question 
should be are those in power able to articulate what empowerment means? Remember they were equally disadvantaged by apartheid". The remark by respondent PAR-1 captures it well when he states that "human development is the same everywhere, no one can skip a stage - South Africa has to learn its lessons step by step". Respondent AR-3 was robust in his commentary when he stated "what I am going to say is controversial, ... it goes against the prevailing mindset which pushes for solutions to public problems to be created by the government; people are responsible for their own progress ... can a programme no matter how well intended bring true empowerment to anyone? ... I think not".

Not surprisingly, most government officials felt that women participation in BEErelated tourism development was high and positive; this is plausible since it was their mandate to promote BEE policies in the area. Nevertheless, a small proportion of the government officials indicated that women participation in BEE policy activities was nowhere near optimum levels. So much that respondent GOR-2 challenged the current approach to BEE, stating that "at the core of this outlook to poverty alleviation is the basic question: Are individuals, able to determine their own future?" While CR-2 highlighted the need to look beyond the apparent, "indeed these women are poor, but poverty is a state not the end all ... there should be a mechanism to allow PDIs to identify their preferred option for poverty alleviation". While a PAR-1 spoke of a prevalent stance by the government bent on "... poverty reduction but focuses too little on growth markets, improved productivity and linkages with other sectors".

\subsubsection{Dependency}

According to GOR-1 "the current implementation of BEE breeds a dependency culture ..." Informants were unanimous in their view that most BEE initiatives have actually created a dependency culture and a sense of entitlement among recipients rather than the intended capacity building and economic empowerment among PDIs. Respondent AR-2 vehemently stated that "the government set these women up to be dependent" he went on to say "this is not how entrepreneurs are made, there needs to be a hunger from within that fuels the women". He (AR-2) went on to pose the question "can entrepreneurship be taught?" and also elaborated that "it is not that these women are incapable, rather the structure is problematic ... Seemingly, DSRAC identified the problem and decided on a solution, then took a finished strategy to the ground ... the recipients had no say in the design of the initiative ..." Interviewee GOR-2 highlighted the dichotomy of BEE, "the issue is that the government has taken a stance that is curtailing the very goal of BEE - handouts are not the way, it is as if on some intrinsic level the government does not trust that the people can be successful, ... 
fundamentally it sees the people as not entrepreneurial so instead they throw money". During an interview with PER-1 the issue of the absence of linkages and partnerships with both tourism and non-tourism businesses was discussed. The interviewee stated "we do not have the mandate to redesign the initiatives, we have to implement the projects as they are ... there are so many improvements that we could effect, but we do not have the power".

\subsubsection{Comparison of Home-stays - Observations}

The summary of the tourism home-stay experiences detailed in Table 4.3 is derived from field research conducted during two field trips to the Eastern Cape province of South Africa between 2009 and 2010.

Table 4.3: Comparison of home-stay visits

\begin{tabular}{|c|c|c|c|c|}
\hline \multirow[b]{2}{*}{ Home-stays } & \multicolumn{2}{|c|}{ Day Visits } & \multicolumn{2}{|c|}{ Overnight Visits } \\
\hline & Physical Attributes & Dialogue & $\begin{array}{l}\text { Interaction with host } \\
\text { families }\end{array}$ & Experience \\
\hline $\begin{array}{l}\text { Government } \\
\text { funded } \\
\text { home-stays }\end{array}$ & $\begin{array}{l}\text {-Excellent standards of } \\
\text { cleanliness both inside \& } \\
\text { outside of the } \\
\text { homesteads [quality } \\
\text { control] } \\
\text {-Adequate technical } \\
\text { capacity to operate the } \\
\text { home-stays } \\
\text {-Décor in the home-stays } \\
\text { is nuanced to } \\
\text { modern/European } \\
\text { furnishings } \\
\text { (see Appendix 1) }\end{array}$ & $\begin{array}{l}\text {-Reserved but welcoming } \\
\text {-Dependent on } \\
\text { government for financial \& } \\
\text { material resources to run } \\
\text { the home-stays } \\
\text {-Insufficient recognition of } \\
\text { private information } \\
\text { services } \\
\text {-Passive, looks to } \\
\text { government for } \\
\text { assistance and direction } \\
\text {-Lack confidence to } \\
\text { design, implement and } \\
\text { manage }\end{array}$ & $\begin{array}{l}\text {-Very limited interaction } \\
\text { with the hostess and her } \\
\text { family } \\
\text {-Hostess served guests } \\
\text { with the food and } \\
\text { retreated to the kitchen, } \\
\text { where the family took } \\
\text { their food } \\
\text {-After dinner there was no } \\
\text { interaction with the host } \\
\text { family, guests were left to } \\
\text { interact alone in the living } \\
\text { room with the television }\end{array}$ & $\begin{array}{l}\text {-Pleasant atmosphere } \\
\text {-Excellent food } \\
\text {-Elaborate selection of } \\
\text { dishes both at dinner and } \\
\text { breakfast [reminiscent to } \\
\text { a buffet in a restaurant] } \\
\text {-Very luxurious night } \\
\text { [bedrooms were } \\
\text { contemporarily furnished] } \\
\text { - Modern fittings in } \\
\text { bathrooms }\end{array}$ \\
\hline $\begin{array}{l}\text { Entre- } \\
\text { preneurially } \\
\text { funded } \\
\text { home-stays }\end{array}$ & $\begin{array}{l}\text {-Excellent standards of } \\
\text { cleanliness both inside \& } \\
\text { outside of the } \\
\text { homesteads [quality } \\
\text { control } \\
\text {-Adequate technical } \\
\text { capacity to operate the } \\
\text { home-stays } \\
\text { - Décor in the home-stays } \\
\text { is a mixture of modern } \\
\text { and Xhosa furnishings }\end{array}$ & $\begin{array}{l}\text {-Uninhibited \& welcoming } \\
\text {-Networking between } \\
\text { operators and tourism } \\
\text { community to enhance } \\
\text { visibility of the home- } \\
\text { stays } \\
\text {-Recognition of private } \\
\text { information services } \\
\text {-Self-reliant for financial } \\
\text { and material resources } \\
\text {-Self-starters do not to } \\
\text { look to government for } \\
\text { assistance } \\
\text {-Decisive }\end{array}$ & $\begin{array}{l}\text {-Extensive interaction with } \\
\text { the host family } \\
\text {-Meals were not } \\
\text { necessarily served, plated } \\
\text { by the hosts and guests } \\
\text { were welcome to pick } \\
\text { their plate from the } \\
\text { kitchen and host family } \\
\text { and guests sad down to } \\
\text { eat together } \\
\text {-Conversations with the } \\
\text { host family about history, } \\
\text { current issues and local } \\
\text { culture during and after } \\
\text { dinner }\end{array}$ & $\begin{array}{l}\text {-Pleasant atmosphere - } \\
\text { Guests were invited in the } \\
\text { kitchen to prepare meals } \\
\text { and learn about the } \\
\text { cuisine, breakfast was } \\
\text { self-service of cereal } \\
\text {-Excellent home cooking } \\
\text {-Clean and comfortable } \\
\text { bedrooms } \\
\text {-Modern bathroom fittings }\end{array}$ \\
\hline
\end{tabular}

\subsubsection{Summary of home-stay experiences}

There is a distinct difference in the cultural experience offered by the two types of home-stays as summarized in Table 4.3. The experiences at the government funded home-stays were reminiscent of a stay at a guest house or a small family run hotel, as 
a guest there has very limited contact with the hostess and her family except to greet on arrival. That said the women operators were very welcoming, friendly and their service was wonderful. At the time of the overnight stays these home-stays had no occupancy as it was outside the festival period. On first sight the home-stays look very contemporary (see Appendix 1) on closer introspection it appears there is a deliberate effort to camouflage the Xhosa heritage of the host families to the guests. For instance the lack of interaction with the family ensured that the guest was not exposed to any elements of the Xhosa way of life, there was no opportunity to hear the language as all communication was in English. There was no platform to ask about the history of the community or the vibrant township culture. The home-stays had Eurocentric undertones evident in the food served; although delicious, it was a selection of European dishes such as lasagna, shepherd's pie and roast potatoes, the table settings were also in the same category. The only exception was in one home-stay that served dumplings and meat that were made on the fire, when asked on her reasons, she replied "I do not know how to cook good food ... when I have enough money I will go for culinary training, then I will be able to make really special dishes [she smiles nervously].

It emerged from the conversations with the government project women operators that the current theme of the home-stay is in line with the training received; one woman stated "we were told to do things this way by DSRAC". By comparison the entrepreneurially run home-stays were more embracive of their Xhosa heritage, evident from the ambience, food and décor and intermingled with aspects of modern living. The entrepreneurial home-stays offered more interaction opportunities with the host family by comparison to the government funded establishments. The women were outgoing, always asking questions and offering additional products and services offered in their network, such as shabeen tours. Additionally, at both home-stays there was also another guest in each of the home-stays on nights the author spent with the families. The families were a huge part of the experience; the women played the central role in food preparation and most of the chores, with assistance from family members, and as the guest you participated in women household chores while the men mainly entertained by narrating stories about the culture and history of the township and life in general. The entrepreneurial women in the Port Elizabeth study area have established a roundtable scheme in which members pool money at no interest rates. 
Table 4.4: Home-stays' characteristics

\begin{tabular}{|c|c|c|}
\hline Characteristics & $\begin{array}{c}\text { Government funded tourism } \\
\text { home-stays }\end{array}$ & $\begin{array}{l}\text { Entrepreneurially driven tourism } \\
\text { home- stays }\end{array}$ \\
\hline Advertising & $\begin{array}{l}>\text { Listed in the Grahamstown } \\
\text { Tourism Office brochure }\end{array}$ & $\begin{array}{l}\text { Listed in the Port Elizabeth } \\
\text { Tourism Office Brochure } \\
\quad \text { Advertised through a township } \\
\text { tours company } \\
>\quad \begin{array}{l}\text { Advertised at the Addo Elephant } \\
\text { (Game) Park }\end{array}\end{array}$ \\
\hline Product range & $\begin{array}{ll}> & \text { Bed and breakfast } \\
& \text { (Accommodation) } \\
> & \text { Dinner and lunch on re } \\
> & \text { Quest }\end{array}$ & $\begin{array}{l}>\quad \begin{array}{l}\text { Bed and breakfast } \\
\text { (Accommodation) }\end{array} \\
>\quad \text { Dinner and lunch on request } \\
>\quad \text { Cultural activities in the } \\
\text { community }\end{array}$ \\
\hline Linkages & $>$ DSRAC officials & $\begin{array}{ll}> & \text { Local Shabeen (Bar) } \\
> & \text { Township tours company } \\
> & \text { Addo Elephant (Game) Park } \\
> & \text { Switzerland cultural exchange } \\
& \text { program } \\
>\quad \text { Local primary school }\end{array}$ \\
\hline $\begin{array}{l}\text { Cultural } \\
\text { experience }\end{array}$ & $>$ Interaction with the host family & $\begin{array}{l}>\text { Interaction with the host family } \\
>\quad \text { Arts and Culture Village } \\
>\quad \text { Inclusion in host family activities }\end{array}$ \\
\hline
\end{tabular}

Empirical research shows that the women operators of the government funded homestays have not independently advertised (see Table 4.4) and rely solely on the inclusion in the destination brochure to attract business and patronage from DSRAC officials. There has been no contact with other tourism operations or efforts to incorporate additional products from other sectors. In contrast the entrepreneurially run tourism home-stay operators have collectively sought alliance with other tourism operations in the area. The women operators highlighted their efforts on marketing and the financial commitments made to steer their establishments towards set targets. For example they have formed linkages with the local Game Park, where they set up a reciprocal arrangement to send clients to each other. Furthermore, they are linked to a township tours company which includes visits to a local primary school and shabeen (tavern). Both groups of operators relay a sense of pride and achievement for having operational home-stays. Statements like "I am so proud to have my own business" and "I am so happy to have income from my home" were repeated frequently during discussions. 


\subsubsection{Institutional arrangements}

One of the major issues to arise during discussions concerned married women in both groups, in order to operate their establishments first they had to acquire their husband's permission. As household owners, men must approve any activities their wives are involved in. For instance, one woman said "... I had to seek permission from my husband before I could join the project" while another said "I had to convince my husband of the benefits of opening our home for business to strangers, I also promised to not let the business interfere with my household responsibilities". One woman entrepreneur pointed out that "a man is the head of the family and a woman has to listen to her husband". While a woman from the government funded initiative mentioned that "we don't work every day. We are very busy for about three weeks a year. For the rest of the days, we are at home doing our usual work, so my husband is very supportive". It also emerged during conversations that children help their mothers with chores especially after school hours and during school holidays. A divorced single mother from the government initiative said that her mother handles childcare responsibilities on her behalf during the festival period. Another woman in the initiative is helped by her mother and younger sister-in-law who volunteer to care for her toddler and to also help out with chores during the festival.

\subsection{Discussion of Results}

\subsubsection{Women entrepreneurship in tourism home-stays}

As highlighted in literature (Roomi and Parrot 2008) the study investigated the notion that entrepreneurs are risk-takers and have a high need for achievement, control and autonomy. Findings from research suggest that women in the government initiative have low entrepreneurial steering while the entrepreneurial counterparts displayed all three attributes (refer to Table 4.5) of entrepreneurs according to Roomi and Parrot (2008).

Table 4.5: Home-stays entrepreneurial performance

\begin{tabular}{llcc}
\hline & Achievement & Control & Autonomy \\
\hline BEE Home-stays & $\checkmark$ & & $\checkmark$ \\
Entrepreneurial Home-stays & $\checkmark$ & $\checkmark$ & $\checkmark$ \\
\hline
\end{tabular}

These findings add weight to the study by Malecki and Poehling (1999) that showed that entrepreneurs are extroverts had larger networks, sought out information from a larger number of sources, and looked to customers, suppliers and competitors for 
ideas. The women entrepreneurs have also begun to collectively invest in, and to have control over, productive resources in this case their homes as they have dual roles as home and enterprise. In a way the women are confirming the assertion made by Lee (2001) found that Jews and Koreans are more successful entrepreneurs than AfricanAmericans because they enjoyed better access to capital through family or ethnic networks than others. By setting up the roundtable scheme the women have set up their own ethnic network capital financing scheme. This is slowly challenging cultural norms regarding resource ownership. Thus, dominant gender norms and discourses surrounding resource ownership, household breadwinning, and community respect are slowly evolving as women negotiate and access the tourism economy. In turn, this presents possibilities for women's empowerment. On the other hand, for the women in the Grahamstown study area, progress on the same issues is much slower because patronage to their home-stays is concentrated to a limited period and as a result their income is not regular and considerably less compared to their entrepreneurial counterparts.

\subsubsection{Institutional arrangements}

For the women from the government project the economic independence is gaining them self-esteem and community respect as some women are able to employ locals on a part time basis. The assistance that the women receive from family demonstrates the importance of informal institutional arrangements especially among fellow women and children (the family institution), in ushering the women into the entrepreneurial space of tourism. The women are also bargaining through effective time management, evident in how they schedule their activities so they do not clash with their household responsibilities (the marriage institution). The women's lived experiences depict their individual negotiations and how they are trying to balance life and tourism entrepreneurship demands. The findings corroborate with discussions reported earlier (Storey 1994; Dakhli and de Clercq 2004) and also show the crucial role of social capital and networks in boosting women's entrance to the tourism entrepreneurship domain; and the critical need for understanding individual women's lived experiences to counteract economic inequalities and so lead towards better more egalitarian social arrangements.

In the case of the entrepreneurially run home-stays it appears much depends on the degree of 'social capital' (see Nederveen Pieterse 2001) largely stemming from friendships and union of women as they embark on the entrepreneurial ladder. . The men are largely in the background, opting for fixed employment over 
entrepreneurship, but like Moser (2009) one is aware of the importance and role of marriage, and relationships with men, for the women in the community (marriage institution). The women have multiple roles, they hold fixed employment, operate the home-stays, are wives and mothers) and through their unity they emerge as leaders in their own right. In a highly patriarchal society they manage to steer the course of their development through self-determination. The entrepreneurial home-stays make a case for the argument that "a community, however impoverished, has assets to offer to its own reshaping and it enables people to focus on what is possible, that certain steps are immediately possible" and, "this builds momentum for change that comes from within to which external interventions can be harnessed"(Green 2010:1). As stated by Saul Alinsky of community organizing, 'start with small victories'.

\subsubsection{Dependency}

An evaluation of the home-stays against the second BEE principle that focuses on skills development with the aim to develop capabilities and to empower people to be able to make decisions and build confidence reveals that the government initiative is facing some challenges. As Presister (1989: 20) notes "locally affected people are not shaped passively by outside forces but react as well, at times even changing the conditions of the larger system". Presister (1989) also argues that the development outcome is a 'negotiated process' between local groups or individuals and structural forces. The women entrepreneurs have shown how this 'negotiated process' is operationalized and thriving. Findings illuminate that in the government initiative the 'negotiation process' has been thwarted owing to the institutional arrangements in place that have not promoted entrepreneurial steering (see Chapter 6). Findings corroborate with literature (Ramphele 2008; Mbeki 2009) that BEE seems to have enabled a dependency culture. Mbeki (2009) maintains that as a direct result of the origins of BEE for the PDIs it is critical that they remain perceived as victims and as weak. Maathai (2006: 173) wrote on Kenya "... one way was by not standing up for what they strongly believed in and demanding that the government provide it". To overcome this she maintains that "you need to do something about your situation. Do whatever is within you power" (Maathai 2006: 173).

\subsubsection{Constraints to Black Economic Empowerment}

There have been arguments, acceptance and rejection of the BEE policy initiatives in literature (Lalu 2004; Rogerson 2004; Ramphele 2008; Jauch et al. 2009; Mbeki 2009; Andreasson 2010). Some views obtained from the research hold that the BEE policy initiatives are not successfully contributing to entrepreneurial tourism development; there is a contention that currently beneficiaries of the BEE policy are a selected few. 
In the interviews the implementation of BEE was criticized for its lack of communication about the policy to the majority. A number of the informants indicated complete unawareness of how the BEE concept has been meaningfully operationalized for community empowerment. These findings seem to support the views of Mbeki (2009) that it is unfortunate that the whole BEE trajectory is dependent on giving opportunities to the learned, connected and privileged. Emerging from interviews BEE is seen as not meant for the poor black people with entrepreneurial expectations. Rather as stated by Mbeki (2009) the current BEE institutional arrangements reinforce the position that PDIs remain perceived as victims and as weak. Therefore, much work still has to be done in transforming the business landscape, particularly as it relates to benefitting PDIs. While those more familiar with BEE expressed concern about the perceived misuse of BEE for the benefit of a few. There are various reasons for this, such as the political nature of the concept, accessibility of information and the role of the media as well as low educational levels (Magi 2010). The latter is an issue as reflected in the government initiatives compared to the entrepreneurs from the Port Elizabeth with higher education levels. This is in tandem with remarks made by Evans and Leighton (1990) that people with higher educational attainment tend to found new businesses more often than those with less educational attainment.

Pursuant to the argument cited above, this chapter sought to establish the extent to which the BEE policy contributes to entrepreneurial tourism development using information available in the study areas. This meant establishing if the policy contributions or inputs are of a high order or low order to tourism development and entrepreneurship. Analyses of the three stakeholder groups: tourism home-stay entrepreneurs, tourism officials and BEE tourism home-stay operators, reveals varied results. The majority of respondents indicated that they perceived the BEE policy inputs or contributions towards tourism development and entrepreneurship to be low. A significant number supported a negative perception by saying they were not sure of the situation. A majority of tourism officials perceived the contribution of BEE policies towards tourism development to be of a low input. The reasons for the negative responses might be linked to the degree of difficulty experienced in accessing BEE tourism development opportunities. The responses of the stakeholders show that there is a low participation rate by PDIs in tourism entrepreneurship. It is important to note that the stakeholders did not necessarily base the level of participation on the basis of successes achieved in tourism-related enterprises, but simply that there were people on hand to participate. Interview respondents indicated that many community members are invited, to participate in BEE but very few are chosen; in other words, it remains difficult to get funding and tenders as an individual. Importantly, the 
Grahamstown women operators showed a reverse trend of what the stakeholders indicated as they are beneficiaries of a predefined BEE initiative.

Discussions with the women operators in the Grahamstown area on their levels of awareness to BEE opportunities, indicated that they were fairly aware of the tourismbased opportunities. The justification for this might be that the women were well exposed to the workings of $\mathrm{BEE}$, as they were already active in one such initiative. These participants were supposedly inhibited by 1) lack of skills and low education levels; and 2) scarcity of start-up capital for business ventures, hence they were selected to be participants in a government tourism pilot project aimed at promoting entrepreneurship. The women entrepreneurs from the Port Elizabeth study area had limited knowledge of government BEE tourism opportunities. There was also a general sense of discontentedness surrounding the effectiveness of government BEE development programmes, one entrepreneur stated that "it is better to start my business with my own money I will value it more" while another pronounced "I don't need handouts if I work to establish my business I will be successful, it is not easy but it is better". The negative reports by BEE commentaries in the media might have impacted negatively on the women entrepreneurs in the Port Elizabeth area. These negative reports corroborate with literature which highlights issues like selective and preferential treatment towards accessing BEE deals; lack of support for emerging entrepreneurs; lack of capital or funding; over-dependence on government hand-outs (Southall 2007; Mbeki 2009). It has been alleged that the current BEE state is disappointing, it was envisaged that BEE forerunners would become role models for the black youth, showing them that given the opportunity, PDIs are as capable as any other group to be successful entrepreneurs (Manyara and Jones 2007; Southall 2007; Ramphele 2008).

\subsubsection{Power and access}

Findings from the study show there is need for the women from the government initiative to build their capacity to entrepreneurially steer the project. The outcomes of the analyses covering the state of awareness, participation, contribution to tourism and its management, point to the fact that the present BEE tourism development strategies are not adequately enhancing the level of entrepreneurial steering for these women. It is reasonable therefore to postulate that the tourism transformation envisaged by the government, seems to falter in becoming a respectable way of compensating the women. By its nature and design BEE policy as it is applied in this context can be seen as a tourism economic model which seeks to channel 
opportunities from the advantaged groups to PDIs. Earlier, reference was made to the fact that there were many factors that can limit the meaningful involvement of PDIs in the tourism industry, particularly as it relates to BEE policy for tourism development (De Villiers 2005). Findings from the government initiative point to lack of knowledge and misunderstanding of what the tourism home-stays are really about. Past inequalities resulting in diminished access to education is also another contributory factor that has influenced the extent of the women's participation.

Some analysts (Southall 2007; Ramphele 2008) view BEE policy as still being in an experiential process, and not a finished product. This substantiates earlier observations by Clarke (2002 in Kaplan 2004) that "... there does not yet exist a clear contextual framework or common definitions within which local economic development can be understood". BEE has been described as not being a fool-proof tourism model and the absence of another elsewhere in the world that can be adapted or replicated, hence it has been explained as a model in its infancy that will undoubtedly have hitches (Rogerson 2004; Ramphele 2008). The comments decrying the government tourism initiative, discussed above, highlight the need to adopt an approach that can salvage the project. A proposed starting point is candor and this reinforces the proposition made by Biko (1978: 92) when he said that "to get the right answers, we must ask the right questions, we have to find out what went wrong where and when".

\subsection{Conclusions}

Indeed, BEE has had some economic impact, however more has to be done in order to realize meaningful success, the chapter has shown that the BEE financing approach to tourism development is less effective than the entrepreneurially driven counterpart. The approach sees the PDIs, as accepting and this determines the "top-down" approach to poverty reduction such that their future hangs in the balance and in the hands of others. With a legacy of minimal basic education and business management skills, inevitably, PDIs seeking to become entrepreneurs will face numerous challenges to be established. Undeniably, this may appear to be a more cumbersome and less appealing approach, but without a detailed intervention the possibility of setting selfsustaining BEE initiatives that promote entrepreneurship among black South Africans remains remote. In conclusion $B E E$ is a necessary first step in addressing the legacy of black poverty in South Africa; the goals are commendable, however, the delivery is somewhat problematic and still needs significant attention. Nevertheless, with 
concerted effort from all stakeholders the situation can be turned around. To effect this there is need for an order centered on black consciousness. In addition an integrated approach to tourism planning and training that includes support from tourism, government, and academic institutions. Finally, if the BEE policy, supporting the tourism development opportunities, is to be successful and eventually beneficial to the women, it would have to be better understood and recognized by the PDIs, and not only by the government and the business sector, as is seemingly the case now. 


\section{Chapter Five}

\section{Evaluation of Local Tourism Development as a Tool for Women Economic Entrepreneurial}

\subsection{Background}

The creation of cooperative networks implies development of social interdependence. This suggests a positive relationship between the interdependent units, such that each will suffer if the relationship is harmed (Johnson and Johnson 1989). Meyer (2004) maintains that a necessary pre-condition for establishing sustainable development initiatives is the buildup within a locality of a good framework of collaboration between government, local council, private enterprises and associations. Cooperation is viewed as a productive factor that is vital to harness entrepreneurial energies for the benefit of the community. Conceptually, these collaborative associations are considered as 'networks' (Meyer 2004). "Social interdependence exists when the outcomes of individuals are affected by each other's actions" (Johnson and Johnson 1989 in Johnson and Johnson 2009: 366), according to Johnson and Johnson (2009: 366) "there are two types of social interdependence", the first is positive, "when the actions of individuals promote the achievement of joint goals", and the second is negative, "when the actions of individuals obstruct the achievement of each other's goals". They go on to explain that social interdependence is distinguished from "social dependence, and helplessness. Social dependence exists when the goal achievement of person A and is affected by person B's actions, but the reverse is not true" (2009: 366). While "social independence exists when the goal achievement of person $A$ is unaffected by person B's actions and vice versa", the outcome being individualistic efforts. Another factor described as social helplessness also "exists when neither the person nor others can influence goal achievement" (Johnson and Johnson 2009: 366).

Plans for developing locally driven and innovative growth in the form of LED have been applied in many parts of the world in order to sustainably improve economic conditions, particularly for small scale entrepreneurs (Zaaijer and Sara, 1993; Demaziere and Wilson 1996; Nel and Rogerson 2005; Rogerson 2006). According to Binns and Nel (2001) key features of LED are that it seeks to encourage economic growth and to diversify the local economic base into sectors that are usually quite different from those in which recent hardship has been experienced; which is an important consideration in regions undergoing economic change. In entrepreneurially 
driven LED there is tension between enhancing interdependence and promotion of self-reliance and autonomy as an underlying driver to economic empowerment. The autonomous perspective often adopted ignores or downplays the influence of situational or social structural factors and artificially disconnects human behavior from the larger sociopolitical context (Prilletesky 1989; Uchida et al. 2004;). LED implies empowerment by decentralization - the deliberate and planned transfer of resources away from central state institutions (Briedenhann and Wickens 2003; Rogerson and Nel 2005). Extant literature on LED assessment has tended to not examine how social interdependence impacts on LED efficacy among disadvantaged groups. Here we adopt the standpoint that history, environment and culture shape the concepts that are used to explain human action and how it impacts the success of LED. Hence the notion of social interdependence is visited with regards conceptions of well-being, empowerment and efficacy inherently linked to LED.

This chapter frames tourism within the context of its potential role as a major LED option with reasonable entrepreneurial economic empowerment credentials. After first examining debates regarding tourism-based LED, the discussion moves on to examine how social interdependence impacts the process of attaining tourism-LED in South Africa. Against this background the chapter investigates how the women homestay operators negotiate formal and informal institutional arrangements to derive economic entrepreneurial empowerment through government LED cultural tourism home-stays. The chapter sets out to establish if the women home-stay operators are satisfied with their present relationship with DSRAC - is there a desire by the women for the project to operate autonomously from DSRAC and progress to a social interdependence operational environment? The chapter concludes with a synopsis of the victories and confounding challenges faced by the women home-stay operators.

\subsection{Local Economic Development in South Africa}

In South Africa, LED is motivated by high levels of poverty, under-utilization of human potential and the need to address the country's apartheid legacy, as well as the common internationally accepted motives of employment growth and wealth creation in response to factors such as deindustrialization and global competition ( $\mathrm{Nel}$ and Rogerson 2005; Jauch et al. 2009; Robbins 2010; Rogerson and Rogerson 2010). Zaaijer and Sara (1993: 129), regard LED as “... a process in which local governments and/or community based groups manage their existing resources and enter into partnership arrangements with the private sector, or with each-other, to create new jobs and 
stimulate economic activity in an economic area". To be self-sustaining the LED needs to provide the appropriate conditions for stimulating enduring entrepreneurial activity which in turn drives the local economy. Post-independence LED has been specifically encouraged by the RDP. It prioritizes community-based development as the way through which the most marginalized sectors can be economically empowered (Rogerson 2006: 2008). Local governments became increasingly involved in LED receiving considerable implicit and explicit support in a range of government policy documents, including the 1996 Constitution, the 1998 Local Government White Paper and the Municipal Systems Bill (DEAT 1996, 1998, 1999). Community development was combined with local realities in a way that is unique to the country for example, democratically elected local government, rather than community based structures, are expected to manage and sustain LED initiatives and to mediate between the various interest groups at the community level (Clarke 2002 in Kaplan 2004).

The devolution of authority and development leadership to local governments, as reflected in the country's move to 'developmental local government' (Rogerson 2002), obliged local governments to seek innovative growth options to address development challenges (DPLG 2006). This also saw the reformulation of LED as a 'pro-poor' strategy. Within this context, LED, in utilizing local resources and skills, has long been recognized by government as a key vehicle for bringing about economic empowerment (Binns and Nel 1999, 2000; Nel 1999; Nel and Binns 2001; Meyer 2004; Rogerson 2006; Rogerson and Visser 2007; Robbins 2010). The current National framework for LED (2006-2011) still maintains that all economic development takes place at the local level and local government must influence the shape and direction of local economies.

\subsection{Tourism and Local Economic Development}

Many African countries regard tourism as an important and integral part of their LED strategies (Burns and Novelli 2007; Raymond and Hall 2008; Magi and Nzama 2009; Robbins 2010). Tourism is often regarded as a panacea for their fragile economies that are characterized by a scarcity of development resources such as private sector finance for capital investment and expertise (Tefler and Sharpley 2008). The argument advanced by scholars (Tefler and Sharpley 2008; Andreasson 2010) is these resources are needed to increase the economic surplus, thus the recognized benefits of tourism are the usual reasons advanced by governments for support of the sector (Magi and Nzama 2009; Tosun 2006; Tosun and Timothy 2003; Dieke 2003). Within this context, advocacy of tourism as a so-called 'pro-poor' strategy has gained prominence in 
development literature (Ashley and Roe 2002; Ashley and Ntshona 2002; Ashley and Mitchell 2005), as are parallel debates concerning the potential of tourism for promoting LED and sustainability in a manner that does not lead to drastic environmental and social change (Wahab and Pigram 1997; Elliott et al. 2001; Sharpley 2002). In locations marked by economic collapse or challenges, and in the absence of significant alternatives, this is an understandable option. Sharpley (2002) cautioned that tourism can seldom be regarded as a 'development panacea'. More recently, Breidenhann and Wickens (2007) warned against creating unrealistic expectations of what tourism can accomplish in terms of LED and poverty alleviation in South Africa. They argue that, by itself, tourism is unlikely to create sustainable jobs for impoverished communities. Thus, unless tourism projects are approached from a business as well as a social development project perspective, they are destined to failure (Breidenhann and Wickens 2007), a lack of a financially viable business plan and careful strategy is likely to result in a short lived project .

Tourism was seen from the start as an important development tool in South Africa and was specifically flagged as such in the RDP; the promotion of tourism is still widely recognized in the country as a key growth alternative (Kaplan 2004; Rogerson 2006; Magi and Nzama 2009). A number of tourism-led initiatives have been launched as a basis for promoting LED, most of the noteworthy cases in South Africa have been in areas where dynamic community organizations or nongovernmental organizations (NGOs) have sought to improve human welfare and employment (Nel 1999). Karamata and Gwari (2007); Binns and Nel (2002a, 2000) postulate that tourism-LED goes far beyond the transformation of the existing industry as it attempts to spread the economic benefit of tourism outside of the metropolitan areas to the more marginalized parts. That said, LED initiatives have met with their fair share of challenges. In part, the lack of an integrated and comprehensive approach to national tourism planning (Lalu 2004) is related to the confusion around the various tourism planning concepts used by the different government departments and agencies (Rogerson 2002; Kaplan 2004). Kaplan (2004) advises that clear definitions of tourism concepts are important in ensuring that successful project outcomes can be replicated. This is similar to Clarke's (2002: 3 in Kaplan 2004) who remarked that a number of "tourism and communities" concepts are used interchangeably by tourism professionals and policy makers in South Africa without a common understanding of what these various concepts mean. The promotion of LED is inherently based on local ownership and governance (DPLG 2006) which is in contrast to the unequal ownership pattern of the private sector. On the other hand, LED offers new skills development, entrepreneurial and employment opportunities for black South Africans in both rural 
and urban areas and therefore increasing the number of beneficiaries in the tourism sector. Undeniably, unlike private enterprises, community-based ventures often lack basic entrepreneurial skills which are essential in tourism (Karamata and Gwari 2007).

\subsection{Social Interdependence}

When social interdependence is applied to LED it juxtaposes "economy and society, showing how economic decision-making and action is shaped by the shared values, norms beliefs, meanings, history and rules, of the formal and informal institutions of society" (DPLG 2006: 3). This study follows the notion advanced by Sampson (1983 in Riger 1993) that the individual is the creation of exposure to a particular sociohistorical system. This merging of economy and society helps to develop "shared meaning and values, and to strengthen the networks of social interaction" (DPLG 2006: 3). This has also been variously described as building social capital, or developing social cohesion (Minang 2007). Developing societies and cultures are claimed to value interdependence or even dependence and pursue group obligations rather than individual autonomy (Diener and Suh 2000; Uchida et al. 2004). Interestingly, the popular paradigm advanced in empowerment literature rests on the assumption that the empowered individual is one who is self-contained, independent and self-reliant, capable of asserting himself and influencing his environment (Riger 1993). According to some (Markus and Kitayama 1991; Christopher 1999) this limits the applicability of the notion of autonomy to other cultures. This is especially so in developing countries where hierarchical and collectivist values are strong (Chirkov et al. 2003). This chapter adopts social interdependence to explain when the social economy can work as a complement to LED, Salamon and Anheier (1998) specify at length the circumstances under which such a mutual relationship is likely to emerge. This does not however explain how and when the social economy can work as a complement to LED, a gap this chapter aims to address.

Social interdependence theory serves as a foundation for a number of other theories, the theories, among other issues, deal with trust conflict, integrative negotiations, distributive (social) justice, positive power, and values (Johnson and Johnson 2005). Trust is based on the belief that the other person will behave in a cooperative, not a competitive manner (Deutsch 1962). Conflict resolution is based on restoring cooperation among disputants and reducing competitive behavior (Deutsch 1973). Integrative negotiations are grounded in promoting a cooperative problem-solving (as opposed to a competitive) process of coming to an agreement (Johnson and Johnson 
2003, 2006). Distributive (social) justice maybe based on equality (cooperative rationale), equity (competitive rationale), or a need basis (altruistic rationale) (Deutsch 1985). Conceptualized views of positive power are based on the view that power is positive when it enhances the cooperative aspects of the situation and reduces the competitive aspects (Coleman and Tjosvold 2000 in Johnson and Johnson 2005). Cooperation is the basis for social identity theory and procedural justice (Tyler and Blader 2000 in Johnson and Johnson 2005). Discussions on instilling values show how cooperation tends to promote pro-social values while competition tends to promote more self-centered values (Deutsch 2000; Johnson and Johnson 1999, 2000). According to Johnson and Johnson (2005) without social interdependence theory, these theories would not be as well formulated or as meaningful, Figure 5.1 illustrates this connection to social interdependence theory. Here we agree with Johnson and Johnson (2005) that greater validation for social interdependence theory leads to more validation for these and other related theories.

Figure 5.1: Social Interdependency as foundation for other theories

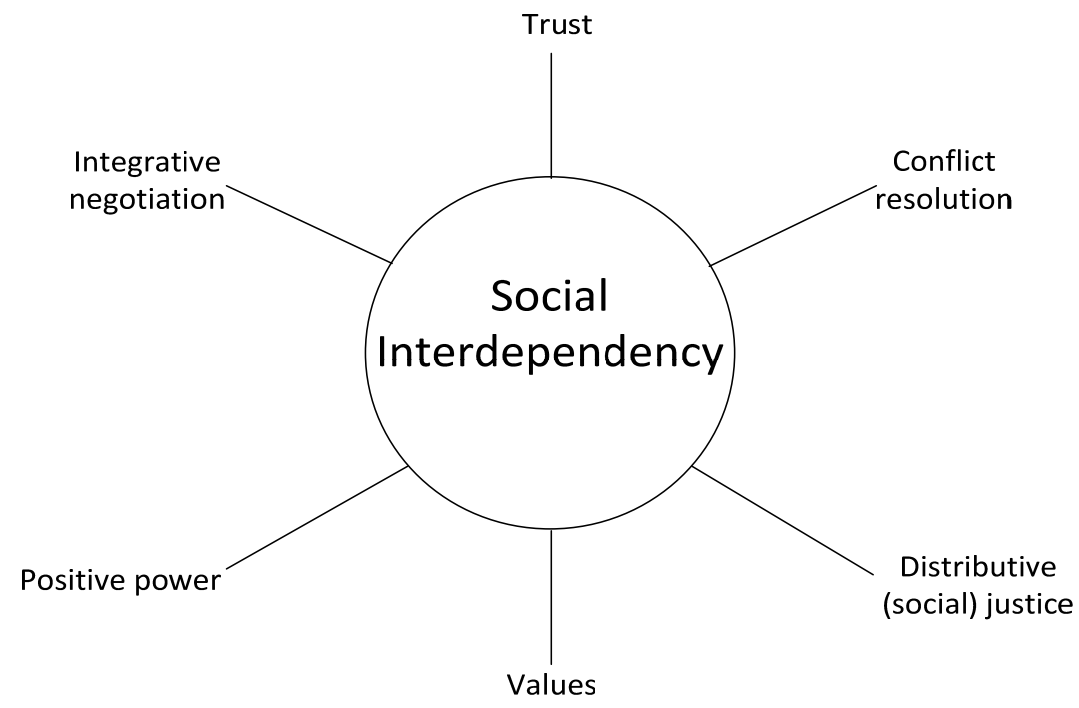

Lewin (1935) claimed positive and negative interdependence result from mutual goals. However, a number of researchers demonstrated that positive and negative interdependence may be structured through complementary roles (Thomas 1957 in Johnson and Johnson 2005), group contingencies (Skinner 1968 in Deutsch 1985), and dividing information into separate pieces (Aronson et al. 1978 in Deutsch 1985). "Various researchers and practitioners have structured interdependence in other ways, such as divisions of labour, mutual identity, environmental spaces, and 
simulations involving fantasy situations" (Johnson and Johnson 2009: 367) outcome, means, and boundary. We will apply social interdependence to LED, agreeing with Johnson and Johnson (2005) and assume that first, when people engage in cooperative situations, they are orientated toward a desired outcome, such as a goal or reward. Second, the means through which the mutual outcomes are to be accomplished specify the actions required on the part of group members. As suggested by Johnson and Johnson (2005) this implies that interdependence includes resource, role, and task interdependence, which are overlapping and not independent of each other. Third, "the boundaries existing among individuals and groups can define who is interdependent with whom. Koffka (1935) pointed out that abrupt discontinuity produces dividing forces between the parts ..." (Johnson and Johnson 2009: 367). Johnson and Johnson (2009) warn that boundary interdependence may arise as a result of environmental factors, similarity, proximity, shared history, expectations of being grouped together, and differentiation from other competing groups. Within the context of this study, we developed a model (see Appendix 2) that presents the reasoning that to achieve sustainable positive LED, competing groups tend to merge over time until grand cooperation is formed.

Structuring positive outcome interdependence (i.e. mutual goals or joint rewards) into a state tends to produce an increase in achievement and productivity (Scott and Cherrington 1974; Johnson and Johnson 2000; Jensen 2009). Johnson and Johnson (2005) mention studies that have been conducted to clarify the effect of positive interdependence on productivity and achievement. Johnson and Johnson (2009: 367) mention that "that positive interdependence has effects greater than group membership or interpersonal interaction". According to Hwong et al. 1993 "there is evidence that group membership, in and of itself, does not seem sufficient to produce higher achievement and productivity - positive interdependence is required" (in Johnson and Johnson 2009 ). "Knowing that one's performance affects the success of group-mates seems to create responsibility forces that increase one's efforts to achieve. There is also evidence that interpersonal interaction is insufficient to increase productivity - positive interdependence is required" (Lew et al. 1986 and Mesch et al. 1988 in Johnson and Johnson 2009: 367). A study by Kerr and Bruun (1983) established that individuals achieved more under positive goal interdependence compared to when working individually with the opportunity to interact with classmates. When people clearly perceive positive interdependence, individuals realize that their efforts are required for the group to succeed, that it is not possible to get a free ride and that they make a unique contribution to the group's efforts (Johnson and Johnson 2009). The reasoning applied being when members of a group perceive their efforts as 
dispensable for the group's success, they may reduce their efforts (Kerr and Bruun 1983) and when group members perceive their potential contribution to the group as being unique, they increase their efforts (Kerr and Bruun 1983). Using economic theory combined with game theory reasoning, we show in (Appendix 2) that positive interdependence will lead to sustainable LED.

\subsection{Kwam eMakana Case Study}

In assessing how Kwam eMakana women run tourism LED home-stay project we borrow from Bakan's (1966) view, that men's achievement strivings are directed at agentic concerns of self-assertion, attainment of status, and mastery over the environment; whereas in contrast, women strive to achieve communion and are motivated to work cooperatively to attain a sense of harmony with others. Similarly, Gordon (1986) observed that women do have different experiences of business ownership, and that the male should not be used to stand for the universal, as women have a different voice and a different experience of love, work and family. This thinking is the basis of the view advanced by Okin (2003) that poor women's incomes are usually spent on things that matter to the entire family. Notably, Bakan did not define the concepts of agency and communion as bipolar opposites, but as separate, independent dimensions capable of co-existing within one person. This line of reasoning has been pursued elsewhere for example, Wilce (1998) argues that autonomy is not an ideal goal that people value and strive for. Instead he maintains that people are far more aware of and concerned about the effectiveness of their interpersonal, intergenerational, and inter-group relations because these represent the crucial focus of power and identity that permeate the entire range of life activities. In this regard certain circumstances in history become important in how they can affect the level of social interdependence and how they in turn impact LED. This raises the important but as yet unexplored question about the extent to which levels of constraint or coercion in particular contexts influence the way people endorse or enact social interdependence in promoting LED.

The execution of LED rests with the municipality and the vision is encapsulated in the Makana LED goals (Table 5.1; Makana Tourism 2010) and the National Framework for LED (2006-2011). The Makana tourism vision is informed by LED goals 3 and 6 (Table 5.1) which highlight the importance of SMME and tourism development, which were then translated into strategies and projects. For example, Makana edutourism partnership and Kwam eMakana pilot projects were initiated to stimulate SMME 
development in the tourism sector (Makana Tourism 2010). According to the situational analysis of the LED strategy, Makana's comparative advantages are linked to the agricultural service and the tourism sectors (Makana Tourism 2010).

Table 5.1: Aims of the Kwam eMakana Project, Makana LED Goals and Makana Tourism Vision

\begin{tabular}{|c|c|c|}
\hline $\begin{array}{l}\text { Aims of the Kwam eMakana } \\
\text { project (Makkink 2009) }\end{array}$ & $\begin{array}{l}\text { Makana LED goals } \\
\text { (Makana Tourism 2010). }\end{array}$ & $\begin{array}{l}\text { Makana Tourism Vision } \\
\text { (Makkink 2009) }\end{array}$ \\
\hline $\begin{array}{l}\text { 1. Act as a lever to unlock LED } \\
\text { potential } \\
\text { 2. Be a platform to promote } \\
\text { the unique culture and } \\
\text { heritage } \\
\text { 3. To attract national and } \\
\text { international tourist markets } \\
\text { all year round } \\
\text { 4. Roll out a successful model } \\
\text { to other municipalities within } \\
\text { the province }\end{array}$ & $\begin{array}{l}\text { 1. Increase R-GDP by } 3.5 \% \text { per year to } \\
\text { match district and the provincial growth } \\
\text { rates by } 2014 \\
\text { 2. Maintain employment at current levels } \\
\text { from } 2010 \text { to } 2011 \text {, with the view of } \\
\text { increasing trade and service sector } \\
\text { employment by } 4 \% \text { from } 2012 \text { to } 2014 \\
\text { 3. Grow the tourism related component of } \\
\text { the local economy by } 10 \% \text { by } 2014 \\
\text { 4. Maintain sustainable levels of capital } \\
\text { expenditure on key LED infrastructure } \\
\text { from } 2010 \text { to } 2014 \\
\text { 5. Increase the role of formal and informal } \\
\text { strategic partnerships in and between } \\
\text { the public and private sectors of Makana } \\
\text { as a catalyst for growth } \\
\text { 6. Reduce income leakage and support } \\
\text { SMME activity through increased local } \\
\text { procurement and labour force support } \\
\text { measures. }\end{array}$ & $\begin{array}{l}\text { 1. Service visitors to their region by } \\
\text { providing comprehensive } \\
\text { information and advice. } \\
\text { 2. Profile, market and promote all the } \\
\text { different facets of the Makana } \\
\text { Municipal Region. } \\
\text { 3. To assist the LED office of the } \\
\text { Makana Municipality to develop } \\
\text { and facilitate training of previously } \\
\text { disadvantaged entrepreneurs in } \\
\text { establishing and running Kwam } \\
\text { Bookings, as the accommodation } \\
\text { booking arm of Kwam eMakana. } \\
\text { 4. Promote the value of co-operation. } \\
\text { 5. Make the expertise available in } \\
\text { Grahamstown accessible }\end{array}$ \\
\hline
\end{tabular}

\subsubsection{Methods}

Document analysis included literature review on social interdependence and evaluation of policy documents and reports were used to investigate LED decision planning, implementation, decision making, monitoring and evaluation. To develop a clearer understanding of how the processes of government LED financing impact economic advancement opportunities for the recipients the study employed a mixed methodology combining document analysis and qualitative inquiry supported by quantitative data. This included a group discussion session $(n=44)$ and a questionnaire survey $(n=44)$. These were held during the field-study period in 2009 (6 months) with the women operators of Kwam eMakana. We explained the confidentiality agreement and use of data collected with the respondents before data collection. We administered a questionnaire survey at Nduna library in Joza Township, to ensure a maximum participation rate and a quick turnaround time. All 46 of the women participating in the pilot project were invited through the Kwam executive committee, a total of $44(95.7 \%)$ attended. The questionnaire was designed to gather data on a) demographic data b) sense of entitlement and dependence levels of the women c) the 
economic contribution of Kwam eMakana. A group discussion session was held straight after the administration of the questionnaire survey to validate data attained from the questionnaire survey, the discussion guide was designed to gather information regarding: 1) the women's views on the decision-making process of Kwam eMakana; 2) the operational challenges of the project and 3) the women's interpretation of the economic growth opportunities presented by the project. This multi-methods approach was adopted because reliance on a single method may not reveal all factors influencing success or failure of the project.

\subsubsection{Results}

The main results of this study report on the issues affecting LED. Information obtained through the questionnaire survey was used as a way of assessing the project status and progress from the women operators' standpoint. The analysis considered three major levels of the project: formulation, implementation and operation as well as the monitoring and evaluation. Results from the group discussion session are also presented and juxtaposed with data from official government reports.

\subsubsection{Formulation}

The project was targeted to incorporate previously disadvantaged women aged forty and above from Joza Township, into the tourism economy. The women were either unemployed or earned a household income of less than 1500Rands [US\$204.48] per month from government grants and in some cases received financial assistance from family. An analysis of the survey responses shows that prior to 1994, the majority of these women (69.5 \%) were employed as domestic servants, while some were unemployed or housewives. It emerged that the women have low educational levels (48\% and $20 \%$ completed grade 7 and grade 10 respectively; while only $11 \%$ attained a high school leaving certificate [Matric]; with the remaining $9 \%$ and $7 \%$ hold certificates and diplomas respectively). Despite the differences in educational levels all operators relayed a deep desire for their home-stays to work and also voiced their desires with regards the government's role; one operator simply stated that "I want my Kwam to be successful and I need the government support" and another said "I want a better life for my family, I really need funding from government". DSRAC, the National Development Agency, and a hospitality and tourism institute, provided hospitality training for the women. Participants received start-up funding in the form of starter packs (containing bed linen and towels) and follow up funding - the annual 500Rands [US\$ 68.49] inputs grant issued two weeks before the start of the festival. The home-stays receive guaranteed occupancy from DSRAC officers, the bookings are 
made through the Grahamstown Tourism Office. During the discussion session it emerged that there was a general sense of confusion among the women operators concerning the intended direction of the project. The women were unanimous that this was a major factor hampering the performance of their home-stays. One woman stated "we are not progressing, it has been five years and we are still dependent on DSRAC for occupancy" another remarked that "government told us that we would have guests from overseas, this has not happened". Notwithstanding, a majority $89 \%$ indicated that they will continue to plough back their profits into home-stay improvements in the hope of attracting more guests.

\subsubsection{Household economic contribution from the home-stays}

It emerged that the home-stays lacked visibility (the majority of home-stays [96.8 \%] have no occupancy outside of the festival period). The $3.2 \%$ that reported occupancy outside the festival period indicated that guests were sporadic and had come through referrals or chance bookings through the Grahamstown Tourism Office. In the discussion session the women described a lack of knowledge and expertise on how to attract clients explaining that they did not have the experience to design marketing campaigns. Moreover, the women's low educational levels exclude them from participating in management opportunities. Research also established that the majority of the women are solely reliant on the income from the home-stay initiative with very few other income generating projects. This begs the question of the financial viability - are the women satisfied with the financial gains from the home-stays given the very low occupancy rates? A revenue summary of the home-stays for the festival period in 2009 is presented in (Table 5.2). The actual figures were attained from the Grahamstown Tourism Office and the calculated estimates were informed by going market rates.

Undeniably, the women concur that the income has had significant impact on their lives; comments like "the income I receive has allowed me to send my daughter to university", or "I used profits from my home-stay to finish construction work on our home" and "I am better able to provide school supplies for my children" exemplify this. However, the main dissatisfaction reported was on the volume of business - the absence of guests throughout the year. It emerged from questionnaire responses that the women were not engaged in business management prior to their involvement in this project. The questionnaire survey data surmises the various acquisitions made from the home-stays revenue since their inception in 2004 as tabulated in (Table 5. 3). The benefits are divided into two major subgroups namely financial and accumulated assets. 
Table 5.2: Kwam eMakana 2009 Festival Period Revenue Statement

\begin{tabular}{|c|c|c|c|c|}
\hline Maximum guests per night & 2 & 4 & 6 & 8 \\
\hline Government Inputs Grant & $500 / 68.49$ & $500 / 68.49$ & $500 / 68.49$ & $500 / 68.49$ \\
\hline Charge for Bed \& Breakfast & 5 600/ 767.12 & $11200 / 1534.25$ & $16800 / 2301.37$ & 22 400/3068.49 \\
\hline Dinner Charge & $1400 / 191.78$ & $2800 / 383.56$ & $4200 / 575.34$ & $5600 / 767.12$ \\
\hline Less $10 \%$ booking & {$[560] /[76.71]$} & [1 120]/ [153.42] & [1 680]/ [230.14] & [2 240]/ [304.85] \\
\hline commission & $6940 / 945.21$ & $13380 / 1832.88$ & $19820 / 2715.07$ & $26360 / 3610.96$ \\
\hline Labour & - & - & $900 / 123.29$ & $1200 / 164.38$ \\
\hline Electricity \& Water & $200 / 27.40$ & $250 / 34.25$ & $300 / 41.10$ & $400 / 54.79$ \\
\hline Food Cost & $1400 / 191.78$ & $2800 / 383.56$ & 4 200/ 575.34 & 5 600/ 767.12 \\
\hline $\begin{array}{l}\text { Miscellaneous Costs [e.g. } \\
\text { laundry] }\end{array}$ & $200 / 27.40$ & $400 / 54.79$ & $600 / 82.19$ & $850 / 116.44$ \\
\hline
\end{tabular}

Table 5.3: Household economic benefits of Kwam eMakana

\begin{tabular}{|c|c|c|c|c|c|c|c|c|c|c|}
\hline \multirow{2}{*}{\multicolumn{4}{|c|}{ Income from home-stays }} & \multicolumn{7}{|c|}{ Assets accumulated from income from the home-stays } \\
\hline & & & & \multicolumn{2}{|c|}{ Structural Assets } & \multicolumn{5}{|c|}{ Acquisitions } \\
\hline & \begin{tabular}{|l|} 
Increased \\
savings
\end{tabular} & \begin{tabular}{|l|} 
Financial \\
Investments
\end{tabular} & $\begin{array}{l}\text { Ability to pay } \\
\text { bills \& utilities } \\
\text { on time }\end{array}$ & $\begin{array}{l}\text { Home } \\
\text { extension }\end{array}$ & \begin{tabular}{|l|} 
Other \\
income \\
generating \\
projects
\end{tabular} & $\begin{array}{l}\text { Laundry } \\
\text { machine }\end{array}$ & Fridge & Stove & \begin{tabular}{|l|} 
Bedroom \\
furnishing
\end{tabular} & \begin{tabular}{|l} 
Lounge \\
furnishing
\end{tabular} \\
\hline $\begin{array}{l}\text { No. of } \\
\text { Home- } \\
\text { stays }\end{array}$ & 0 & 0 & 41 & 12 & 4 & 19 & 5 & 3 & 18 & 8 \\
\hline
\end{tabular}

Several commentaries revealed that the women were proud of their home-stays, women spoke of the opportunities the project presented for their children. A woman stated that "I have something to leave my children". Most remarkably one elderly woman vehemently stated "we are showing the young girls that they can use their hands to make a living ... this is very important". Document analysis established that the women received training to augment their skills set to better run their home-stays. According to the Makana Annual Tourism Report a Memorandum of Understanding (MOU) between the Fair Trade in Tourism South Africa (FTTSA) and Makana Tourism representing Kwam bookings on the "Strengthening Community Tourism for Sustainable Local Development" project was set up. This involved a 2+2 day workshop (20 products each for two days) sponsored and driven by The South Africa Host Programmme aimed to improve the women's hospitality skills (housekeeping, catering and etiquette). Interestingly, the workshop did not address the marketing and management skills that are lacking yet critical for the project's success. During the 
discussion session the women mentioned that the project has to be advertised. Citing a lot of demand for accommodation in Grahamstown, they also conceded that the home-stays are unknown in potential markets. According to Makkink (2009) the conferences scheduled to take place in Grahamstown between 2009 and part of 2011, were projected to bring in excess of fifty million Rands to the Grahamstown area, this presents potential market growth for the project that is currently not being tapped into. A Kwam eMakana executive member admonished "they are not doing anything to market the home-stays, we want to setup our own office to market our project ... but we don't know where to start, it will be better to do it collectively". Another committee executive described a scenario where the project would be more productive if the women had power to steer the project within a framework that observes their communal values. These perspectives are supported by the cooperation model discussed earlier (Appendix 2).

\subsubsection{Implementation and operation}

Initially 55 homes were designated for the project and now 46 (83.6\%) remain, and a total of 60 women have been trained. The home-stays have not graduated from the start-up phase of assistance receiving; the goal had been that the home-stays would be self-sustaining and operate on the basis of entrepreneurial steering by now. The survey revealed that spin off tourism businesses have been established, the homestays are also contributing to the local labour market at least on a seasonal basis; 1 ) the project contracts 12 Kwam Taxis 2) employs 10 tourism cadets - all are residents of the Makana community. An analysis of the questionnaire responses shows that $30.4 \%$ of the women receive assistance with household chores during the festival from family members while $19.6 \%$ employ women from Joza to help with operational tasks. During the discussion session the majority of the women raised the issue of isolation of the project from the rest of the tourism sector, various women stated that they felt abandoned by DSRAC for the best part of the year, one woman described the project as 'lacking continuity'. The women also highlighted that they have no access to other tourism establishments and they are not part of the local tourism forum. It also emerged that there is a mismatch between the women operators' and government's priorities for the project. For instance, the projects fourth aim 'roll out a successful model to other municipalities within the province' was actualized in January 2010. The Kwam home-stay project was introduced to Ndlambe Municipality under the name Kwam eNdlambe. Interestingly, Kwam eMakana still faces numerous operational challenges and it appears various changes need to be implemented to improve its operation. The women also stated that the annual 500 Rands [US\$ 68.49] input grant they receive was inadequate. A majority (98.4\%) suggested that the government 
should increase the grant. It appears that the exact aim of this grant was not stated as there are no stipulations attached to its use. The women claim to use the grant to purchase food and/or cleaning supplies. It is important to note that the grant is not the only amount injected into the project. To put the financial commitment of this project on the part of DSRAC in perspective, Table 5.4 details the financial allocations for the project for 2009. This breakdown shows the money that DSRAC committed to the project including the cost of administering the project, (with salaries of the officers), the inputs grant, signage of the home-stays, acquisition of Kwam eMakana taxis, booking fees and the accommodation bill. The presented budget does not include operational costs of running the project and the various training workshops that the women attended.

Table 5.4: Kwam eMakana 2009 Budget

\begin{tabular}{l|cc}
\hline Budget Allocation & Amount in Rands & US\$ Equivalent \\
\hline Inputs Grant & 27500.00 & 3767.12 \\
The Project & 43210.00 & 5919.18 \\
Kwam Bookings & 46680.00 & 6394.52 \\
The Hosts (Signage) & 24750.00 & 3390.41 \\
The Kwam Taxis & 208800.00 & 28602.74 \\
Accommodation & 400000.00 & 54794.52 \\
\hline Total & $\mathbf{7 5 0 ~ 9 4 0 . 0 0}$ & $\mathbf{1 0 2} \mathbf{8 6 8 . 4 9}$ \\
\hline
\end{tabular}

*Amounts in ZAR/ US\$ Equivalent - ZAR is the South African Rand and the exchange rate averaged 7.3 Rands to 1 U.S. dollars at the time of field research. Source: Makkink, 2009.

\subsubsection{Monitoring and Evaluation}

The low occupancy levels are of concern to all involved (Marala 2009; personal communication) the intention was for home-stays to graduate from the initial phase of accommodating DSRAC officers during the festival to establishments capable of attracting patronage all year round. Rather, it emerged that the women's focus is on upgrading the home-stays to Bed \& Breakfast establishments, a vision which was communicated at inception. The women assume that attaining the international star rating will market their establishments internationally as Bed \& Breakfasts. As such the common mindset among participants is to view the project as a stepping stone into the tourism industry. Most of the women ambitiously envisage a scenario where the project is aligned to the third aim 'to attract national and international tourist markets all year round'. The women spoke of how every year promises of operational improvements are made, yet all participants concurred that there is no real progress being made. For example the women voiced their frustration at 'government talk' of launching the home-stays internationally, which is frequently repeated but no steps have yet been taken to secure this. This begs the question to what extent 
Grahamstown can attract international all year round patronage. This outlook exposes important issues - what brought this government programme into being, and how does it function? How do the women view their role collectively and how do they perceive their ownership of the project? Of great interest is the way that the women collectively proposed solutions to the challenges faced. In the commentaries none of the women proffered individual strategies for their own home-stay.

\subsubsection{Decision making process and ownership of the project}

The project officers employed through DSRAC are responsible for the implementation of the overarching vision by way of motivating the women to adopt an 'entrepreneurial mindset'. The successful adoption of an entrepreneurial mindset with the project framework would allow the women to operate the project autonomously from DSRAC and progress to a social interdependence operational environment. The Kwam eMakana executive committee represents the women and relays information, concerns and challenges between the women and DSRAC (Ngoma 2009; personal communication). The committee consists of women resident in Joza Township but do not operate a home-stay. This arrangement was agreed upon by all the women; the reasoning was committee members receive a salary during the festival period. According to the women it is fair because this way the benefits of the project can be spread among as many beneficiaries as possible. In response to why they were not advertising their establishments at their churches as there were always summits with out of town participants (the logic was that this is a potential market that the women are familiar with and no money was needed). Interestingly a number of women concurred that it is not proper sell at church, one woman stated "that is greedy".

\subsection{Discussion of Results}

The outlined results show various challenges and contradictions inherent in the LED trajectory linked to the fact that the traditional participation of women in tourism in developing countries is primarily in employment rather than in entrepreneurship where the high capital costs of entry, education and skills are major constraints (Healy 1994). As this is a women LED project the results analysis are also nuanced to the issues that the women perceive as important. The Kwam eMakana women are positioned to benefit from the LED tourism home-stay initiative, the results show that it is difficult for the women operators to sustain LED in the long term from current formal and informal institutional arrangements which are still affected by the historical and social dynamics of South Africa. The slow progress of the project may be 
attributed to women's diminished control in the steering of the project. These findings corroborate with other studies (Ringer 1998; Scheyvens 2002; Briedenhann and Wickens 2007; Karamata and Gwari 2007; Jensen 2009) which suggest that for tourism to be sustainable the locals must have ownership of the project (refer to the argument presented in Appendix 2). It can be argued that the local government in this instance set up a delivery system that has not adequately addressed the challenges associated with the cause of poverty in the first place. In contrast to the assertions by Bakan (1966) we posit that the social (communal) setting of the community was not taken into consideration when introducing the LED initiative as it aimed to promote selfreliance i.e. autonomy rather than interdependence. It is unbalanced to implement LED initiatives for poverty reduction without incorporating mechanisms to address the causes of the poverty. Past socio-spatial arrangements still affect economic wellbeing in South Africa and present a pivotal gap in the LED pillar.

Findings from research support the observations made by Wilce (1998) that autonomy is not an ideal goal that people value and strive for. Instead he maintains that people are far more aware of and concerned about the effectiveness of their interpersonal, intergenerational, and inter-group relations because these represent the crucial focus of power and identity that permeate the entire range of life activities, the model (Appendix 2) supports Wilce's claim. Upgrading the cultural home-stays to Bed \& Breakfast establishments poses challenges for the survival of the establishments. Firstly, this upgrade will result in the loss of the home-stays unique selling point (USP) and put them in direct competition with other accommodation establishments (guesthouses and Bed \& Breakfast) in the Grahamstown area. Secondly, the women would have to aggressively market to attract the clients from this market share - there has been no indication of growth markets on the same, simply put there is no demand for this product in Grahamstown. There is a big possibility that the location of the home-stays can be viewed as a negative by potential Bed \& Breakfast clients. Whereas this is not an issue in the case of cultural home-stays, in fact in this instance the township is the attraction and one of the unique selling points. Another point of concern is that the study established that the women are lacking in management skills and their home-stays are currently suffering from lack of visibility because of the women's lack of marketing knowledge. Finally, upgrading the home-stays to Bed \& Breakfasts means the women will have to operate autonomously considering that the home-stays will not all attain Bed \& Breakfast status at the same time. Comments to emerge from the discussion session where a number of women concurred that it is not proper to sell at church, one woman stated "that is greedy", reveal an interesting concern in the context of the autonomous operator whose focus is profit 
maximization. This is definitely a cause for concern; will these women be able to operate autonomously in a commercial tourism environment considering their communal outlook to business? With these issues in mind upgrading the home-stays to Bed \& Breakfast establishments does not reflect a rational social and economic decision.

Another issue to arise concerns the diminished capacity for marketing and management skills, this highlights a possible oversight on the part of DSRAC. Although the impetus for the pilot project was uplifting previously disadvantaged women, due attention was not paid to the factors that might impede the very entrepreneurial spirit and ability needed to drive this project. The blame is not only with the former apartheid system; an earlier tourism based study (Briedenhann and Wickens 2003) established that in South Africa, while it is at local government level that the responsibility for tourism rests, the inability of officials to undertake their responsibilities is common. Literature reports that LED implies empowerment by decentralization - the deliberate and planned transfer of resources away from central state institutions (Briedenhann and Wickens 2003; Rogerson and Nel 2005). This project has shown that though this decentralization has been effected in South Africa this corroborates assertions in literature that the devolution of authority and development leadership to local governments, as reflected in the country's commitment to 'developmental local government' (DPLG 2006). Interestingly, the local authority appears to be still operating along the parameters set by state institutions. It is also important to note that emphasis on self-reliance/autonomy conflicts with the communal interdependent culture of this community (Bakan 1966). In ignoring basic problems the project offers only short-term remedies (Lapeyre 2009), that do not strengthen/empower the women but instead promotes social helplessness (Johnson and Johnson 2005). Likewise, it has been noted that the project has not implemented any specific mechanisms to promote institutional interdependence. This situation is a direct contradiction to aim number four in the Makana Vision which states: 'promote the value of co-operation'.

Another finding concerning attracting an international market to the home-stays highlights how DSRAC raised unrealistic expectations amongst the home-stay operators - for example, the ability to attract tourist markets all year round without considering to what extent Grahamstown is a year-round tourism destination. Fowkes and Jonsson (2001: 5) make a relevant point applicable to this project when they warn that "it is necessary to approach potential developments from the basis of a strong business case and not a social case". This project validates this point because the 
home-stays are only patronized by DSRAC officials during the festival; in this way DSRAC ensures that its officials have cheap accommodation. DSRAC officials remain the largest client base making it difficult to build a sustainable tourism business while relying on two week annual patronage from one source that dictates the pricing. Admittedly, if the women were to take over the project completely the total cost of running the home-stays would also be transferred to them individually. This begs the question; will the women be able to bear the cost? This certainly throws up many lines of inquiry such as why the women are not organizing themselves to do their own marketing. Is it too costly in terms of time and resources or is the training offered insufficient? In view of the educational and management challenges revealed by the study, the presence of a safety net in the form of government financial support, for the women home-stay operators appears to curb the impetus for entrepreneurship. Moreover, the institutional arrangements of this project entail that the women remain disadvantaged to be eligible for government support; this is an unsustainable approach to LED. This highlights a need for the women to come together in project management to realize the uniqueness of their operating conditions, and accept that it demands a public participation management program, which acknowledges the need to construct a consciousness (Appadurai 1986, 2004) that can facilitate the emergence of group cohesion.

The results indicate that for Kwam eMakana to attain group cohesion a two pronged process that entails both the women operators and DSRAC to assume their roles is necessary. The roles that DSRAC should have instituted from the onset of the project, but did not still need to be implemented for the project goals to be achieved. The results also suggest that it is important for DSRAC to understand the boundaries of what their roles and responsibilities are and what the roles and responsibilities of the women are. Currently there appears to confusion surrounding the operationalization of the project goals (see Table 5.1), which appear to have been designed to promote social interdependence. The role of DSRAC is to facilitate the smooth full handover of the project to the women. DSRAC should equip the women with skills training, insights and ideas, it is important for both DSRAC and the women to support the women assuming responsibility to operate the project. A critical role that DSRAC should have instituted and still needs to implement for the project to be sustainable is to facilitate and encourage group cohesion so as to promote social interdependence. Internally, within the project framework there are several steps that the women need to engage for cohesion to exist within the group and this will allow the project to progress to a social interdependence operational environment. First the women through the executive committee need to establish good lines of communication, this is essential in 
creating and maintaining cohesion. Communication leads to the second step, unity of purpose. For the Kwam eMakana women to work as a cohesive group they must share a common goal and collectively work towards that goal. Research showed that currently the women are not working towards a common goal. This situation is contrary to the assertions made earlier in literature and supported by the socio economic model (Appendix 2) that when people engage in cooperative situations, they are orientated toward a desired outcome, such as a goal or reward (Johnson and Johnson 2005). Finally, the women must have a high level of commitment and understanding that what they do together as a group is better than what they do on their own. Bormann (1990) suggests that group cohesion is as much about the relationships created and success in both fosters the development of social interdependence. This will promote the emergence of social interdependence rather than dependence on this can lead to the emergence of relationships that can enable the women to sustainably engage with the LED initiative. The weight of the social interdependence thrust as raised in literature is that some societies are not characteristically autonomous, thus an autonomous structure is contradictory to the norms and culture of the women (Uchida et al. 2004).

A review of the revenue report shows that the economic contribution of the homestay project to the households is significant, granted that prior to their engagement with the project they earned incomes of 1500Rands [US\$205.48] or less a month. For example taking a home-stay with a maximum occupancy of eight people, the income from the festival period is almost double the annual earnings of the household. Moreover, as the payment is in one allocation it allows for a substantial monetary injection into the households. Other women used their profits for the construction of structural extensions on their homes with the aim to increase their occupation capacities. The women stressed the importance of developing competencies and raising the educational levels in their offspring. They did not emphasise their selfefficacy the absence of a desire for their role to be acknowledged implies the lack of interest in social recognition. This does not reflect weakness in terms of 'self-direction' (Bakan 1966; Finnis 1980) rather it highlights different values that are grounded in communal sharing and service to others. The women's incomes are creating an inspirational positive trickle-down effect, the presence of the home-stays has seen the proliferation of local tourism support businesses such as transport. This is in line with Okin's (2003) claim that poor women's incomes are usually spent on things that matter to the entire family. Comments like "the income I receive has allowed me to send my daughter to university", or "Ï used profits from my home-stay to finish construction work on our home" exemplify this. The thrust of the project on self-reliance by gaining 
control of one's resources overlooks that becoming empowered may reduce the social interdependence that is synonymous with a strong sense of community (Wilce 1998).

The findings also show the crucial role of social capital and networks in boosting women's entrance to the tourism domain. It emerged that there are alternative potential markets throughout the year that are not being exploited, moreover, the inadequate marketing presence leaves some hope for growth markets if the homestays attune to the opportunities. This chapter has shown that the women operators are not devising strategies to access, sustain and benefit from LED tourism opportunities. Indeed, the women have received input assistance and hospitality training; however, there is need for the women to assume a more active role in the steering of their home-stays. Another interesting point to emerge from the study is the asset accumulation pattern (refer to Table 5.3), results show that the women are mainly acquiring assets that enhance their home-stays. It is possible that the investment pattern of the home-stays is connected to the goal of the home-stays being star rated as Bed \& Breakfast establishments. This finding adds weight to the observation by Clarke (2002: 3 in Kaplan 2004) that a number of "tourism and communities" concepts are being used interchangeably by tourism professionals and policy makers in South Africa. The framework of collaboration between the women and DSRAC is not cohesive. This contrasts with Meyer's (2004) assertion that a precondition for establishing sustainable LED initiatives is good co-operation. Comments enunciating fairness and the difficulties in selling to the potential market in the church raised during the discussion session are important in explaining the stagnant position of the project. Considering that the women were able to set up the Kwam executive committee without external directive, this certainly adds weight to the argument that favours social interdependence (Johnson and Johnson 2005; Uchida et al. 2004). When introducing programs centered on promoting entrepreneurship and LED communities might have to reach a different level of consciousness before they can perceive their space differently and be called to make decisions about the nature of their involvement let alone participation in LED initiatives through entrepreneurship (Appadurai 2004). Accordingly, Riger (1993) maintains whether individuals act in an autonomous manner or operate in an interdependent manner reflects their relative position in the social structure. 


\subsection{Conclusion}

It can be noted that Kwam eMakana has the following characteristics:

- The Government positioned itself as the owner, giving the project to the women as recipients; the institutional structure and support are not adequate for the project to attain entrepreneurial steering from the current position.

- From a planning perspective, the women do not participate instead it appears the top-down approach is still used.

- The women see their assistance from Government as aid; thus, it becomes difficult to define management responsibility and obtain entrepreneurial empowerment.

- From the onset there was lack of preparation and of extension services for the women after having received assistance to operationalize the project.

- From the claims it appears that an autonomy driven project will not result in sustainable LED.

Using qualitative data from the women's evaluation of their involvement in the pilot project this chapter has shown that the concept of social interdependence is a relevant lens in the assessment of LED initiatives in that they can capture what the women consider important. Against this background a real concern is how the women negotiate tourism development processes that require the same skills that they were previously excluded from. The situation is further complicated by the top-down approach in decision making which does not equip the women to establish an environment of strong social interdependence. The focus of LED initiatives ought to be on understanding how community shapes the person, in particular, on the conditions that facilitate both efficacy or personal control and also a sense of community. It is therefore important for sustainable tourism planners to consider community differences including historical contexts if local communities are to benefit from LED. In addition, this case study shows that LED tourism developments have the potential to address women's social-economic and cultural needs relevant to their empowerment. This is because LED tourism ventures have the ability to incorporate less educated and historically disadvantaged women through encouragement of cultural-based and less capital intensive businesses. From the results of this study it can be concluded that the Kwam eMakana LED home-stay tourism pilot project has the potential to improve the entrepreneurial empowerment of the women through improved participation, transparency, and accountability. 


\section{Chapter Six}

\section{Emotional Confidence Levels and Success of Tourism Development for Poverty Reduction: the South African Kwam eMakana Home-stay Project ${ }^{1}$}

\subsection{Introduction}

In recent years tourism-related SMME have increasingly become recognized as appropriate tools for poverty reduction by international funding agencies and governments (UNWTO 2005). The UNWTO (2002) asserts that the benefits of tourism should be widely spread in society, and harnessed to address the problems of poverty more directly than is commonly the case in developing country tourist operations. To achieve these goals, an agreement between UNWTO and UNCTAD (United Nations Conference of Trade and Development), was established at the World Summit on Sustainable Development held in Johannesburg in 2002. The agreement culminated with the 'Sustainable Tourism as a tool for Elimination of Poverty' (ST-EP) programme with the main goal of decreasing global poverty by half until 2015 through research and best practice (UNWTO 2002). However, engagement in the tourism industry as a route out of poverty has more dimensions than simply promoting its potential.

The poverty reduction thrust of this paper echoes the views popularised by Sen (1984) which are centred on providing opportunities for enhanced well-being (Sen 1985, 1993; Gasper 2007). Well-being has many facets (Gasper 2007), with an individual's well-being depending not only on material endowments, but also (and especially) on the capabilities of the individual (Sen, 1984, 1993, 1999). In his work Sen $(1985,1993)$ advanced the notion that capabilities imply interconnectedness within a relational conception of society. A particular capability is the outcome of the interaction of a persons' capacities and their position in society (Alkire and Deneulin 2009; Anand et al. 2009).

The purpose of this article is to identify and address some problematic aspects of research on the role of tourism for poverty reduction. The article will first review some of the academic discourse on SMMEs that combine tourism, development and poverty reduction. We suggest that the approach would benefit from a critical assessment of

\footnotetext{
${ }^{1}$ Hazel M. Kwaramba, Jon C. Lovett, Lynette Louw, Juliet C. Chipumuro

This chapter was Published in Tourism Management Volume 33, Issue 4, August 2012, Pages 885-894]
} 
the current position that praises tourism leading to its widespread adoption as a 'cure all' development option by many poor countries. Secondly, an alternative approach based on emotional empowerment will be suggested and its potential for contributing to tourism development discussed. Thirdly, empirical evidence from participant observations, key informant interviews, a questionnaire survey and a group discussion session conducted using a hermeneutical approach to enquiry will be presented. Techniques for estimating Emotional Intelligence (EI) are adapted to provide an indicator of emotional confidence. The following sections provide an overview of the debates surrounding tourism development for poverty reduction.

\subsection{Tourism Development and South Africa}

Adoption of tourism as a development strategy in developing countries was an outcome of outwardly oriented neo-liberal developmental approaches actively encouraged by the World Bank and the International Monetary Fund (IMF) via structural adjustment lending mechanisms (Brown 1998). Similarly, tourism emerged as a key economic development strategy for South Africa (DEAT 1996; Rogerson 2002) and its contribution to the GDP was reported to have significantly increased from $8.5 \%$ in 1994 to 10.5\% in 2008 (PARIS 2010). According to Binns and Nel (2002) the previous apartheid regime prevented the country's full tourism potential from being achieved and left a legacy of widespread disparity and poverty resulting in a high level of socioeconomic inequality (Noble et al. 2004). Against these challenges the Tourism White Paper highlighted the importance of developing the tourism sector along sustainable guidelines in order to economically develop previously disadvantaged groups (DEAT 1996).

The sustainable tourism development trajectory in South Africa emphasizes the importance of participation of the previously disadvantaged in decision making processes (Binns and Nel 2002). Difficulties arise because the structures within most developing countries do not allow for this as development initiatives are almost always predetermined from the top, be it by governments or funding agencies (Sinclair 1997; Scheyvens 2002; Moyo 2009). The groups for whom development initiatives are supposed to be benefiting are generally not given the opportunity to define what development means to them within their context (Moser 1991; Anuobi 2003); and to participate fully in 'development' processes (Mkandawire and Soludo 1999; Anand et al. 2009). Development is largely seen as an aid/donor operation where agents bring both financial support and development models (Moyo 2009). Consequently the 
disadvantaged struggle with achieving entrepreneurship and capitalizing on economic generating opportunities. This makes the capabilities of the previously disadvantaged in South Africa particularly relevant to their inclusion in the tourism economy. Sen (1984, 1992, 1993) argues that "development is not a matter ultimately, of expanding supplies of commodities, but of enhancing capabilities of people" (Sen 1984: 511).

Empowerment is widely recognised as a key aspect of enabling development interventions to be implemented successfully (Tefler and Sharpley 2008). Building on Sen's classic work (1984, 1985, 1992), World Bank projects routinely contain empowerment strategies (Alsop \& Heinsohn 2005) and there are a large number of academic studies investigating a range of different aspects of empowerment (Ibrahim and Alkire 2007; Alkire and Deneulin 2009). Both theoretical psychological studies (Bandura 2002) and empirical observations from field work (Kim et al. 2007) emphasise the importance that enhancing personal efficacy has on people's ability to function as individuals and within groups. In South Africa, with its long history of racial disempowerment, building confidence of actors in the tourism sector from the bottom up is likely to be an important aspect of creating the capabilities for entrepreneurship. The paper argues for a multi-dimensional approach (Moser 1991) in gaining entrepreneurship which encourages attributes such as autonomy, self-direction, selfdetermination, liberation, participation, and self-confidence in the previously disadvantaged.

\subsubsection{Tourism home-stay}

An increasing number of developing countries are seeking benefits from tourism (Telfer and Shapley. 2008) and home-stay tourism has emerged as a popular choice. The concept behind tourism home-stays, which are often run by women, is to accommodate tourists with a host family, enabling tourists to experience and learn about local lifestyle, culture, and nature (Rea 2003). The term home-stay is used variously to refer to types of accommodation where guests pay directly or indirectly to stay in private homes. It covers a range of accommodation types including farm-stays, rural/village host families and urban homes. Home-stays have the advantage of requiring low capital outlay thus increasing access to tourism for the poor (Rea 2003). Financial standing of homes varies: anyone with a home can share their space (Rea 2003). Malaysia, Costa Rica, Nepal and Thailand are some examples of countries where home-stays have been successful. Home-stay tourism provides a potential economic development strategy for the poor offering the promise of jobs, additional income and 
new business opportunities with minimum capital requirements (Dahles and Bras 1999).

Ashley and Mitchell (2005: 1) describe how poverty reduction practitioners unfamiliar with tourism "doubt whether anything that pampers the elite can really help" the poor. Moreover, they assert that tourism industry players tend to be too busy watching tight margins or arrival statistics to worry much about poverty reduction. "Much of the 'tourism and development' academic literature has dedicated itself to cataloguing the 'perils' of inappropriate exploitation of the environment, the local economy, culture and the people" (Ashley and Mitchell 2005: 1). Tourism seems best avoided unless it is so small-scale, indigenously owned, environmentally sensitive and 'authentic' that it disappears from mainstream view (Ashley and Mitchell 2005). Understanding both the potential and pitfalls of tourism as a tool for LED is a necessary first step towards making the industry more sustainable. What is absent from most micro-level analyses of South Africa's LED strategy is an investigation of how the operators (as aid recipients) of these initiatives influence the course of development. Academic insight on how the legacy of apartheid even today still impedes economic development for the previously disadvantaged is still limited. Research has not paid due attention to how this legacy intertwines with aid/donor driven sustainable development. Here we attempt to address this gap by investigating how this intertwinement affects the women's ability to achieve entrepreneurially driven economic development through home-stay tourism initiatives in South Africa.

\subsubsection{Case description - Kwam eMakana}

Kwam eMakana (hereinafter referred to as Kwam) was established in 2004 as a homestay pilot project under the LED strategy for poverty reduction by the South African DSRAC. The initiative was built around the annual Grahamstown Arts and Culture festival. It aimed to incorporate women aged above 40 from Joza Township into the tourism economy. The women were either previously unemployed or earned a household income of less than R1500 (US\$205.48 ${ }^{2}$ ) per month. DSRAC, the National Development Agency, a local NGO and a tourism training institute, provided training for the women. Participants received "starter packs" and an annual R500 input grant. During the festival the home-stays receive guaranteed occupancy from DSRAC officers. Bookings are made through the Grahamstown Tourism Office. A total of 55 homes were initially designated for the project, to date a total of 60 women home-stay

\footnotetext{
${ }^{2}$ Amounts in Rands/ US\$ equivalent - Rand is the South African currency and the exchange rate is currently 7.3 Rands to 1 U.S. dollar.
} 
operators have been trained, of which 46 remain; most have not graduated from the start-up phase. Supporting tourism services have been established, for example, the project contracts 12 Kwam Taxis and employs 10 tourism cadets. The women are contributing to local employment by engaging part-time help, while some receive assistance from family.

The Kwam pilot project intended to enable the women to use their homes as tourism home-stays as 1 ) a lever to open LED potential 2) a platform to promote the unique culture and heritage 3) to attract national and international tourist markets all year round 4) to roll out a successful model for other municipalities within the province (Makkink 2009), the aims are referred to later in the paper.

Unemployment in Joza is estimated at 70\%, depending on the size of the home, income realised from the home-stays ranges between R8000 and R28000 annually. Most of the home-stays have occupancy for two weeks annually during the festival. This situation is of concern to all involved: the intention was for home-stays to graduate from the initial phase of 'assistance receiving' to 'entrepreneurially steered' capable of operating independently in all respects. At the highest level the project focus is on upgrading the home-stays to Bed \& Breakfasts. However it appears that product knowledge is low; changing from home-stays will position the project in a different segment with different challenges. Rather a clear understanding of homestays as a form of tourism is needed; that they are a different form of tourism accommodation and not less compared to other forms. The women are changing the futures of their children/grandchildren. Within the community these women are role models providing a practical demonstration to others that they too can run businesses and provide for their families.

This paper reports an in-depth interpretative analysis of the Kwam home-stay tourism pilot project in the Eastern Cape Province. The Province has the most significant disparity between the rich and poor (Perret et al. 2000) the initiative is part of government efforts to redress these inequalities. This initiative is interesting because it was started as a government LED strategy. In contrast, most examples (Indonesia, Malaysia, Nepal even Port Elizabeth, South Africa) of successful home-stays have been entrepreneurially driven (Dahles and Bras 1999). The LED strategy is concordant with the overarching aim of the Tourism White Paper (DEAT 1996) which argues that success of Kwam would result in the women graduating from aid recipients to entrepreneurs fully steering the growth of their home-stays. 


\subsection{Emotional Confidence}

Gender analysis has played an important role in deepening understanding of the tourism sector in general (Sinclair 1997, 1998; Anuobi 2003; Aitchison 2009). However, the impacts of home-stays, which are often run by women, and their potential to enhance the livelihoods of those disadvantaged by apartheid in South Africa, have rarely been analyzed from the perspective of self-confidence and belief in one's own ability to achieve entrepreneurial success. Experimentation with various developmental policies and measures throughout the years indicate people are poor, not because they are lazy or corrupt (Friedman 1992), but because aid and their policies do not work since they do not aim to combat poverty at the root due to prevailing interests (Easterly 2006; Moyo 2009). Here we attempt to offer alternative explanations of why the aid/donor development trajectory is problematic for achieving entrepreneurial success. We use an El methodology to obtain a measure of the 'Emotional Confidence' possessed by the women operating the Kwam home-stays. The concept of $\mathrm{El}$ has received significant attention since Goleman's (1995) book (Emotional Intelligence: Why it matters more than IQ). An active debate has ensued regarding its definition (Landy 2005). According to Goleman (1995) El encompasses issues of self-esteem, emotional management, motivation and social skills. The paper bases its argument on Goleman's (2001) competence-based model of El, an augmentation of his earlier (1995) work.

The definition of El is not without contest. Mayer and Salovey (1990: 189) describe it as "the ability to monitor one's own and others' feelings and emotion ... to use this information to guide one's thinking and actions". Goleman (1995) posits that individuals are born with a general El that determines their potential for learning emotional competencies. Likewise, Dulewicz and Higgs (2003) suggest that El is a crystallized intelligence because it draws on and develops with life experiences. Goleman (1995) concurs that emotional competencies in the construct of El are not innate talents, but rather learned capabilities that must be worked on and can be developed to achieve outstanding performance. Thus it is reasonable to argue that $\mathrm{El}$ is a multifunctional array of interrelated emotional, personal and social abilities which influence overall ability to actively and effectively cope with demands and pressures (Bar-On and Parker 2000). Hence we posit that there is a strong connection between one's personality, performance level and potential for advancement. 


\subsubsection{Emotional confidence and tourism development}

The emotional confidence attributes measured by El include self-awareness, selfregulation, and motivation. These are essential for success as they improve an individual's ability to recognise personal strength (Abraham 2006). The critical success factors for work and life are considered to be predicted by scores on the El assessment (Abraham 2006) suggesting that $E I$ is an essential element for professional and personal success. El has received much attention in human resource management as a tool for achieving productivity, motivation and loyalty from employees (Landy 2005). When El is juxtaposed with the aid/donor driven approach to tourism development it offers a new way of assessing the viability of current LED initiatives in South Africa. The common approach to tourism development in developing countries has been to situate power with external agents and governments who are then tasked with driving the sector (Britton 1982; Frietag 1994; Tosun 2006). We prefer the viewpoint that development is really a multidimensional course of action (Moser 1991; Anuobi 2003; Moyo 2009) which entails fundamental transformations not only at an economic level with particular emphasis on the institutional and organisational culture of formal establishments, but also on the popular culture of those at the grassroots (Todaro 1994). The current outlook on tourism development has met many challenges, principally lack of ownership of the development initiatives and exclusion of the disadvantaged from decision making processes (Scheyvens 2002; Rogerson 2002). This has seen an increase in the bottom-up approach to tourism development initiatives that aim to place ownership of the development initiatives in the hands of the local people emphasising the importance of local participation (Tosun 2000, 2006).

\subsubsection{Emotional intelligence approach}

The El approach is selected as a measure of the emotional confidence of the Kwam home-stay women operators because El situates the responsibility of advancement within the individual and not with external agents. Academic tourism development studies have not explicitly questioned the role that emotional and psychological conditioning born out of being poor can have, as has been the case in some other disciplines, such as sociology and anthropology (Becker 1963; Wood 1996). The paper argues that this conditioning has a bearing on how the poor will/will not engage with opportunities for development presented to them. Adopting an El outlook we attempt to illustrate how current literature on tourism development in South Africa does not give due attention to the possible role that the history of apartheid plays in the shaping of development consciousness. We raise the question: why is it that previously 
disadvantaged South Africans appear to need so much leverage from government or stakeholders?

Literature on tourism development and local participation in South Africa (Rogerson 2002; Briedenhann and Wickens 2003; Allen and Brennan 2004) has not explicitly queried the feelings of insecurity planted and nurtured by the people's long history of engagement with apartheid and how this can affect the viability of poverty reduction strategies. Adopting the El concept in relation to home-stay tourism development and poverty reduction, we suggest that El levels are an important aspect of achieving success in poverty reduction strategies. The eradication of extreme poverty tops the list of the MDGs. With the potential to provide labour intensive jobs and economic opportunities, particularly to women, tourism offers an effective tool to achieve this goal (UNWTO 2005). If tourism is poised to reduce poverty then it is necessary to probe deeper into the workings of this engine for development.

\subsection{Methodology}

We adopt a hermeneutical approach, which uses naturalistic methods to develop an understanding of human experience in a specific context (Yanow and Schwartz-Shea 2006). This approach was based on the need for a suitable research design that would restrict our own biases and prejudice. To limit this there was frequent liaison electronically between the two researchers in the field and those in the office with respect to field work observations and findings and how these should be theoretically framed and consequently inform the next stage of research. This helped to limit bias given the different backgrounds of the authors (2 Zimbabweans, 1 South African and 1 British). A case study approach was selected based on the assertion that a reliance solely on our own construction would constrain the nature of the interactions, the diverse experiences and perspectives, of the participants and researchers and to probe multiple realities present. The issues governing the participants' confidence and selfawareness levels were made explicit through observations, discussions and questionnaire responses. While, the issues governing our identities, positionality, methodological knowledge and resulting experiences were made explicit through a process of analyzing our recollections, perspectives, and feelings in an introspective procedure of memoing (Moustakas 1994). 


\subsubsection{Observations}

We set out to investigate why, after more than five years; the home-stays are still at the start-up phase. During our 39 home-stay visits with an average stay of two hours we engaged with the women through observations and informal discussions; and observed themes that had previously not been identified through the literature review giving rise to new lines of inquiry. We took notes of both the observations and tape recorded informal discussions. The project officer (Xhosa speaking) translated any complex issues as she was present at all home-stay visits. We did not visit seven homestays because of scheduling difficulties, three of the women were said to have travelled to their rural homesteads, while one had just come out of hospital; and at three home-stays appointments were made but on arrival the operators were absent. While observing the women in their home-stays, we were aware that their space had dual roles/functions as home and enterprise. We determined that this was an important distinction; we set out to establish if the women also identified this distinction of their space.

\subsubsection{Semi-structured interviews}

The first author carried out all three key informant interviews. The balance between greater methodological knowledge and greater cultural knowledge was an issue constantly negotiated. The power of the position of the first author as a doctoral researcher facilitated connecting with gatekeepers to gain access to participants. On the other hand, those interviewed subtly negotiated power with the researcher by determining where and when the interview was held, who would be present, and the information shared. The three key interview informants comprising a government officer, a Kwam executive committee member and an independent tourism consultant, were selected on the merit of insider knowledge of the project. Initial contact with two of the key informants was set up through the Kwam project officer. She was contacted by telephone and at this point agreed on the various conditions that would govern the interviews. The third interview was scheduled by the researcher through a contact from previous projects. Issues regarding confidentiality and uses of data collected were clarified with the respondents. All interviewees agreed to be tape recorded and notes were also taken. Use of open-ended questions allowed the probing of arising lines of enquiry and elaboration of points of interest which in turn enabled the attainment of "real," "rich" and "deep" data (Fouche 1993). The interview guide consisted of three issues: 1) the women's role in Kwam; 2) the challenges at the leadership level of Kwam; 3) the respondent's interpretation of the future of Kwam. 


\subsubsection{Questionnaire survey}

Issues arising from the analysis of both the observations and interview data informed the questionnaire design. Prior to administering the questionnaires the two field researchers carried out a week long training workshop with 10 female native Xhosa/English speaking university students to assist with translating the questionnaire to the women operators. This was to ensure that the women fully understood the questions as they are not native English speakers and the researchers are not native Xhosa speakers. We deliberately chose to have female interpreters. It was agreed that bringing in male interpreters would most likely introduce other dynamics that were not under observation in this study (Yanow and Schwartz-Shea 2006). The translators were coached to avoid leading the women to a perceived desired response; and we monitored the session. We administered the questionnaire session at Nduna library in Joza Township to ensure a maximum participation and a quick turnaround time. All (46) of the women were invited through the Kwam executive committee and the Grahamstown Tourism Office arranged the venue. The response rate from this session was 44 (95.7\%). The questionnaire was designed to gather data on: a) demographic variables; b) dependence levels; c) the El levels of the women of Kwam as a measure of emotional confidence; here questions that attempt to measure on an interval level were used. We adopted Goleman's El competencies measurement tool which uses Likert scaling questions with a 1-to-4 rating, this instrument had no centre or neutral point - the respondent had to declare whether she was in agreement or disagreement with the item (Hellriegel et al. 2009: 42-43).

\subsubsection{Group discussion}

We were also interested in the interaction within the group as a means for eliciting information, rather than just collecting each individual's point of view (Creswell 1994). Therefore we carried out a discussion session with the women immediately after administering the questionnaire ensuring participation of all 44 women present in the questionnaire session. All ten translators and the Kwam officer were also present and the Kwam officer was tasked with posing the questions in Xhosa and relayed the responses to the researchers in English, the discussion session was also tape recorded. During the session we observed power based dynamics rooted in cultural norms and seniority. This entailed negotiating the process to allow for a balanced view while remaining nuanced to not offend the women by observing the culture. This meant giving the floor to the senior women first and being respectful of issues raised earlier even if they contradicted another view point. We asked open-ended questions in order to minimize predetermined responses (Patton 1985). The discussion guide consisted of 
three issues: 1) the experiences instrumental in the participants' role in the government LED initiative; 2 ) the participants' involvement in the development of their home-stays; and 3) the participants' interpretation of their needs with regard to the future of the initiative. The guide allowed us to word questions spontaneously and to establish a conversational style (Patton 1985). This enabled us to present new questions while maintaining the flow of the discussion. The data collected consisted of narrative sets of individual lived experiences. The open-ended nature of questions permitted individual participants to focus on what information about their experiences they felt were most pertinent to their home-stay. This is reflected in the narrative sets of the participants. For example, while respondent KMHS -IP/0011 shared considerable information regarding her financial challenges and KMHS -IP/0003 focused on her experiences as a single mother, KMHS -IP/0041 went into greater detail regarding her approach to service delivery. While KMHS -IP0033 proudly stated that "...because of my home-stay my daughter is reading Economics at university...".

\subsubsection{Explication of the data}

The heading 'data analysis' is deliberately avoided because Hycner (1999) cautions that 'analysis' has connotations for hermeneutics. Emphasis was placed on how this affects ' $m e^{\prime}$ as researcher and to describe the researcher's experience and the idea that this is all research is or can ever be (Lofland and Lofland 1995). Moreover, the diverse perspectives and value systems of the researchers and participants "interact in unpredictable ways to influence the outcome" of the study (Lincoln and Guba 1985: 41). Thus to derive insight from the role of home-stay tourism development as a LED poverty reduction strategy and how El levels impact the development of women entrepreneurs, thick descriptions are necessary. We had to be disciplined to record each observation, interview and discussion, as comprehensively as possible, but without judgmental evaluation. We constantly engaged with the data from the different angles questioning what had happened. What was involved? Who was involved? This process allowed us to see why interpretive methodologies provide conceptual grounds for understanding why research, writing, and reading should be intertwined (Yanow and Schwartz-Shea 2006).

\subsection{Results}

In this section we present results on the factors that influence emotional confidence levels in the women as revealed by the El methodology. We group the findings 
according to the different methods used in the following order: semi-structured interviews, observations, questionnaire survey and the discussion session held with the women. This is followed by a description on how we interpreted emerging issues and how we used these to inform the whole data gathering and explication processes.

\subsubsection{Interviews}

While interviewing KMHS-CL/0001 it emerged a lack of direction at the highest level of the project. The respondent described how the initial intentions have been sidetracked. "Since Nosimo Balinhela [former Eastern Cape Premier; inceptor of Kwam] left, things have become very difficult for us". Respondent KMHS-CL/0001 narrated how "the current Premier's office does not recognize us ... and the Municipality sends us back to them!" Additionally, KMHS-CL/0001 vehemently stated "we are confused ... after the last festival ... we confronted them about the misallocation of Kwam resources to other home-stays and nothing was done". The problem KMHS-CL/0001 lamented is "these other home-stays receive preferential treatment for occupancy using our taxis ... because they have better homes... every time they want to show off to the big bosses ... [shifts in chair, heaves and unflinchingly looks me in the eye] and states "they call us to come and sit there, listen to their speeches and give us lunch ... we are not children! ... we want our own office for marketing and bookings this is not benefiting us". This was the first time that we witnessed expressed anger in any of the women. We interpreted this anger to mean that there is desire in the women for the project to be more successful, but there is a lot of frustration. A process of empowerment is incomplete unless it attends to peoples' abilities (Moser 1991) to act within the institutional structure. We interpreted this frustration to mean that the project structure is causing a chain reaction for these women creating a sense of not being in control, so we probed deeper. We asked whether there has been encouragement for the women to make links with local restaurants or museums as a way of marketing. To this KMHS-CL/0001 stated that "we have never done it, we were not told to do so" [pause, shuffles in seat and leans in] "our people $\mathrm{mmm}$... [sighs, pause] do not know where to start, the government should help us, [pause] we do not know where to start sisi [sister] ... they brought the project to us and now they are just neglecting us ... every year we go back to the beginning we are not moving ... aaaaya", [makes clicking sound with tongue - denotes frustration]. The initial thought was the women are leaving everything to the government, if not why are they not seizing the opportunity presented? It occurred to us that these women were not fighting; however, this is contradictory to the investments they are making in their home-stays. 
We discussed among ourselves that a true entrepreneur would never give up that easy; they would relentlessly fight against obstacles.

In another interview KTOG gave a brief overview of how "the project faces real challenges with marketing ... no budget" as a result awareness of the product is minimal. The interviewee also stated that the only form of marketing for the project is the "Kwam logo and the contact details of the home-stays included in the official Grahamstown tourist brochure ... little traffic comes in as independent bookings". During the interview KTOG described a scenario where they receive large numbers by way of DSRAC officials during the festival and after that it is quiet. The respondent KTOG narrates that "the goal is to be able to attract an international market at the moment there are no real growth possibilities because the market is saturated ... [leans in] ... there is real need to grow the market" and explains the target of attracting a share of the international travel that already visits the province. This is interesting! Sights are already set on an international market; this is the third aim (see Section 6.2) already! What about the first two aims? Is there an enabling environment to see that these aims are achieved? We queried further: When questioned if the market is perhaps saturated. KTOG emphatically stated "yes! Everyone is pulling for the same market, the city needs market growth". In response to a question about the economic impact of Kwam of the women KTOG stated "compared to what they would be earning otherwise ... the project has done a lot for the women, however much more can be done! It has a lot of promise ... we do not regulate the workings of the project; our role is to market the accommodation in the city ... for a fee".

What we captured from this is that Kwam was started as an aid/donor driven LED strategy that is plugged into a business driven distribution system. This requires a level of business skills such as negotiation with suppliers and partners for best prices to navigate to a competitive position in the market and achieve higher return on investment. Tourism is an interconnected web of industries working together to realize individual economic goals. How will the women achieve the set goals if the project basis is a different model to the tourism system to sustain it? After these interviews the researcher also interviewed an independent tourism consultant and entrepreneur, who coincidentally had been contracted to train the Kwam women in the past. In extract 6.1 below we show how PEMP provided an overarching viewpoint of the project.

\section{Extract 6.1}

Interviewer: "What are your views on Kwam?" 
PEMP: "People were selected on the basis of poverty; the women never had a voice in selecting of initiative. They got financial assistance and training; hospitality training". Interviewer: "You sound as if the project was a bad idea" PEMP: "Kwam has become a political football, when convenient everyone owns it, viva Kwam! But to work no one owns it ... these women are poor, Apartheid took care of that no doubt! ... Poverty is not the only thing! These women have skills and drive to work ... not necessarily home-stays for all of them ..."

Interviewer: "The women were poorer before the start of the project?"

PEMP: "Yes, but, now they wait for financial assistance the government taught the people to receive, in this way they set these women up for failure, for the home-stays to work they need entrepreneurial steering ... this hunger pushes people and breeds success ..."

Interviewer: "What can be done to achieve this success??"

PEMP: "Let us not forget these mamas have never been tourists themselves ... selling a cultural experience ... can work but not with the numbers involved ...".

The message from this interview led us to question if the government had acted too fast owing to the desperation of the situation. From the viewpoint of the government one gains an understanding of the pressure on the government to do something to promote the inclusion of the previously disadvantaged. However, instead of abating the problem did the government enable a sense of dependency and entitlement? What could have been done differently?

\subsubsection{Observations}

We visited the home-stays during October and November 2009. All of the home-stays had no occupancy during this period. The home-stays were very clean, and comfortable with modern furnishings. We arrived without appointments, and in Xhosa culture, guests are always welcome. Upon arrival the women welcomed us warmly into their homes and showed us around their home-stays. They were very happy to see the Kwam officer; these visits were after the festival and too early for the next scheduled visits. It is important to note the distinction here between 'home' and 'home-stay'. We observed a difference in the two upon arrival a very warm greeting and welcome was always extended. However after an explanation by the Kwam officer of the aim of our visit we observed a changed tone in the women. During the tour of the 'home-stays' the women were always quick to point out renovations that were underway also made a point to describe future improvement plans. Interestingly the women stated that they are financing the renovations using income from the home- 
stays. This happened in 38 of the 39 home-stays we managed to visit and we began to ponder on an unspoken wish the women might have, their actions and explanations meant something; perhaps that if we could come back later they would have improved their home-stays? Why the emphasis on their future plans and developments? We noted this.

\subsubsection{Questionnaire}

From the data collected through the interviews and observations we designed a questionnaire to probe the issues that had arisen.

\subsubsection{Levels of education}

To establish if the women's past has a bearing on their present situation we analysed their education levels and it was established that (79.6\%) of the women are above 40 years with the remaining $20.4 \%$ aged between 30 and 40 . A majority (48\%) attained grade 7 levels, with $20 \%$ having completed grade 10 while $11 \%$ having qualified with a high school leaving certificate (Matric), with $9 \%$ and $7 \%$ holding Certificates and Diplomas respectively.

\subsubsection{Distribution channels of Kwam}

One way to explicitly see whether the women have taken on the program and are actively seeking to improve their home-stays is to examine the relative improvement in the use of distribution channels over time. Most of the respondents (87\%) said the majority of their clients came through the GTO, while $9 \%$ answered through friends and family with only $2 \%$ saying word of mouth and the local church. To corroborate these findings the respondents were asked to state the busiest period in their homestays, all (100\%) of the respondents answered that it was during the two week period of the annual Grahamstown festival. When asked if they had made any promotional material, $78 \%$ indicated that they had not made any; while $7 \%$ stated that they have made posters and business cards, with $6 \%$ stating they had made fliers and $2 \%$ using other methods.

\subsubsection{Emotional intelligence and discussion responses}

El competency scores of the Kwam women are presented in Table 6.1. The more emotionally confident an individual, the higher the score in each of the four competencies: Self-Awareness, Social Awareness, Self-Management, Social Skills (Goleman 1995). The results indicate that the El levels and hence confidence, of the majority (74.3\%) of the women of Kwam are very low. A detailed interpretation of these results is given below. 
Table 6.1: Emotional Intelligence Competency Scores of Kwam eMakana Women Tourism Homestay Operators

\begin{tabular}{lllll}
\hline Score & Self-Awareness (\%) & Social Awareness (\%) & Self-Management (\%) & Social Skills (\%) \\
\hline Below & $86.4_{\{-36\}}$ & $81_{\{-18\}}$ & $68.2_{\{-24\}}$ & $61.4_{\{-18\}}$ \\
On-par & $6.8_{\{36\}}$ & $10.9_{\{18\}}$ & $20.5_{\{24\}}$ & $22.7_{\{18\}}$ \\
Above & $6.8_{\{+36\}}$ & $8.1_{\{+18\}}$ & $11.4_{\{+24\}}$ & $15.9_{\{+18\}}$ \\
\hline
\end{tabular}

Scores 'below' $\{-36\} ;\{-18\} ;\{-24\}$ and $\{-18\}$ indicates low scores in the respective competencies Scores 'on-par' $\{36\} ;\{18\} ;\{24\}$ and $\{18\}$ indicates pass scores in the respective competencies Scores 'above' $\{+36\} ;\{+18\} ;\{+24\}$ and $\{+18\}$ indicates high scores in the respective competencies

\subsection{Self-awareness}

Self-awareness has been described as knowing one's internal states, preferences, resources and intuition this will allow one to have choices to alter behaviour (Goleman 1995). We grow up learning to cope with less than perfect formative environments provided through parents, teachers, or significant others. These coping mechanisms, some good, some not, get us through to adulthood. Increasing levels of self-awareness therefore, empowers one to make different choices, not that things will be automatically different. After all, some habits die hard, but over time, as these levels build up one will better recognise undermining tendencies (Landy 2005). Only 6.8\% of the respondent scores for 'On-par' and 'Above' representing the percentage that recognize their emotions and their effects on others and can accurately assess their strengths and limitations and have a strong sense of self-worth. $86.4 \%$ of the respondents had a low score (less than 36 ), indicating that they cannot recognize their emotions and interpret their effects on others; they cannot accurately assess their strengths and limitations and have a limited sense of self-worth and capability (Hellriegel et al. 2009). This situation was evident to the researchers during the open ended discussion session, the women lamented on various issues that can be attributed to limited capabilities as evidenced in extract 6.2 from the discussion session:

\section{Extract 6.2}

Discussant: "Are you happy with the price that you are charging for an overnight stay and breakfast?"

KMHS -IP/0023: "No it is too little"

Discussant: "Why are you not charging more?"

KMHS -IP/0023: "Because they told us to charge R200"

Discussant: "Are you making a profit?"

KMHS -IP/0023: "Not a good one, things are expensive." 
Multiple Participants: "Yes, we need to get more money from government, the R500 grant input is not enough ... Yes government needs to give us more money it is so difficult for us".

Hearing the women agree and proffer their solution to the challenges at hand it was striking how easily it came to them to demand for more money from the government. None expressed the option of approaching DSRAC for a negotiation with a minimum acceptable price in view of the low price point set by DSRAC. Their emphasis on receiving more financing alerted us to issues of how the women perceive their own assertiveness and independence as well as their limited capabilities in running their home-stays.

\subsection{Social-awareness}

Social awareness involves a consciousness of others' feelings, needs and concerns. It refers to a spectrum that runs from instantly sensing another's inner state, to understanding another's feelings and thoughts, and complicated social situations (Goleman 1995). Most of the respondents (81\%) obtained a low score (less than 18 ) on social awareness indicating a poor understanding of others, taking an active interest in their concerns, and empathizing with them, and have problems recognizing the needs others have. $10.9 \%$ scored 18 and $8.1 \%$ scored higher than 18 showing that they had increased levels of social awareness. (Hellriegel et al. 2009). Below is an extract (6.3) from the discussion session that illuminates the degree to which social awareness can be low with the participants.

\section{Extract 6.3}

Discussant: "Do you spend time with the guests (interact)?"

KMHS-IP/0010: "No, I serve them the food and tend to their needs and retire" Discussant: "Do you all do the same as she does?"

KMHS -1P/0043: "Yes, I do the same... I do not want to disturb my guests"

This comment drew our attention to the women's social cognition and empathy. Coupled with their low self confidence levels this revealed yet another dimension. It dawned on us that the women do not know that their culture, experiences and voice, which is the most important part of their product, is not something to be hidden.

\subsection{Self-management}

Self-management involves one's internal states and impulses, encompassing skills such as problem solving, decision making, resource utilization, and action planning, and self- 
tailoring (Landy 2005). A low score (less than 24) on self-management means individuals cannot keep disruptive emotions and impulses under control, and it's difficult to be a self-starter; they are not able to easily maximise opportunities and have problems adapting behaviour to changing situations (Hellriegel et al. 2009). A majority (78.2\%) of the respondents scored low levels in this competency while $10.5 \%$ and $11.4 \%$ scored 24 or greater respectively. Extract 6.4 below from the discussion session illustrates the competency.

\section{Extract 6.4}

Discussant: "Would you like to have more clients throughout the year?"

KMHS-IP/0008: "Yes, because I would have money to finish the extension to my house."

Discussant: "Are you advertising your home-stay?"

KMHS-IP/0008: "No, sisi [sister] I don't feel comfortable asking people to come and pay to stay with me, [pause] ... 'Ubuntu' ... so I wait for the tourism office"

Discussant: "Why are you not comfortable?"

KMHS-IP/0008: "My place is ... [looks away] it is not up to standard"

These women are not bad hostesses; they do not need more training. They have all the experience of living their life which is what a home-stay experience is essentially about - cultural experience. It has to do with 'Ubuntu', (an African concept that loosely translates into the humanity you extend to others as a fellow human). It is not the norm in Xhosa culture to charge a guest for food and accommodation, the very premise the project was built around. This realization opens up new ways of framing the challenges of Kwam.

\subsection{Social-skills}

A low score (less than 18 ) by $71.4 \%$ of the respondents on social skills suggests problems with leading and inspiring groups, having problems with articulating convincing messages, building effective interpersonal relationships, and difficulties working well with others to achieve shared goals. Extract 6.5 below gives a viewpoint from the discussion panel. A high score (greater than 18) indicates individuals who can sense others' developmental needs, inspire and lead groups, send clear and convincing messages, build effective interpersonal relationships, and work well with others to achieve shared goals (Hellriegel et al. 2009).

\section{Extract 6.5}

Discussant: “Are you advertising your home-stay more?" 
KMHS -IP/0023: "No, I do not have the money to advertise my house"

Discussant: "So what are you going to do?"

KMHS -IP/0023: "I hope that the government will help us, we really need help for our home-stays to become successful and earn more money"

Multiple Participants: "Yes, the government should help us to market our home-stays ... We need help we do not know where to start."

This response points to a sense of dependency among the women. It actually struck us that these women do not think that they have power to move towards a success either individually or as a group. There was no visible conflict among the women but there was also no cohesive force meshing the team together to achieve a common goal. It occurred to us that there was no catalyst for a change factor that one would expect of a group with a common goal.

It is important to mention that with the benefit of hindsight the use of the interpreters during the discussion session could have resulted in data contamination. This is because sometimes words in another language do not have an exact translation as intended. Additionally the women might have assumed there was a more correct/desired response and gave that instead. However, having 10 students as interpreters as well as the presence of the Kwam officer during the discussion session allowed for instant clarification on the translation provided by the other interpreters on issues that might have been misinterpreted. Additionally, translations given to the researchers were relayed to the participant in Xhosa and at which point they would either agree or disagree. In the case of misinterpretation the Kwam officer would interject and provide a translation agreeable to the woman to both parties.

\subsection{Discussion}

More than five years after the inception of Kwam, the home-stays are still operating within the initial set parameters. A review of the project objectives (Makkink 2009) reveals that DSRAC raised unrealistic expectations amongst the women. For example the third aim mentioned in Section 6.2 places emphasis on attracting national and international tourists markets all year round. This begs the question to what extent Grahamstown as a destination is able to either attract international tourists or all year round patronage. In an interview KTOG made reference to objective three "the goal is to be able to attract an international market ..." given his position with the project it is reasonable to presume that the same aspirations are communicated to the women, 
and this is certainly misleading. This observation is solidified by the notion advanced by Moyo (2009) that current approaches to development and poverty reduction focus too little on business logic such as growth markets, improved productivity and linkages with other sectors. Rather the model promotes handouts under the banner of aid/donor development funding (Moyo 2009). For development initiatives to be successful they have to be viable in the market only then can they have meaningful economic impact.

From the results more than half of the women have not independently advertised their home-stays. Findings show that there is low awareness of the product outside of the DSRAC officials already patronizing the establishments during the festival. As such the women are dependent on the government through the Grahamstown Tourism Office for occupancy, the women are not aggressive in advertising their home-stays instead they seem resigned to receiving guests for two weeks annually during the festival. This reveals a lack of confidence as the women appear reluctant to engage with other businesses. It must be noted, however, that this passive stance contradicts the women's actions of continued investment in their home-stays using income realized from the festival period. Based on the data from the questionnaire survey all the participants were over 30 years and had low educational levels. Given that apartheid was abolished as recently as 1994 all the participants would have been affected by the regime's educational policies. This goes some way in explaining the seemingly diminished capabilities of the women as discussed in the literature EI is a crystallized intelligence because it draws on and develops with life experiences (Dulewicz and Higgs 2003); it is plausible that these educational policies negatively impacted on the women's El levels. In this context it is reasonable to assume that the women of Kwam developed coping mechanisms during turbulent times. Since the democratic transition the younger members of Kwam who were teenagers in 1994 have been exposed to greater educational opportunities. However, there has not been a propagation of higher educational qualifications among the same women. A possible explanation of why these women have not developed their El levels and fully utilized these opportunities is diminished self-confidence and self-determination levels.

The results suggest that the motivation of the women to integrate into the tourism economy can be affected by their view of development initiatives. In their own assessment, they can see that their participation will see them partaking in activities that will have no significant impact on their poverty situation. This is similar to labelling theory in sociology (Becker 1963), after consistently viewing the communities' role through the lenses of 'small-scale ventures' and 'micro-credits', the communities also 
tend to see their role in such a limited way. Findings corroborate with existent views on community participation (Tosun 2000; 2006) in the manner in which it largely attributes the failure of community participation on either or both governments' and technocrats' attitudes and management practices. The discourse also seems to suggest that local communities must be helped to set up small tourism projects, and receive training and various support from outside forces (Scheyvens 2002; Ashley and Roe 2002).

Lediga (2006) maintains that for SMMEs to be viable networking and negotiating are paramount among a range of skills, in enabling collaboration with the larger and established tourism enterprises. In the case of the Kwam operators it highlights the need for entrepreneurial and management skills training, which it could be argued, would enhance self-confidence. He captures it well in his article titled 'Empowerment needs entrepreneurship too' (Lediga 2006). The argument advanced in this paper, is that the disadvantaged seem to be presented as naturally belonging to the world of 'small scale ventures' and 'micro credits'. The women of Kwam appear to have adopted a similar outlook; they do not envisage their home-stays taking off as a result of their own entrepreneurial steering and growing into larger tourism establishments that have high occupancy rates throughout the year. Of particular interest to emerge from this study is how the project design as a government initiative, rather than entrepreneurially driven, actually promoted a dependency culture among the women as highlighted in the literature review, it is plausible that the dependency is exacerbated by the low levels of El competencies (Easterly 2006; Moyo 2009). The comments by interviewees KHMS-CLO001 highlight this dependency "... the government should help us" and PEMP "... the government taught the people to receive ..."

The confidence levels represented by the El scores were low on all the four competencies, this reveals in part why the participants face difficulties in assimilating into the tourism economy as a result of diminished El competency levels; selfawareness, social awareness skills, self-management and social skills. The roots of these low El competency scores have to be understood to determine their possible impact on the attitudes and behaviour patterns of the women towards participating in economic mainstream activities. The lack of awareness by the women to business trends and practices coupled with their low confidence levels possibly curbs their expressive potential as well as their understanding and interpreting of communication, which presents an additional challenge. Another issue to come up concerns a patronising stance by government officials KMHS-CL/0001 "they call us to come and sit 
there, listen to their speeches and give us lunch ... we are not children!" Most people dislike being patronised and clearly the home-stay operators are no exception. This highlights the need for candour in assessing the capabilities in the sense of Sen (1992) of disadvantaged communities prior to engaging them in government funded development projects. Development initiatives in society run into difficulty when people's concerns are overlooked. It therefore has relevance for both the selection of people to benefit from government initiatives and for training. Maybe then the women will be able to make decisions that do not disadvantage them in the end.

\subsection{Conclusion}

Theoretically, the limitations to economic empowerment have to be reduced by focusing attention on the creation of a mentally and physically accommodating and conducive operating environment, to one which encourages 'approach behaviour' (Zeithamal and Bitner 2000). We borrow from the work on community participation adopting the view that the disadvantaged should be allowed to "seize back their creative initiative" (Ngugi 1981: 6) and feel intrinsically motivated and encouraged to immerse themselves in the productive processes of engaging the environment sustainably for their economic and social benefits. Chambers (1995) argues that activities that used to be thought better performed by outsiders, could be carried out equally well by the disadvantaged, 'literate or non-literate'. Outsiders however have a role to play in encouraging, confidence building "... they can do it" (Chambers 1995: 37). This role of confidence building is integral to the raising of self-esteem of the women of Kwam. Lack of confidence and self-belief could explain why these women are not so active in the management of the project at their disposal. Poverty reduction requires a shift to "... expand the capabilities of people" (Sen 1984: 497). In conclusion, government actions may prove more effective if they to focus on building confidence to develop entrepreneurial activities rather than the provision of top-down 'opportunities' over which the women have no control. The issue of reduced selfconfidence presents a starting point for a training program for the women. Finally, owing to diminished networking capabilities with other sectors the home-stays remain dependent on the government structure thus curtailing the capacity needed for entrepreneurial steering. 


\section{Chapter Seven}

\section{Beyond Hosts and Guests: The Role of Indigenous Knowledge and Emancipative Beliefs in Negotiating Cultural Commoditization in Township Tourism ${ }^{1}$}

\subsection{Background}

This chapter is the last of the empirical chapters and it brings together the issues that were discussed throughout this study. The operationalization of BEE (Chapter 4) through the LED framework (Chapter 5) has consequences in the ways that women home-stay operators commoditize their culture. Additionally, the institutional arrangements in place in the project also affect how the operators interact within the capacity of their capabilities (Chapter 6) with guests. Simultaneously, the women operators impact on guests perceptions and experiences of cultural home-stays (Chapter 2) in particular and Township tourism in general.

Tourism is foremost a form of development bound to economic realities (Tefler and Sharpely 2008) with cultural resources at its foundation (Scheyvens 2002) a means by which individuals and societies can access and gain insight of one another's places and pasts (Robinson and Picard 2006; UNWTO 2009; Jensen 2009). Tourism is also a way of capturing values of host communities at the same time it preserves natural resources (including culture - a social construct). There has been growing recognition globally that engaging with and experiencing culture is no longer a marginal activity to other aspects of social, political and economic life (Jensen 2009). Robinson and Picard (2006) posit that through experience, education and satisfaction, tourism can be a liberating vehicle for gaining and exchanging meaning and understanding in an intellectual, emotional and spiritual sense. This ushers in the importance of contact theory which stems from the field of social psychology and implies that contact between people, generally of different ethnicity, will lead to a change in, or a reaffirmation of, intercultural attitudes towards other ethnic groups (Pettigrew 1997). Increasingly, the value of culture in tourism has received focus (Aitchison 2009) forming a cornerstone of economies and development agendas (Higgins-Desbiolles 2005). According to Robinson and Picard (2006) tourism is an important element of emergent

\footnotetext{
${ }^{1}$ Earlier version presented at International Conference on Resilient Societies - Governing Risk and Vulnerability for Water, Energy and Climate Change, 19-21 October 2011, Enschede, the Netherlands.
} 
transnational 'cultural economies' - or economies of the cultural - in that it connects new audiences, and generates new pressures and opportunities.

It is important to recognize that any discussion of the inter-relationships between tourism, culture and development is confronted by several layers of complexity (Robinson and Picard 2006). The very nature of culture entails that it is not static. Rather it evolves and changes, and as such the multifaceted relationships it shares with tourism also change (Fabrizio et al. 2000). In addition, the structures and practices of tourism are seldom isolated from other aspects of life; rather tourism, in structural terms and in social practices, is inter-connected with all aspects of daily life such as food, music, dance and cultural norms (Jensen 2009). Robinson and Picard (2006) highlight that tourism touches upon people's connections with other people, places and the past (all being highly contested terms at both the individual and collective level). The overlaps and competing priorities make it difficult to devise and even to discuss the issues involved becomes complex as themes merge and intersect (Fabrizio et al. 2000). Jafari (2010) maintains that a starting point is with cultural tourism that respects and enhances the historic heritage, authentic culture, traditions and distinctiveness of host communities and local destinations. Both culture and tourism are viewed as important components of development, in the context of a globalized world it is difficult to consider one without the other (Appadurai 2002, 2003).

There are some questions that need to be considered - and answered - in order to avoid a priori viewpoints about the components and features of culture, human motivation and action and the possibility of cultural misconceptions. Firstly, to what extent township tourism operators within the set institutional framework (Chapter 5) manipulate their culture. Secondly, how this manipulation impacts their economic empowerment and capabilities (Chapter 6). The chapter adopts dual lenses of indigenous knowledge and emancipative beliefs to assess the impacts of cultural commoditization on economic empowerment of Kwam eMakana women home-stay operators. Through comparing perceptions and feelings of home-stay student guests of different nationalities the reader is invited to consider the destination as a constantly negotiated and constructed socio-material space (Latour 2004). The chapter concludes that human diversity provides an alternative perspective to cultural misconception in diverting its focus away from structural or action-based differences to human motivation and action issues. Hence, misconceptions are part of a continuously negotiated and assembled relational destination network. The chapter will show that the assessment of cultural commoditization in Kwam eMakana also highlights the consequences of cultural misconception, and reveals other explanations 
and the role of culture in the shaping of and, in turn, being shaped by touristic experiences for the women operators. These explanations focus on the relational, the process and the socio-material character of tourism and also demonstrate the heterogeneous and often subtle ways in which power and marginalization are exerted. It challenges more traditional ways of perceiving the workings of cultural tourism, and on a more general level, social action and cultural expressions, this opens new possibilities and offers great potential for new understandings that can lead to new solutions.

\subsection{Cultural Tourism as a Means of Economic Diversification}

Although tourism's positive contributions to societies have long been contested (Pizam 1996; Appadurai 2003; Ashworth 2003), tourism has been accepted as one of the world's more important economic sectors (UNWTO 2005; Robinson and Picard 2006; Jensen 2009; Magi and Nzama 2009). One of the most remarkable traits of development has been the mobilization of tourism as a preferred form of economic development at local, regional and national level (UNWTO 2002; 2005; Robinson and Picard 2006). For developing countries, mass tourism development is an attractive option because of the perceived economic benefits. However, as has been highlighted by numerous studies (Jafari, 1982, 1996, 2002; Ashworth 2003; Tosun and Timothy 2003; Tosun 2006; Jensen 2009; Kwaramba et al. 2011) there are serious drawbacks to this 'cure all' label often attached to tourism. Goudie et al. (1999) argue that the emphasis of mass tourism is mainly fixated upon the provision for predominantly hedonistic activities; culture can often be reduced to brief and selective displays through limited interaction between host and guest. This skeptical outlook has seen a proliferation in alternative forms of tourism, diverting from the criticism laden mass tourism. Mass tourism has been described as being able to transfer the power of development away from the host government and communities toward the tour operators and the tourist generating nations resulting in leakages (Jensen 2009; 2010) including the power to terminate development and switch investment to other destinations (Pleurom 1994; Ringer, 1998). Second, it tends to be limited spatially to particularly attractive developed and pristine environments and does not seek to engage with problem zones and communities (Appadurai 2002; Timothy and Boyd 2003; Higgins-Desbiolles 2006; 2010). Third and related to the above, levels of investment tend to be directed toward surface issues of aesthetic concern and the needs of tourists rather than to deep-seated socio-economic problems and the needs of host communities (Mowforth and Munt 1998; Jensen 2009). Fourth, economic 
returns tend to be restricted to short term gains in terms of employment in the tourist sector and related services (Robinson and Picard 2006).

\subsubsection{The commodification process of culture in tourism}

It is common for destinations to use their culture as a means to attract tourists translating culture into a commodity hence its packaging and selling for consumption (Cole 2007). According to Shepherd (2002) the growing tourism demand unsurprisingly leads to the commoditisation of cultures, as the foundation of tourism is centered on the desire by tourists to experience cultures different to their own. Taylor (2001) is of the view that this commoditisation actually destroys the local culture as it gives way to exploitation of culture for economic gain, which is often adapted to suit the tastes of tourists - making it inauthentic. Cohen (1992) postulated that tourism in its widest sense has long assembled culture as a central means to make sense of the 'other' and to make the 'other' visible. Poets, artists, administrators, academics and travel writers have often used very elaborate systems of sub-categories to translate and make meaningful the social life of peoples visited or otherwise encountered (Blanchard et al. 1995). Such categories typically include fields such as geography, history, demography, politics, kinship, festivity, economy, arts, architecture, literature, music, religion, and gastronomy. Similarly, archaeologists and historians have used similar categories to study the social life of ancient and past cultures and how cultural contact and creativity transformed social life (Geertz 1973). Jensen (2008; 2009; 2010) maintains that touroperators, tour guides, and tourism planners translate, commodify or package particular types of artifacts, spaces, stories and social practices into discourses, products and events that are accessible to tourists as cultural exchange.

\subsubsection{Tourism as Industry}

Tourism and its wider institutional networks operate an asymmetric relation of power, imposing touristic aesthetics and underlying values to the selection and interpretation of various cultural resources (Nash 1989; Ringer 1998; Jensen 2010) For instance, tourism typically creates its own forms and types of landscape, often revolutionizing the spatial and demographic realities of a place. Accordingly, tourism has transformed traditionally marginal spaces like mountains, shores or country sides into touristic visited landscapes (Urry 2002). On the other hand, however, Goudie et al. (1999) describe the Victoria and Alfred Waterfront in Cape Town, as being far from a true reflection of local cultures. According to them what is presented is a sanitized and carefully reconstructed history; the lives of black dockworkers, slaves, convicts, beggars and others who made up the social fabric of everyday life in early Cape Town, 
lie beneath these depthless and romanticized images. In an effort to make tourism more inclusive there has been a proliferation of tourism that is the antithesis of conventional tourism known as "reality tours". These tours go to developing communities and endeavour to show what real life is like in that community, including problems of violence, poverty and disempowerment. The aim of these tours is to help tourism contribute to the solutions to these problems by educating the tourists not only to see the problems in the places they visit, but relate them to their own community and take up action to improve the world in some way as a result (HigginsDesbiolles 2005, 2010).

Research is yielding insights into claims that tourism can foster attitudinal change in tourists and promote cross-cultural understanding (Kelly 2006b; Jensen 2010; HigginsDesbiolles 2010). This has ramifications as it challenges the social equity of tourism when it includes only parts of the community and the benefits are accrued as such (Fainstein 2007) and highlights the place and its role in shaping (and being shaped) by tourism (Chapter 2). As Massey (1992: 80) notes, "space is constructed out of interrelations, as the simultaneous coexistence of social interrelations and interactions, at all spatial scales ..." while for Lefebvre (1974) our conception of the world is fundamentally spatial and the idea of 'space' is essential to our everyday experience. The collections of essays edited by Ringer (1998) highlight the active role of tourism in the social construction of space through place. Place, therefore, is not just historically constructed in space, it is actively mediated upon and acts in conjunction with 'outside' and 'inside' factors at all times. In the same way, Mbembe (2004) describes social spaces of modernity as being as much cultural as economic constructs.

\subsubsection{Significance of cultural resources}

The second observation concerns processes of contextualisation and significance of culture and cultural resources mobilized for touristic exchange (Kirshenblatt-Gimblett 1998). The introduction of tourists often enlarges the social spaces of host communities - particular elements, social practices or spaces originally without any considered intrinsic relevance for a community's social life may be highly relevant to the tourist gaze and vice versa. Often communities only become aware of particular cultural elements through the interaction with tourists and various tourism operators (Jensen 2009). Urry (2002) argues for the visual nature of tourist experiences which underlies his concept of 'tourist gaze'. The concept refers to "visual elements of landscape which distinguish it from what is conventionally encountered in everyday life" (Urry 2002: 3). However, he points out that there are different tourist gazes that 
may vary according to social groups and historical periods; these can be a means for communities to exchange with the world and as a symbolic resource mobilized to define forms of local and social identity (Lash and Urry 1994). Commoditization of culture can actually lock cultures and communities in a certain stage of development (Cole 2007). For example Kilian (1994) observes that in an attempt to minimize risk the Victoria and Alfred Waterfront in Cape Town opted for the profitable tried-and-tested combinations of postmodern styles rather than attempting new forms reflective of Cape Town's unique cultures.

Critics (Goudie et al. 1999) maintain that success of the Victorial and Alfred Waterfront has been achieved at the expense of local cultures, the paradox is that for the locals there is conflict between retaining traditions and rituals, and fully adopting modernisation for example electricity, running water and infrastructure (Cole 2007). Cole describes this situation as being brought about by Western tourists in search of 'authenticity' which he and Urry (1994) interpret as generally in search of the pristine and untouched areas with most opting not to visit areas if they are too developed (Urry 1994). Cole (2007) reported that in the Flores islands in Indonesia a tourist stated that the electricity poles made the scenery of the rural village inauthentic, in this case the government regulated how the villagers had to restore their houses, specifically prohibiting them to have opening windows in their huts. Is it then, as raised by Nadine Fiaux in her article "Culture for sale!" - commoditisation in tourism; that the western view of authenticity is fostering poverty in other parts of the world for their own benefit? The issue addressed in this study centers on how to find the appropriate balance such that both locals and tourists can benefit. The viewpoint here borrows from the work of Squire (1994) and Crang (1997) that tourism geography has to take both its economic and cultural dimensions seriously.

Closely linked to the notion of commoditization is the concept of authenticity. Of interest in this vein is the view that cultural commoditization in tourism erodes the local culture and its authenticity leading to so called 'endangered cultures' (Taylor 2001); while the other standpoint claims that it can actually help and empower the locals (Urry 2002; Cole 2007; UNWTO 2009). However, it is difficult to say which view is correct, as the very nature of tourism development presents a paradox for the local communities.. There have been growing attempts by economic, cultural and social geographers to reconceptualize their sub disciplines and embrace the diminishing gap between 'economy and culture' (Amin and Thrift 2000). Ateljevic (2000) claims that there has been a rise in approaches that attempt to account for both the material condition and specific experience of individuals, while at the same time situating the 
individual with political and economic structures of power, conflict and resistance. According to Stenou (2004) in order to accommodate these concerns, 'new' fields have emerged that increasingly recognize the difficulties inherent in the separation of economic, cultural and social geographies and which acknowledge the dialectics of structure and agency (Bruner 2004). It is important to note that traditional issues of inquiry in economic geography (production, circulation and exchange) have not (and should not) be abandoned, but rather reshaped to embrace the cultural and social construction of economic geographies (Ateljevic 2000).

\subsubsection{Tourism: Africa's culture industry}

Tourism has been earmarked by a number of African countries, including South Africa, as a way to gain recognition or comparative advantage. The South African DEAT has specifically acknowledged the importance of this industry (DEAT 2009). However, the economic realities of tourism, and especially cultural tourism, play a large part in determining just how Africa, and specifically South Africa, packages and defines itself in order to gain advantage in a competitive global tourism market. Preston (2007) argues that the need to compete for primarily Western tourists leads to a process whereby Africa as a destination is defined by the perceptions of what is appealing to the West. Preston (2007) maintains that often these definitions of what is 'African' for the tourist market are the products of hundreds of years of negative or overromanticised Western perceptions of Africa as previously demonstrated. This is important given that one of the objectives of the project is to attract international guests all year round. In Chapter 5 it was shown that this objective is of high priority to the women, and in Chapter 2 while visiting a home-stay a hostess asked the author "do you think my home-stay meets the standard to hosts international guests?" The presence of international student guests in methodology employed will provide a chance to observe the hosts interaction with much sought after 'international guest'. For this study it is necessary to explore the specific role of tourism as a function of the attempts by township destinations to achieve economic empowerment. First as suggested by Preston (2007) it is necessary to look at the tourism industry as a byproduct of the capitalist system. "Tourism, within the global perspective, fits in with trends in economic development towards service based, consumer oriented industries associated with the production of symbolic or cultural capital rather than material goods. The role of culture in this process is multi-faceted culture is simultaneously a resource, a product, an experience, and an outcome" (Craik 1997: 113).

In order to thrive, a tourist destination needs to achieve status of a tourist site, whereby the space itself becomes commodified and the site itself becomes symbolic in 
its own right (Britton 1996). These spaces become crucial as physical and symbolic spaces of consumption and economic development. In Africa, these spaces also are highly symbolic as it is often indigenous (authentic) culture that is used to imbue these physical spaces with the meaning that is so attractive to tourists. Therefore, apart from the potentially exploitative structure of the industry itself, the way in which identity and culture are commodified for the Western tourist's gaze is also often problematic (Preston 2007). Hall (2007) described this process as "the current tourist interest in indigenous societies is perhaps reflective of a desire for authenticity in Western society and of the role that heritage plays in establishing identity the desire for authenticity and the implications that has for the presentation of certain social realities for the tourist gaze have significant political significance" (Hall 2007: 122). Tourist attractions are constructed with the needs of the tourist market in mind. The demand within the industry is increasingly becoming for so-called authentic experiences of the 'other' or non-Western indigenous peoples (Preston 2007). Hall (2007: 122) points out, "the dominant Eurocentric vision has important implications for the manner in which indigenous peoples are perceived". For South Africa this has meant that it has to recast the negative perceptions of tribalism and violence as "an authentic primitive innocence" (Rassool and Witz 1993: 337). Rassool and Witz claim that to position itself within this global tourist market, South Africa is "reinforcing stereotypes ... through staged primitiveness and modernity" (Rassool and Witz 1993: 365). The challenge arises because destinations are not stagnant but evolve as they go through the stages of the tourism area life cycle [TALC] (Butler 1980). Destinations of commoditized cultural tourism once popular will see a decline in visitor numbers as destinations reach maturity and decline stages which will impact the economic earnings of the destination. Destinations reliant on a constructed cultural image will be left to bear the socio-economic costs of staged cultural authenticity and this model to tourism development does not promote economically resilient societies.

Preston (2007) writes that tourism as an industry is in the business of producing cultural symbols and content for consumption. The less obvious point is that the symbols, attractions, and commodities produced by the industry have an impact on shaping social reality and urban physicality. The power of the tourist industry to construct social reality and transform urban spaces should not be underestimated. Linked to this process is the fact that, in the course of attempts to reconstruct an African identity, culture becomes "commoditized", [in that] "the once 'authentic' public ritual became a staged performance, a cultural 'commodity"' (Cohen 1988: 381). These rituals and cultural activities may then "be adopted to the tastes of the tourists" (Cohen 1988: 381). This commoditization of space can lead to situations as in 
Johannesburg as described by Mbembe, as "more than ever in its history, Johannesburg's city space is a product that is marked, measured, marketed, and transacted. It is a commodity. And as such its representational form has become even more stylized" (Mbembe 2004: 393). Africa, as a distinct identity for a destination, has thereby become a stylised product for the foreign visitor. This newly constructed notion of African culture then becomes a tool for city planners to overcome the stereotypically negative perceptions of African cities enabling the formation of economically resilient African societies through the commodification of their natural resources. However, the experience of the tourist, will not necessarily achieve the goal of constructing a new African identity.

As Craik points out, for tourists, "the advantages, comforts, and benefits of home are reinforced through the exposure to difference" (Craik 1997: 115). In other words, cultural tourism can actually continue to perpetuate stereotypes that Africa is inferior to the West. Craik also points out, that "despite the intentions of cultural tourism practitioners to create so called 'authentic' experiences that will construct a new cultural identity, cultural experiences offered by tourism are consumed in terms of prior knowledge, expectations, fantasies and mythologies generated in the tourist's origin culture, rather by the culture offerings of the destination" (Craik 1997: 118). Moreover, while cultural tourism and components may revitalise an existing tourism industry and cultural production; such developments simultaneously threaten the culture of the destination and longer term cultural integrity (Craik 1997). Hence a consequence of cultural tourism is that the cultural product becomes frozen in time and while staged as real and authentic, the meanings of the arts and culture simply become products within a system of economic exchange. This process has serious implications for the development of local arts and culture within a given environment and the formation of resilient societies in any case. So while cultural tourism is perceived by many developing countries and cities as a panacea for a host of economic problems and as a way to develop the arts, it is not without its own serious consequences (Preston 2007).

\subsubsection{The role of food in cultural tourism}

Until recently, the contribution of food (gastronomy) to tourism has been largely ignored in spite of its apparent importance and potential (Telfer and Wall 1996; UNWTO 2000). Handszuh (2000 in du Rand et al. 2003) indicated that food and drink products of a country can be among its most important cultural indications. Anthropologists have identified peoples on the move-migrants, refugees, and 
colonizers - as agents of dietary change. Lockwood and Lockwood (2000) explored changes in the eating habits of Detroit's Arab community, where not only the foods of the larger society, but also the cuisines of different ethnic groups within the community have inspired dietary shifts. Goody's examination of Chinese migrant food focuses not on their diets, but rather on their influences on diets in the countries to which they move (Goody 1998). While, Wilk (1999) examines the complex culinary reactions of Belizeans to colonialism, class differentiation, and modernity. Tackling colonialism from a different angle, Dennett and Connell (1988) and their commentators have stirred up debate over the effects of acculturation on the diets of aboriginal peoples. Historians, too, have examined how broad social processes have led to culinary change (Mennell 1985). Cusack (2000) maintains that on a practical level a nation's identity is reflected and strengthened by the food experiences that it offers. Bessiere (1998 in du Rand et al. 2003) wrote that the way that people combine various ingredients forms an important element of a cultural identity.

Handszuh (2000 in du Rand et al. 2003), posits that local food holds much potential to enhance sustainability in tourism, whereby the tourism planner and the entrepreneur should work hand in hand to satisfy the consumers; contribute to the authenticity of the destination; strengthen the local economy; and provide for the environmentallyfriendly infrastructure, including the ways and means by which food resources, both local and imported, are handled. This approach was not always common practice at the local level. Traditionally many local people in South Africa did not hold their own cuisine in high regard, and often viewed it as not being sophisticated enough and definitely not something a tourist would want (Kapner 1996 in du Rand et al. 2003). Wagner (2001 du Rand et al. 2003) asserts that tourists enjoy indigenous food, particularly items of local or ethnic nature. Furthermore knowledge of the local, regional and national cuisine has become an interest for tourists (Cohen 1992, 2001; Gallagher 2001). Santich (1998 Santich du Rand et al. 2003); MacDonald (2001) and Bessiere (1998 in du Rand et al. 2003) report that people interested in travelling for gastronomical motivations are on the increase. If food is changed only to suit the taste of foreign tourists, then traditional foods of the region can be lost, which has wider implications regarding the sustainability of the community (Chappel 2001 in du Rand et al. 2003). However, consideration has to be given to the fact in numerous destinations the incorporation of ethnic cuisines (Belasco 1987), the interactions among the technologies of food production and processing, the refinement of packaging to entice consumption (Hine 1995), the physical characteristics of new foods, and consumer responses to new foods are critical determinants of dietary change (Leach 1999) as these have real consequences for retaining local cuisine in its pure authentic form. 
In the context of this study Kwam eMakana the use of local food can directly contribute to the various elements of tourism sustainability namely stimulating and supporting agricultural activity and food production; preventing authentic exploitation; enhancing destination attractiveness; empowerment of the community (by means of job creation and encouraging entrepreneurship); generating pride, specifically regarding food; and reinforcing brand identity of the destination with the focus on food experiences in that area (Telfer and Wall 1996). Furthermore, food service is a generator of jobs and income that is of major importance to the tourism sector and can contribute to the establishment of a destination that is both sustainable and competitive (Elmont 1995).

\subsection{Theoretical Underpinning}

Contact theory (Amir 1976; Pettigrew 1997), stems from the field of social psychology and implies that contact between people, generally of different ethnicity, will lead to a change in, or a reaffirmation of, intercultural attitudes towards the other ethnic group (Allport 1954; Amir 1976; Cook 1978; Pettigrew 1997; Tropp and Pettigrew 2005a, b). Contact theory can be regarded as the 'science' behind attitude change, and if it is assumed that positive attitude change is a precursor to healing and transformation (Pizam 1996; Tomljenovic and Faulkner 2000) its importance becomes obvious (Chapter 2). "When we feel love and kindness toward others, it not only makes others feel loved and cared for, but it helps us also to develop inner happiness and peace" (Gyatso 1989: 258 in Kelly 2006a). The wealth of information on contact theory is so large that a comprehensive review is not within the scope of the current chapter Allport in his book, 'The Nature of Prejudice' (1954), outlined the situational conditions whereby intergroup contact will lead to a decrease in prejudice. Here contact theory is viewed in the context of positive encounters between host communities and guests, the hosts' indigenous knowledge is valued by guests thus providing an avenue to healing and transformation through emancipative beliefs. These approaches are described below and how they were used to inform the study.

\subsubsection{Indigenous knowledge approach}

The concepts of indigenous knowledge and emancipative beliefs are assessed on how they impact the commoditization of cultural tourism. These concepts are used to illuminate the veiled assumptions and challenges for previously disadvantaged South African women in the operation of cultural township tourism home-stays (Chapter 2). 
Academic tourism studies have not explicitly examined the roles that indigenous knowledge and emancipative beliefs play in cultural commoditization. Indigenous knowledge is local and unique to a given culture or society, it is the basis for local decision-making in agriculture, food preparation, health care, education, natural resource management, arts and culture and a host of other daily activities (Minang 2007). Such knowledge is passed on from generation to generation, in many societies by word of mouth (Warren 1991 in Tripathi and Bhattarya 2004). According to Minang (2007) 'local', 'indigenous', 'community', 'traditional' and 'rural peoples' knowledge and concepts have many commonalities, he maintains that the most important commonality being its localness in ownership and purposes. International policy documents such as Agenda 21 and organizations like United Nations Education, Scientific and Cultural Organization [UNESCO] recognize indigenous knowledge as a legitimate source of information for the enhancement of sustainable development (Minang 2007). Although there is acknowledgement of the divide that exists between indigenous and scientific knowledge (Agrawal 1995; Mathias 1995), the epistemological and methodological similarities between 'local' and 'scientific' knowledge are recognized by some natural resource scientists (McCall 2004 and Johnson, 1992 in Minang 2007). Johnson (1992) distinguishes traditional knowledge in an environmental context and describes it as being a body of knowledge built up by communities through generations of living close to the environment. It includes a system of classification, a set of empirical observations about the environment and a system of self-management that governs and preserves resource use (Chapter 2 ). This chapter applies the same logic to a cultural context of indigenous knowledge.

Brodnig and Mayer-Schonberger (2000), drawing from Johnson's definition, decipher a number of characteristics which are true of indigenous knowledge and also relevant for cultural commoditization. These include 1) that indigenous knowledge is in essence a geographical and cultural information system derived from and embedded in close relationship of local people with their space; 2) that the knowledge system functions like a distributed database, with members of the community serving as repositories for different types and categories of data, according to their experience, age, gender and social status; and 3 ) it is a 'scientific' system in that it consists of taxonomic structures, employs particular methodologies (for instance oral histories) and relies on its own 'experts'. McCall (2004 in Minang 2007) adds two more important dimensions of indigenous knowledge; firstly, ownership is by the community, implying that it is connected with the local social priorities. It is therefore the main resource local people own and control whilst market forces appropriate other resources. Secondly, indigenous knowledge is more holistic because of its purposiveness and context 
specificity. Minang (2007) argues that indigenous knowledge has a central role in gaining economic empowerment which implies empowerment of any community (Chapters 2 and 6). Of particular relevance in the South African tourism context is the legacy of a past that was centered on veiling black culture from view, now the same culture is on display and the women are required to showcase it to people of varied backgrounds. Ramutsindela (2007) in his analysis of the position of grassroots communities does not locate the reasons for the grassroots communities' less than enthusiastic response to a productive engagement with the culture, in the feelings of insecurity planted and nurtured by the communities' long history of engagement with Apartheid (Chapter 2). This chapter notes this gap and maintains that the development discourse is still being shaped by the government whose role in developing previously disadvantaged communities remains central. This begs the question to what extent communities are able to direct their actions in developing tourism products for economic gain.

\subsubsection{Emancipative beliefs}

Borrowing from the threefold human empowerment framework developed by Welzel (2006) which looks at the empowerment of people in terms of their objective capabilities (Sen 1984), their subjective motivations (Moser 2009), and their legal entitlements (Rai 2003, 2010) to pursue self-chosen activities and mutually agreed interests with others. Sen $(1984,1985)$ maintains that economic development empowers people on the level of their capabilities. For it widens ordinary people's objective action repertoire through increasing their material means, their intellectual skills, and their social connectivity (Chapter 6). Democratic freedoms empower people on the level of legal entitlements in that they widen people's legal action radius by granting them civil and political rights (Rai 2003). Yet, empowering people is not only about their objective action repertoire and their legal action radius. It is also about their subjective action horizon, which is shaped by people's beliefs. Emancipative beliefs widen people's subjective action horizon in making people strive for more ambitious goals in developing and expressing their personalities, in making them feel more efficacious in their actions, more comfortable in dealing with other people, especially people who are not part of their norm (Welzel and Inglehart 2008). Hence, emancipative beliefs become manifest in a syndrome of 'self-expression values' (Inglehart and Welzel 2005) they are the subjective component in a wider process of human empowerment (Chapter 2). In this process, emancipative beliefs emerge in response to socio-economic transformations that widen people's objective action repertoire (Welzel and Inglehart 2008). 
This paper combines indigenous knowledge with emancipative beliefs in the assessment of cultural commoditization. It specifically queries to what extent indigenous knowledge (that was previously suppressed) is incorporated into cultural township tourism, given its former position (Chapter 2) the chapter argues that previously disadvantaged women require emancipative beliefs to successfully bargain with their culture as a tool for economic development. The chapter posits that it is essential to continue to evaluate the place and role of culture in discussions of economic development of tourism 'whether its cultural place be the individual (as representative of some wider spatial scale), the firm, the region or the nation-state' (Crang 1997: 12).

\subsubsection{Study context}

Black South Africans involvement in the tourism industry has been of increasing importance in recent decades. The demand for township tourism experiences has been growing over the years in post-apartheid South Africa and after the successful hosting of the Soccer World Cup 2010 (Olutola and Mofokeng 2010). Township tourism products and imagery are significant to the South African tourism industry because marketing cultural township tourism product helps create and brand 'rainbow nation' South Africa and distinguish the country as a destination in a highly competitive market (see Selling Australia 2001). The irony, however, is the black South African communities relied upon to supply this product are facing much bigger issues simultaneously (Magi and Nzama 2009). While tourism from a mainstream perspective appears to be a frivolous activity because it is concerned with pleasure, luxury and enjoyment, from an indigenous perspective it is a much more serious topic. Challenges of health care, education, access to clean water, electricity and energy remain burning concerns for these communities. This situation is similar to that of Australia in the run up to the 2000 Sydney Olympics, the Aboriginal peoples who became a focus in the international media spotlight and were the delight of the Opening Ceremonies were suffering Third World levels of poverty, ill-health and premature death rates (Pilger 2000). The chapter views black South African involvement in contemporary tourism within the context of apartheid history and politics from which it developed. In former times black participation in tourism was limited to menial labour positions, as such black South Africans involvement in tourism has an important historical context that is distinct from that of mainstream tourism operators and the tourism industry. This context reveals that when black South Africans engage with tourism they may be simultaneously attempting to secure their native title rights, build the self-esteem of their heritage through revival of culture and secure a reconciled community in which 
their children can grow up in safety and comfort - as well as the obvious economic benefits that tourism can provide.

\subsection{Methodology}

The research investigation of this chapter embraces the epistemological assumptions of an interpretive study. The methodological approach follows hermeneutics thought, using a single case study design. Using this attitude, the researcher strives to be open to the 'other' and to attempt to see the world freshly, in a different way. The "process has been described variously as disciplined naïveté, bridled dwelling, and/or the process of retaining an empathic wonderment in the face of the world" (Finlay 2008: 6). For over six years, the research site under investigation positioned itself as a cultural tourism destination as a way of promoting economic self-reliance among previously disadvantaged women. Employing a mixed methods approach, data were collected using various techniques including; personal interviews, documents analyses, and three mini questionnaire surveys combined with discussion sessions. Drawing on works of Schein (1987), Ray (2001) and Bourdieu (1987), an integrative theoretical framework (indigenous knowledge and emancipative beliefs) was constructed to help explain how local culture, a social construct of community, becomes a commodity for tourism consumption aimed at creating a resilient society through the management of its natural resources, and to reveal some potential implications associated with the process. Within the context of the adopted methodological approach, it is of importance to note that as a researcher the author needed to face, address and question the assumed more or less implicit role as judge of development and/or culture pronouncing a verdict of cultural misconception.

\subsubsection{The student overnight home-stay experience}

As a scholar investigating tourism and culture, taking, gestures, opinions and statements seriously is a vital part of research and of the employed methodology. Through interviews and mini questionnaire surveys supplemented by discussion sessions and document analysis the study goes beyond the descriptive 'whats' of cultural tourism to also afford answers or perspectives to more subjective and explorative 'whys' and 'hows'. In the context of cultural commoditization, the aim therefore is to understand why and how culture is created and how it can be conceptualized. Based on this normative research agenda, how does one justify not using the concept of difference as the starting point of analyses, when there are 
claims, that differences are the cause and background for cultural commoditization? The aim is not to reject the fact that differences can also cause misconceptions of culture, but rather to provide a different and hopefully more analytical view of cultural commoditization. The point is that seeking explanations in culture and human differences may very easily, result in the halting of juxtapositions between individuals or groups already pointed out as disproportionate. The paper draws on data from semi-structured interviews and 'before' and 'after' workshops where participant home-stay overnight visits evaluation surveys conducted by three groups of students in November and December 2009. A total of 18 students across three groups participated in the study (see Table 7.1 below). The groups comprised different nationalities and sexes as detailed in Table 7.1. The students were credited with academic points after full completion of all stated requirements of the home-stay visit by their study institution where the author is a visiting research fellow.

Table 7.1: Composition of student groups

\begin{tabular}{|c|c|c|c|c|c|c|c|c|c|}
\hline \multirow[b]{3}{*}{ Nationality } & \multicolumn{3}{|c|}{ Group KL } & \multicolumn{3}{|c|}{ Group KK } & \multicolumn{3}{|c|}{ Group KE } \\
\hline & \multicolumn{2}{|c|}{ Sex } & \multirow[b]{2}{*}{ Total } & \multicolumn{2}{|c|}{ Sex } & \multirow[b]{2}{*}{ Total } & \multicolumn{2}{|c|}{ Sex } & \multirow[b]{2}{*}{ Total } \\
\hline & Male & Female & & Male & Female & & Male & Female & \\
\hline South African & - & 2 & 2 & 2 & 3 & 5 & - & 4 & 4 \\
\hline Ghanaian & - & 1 & 1 & - & - & 0 & - & - & - \\
\hline German & - & 1 & 1 & - & - & 0 & 1 & 1 & 2 \\
\hline Dutch & - & 2 & 2 & & - & 0 & - & - & 0 \\
\hline Russian & - & 1 & 1 & - & - & 0 & - & - & 0 \\
\hline Researcher & - & 1 & 1 & - & 1 & 1 & - & 1 & 1 \\
\hline Total & 0 & 8 & 8 & 2 & 4 & 6 & 1 & 6 & 7 \\
\hline
\end{tabular}

Participation was voluntary; hence the group composition was determined by the students' availability. Illustrations in Table 7.1 show that South African students were part of the home-stay visits, it is noteworthy to highlight that only black students volunteered to participate. It is also important to mention that the decision before arriving at the home-stays was that female students would room together and the same for males. The home-stays were selected based on their capacity to house the respective groups, a total of ten home-stays were approached but seven turned us down as they could not accommodate the group for different reasons. For four of the homes this was because the visits fell during the school term the families' could not arrange for their children to go stay with family members as they normally do during the festival period which occurs during the school holidays. At the time two of the home-stay operators approached had travelled and another operator was hospitalized. 


\subsection{Results}

\subsubsection{Student-guest feedback}

It was important to gather feedback from both the students and women home-stay operators. This process began prior to leaving the hospitality and tourism institute when, as an academic course activity, the students were required to briefly describe what they envisaged home life to be like in Joza Township in a mini questionnaire survey. Upon return from the overnight stay, the students were also required to describe their 'actual' experience. This allowed for a 'before' and 'after' introspective look at the respondents opinions and possible insight into any variations between the 'perceived' and 'actual' experiences. The responses regarding the home-stay experiences are tabulated below in Tables 7.2; 7.3 and 7.4.

\subsubsection{Interpretation of Table $K L$}

Some interesting points came out in the students' responses, for instance, Table $2 \mathrm{a}$ above illustrates how for the majority of the participants their value of experience actually went up after their home-stay visits. The responses from all non-South Africans (KL-G1; KL-D1; KL-D2; KL-R and KL-Gh) in the group highlight the forging of some level of a bond with the host family, despite the short duration of the visit. This is epitomized by statements by KL-D1 like "I think the home-stay experience in so many ways is the highlight of my stay in South Africa ... close knit way of life..." While KL-D2 proffers "... I would come back just to hang with my host family again". It is notable that the participants compared their experiences to German and Ghanaian lifestyles, KL-Gh stated that the visit "... was just like Ghana". The comment regarding cleanliness and neatness by KL-G1 is an interesting observation that can be interpreted as either complementarily and/or derogatory in nature. On a separate matter KL-R captures well a very relevant argument in the South African context "... what I found unpalatable in South Africa is how poverty it is defined almost completely along skin color". While KLD1 brought up a similar issue when she refers to the difference in standards of the 'white' and 'black' areas and expresses surprise that "inside the home-stay it was very clean". It is interesting to note that the South African students' 'actual' write ups were largely reminiscent and nostalgic, comments like "... visit with one of my relations" (KLSA1) or "a night that is as close to a home experience ..." (KL-SA2) were common. 
Table 7.2: Group KL - Student perceptions of home-stay overnight experience

\begin{tabular}{|c|c|c|}
\hline & & Group KL \\
\hline Participants & Perceived Experience & Actual Experience \\
\hline KL -G1 & $\begin{array}{l}\text { 1. Will get to experience their life, even if } \\
\text { it is only a little piece of it for a very } \\
\text { limited time } \\
\text { 2. Expect to experience South African } \\
\text { food and décor }\end{array}$ & $\begin{array}{l}\text { 1. Closer knit to community and extended family, closer engagement } \\
\text { with the land than average German citizen - less stress, more } \\
\text { engagement in human valuable life ways } \\
\text { 2. Much more concern with cleanliness [and] neatness than expected. } \\
\text { 3. It was a great opportunity to see a different way of life, I really } \\
\text { enjoyed the limited time we shared with the host family, I would } \\
\text { have loved to interact more with the host family } \\
\text { 4. Enjoyed the evening walk around the township }\end{array}$ \\
\hline KL-D1 & $\begin{array}{l}\text { 1. I envisage it will be a setting where } \\
\text { people will be laughing, understanding } \\
\text { each other without lots of explanation } \\
\text { 2. African décor and the ambience, } \\
\text { maybe we will meet a 'Zulu Warrior' - I } \\
\text { am excited }\end{array}$ & $\begin{array}{l}\text { 1. I think the home-stay experience in so many ways is the highlight of } \\
\text { my stay in South Africa so far, from what I observed in the limited } \\
\text { time we had; a Pleasant, unencumbered, close knit way of life with } \\
\text { extended family members. } \\
\text { 2. The Township was very dirty with bad roads a real contrast to the } \\
\text { almost 'paradise' where the school is located, surprisingly inside the } \\
\text { home-stay it was very clean and the décor was very modern - it was } \\
\text { beautiful } \\
\text { 3. No Zulu warriors here found out it is actually Xhosa land - My } \\
\text { ignorance is so embarrassing! } \\
\text { 4. Loved the little tour on foot }\end{array}$ \\
\hline KL-D2 & $\begin{array}{l}\text { 1. To experience daily life in the } \\
\text { townships } \\
\text { 2. I look forward to the entertainment } \\
\text { 3. Cultural Exchange }\end{array}$ & $\begin{array}{l}\text { 1. The home stay was an invaluable experience that I would not give up } \\
\text { for the world and has truly changed my outlook on life. If I could, I } \\
\text { would come back just to hang out with my host family again } \\
\text { 2. The furnishings were very Western I expected to see more African } \\
\text { décor - I guess what you see on African documentaries } \\
\text { 3. The walk was lovely it was good to explore }\end{array}$ \\
\hline KL-R & $\begin{array}{l}\text { To participate firsthand cultural exchange, } \\
\text { I hope to experience their } \\
\text { 1. Food } \\
\text { 2. History } \\
\text { 3. Music and Dance }\end{array}$ & $\begin{array}{l}\text { 1. The disparity between the environment around the location of the } \\
\text { school and the Township is so huge. Poverty itself is not shocking; } \\
\text { this is present in every country, in every society. What I found } \\
\text { unpalatable in South Africa is how poverty it is defined almost } \\
\text { completely along skin color. } \\
\text { 2. The ambience was so welcoming and the home was well furnished } \\
\text { and very comfortable } \\
\text { 3. The hostess was very kind and so accommodating of us taking over } \\
\text { her space } \\
\text { 4. Would have loved to interact with the host and her family more, } \\
\text { wanted to know about her history and life } \\
\text { 5. Did not really enjoy the walk, it felt like the locals we gazing at us in } \\
\text { their space, there was no interaction, it was 'us' and 'them'. }\end{array}$ \\
\hline KL- Gh & $\begin{array}{l}\text { 1. To share in elements of their space, } \\
\text { food and culture } \\
\text { 2. I hope to hear stories about South } \\
\text { Africa }\end{array}$ & $\begin{array}{l}\text { 1. Lots of conversation and human togetherness - it was just like } \\
\text { Ghana } \\
\text { 2. Wanted to talk to the owner, but maybe she was not comfortable, I } \\
\text { respect her reasons to keeping to herself, she had already opened } \\
\text { her home to us - I feel so honored }\end{array}$ \\
\hline KL-SA1 & $\begin{array}{l}\text { 1. I imagine it will be like going to visit } \\
\text { with one of my relations }\end{array}$ & $\begin{array}{l}\text { 1. Perfect, exactly as I thought it would be - the dumplings were } \\
\text { delicious } \\
\text { 2. Lovely home, lovely décor } \\
\text { 3. I will definitely go back, would love to hear her story - she inspired } \\
\text { me, even in the Location we can do things to change our lives. There } \\
\text { is no excuse. }\end{array}$ \\
\hline KL-SA2 & $\begin{array}{l}\text { 1. To have a night that is as close to a } \\
\text { home experience as possible in the } \\
\text { middle of the semester }\end{array}$ & $\begin{array}{l}\text { 1. Just what the doctor ordered, the atmosphere the food and the host } \\
\text { were truly a Xhosa experience } \\
\text { 2. Very encouraging, this is an example to the community that you can } \\
\text { be the positive change you want to see in the world. }\end{array}$ \\
\hline
\end{tabular}


Additionally, participants KL-SA1 and KL-SA2 spoke of being inspired by the project, describing that the home-stays as a vehicle to showcase black culture in the 'Location' (also known as the Township) in a more positive light. A common theme to emerge among all participants centered on the food served, all concurred that the food was delicious. The limited time and lack of interaction with the host family were also points that were raised by all participants. In (Picture 7.1) Group KL is shown just before dinner with the owner of the home-stay.

Picture 7.1: Dinner at Kwa Lulu's

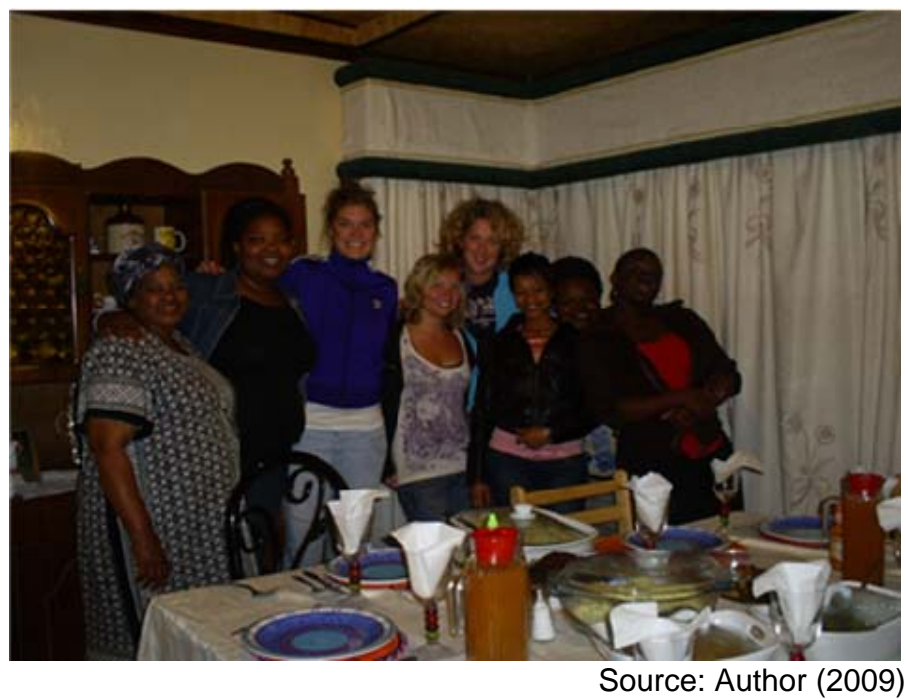

\subsubsection{Interpretation of Table KK}

Responses from the South African students in Table 7.3 were akin to those of South African students in Table 2. An analysis of the responses shows that the South African students did not highlight an interest to learn cultural exchange. Rather, the statements were brief and all emphasized a much anticipated 'home-coming' experience. Comments like "I think it will be a fun overnight stay" by KK-SA3 reflected a popular outlook among the participants. An interesting theme to emerge in the 'actual' commentaries from this group was a new gained sense of cultural appreciation and pride within a tourism context. This analysis is solidified by a statement issued by KK-SA4 "I never thought of our way of life as a tourism product". In the same vein KKSA5 writes "I felt so proud to be Xhosa" while KK-SA1 reports that "It was also encouraging to hear and see the efforts of the home-stay owner ..." other issues also arising with group KK as with group KL centered on the enjoyable food and the homelike feeling of the visit. 
Table 7.3: Group KK- Student perceptions of home-stay overnight experience

\begin{tabular}{|c|c|c|}
\hline \multicolumn{3}{|r|}{ Group KK } \\
\hline Participants & Perceived Experience & Actual Experience \\
\hline KK-SA1 & 1. I expect that it will end too soon. & $\begin{array}{l}\text { 1. I really enjoyed myself, it was like being at home, I have relatives } \\
\text { who live exactly like this. } \\
\text { 2. It was also encouraging to hear and see the efforts of the home-stay } \\
\text { owner and her dressing up in Xhosa traditional dress was so heart } \\
\text { home warming. }\end{array}$ \\
\hline KK-SA2 & $\begin{array}{l}\text { 1. It will be a much needed break I am tired } \\
\text { of the 'beachfront' life and all that comes } \\
\text { with it. }\end{array}$ & $\begin{array}{l}\text { 1. I loved it, home cooked food, just like home. It was exciting to talk } \\
\text { with the host. } \\
\text { 2. I did not now that black culture was this sellable because it is our } \\
\text { way of life, even though my parents now live in the suburbs. It would } \\
\text { have never occurred to go to the township for a holiday, or to relax, } \\
\text { it was so nice in a back to roots kind of way. }\end{array}$ \\
\hline KK-SA3 & 1. I think it will be a fun overnight stay & $\begin{array}{l}\text { 1. Oh so refreshing, I wish I could do this every week. } \\
\text { 2. It allowed me to see that tourism is everywhere not in just in } 5 \text { star } \\
\text { white owned operations. } \\
\text { 3. I was also proud to see the township reflected in a positive light. }\end{array}$ \\
\hline KK-SA4 & 1. A chance to interact in a Xhosa setting & $\begin{array}{l}\text { 1. Had a great time would do it again, wish we had more time. } \\
\text { 2. It was inspiring to hear about the history of the home-stay. I would } \\
\text { have never thought of our way of life as a tourism product. }\end{array}$ \\
\hline KK-SA5 & $\begin{array}{l}\text { 1. I am confident there will be good home } \\
\text { cooking in a very warm and welcoming } \\
\text { atmosphere }\end{array}$ & $\begin{array}{l}\text { 1. It was like going home and the food was just what I needed, this is } \\
\text { how we live, lovely experience shared with University friends. } \\
\text { 2. I felt so proud to be Xhosa. }\end{array}$ \\
\hline
\end{tabular}

Table 7.4: Group C - Student perceptions of home-stay overnight experience

\begin{tabular}{|c|c|c|}
\hline \multicolumn{3}{|c|}{ Group KE } \\
\hline Participants & Perceived Experience & Actual Experience \\
\hline KE-G1 & $\begin{array}{l}\text { 1. A chance for an authentic African cultural } \\
\text { experience } \\
\text { 2. Look forward to tasting African food }\end{array}$ & $\begin{array}{l}\text { 1.I noticed that for breakfast she used numerous imported } \\
\text { packaged products including canned beans, boxed juice and } \\
\text { cereal. This may be what her family eats every day, which is one } \\
\text { thing. It may be that she expects we like it. }\end{array}$ \\
\hline KE-G2 & $\begin{array}{l}\text { 1. An opportunity to interact with the family on } \\
\text { their own terms and in their space } \\
\text { 2. Music and dance }\end{array}$ & $\begin{array}{l}\text { 1. Given the amount of time I think that it would have been much } \\
\text { more beneficial to stay with the family two nights, it is absurd to } \\
\text { presume that I learned any real thing about their daily lives }\end{array}$ \\
\hline KE-SA1 & $\begin{array}{l}\text { 1. Will be presented with a place and chance } \\
\text { to unwind }\end{array}$ & $\begin{array}{l}\text { 1. Wanted to make plans for more things to do with the family, but } \\
\text { we didn't have enough time } \\
\text { 2. The food was amazing } \\
\text { 3. Provided insights on the importance of preserving black culture } \\
\text { and heritage }\end{array}$ \\
\hline KE-SA2 & $\begin{array}{l}\text { 1. I am looking forward to really good food and } \\
\text { good company }\end{array}$ & $\begin{array}{l}\text { 1. The host did not really interact with us. } \\
\text { 2. She served us excellent food and retreated with her family to an } \\
\text { out building. It would have been more enjoyable to have her } \\
\text { interact more with us. } \\
\text { 3. There were many valuable lessons in terms of advancement } \\
\text { opportunities. }\end{array}$ \\
\hline KE-SA3 & $\begin{array}{l}\text { 1. Fun filled evening with school friends which } \\
\text { will allow for interaction in an African setting }\end{array}$ & $\begin{array}{l}\text { 1. We spent very little time with the family but they still provided a } \\
\text { wonderful and relaxing experience in their home. } \\
\text { 2. Great home food! } \\
\text { 3. Gained insight on government involvement in poverty alleviation } \\
\text { at the grassroots level. }\end{array}$ \\
\hline KE-SA4 & $\begin{array}{l}\text { 1. Simply put I know this will be a fun } \\
\text { experience }\end{array}$ & $\begin{array}{l}\text { 1). It was like going to my grandparents, } \\
\text { 2). More interaction and time with the host family would have } \\
\text { enhanced the experience especially for the foreigners who do not } \\
\text { know much about our culture. } \\
\text { 3). A good example of empowerment for the children in the } \\
\text { community. }\end{array}$ \\
\hline
\end{tabular}




\subsubsection{Interpretation of Table KE}

Findings show that respondent KE-G1 had high expectations for an 'authentic cultural experience' and some disappointment is evident in the 'actual' commentary stating "... used numerous packaged products ... This may be what her family eats every day, which is one thing. It may be that she expects we like it". It is conceivable that this is what her family eats every day because responses from the South African participants (KE-SA1, KE-SA2 and KE-SA3) in the group emphasized their enjoyment and alerted their familiarity with the food served with statements like "great home food" and "the food was amazing". Again an important observation made by the majority of participants in this group concerned the limited time of the visit; participants felt that the time was too short with KE-G2 vehemently stating that "given the amount of time I think that it would have been much more beneficial to stay with the family two nights, it is absurd to presume that I learned any real thing about their daily lives". Likewise, KE-SA4 reiterated this stating that "more interaction and time with the host family would have enhanced the experience especially for the foreigners who do not know much about our culture". All respondents agreed that the hostesses extended hospitality of an impeccable standard. As with the other two groups the South African participants made reference to an awareness rising on their part on the benefits of such a project implemented in and for the Township. Participant KE-SA4 highlighted that "this is a good example of empowerment for the children in the community" while KE-SA1 indicated that the visit "provided insights on the importance of preserving black culture and heritage". While student KE-SA3 wrote that "gained insight on government involvement in poverty alleviation at the grassroots level".

\subsubsection{Integrated summary of tables}

In the responses that remained unchanged in the groups, the 'perceived' and 'actual' descriptions were positive. In the responses with variance some things stand out. Most predictably, the majority of responses collected after the visit to the home-stays were more detailed and informative than those collected before the visit. Despite the fact that the perceived value of the experience dropped for some, it appears it was still a positive learning experience for most involved. It is also important to note that it is possible that several different experiences from the trip comprise the formation of the 'actual' experience. Therefore, changes in 'perceived' and 'actual' descriptions by participants may be the result of personal enjoyment of one experience over another and not necessarily a positive or negative criticism of the home-stay. In looking at the responses of those students whose perception of value went down in the 'actual' responses the main grievance was linked to lack of cultural emphasis and limited time. A number of participants spoke of a lack of interaction with the host family and limited 
access to the township in general. For those participants whose responses went unchanged, several had close to the same descriptions to both. In this sense, the author is convinced that the experience was important as such it is more beneficial to deduce their encounters from their own words.

\subsubsection{Kwam eMakana hosts' feedback - Informal discussions}

As part of the overnight visit, through the project officer and prior to arrival the author scheduled discussions with the women to be held after breakfast on the morning of the departure. There are some interesting issues arising to note. Most commonly, the women expressed a deep appreciation for the patronage and the income realized. KLHO gratefully stated "thank you so much for coming with the students, I can finish work on my extension" (structural expansion of her house) and KK-HO indicated that the money from the visit will help with University costs for her daughter, she was very appreciative. The impression gained was the women were not upset about the limited time spent instead a sense of gratitude for the visit was relayed, that said they would have been happier for longer stays. Interestingly, the women did not express any disappointment about the lack of interaction rather it emerged that they were trained to conduct themselves in this way by the government funded training programme they received at the onset of the project. When asked why she did not interact with her guests KL-HO, responded "we were told to give guests their space during the training, so I do not want to disturb my guests". Likewise, KE-HO reiterated the same, pronouncing that "the guests will be tired" and that she did not want to bother them with "our ways".

Another issue to emerge is related to inquiries on menu selection. According KK-HO currently she serves mainly Xhosa food because she has not received culinary training, in her words "when I make enough money I will take cooking lessons and I will be able to make really special dishes". On the other hand KL-HO served more western dishes when asked for reasons of her choice of food, she served, she looked away and said in a low voice "[sighs] our food is complicated, I don't think people will like it". Similarly, KE-HO was not keen on preparing Xhosa meals citing similar reasons as her counterpart (KL-HO). Related to the issue of food the researcher also inquired if the families ate similar meals as served all the time and the answer was an emphatic "No it is too expensive" from all three women. The food in all houses was a selection of dishes - actually an elaborate buffet of a very high quality. On a separate issue the women operators were unanimous that their costs are high and the government's set prices were constraining their profits. When probed on why they do not charge prices 
that are more reflective of the costs they incur. The women indicated they did not have the mandate to independently set the price during the festival period - the busiest period and for most the only time they receive guests all year. Notwithstanding, all the issues it seemed that all of the women enjoyed spending time with the students and expressed a desire to have had them stay longer and all women indicated that they really enjoy hosting people in their homes.

\subsubsection{Post home-stay visit workshop}

On the drive back with the project officer while discussing the home-stays the author made the most astounding and enlightening discovery when the project officer stated "you know what makes me so angry ... [sighs and clinches steering wheel] ... most of the officials do not stay in the home-stays, ... so some of the home-stays receive bookings and payment but no guests show up!" Upon returning to Port Alfred, the author set up a follow-up student participants' workshop, the students were required to provide open-ended commentaries on the same mini questionnaire they had filled in prior to the home-stay visit. After the questionnaires were collected the students engaged in an open-ended discussion on their home-stay experience in a group setting the author tape recorded the discussion. The purpose was specifically to provide the researcher/author with further data by which to assess the participants' home-stay experiences. All of the 18 students participated in the requested commentary and discussion session - an excellent response rate - though admittedly this was in part connected to the course credits to be awarded on the completion of all required participatory steps. The issue of limited time came up so much that upon deeper reflection it became apparent to the researcher that the insights to this study might be compromised owing to the time factor and the limited interaction with the host family. Additional concern was raised on lack of access to the township at large. These matters were taken into account perhaps the host families might have warmed to the guests over a longer period. This might have been the case however the decision to stay one night was linked to budget considerations as the researcher had a limited budget. That said in the real world the host families can get a booking for one night stay and likewise for the guests, it is up to both parties (hosts and guests) to maximize the experience to learn about each other's culture. Moreover, this platform presents much needed promotional opportunities for the hostesses through repeat clients and/or word of mouth marketing.

There were no instances in the commentaries or during the discussion sessions where negative aspects outweigh the positive and many of the responses offered during the 
discussion session contain insightful and notable quotes. The following quotes come from different participants:

KE-G2 -"As a Westerner the home stay was an invaluable experience that I would not give up for the world ..."

KK-SA3 - "The hostess proves that life is more than 'things'. As I heard from our host, 'there is no such thing as 'a good day', every day is a good day".

Several common themes came up in the home stay commentaries. Many participants wrote positively about the meals, the decor and details about the hospitality but just as intuitive were some of the 'negative' aspects of the experience.

KL-Gh - "The only negative was that I wanted to make plans to do more things in the community, but we didn't have enough time or another day to stay there".

KL-D2 - "I really wanted to learn more about the history of South Africa from the people that experienced the struggle for freedom - however in retrospect this might be a very painful thing to expect a host to recount every time foreign guests come by".

\subsection{Discussion}

According to Ashworth (2009) culture, deeply embedded in the history and development of community, is considered the bloodline of any community. However, much of this culture is not visible; much is deeply hidden beneath the surface and remains sacred to the community. Schein (1987) likens this phenomenon to an iceberg. Thus, many of the impacts of various forces, such as tourism, on local culture are not clearly evident; neither are they easily measurable nor explainable. While culture is implicit in tourism, the paltry research and literature which does exist generally focuses on heritage and cultural tourism development within a larger global context (Featherstone 1995; Boniface 1998; McIntosh et al. 2000; Meethan 2001; Ashworth 2004). The indigenous knowledge and emancipative beliefs focus of this research may have significant implications for the building of resilient societies through management of their natural resources.

\subsubsection{Staged authenticity}

Indigenous Knowledge - Reviews from respondents across all the three groups highlighted the memorable hospitality extended by all the operators. This is not surprising, in African culture there is a generic concept of 'Ubuntu', loosely translated; it refers to the humanity that one extends to fellow humans. Of importance under this ideology is the welcome that one extends to their guests. Hosts are prepared to offer 
the best part of their home and food to their guests because by visiting, guests bestow honor and blessings on the host. This corroborates the responses from the students who were complementary of the food and the hospitality extended to them. The 'Ubuntu' extended to the guests goes a long way in explaining why all the students highlighted that their time at the home-stay was too short and why all the home-stays received excellent reviews concerning the welcome and the hospitality extended.

Emancipative Beliefs -The lack of interaction with the host family emerged as a common theme among the students - there was definitely disappointment for the guests. The retreating of the host families to what MacCannell (1973) terms 'back spaces' after serving the food exacerbated the sense of diminished cultural interaction for the guests. MacCannell (1973) locates space and its usage within the context of tourism settings building upon earlier work by Goffman (1959) who identified behavior associated with front and back regions. In this context the host family adopts an operational system similar to that of a guest lodge and in the spectrum of cultural home-stays this is a loss to both host and guest.

Cultural Commoditization - An analysis of the remark about the packaged foods reveals another interesting and relevant observation in the cultural commoditization process. It is plausible that the family frequently eats most of the products as they are readily available in supermarkets. Connected to this matter is the urban setting of the homestays, had they been in a rural setting perhaps there might have been less of packaged foods (see Appendix 3). It can be argued this is what KE-G1 was seeking when she signed up for what was marketed as a 'cultural home-stay experience'. At the same time it is also conceivable that the extent to which these products were available might be deliberate, in an attempt to provide the guests with what is familiar to them. When juxtaposed with the operators' admittance that they do not eat the same dishes every day because it is too expensive. From a perspective focusing on difference, these statements clearly highlight the culture of Joza Township as unique by connecting it to food, décor and hereby setting up a contrast. By stating "may be what her family eats everyday" (and hence its culture and people), the home-stay culture, cultural differences as well as cultural misconceptions are perceived and explained in this case as structurally embedded. This finding adds weight to the remark raised in literature by Kapner (1996) that traditionally many local people in South Africa did not hold their own cuisine in high regard, and often viewed it as not being sophisticated enough and definitely not something a tourist would want (see Appendix 3). Briedenhann and Wickens (2004) maintain that unless a community realizes the economic value of their heritage, they themselves are likely to destroy it and with it also the foundation of 
their tourism potential. Of course the women and their families have these dishes but they are not the 'normal' Tuesday dinner or breakfast. This brings into focus the issue of 'authentic African culture' (see Appendix 3), as with all cultures there are challenges with preserving cultural authenticity. Culture everywhere is dynamic and ever changing, in the same sphere it begs the question what is 'authentic African culture'.

The host family serving boxed cereal, jam, canned beans might represent a true and genuine experience for them; indicating how their culture has evolved. In this instance it might be that the experience that the tourists are seeking might no longer exist in its original form in this case traditional Xhosa cuisine has been influenced by and many elements have been adapted to modern conveniences. Modern Xhosa Cuisine has adapted a variety of processed foods this can be attributed to comment made by KEG1 concerning the packaged foods highlights a relevant question similar to one posed by Nadine Fiaux "is it then that the western view of authenticity is actually fostering poverty in other parts of the world for their own benefit?" This makes a case for the observations raised in literature that highlight the interactions among the technologies of food production and processing, the refinement of packaging to entice consumption (Hine 1995) as factors for consideration with regard authentic cuisine. It can be questioned whether culture should be preserved in a certain state. Fainstein (2007) maintains that this scenario presents a dichotomy as turning a culture into something static when it is actually constantly evolving implies that it is no longer natural. Fiaux posits that it is self-serving to say that certain cultures should not progress so that tourists can enjoy it during their holiday and then happily return to their 'developed' world afterwards.

Hayes and MacLeod (2007) propose that interpretation is a key requirement to engage the visitor in a memorable experience. Pine and Gilmore (1999: 46-47) suggest that the experience should have a - "compelling and captivating theme that alters the visitor's sense of reality to something other than the everyday - for doing, learning, staying and being". In this case the home-stays need to reflect the nuances of the local culture, as visitors are attracted by the natural and cultural heritage (Hardy 2003: 326). At the same time the visitors need to seek out the adventures they desire and not expect communities to remain static for their 'weeklong' vacation. Interestingly, the South African students did not highlight an interest in cultural exchange because it is their culture hence it is not so much a learning curve but rather 'a return to the familiar'. From the analysis it appears that for the first time these hospitality and tourism management degree students saw their own culture as a viable tourism product. Comparisons were made in respect to traditional tourism establishments situated in 
'more tourist appealing locations'. Interestingly none of the foreign students made this connection that was of such importance to the South African students that each one of them brought it up in their commentaries. This is similar to Bruner's (2004) observation that particular elements, practices or spaces essential to a community's social life may be ignored by tourists when untranslatable in terms of their aesthetics and ways to understand the world. In these cases, central cultural resources remain unaesthetic and invisible to the touristic mind because they do not correspond to any meaningful category.

\subsubsection{Culture as a product}

Indigenous Knowledge - Interviews with the home-stay operators showed that the women considered themselves part of the tourist industry and not necessarily as participants in a cultural exchange program. In this way, hosts and their families do not seek to vicariously experience other cultures. Guests, who in this case are students, act as mediums through which cultural information can be conveyed findings suggest that this process was stunted. Ren (2010) maintains that a similar - or rather supplementary - discourse on cultural misconceptions working to contrast groups involved in tourism relate to development strategies. Two divergent positions are identified and one focuses on the preservation of the unique local culture against tourism, the other on active tourism development. Both discourses relate to human action, in the way that people or groups are identified or identify themselves as actively engaging in either preservation or development in regards to tourism (Ren 2010). Also, the discourses are either grounded in the relativist ideology of local culture as essentially different to others, or in the universalist idea that local culture must evolve from its present (low) stage to a future higher one, often encompassed as European or international (Ren 2010). The latter can be argued to be the case with Kwam eMakana, where the government offered training and operational parameters that do not necessarily encourage local culture.

Emancipative Beliefs - Findings from the study reveal challenges with the conceptualization of culture as a commodity for the tourism home-stays. It appears the misconception of culture is rooted in the project design; culture was never highlighted as the primary product of the home-stays, in fact it was not identified at all. As such it throws important considerations of the institutional structure of the project (Chapter 5). From the interviews it emerged that the government offered hospitality training and it can be argued that the training diluted the women's cultural influence in the delivery and interaction with guests as displayed during the overnight 
visits. This emphasis of the training appears to have been on making the home-stays contemporary so as to appeal to international guests by offering the familiar. The results corroborate with other findings that tourists want to experience difference from their normal lives (Briedenhann and Wickens 2004). This misconception speaks to the emancipative beliefs that the women hold over their cultural identity and is comparable to Koutra's, (2007) observation that colonialism did not manage to 'reterritorialise' Ghana to the extent that it would entirely suppress the local mentality and culture, they left behind remnants in the subconscious of local people. This is seen in their beliefs that anything foreign is superior to their culture. This is an issue in all former African colonies (Koutra 2007) for example Algeria, Senegal, Zambia, Kenya and Mozambique to name only but five.

In connection with tourism local people believe that foreign visitors will not be keen on experiencing anything they are not familiar with, and that depicts local cultural elements. Mercer et al. (2003) argue ignorance in the past was detrimental to the African states because it halted development. In modern times the halting of development is demanded in part by tourists who demand for rustic and natural environments to holiday. The main reason tourists visit places is to experience the local culture, either by staying in accommodation that is typical of the local character or/and by tasting local food. This is connected to the snubbing of the home-stays by government officers, what are the implications for the women in the steering of their home-stays successfully if there is no support and beliefs in the product from the government officials? What signals are being sent to the women by this action about their culture? It is possible that in their minds the impression formed is that the officers are of the mindset that the home-stays are not good enough to be tourism enterprises, this action has a double effect as the home-stays have dual roles as home and enterprise; and this impacts the women's emancipative beliefs. It is a huge blow to have the project inceptors frown on the home-stays. At the same time it says something about the government officers' emancipative beliefs given their own engagement with Apartheid.

Cultural Commoditization - Considering this background the behavior of the women is understandable, in essence the women were displaying what they were taught is more valuable to the guest, in a matter of speaking an 'enlightened' cultural conception (Ren 2010) as perceived by DSRAC. This explanation addresses the responses from the students on the issue of limited interaction and sheds light on the seemingly 'neglected' impression formed by the students/guests. These challenges are linked to how the home-stays were incepted, it is plausible that cultural commodification was 
never highlighted from the onset and unfortunately its importance downplayed. This also elucidates a lack of understanding of the product on sale at the highest level of the project and how this misconception is passed on to the hosts and finally the guests. According to Ren (2010) misconceptions are enacted through objects, places, performances and discourses as they are assembled and translated, constantly constructing and challenging opinions of what should be included. This reveals a relevant inquiry; to what extent do the home-stays offer a Xhosa cultural experience. To avoid inundation locals need to appreciate that tourism as an industry that produces cultural symbols and content for consumption. The less obvious point is that the symbols, attractions, and commodities produced by the industry have an impact on shaping social reality and urban physicality (Mbembe 2004). The power of the tourist industry to construct social reality and transform urban spaces should not be underestimated. Linked to this process is the fact that, in the course of attempts to reconstruct an identity, culture becomes "commoditized", [in that] "the once 'authentic' public ritual became a staged performance, a cultural 'commodity". (Cohen 1988: 381) These rituals and cultural activities may then "be adapted to the tastes of the tourists" (Cohen 1988: 381). This commoditization of space can lead to situations as in Johannesburg as described by Mbembe, "more than ever in its history, Johannesburg's city space is a product that is marked, measured, marketed, and transacted. It is a commodity. And as such its representational form has become even more stylized" (Mbembe 2004: 393).

In an attempt to transcend this dichotomized field, student guests' and home-stay hostesses' commentaries and narratives were presented as a relational analytical tool to surpass the focus on difference blinding other views and muting other interpretations on cultural misconceptions. Instead of ontologically seeking for proof and reasons for immanent differences or inherent mismatches between people and groups, the paper instead focuses on tracing how misconceptions are constantly and contingently created as effects through the workings of cultural commoditization. In this regard, a relational and materially sensitive approach may potentially provide richer, broader, and hence culturally more sustainable notions of destination cultures, not only in research but also in the communication, marketing and managing of destinations. The article has shown how cultural misconceptions at the destination result from human action of all stakeholders; tourists, tourism planners and operators; the argument being misconceptions are either the workings of immanent cultural structures or understood as the result of directed, intentional human action. 


\subsection{Conclusions}

Based on the empirical findings and the discussion some tentative overall conclusions related to the Kwam eMakana case can be suggested.

1. The aims of promoting cultural township tourism are two-pronged; firstly they are economic in the sense that the planners believe cultural tourism can stimulate economic growth, and the second aim which is symbolic, that of constructing a Xhosa identity in tourism as a product has been ignored.

2. The commoditization of cultural township tourism has to observe the values of the host community and natural resources to promote societies that are more economically resilient.

3. Incoming international tourists (guests) should demonstrate an increased appreciation of local cultural norms and traditions as attraction resources for example, the differences between the local Xhosa social norms and Western norms and style of living.

4. The women home-stay operators (hostesses) need to be sensitized on the importance of culture as the main product on sale in the home-stays and the need for interaction with guests for enhanced cultural exchange. 


\section{Chapter Eight}

\section{Conclusions and Recommendations}

\subsection{Introduction}

The main objective of this study is to contribute to the understanding of the dynamics of local government and project level realities that enable or inhibit the realization of BEE entrepreneurial goals in order to inform future project design. This chapter answers the main research questions of the study as presented in Chapter 1. First, the methodology used to establish the key findings of the research will be outlined. Then the key academic contributions are presented, highlighting how selected concepts are used to provide new insights to the issue of attaining BEE through entrepreneurship. Thirdly, in addressing the main objective of informing project design some recommendations are made at local government and project level. Finally, the chapter concludes with possible areas for future research.

The research seeks to answer the following main research questions;

1. What is the relationship between economic empowerment and progressive human values for the previously disadvantaged in South Africa?

2. Can entrepreneurship be taught, inspired, and diffused through a society to achieve BEE?

3. What are the most significant qualities of a successful entrepreneur, especially in the uncertain environment of a developing country context?

4. To what extent does cultural commoditization drive the economics of government LED tourism home-stays?

I approached these questions by looking at the overarching LED framework which is informed by BEE legislation. I focused on the local government and the project levels, owing to the country's commitment to 'developmental local government' achieved through the devolution of authority and development leadership to local governments (see Chapter 5). Within the parameters of the National LED framework (2006-2011) local government is required to coordinate, negotiate and manage project development and monitoring. The dual level analysis allowed for insights on the concealed and obvious influences that actors (government officials and project participants) have on each other and the power dynamics associated with the institutional arrangements in place to achieve BEE (Chapter 4). The Kwam eMakana 
project evaluation facilitated the capturing of how BEE legislation is operationalized within the LED framework.

\subsection{Methodology}

Research on BEE, to date, has been epitomized by stories published in the popular press about partnership and success strategies (see Chapter 5), and has been further characterized by small empirical studies, none of which have combined a women, tourism and a township focus. This research showed that when BEE is operationalized within a LED framework in a township tourism context to promote entrepreneurship it is not only about economic empowerment. Rather it includes various issues and not only limited to the lenses of culture, heritage, conscientisation, institutional arrangements, social interdependence and socio-spatial arrangements adopted in this study. Insights were gained through a review of the relevant literature; and contributed to the study methodology and directions (see Chapters 2 and 3). Existing research approaches and methodologies have not adequately incorporated the reality of LED in South Africa for enhancing women's entrepreneurship. The experience of women operating tourism home-stays has not been widely explored in the tourism literature and often tourism research appears to choose particular conceptions of reality over others (Murdoch and Pratt 1994). It has become clear during this research, through the triangulation of literature and the use of both quantitative and qualitative techniques, that there are actually at least two "realities" to capture:

1. The reality of what it is like - who does what? And

2. The reality of how the women home-stay operators experience this.

The methodology employed was pivotal in capturing these two realities. The quantitative research reported on in this thesis provided information about descriptions of the women operators and the home-stays, and what happens within the project (the reality of who does what?), while the qualitative part of this research offered insights into women's experiences of this - not what happens, but how it is experienced. Moreover, the key informant interviews with a cross section of experts conducted in this research meant that the challenges of the project became concrete and vivid. Exploring both 'realities' of cultural tourism home-stays in townships has shown that while BEE is laudable in principle when implemented through LED frameworks as a tool for enabling women entrepreneurial economic empowerment, various shortcomings are revealed. 
In order to ascertain to what degree social interdependence in Kwam eMakana influences the course of attaining LED the study was also interested in the interaction of the project participants within a group setting as a means for eliciting information, rather than just collecting each individual's point of view. This is the justification for carrying out a group discussion session with the women project participants straight after the dissemination of the questionnaire survey. Timing was important as this ensured that the same number and women who were the questionnaire respondents were the participants of the group discussion. Observations captured what women actually do rather than what they say they do. The purpose of the observations was to deepen the understanding of issues surrounding the compatibility of the project structure with the operations in the stimulating of entrepreneurial capabilities among the women operators. Through mini interviews with hosts and mini questionnaire surveys, supplemented by discussion session commentaries with student guests the study goes beyond the descriptive 'whats' of cultural tourism to also afford answers or perspectives to more subjective and explorative 'whys' and 'hows'. In the context of cultural commoditization, the aim to understand why and how culture is created and how it can be conceptualized was achieved.

The literature search and review processes provided secondary data for document analysis based on existing works in the areas of BEE and tourism development as a tool towards LED. This involved the use of academic and professional journals, books and the internet, supplemented by the use of the library facilities provided by the University of Twente. Books offered a holistic approach to the principles and theories that underpin this study; conscientisation, capabilities, entrepreneurship, space, spatial socialization, social interdependence, institutional arrangements, indigenous knowledge and emancipative beliefs. Official South African government reports and policies provided the government's perspective on the inclusion of previously marginalized citizens in the tourism economy as a vehicle for BEE. Publications from international development agencies such as the UNESCO and UNWTO provided a basic understanding of development in relation to 'pro-poor' growth and tourism; their merit resided in the fact that they outline policy formulation processes and guidelines for a more sustainable approach to tourism, development and poverty reduction.

\subsection{Problem Statement}

The study has established that tourism as an economic powerhouse in South Africa is not disputed. Its contribution to the marginalised communities is however 
questionable. The government's position has been to include the previously disadvantaged into the tourism economy; in this case through cultural home-stay township tourism (see Chapters 4 and 5). The following were highlighted in Chapter 1 as challenges to achieving the aforementioned:

- Inadequate education, training and awareness (capabilities) of the benefits the industry can afford the poor as partners and stakeholders;

- Weak institutional structures and capacities at all levels to promote LED tourism;

- Currently local communities are seen as tourism products rather than inputs in the product development.

These factors lead to limited integration of local communities and previously neglected groups into the tourism economy.

\subsection{Key Findings}

This study has contributed to shaping the understanding of women-related social constructions, in relation to the wider literature on home-stays and on township tourism. It has become clear, however, to the researcher that the claim that "there is some doubt as to whether current research approaches adequately incorporate the "reality" of LED in this instance enhancing women's entrepreneurship" (de Bruin et al, 2007: 329) may even understate the case. This research set out to answer the following main research questions:

\section{Research Question 1:}

What is the relationship between economic empowerment and progressive human values for the previously disadvantaged in South Africa?

To establish if there is a relationship between economic empowerment and progressive human values for the previously disadvantaged in South Africa (Chapter 2), the research examined discourses that shape BEE and identified gaps in knowledge of the relationship between entrepreneurship and BEE. Black South Africans in the townships face challenges in attaining BEE through township tourism. From the discussion in Chapter 2 it is clear that issues of culture, identity and equality remain significant in gaining BEE. The analysis of the empirical findings highlighted how the psychological damage on the black population brought about by apartheid will take 
time to correct. An oversight in the operationalization of the LED framework on the significance of the trauma is revealed. Propagation of the benefits of the industry alone are not enough to attain the much sought after BEE rather an account of the impacts institutional arrangements of apartheid should inform LED trajectory. The socio-spatial organization (townships) as defined by apartheid is of significance in achieving BEE through home-stay tourism development. To a degree, township tourism as an economic empowerment strategy reinforces a stigma for the black South Africans given that formerly everything about the township space was deemed inferior and forcibly positioned on the exterior. The show casing of the cultural heritage of this space that black South Africans were forced into has its pitfalls in view of BEE goals.

Following the post-apartheid transformation the country adopted the view that a stronger focus on equality could help find ways to promote social justice and address the neglect and misrepresentation of black culture and spaces in the township tourism context. In post-apartheid South Africa as suggested by Ashworth (2004) the heritage of apartheid, its systematic imposition of suffering and of the ultimately successful resistance to it, is central to the founding narrative of the new state, the reconciliation of its 'rainbow' constituents, and the way that the state projects itself. It will be enhanced and expanded as the state develops and will play an increasingly significant role in BEE through township tourism. The analysis in Chapter 2 shows that the future, not only of a bourgeoning township tourism industry in an economic sense but of South Africa itself, and especially of its unique multi-racial and multi-ethnic experiment in nation building, may depend upon the successful management of this past.

\section{Research Question 2:}

Can entrepreneurship be taught, inspired, and diffused through a society to achieve $B E E$ ?

With respect to the question if entrepreneurship can be taught, inspired, and diffused through a society to achieve BEE? The analysis was covered in two parts and presented as Chapters 4 and 5 . Chapter 4 shows that apartheid as a system has had profound psychological impact on the PDIs. The introduction of BEE legislation by the postapartheid government aimed to reverse the systematic economic disempowerment of the black population. BEE legislation has been driven by the need to fulfill economic and political goals, rather than social objectives. This has resulted in a focus on providing reparations for the PDIs, BEE has received criticism that blacks are 'given fish and are not taught how to fish'. Chapter 4 has shown that the establishment of BEE for 
the promotion of entrepreneurship is more than simply a case of identifying a market, funding an initiative and drawing in participants who fit a predetermined classification. Instead, what is needed is a longer, slower and perhaps more costly intervention (see Figure 8.1) first aimed at building consciousness in the black population focusing on the power of self and capabilities (Chapter 6) as witnessed in the entrepreneurially run home-stays (Chapter 4). Maathai (2006) writes "as the Green Belt Movement developed, I became convinced that we needed to identify the roots of the disempowerment that plagued the Kenyan people" the same is applicable to South Africa. The analysis in Chapter 2 supports the observations made by Mkandawire and Soludo (1999) the main issue compounding the state of 'underdevelopment' is that in this case black South African women home-stay operators for whom the LED initiative is supposed to be benefiting are generally not given the opportunity to define what development would mean to them within their context and to participate meaningfully (not as a window dressing exercise) in 'development' processes and not merely as defined by the powers that be. Findings from Chapter 4 are a good example of the argument that theories are not enough to make sense of a place (Moser 2009). Often what was thought to be economic, political, social and family structures may not in fact be that constraining; and at the same time that the agency believed in may not in fact have been that autonomous after all. This chapter presents an engagement with a place and a people that shows how places have to be understood within a cascade of relationships. It shows how township tourism home-stays have to be understood in terms of their relationship to South Africa's politics, political economy and history.

\section{Research Question 2.1:}

How do women home-stay operators negotiate formal and informal institutional arrangements to derive economic entrepreneurial empowerment through government LED cultural tourism home-stays?

In Chapter 5, I provided an overview of how the women home-stay operators negotiate formal and informal institutional arrangements to derive economic entrepreneurial empowerment through government LED cultural tourism home-stays. As shown in Chapters 6 and 7 on the project level analysis; the operationalization of BEE through the LED framework has consequences in the ways that the women homestay operators commoditize their culture. The institutional arrangements also affect how the operators respond to guests, and how they impact on their perception and experience of their establishments, given their dual roles as home and enterprise. Findings suggest that government funding without strong follow-up and advancement 
opportunities for technical skills for the project participants hinders the anticipated levels of tourism. This presents challenges for the women assuming ownership of the project. The analysis in Chapter 5 shows that the women home-stay operators are not satisfied with their present relationship with DSRAC - the women have a desire for the project to operate autonomously from DSRAC and progress to an operational environment of social interdependence. These institutional arrangements of the project ensure that the Kwam eMakana women remain financial aid recipients instead of progressing to entrepreneurs. As a result the government's role is perceived to be financial benefactor, who raises expectations of entitlement in the women. At the same time, creating a situation where the women in a sense want to remain disadvantaged so that they continue to qualify for BEE reparations where they are assured a safety net as the minimum. LED in its current form brings with it contradictions of what it means to be economical empowered, given its interpretation of the women's roles in LED and how it defines the product.

From the women's evaluation of their involvement in the project Chapter 5 shows that the concept of social interdependence is a relevant lens in the assessment of LED initiatives in that it captures what the women consider important. It reveals the women operators' struggle with negotiating tourism development processes that require the same skills that they were historically excluded from (education, business and tourism management skills). The situation is further complicated by the top-down approach in decision making which does not equip the women to establish a strong social interdependence environment. In Chapter 5 it is shown that the current focus of the home-stay initiative does not include dimensions of understanding how community shapes the person, in particular; or the conditions that facilitate both efficacy or personal control and also a sense of community. The sustainable tourism planners have not considered historical contexts of local communities and how this impacts on their development consciousness (Chapter 6). In addition, this case study shows that LED tourism developments have the potential to address women's socialeconomic and cultural needs relevant to their empowerment. This is because LED tourism ventures have the ability to incorporate less educated and historically disadvantaged women through encouragement of cultural-based and less capital intensive businesses. From the results of this study it can be concluded that the Kwam eMakana LED home-stay tourism pilot project has the potential to improve the entrepreneurial empowerment of the women through improved participation, transparency, and accountability. 


\section{Research Question 3:}

What are the most significant qualities of a successful entrepreneur, especially in the uncertain environment of a developing country context?

With respect to the question of how emotional confidence levels of the women homestay operators impact the success of tourism development for poverty reduction Chapter 6 presents a discussion on how experimentation with various developmental policies and measures has shown that people are poor, not because they are lazy or corrupt (Friedman 1992), but because aid and their policies do not work since they do not aim to combat poverty at the root due to prevailing interests (Easterly 2006; Moyo 2009). Chapter 6 lays claims that emotional competencies in the construct of El are not innate talents, but rather learned capabilities that must be worked on and can be developed to achieve outstanding performance (Goleman 1995). El is defined as a multifunctional array of interrelated emotional, personal and social abilities which influence overall ability to actively and effectively cope with demands and pressures; in other words there is a strong connection between one's personality, performance level and potential for advancement. A juxtaposition with the donor driven approach to tourism development offers a new way of assessing the viability of current LED initiatives in South Africa. The common approach to tourism development in developing countries has been to situate power with external agents and governments who are then tasked with driving the sector. It establishes development as a multidimensional course of action (Moser 1991), which entails fundamental transformations not only at an economic level with particular emphasis on the institutional and organizational culture of formal establishments, but also on the popular culture of those at the grassroots (Todaro 1994).

Chapter 6 highlights the roles of emotional and psychological conditioning born out of being poor can have; arguing that this conditioning has a bearing on how the poor will/will not engage with opportunities for development presented to them. The analysis in Chapter 6 establishes that the women operators' confidence levels represented by the El scores were low on all the four competencies, this reveals in part why the participants face difficulties in assimilating into the tourism economy. The roots of these low El competency scores are historically linked and still impact on the attitudes and behaviour patterns of the women operators towards participating in economic mainstream activities. Theoretically, the limitations to economic empowerment have to be reduced by focusing attention on the creation of a mentally and physically accommodating and conducive operating environment, to one which 
encourages 'approach behaviour' (Zeithamal and Bitner 2000). Finally, the role of confidence building is identified as integral to the raising of self-esteem of the women. Lack of confidence and self-belief is used to explain why these women are not so active in the management of the project at their disposal. The chapter concludes that government actions may prove more effective if they first focus on building confidence to develop entrepreneurial activities rather than the provision of top-down 'opportunities'.

\section{Research Question 4:}

To what extent does cultural commoditization drive the economics of government LED tourism home-stays?

In Chapter 7 I show that there is significant conflict between what is desirable for the guest and maintaining cultural integrity (Chapter 7). This throws light on the tension between the cultural and the contemporary. I examine the implications of cultural commoditization on cultural tourism home-stays and discuss how cultural misconceptions may be encompassed during human interaction in tourism. In Chapter 7 the concepts indigenous knowledge and emancipative beliefs are introduced as ways of capturing values and their potential role to minimize cultural misconceptions. Misconceptions are viewed as effects of the socio-material workings in the commoditization of townships for tourism. The chapter shows how implementing objectives of BEE at the project level, based on assumptions fail as a result of a lack of a clear contextual framework or common definitions within which local economic development can be understood, as shown in Chapter 4 (Clarke 2002 in Kaplan 2004). This approach explicates the intricate relations between cultural practices, human action and the differences in material cultures of hosts and guests during tourism transaction. Host families must negotiate these actions that can potentially cause tension, or move from desire to stigma within the space with dual roles.

In summary, the research established that the Kwam eMakana tourism home-stay pilot project has the following characteristics:

1. The promotion of the equality discourse is a necessary agent in the process of conscientisation and this is central to the overarching national goal of BEE.

2. The Government positioned itself as the owner, presenting the project to the women as recipients; hence the current institutional structures are not promoting entrepreneurial steering for the project participants. 
3. From a planning perspective, the women do not participate. Instead it appears the top-down approach is still used and this has its roots in the former highly centralized governance structure.

4. The women see their assistance from Government as aid, thus, it becomes difficult to define management responsibility and obtain entrepreneurial empowerment within the current institutional arrangements.

5. From the onset there was no framework for the hand-over of ownership to the women after having received assistance to operationalize the project, the local government remains in the driving seat.

6. The aims of promoting cultural township tourism are two-pronged; firstly they are economic (LED) in the sense that the planners believe cultural tourism can stimulate economic growth, and the second aim which is symbolic, that of constructing a Xhosa identity in tourism as a product has been ignored.

7. The commoditization of cultural township tourism has to observe the values of the host community and natural resources to promote societies that are more economically resilient.

8. Incoming international tourists (guests) should demonstrate an increased appreciation of local cultural norms and traditions as attraction resources. For example, the differences between the local Xhosa social norms and Western norms and style of living.

9. The women home-stay operators (hostesses) need to be sensitized on the importance of culture as the main product on sale in the home-stays and the need for interaction with guests for enhanced cultural exchange.

\subsection{Recommendations}

The conditions derived from this study, which are necessary for the implementation of tourism LED that address the practical challenges and promote the attainment of BEE are the introduction of:

1. Institutional arrangements that promote synergy;

2. Emotional intelligence and conscientisation.

These conditions have emerged as those that must be actively catered for in order to ensure effective application of BEE. In other words for BEE to be effectively implemented through the LED framework at project level, it is necessary to do the following: 
1. Actively promote positive driving forces at both the local government and project level; and

2. Ensure that constraining factors are continuously checked and amended at both levels.

In the ensuing sections, I will elucidate on these enabling conditions following the findings from preceding chapters.

\subsubsection{Institutional arrangements that promote synergy}

The local government and project levels in South Africa are very interconnected, this is because of the decentralized policy implementation structure in the country. Local government is tasked with the steering of policy and this is a shift from the former highly centralized structure. However, this policy changeover has not necessarily been operationalized; this is especially evident in the institutional framework of the Kwam eMakana project. Notably, at the local government level the following was established:

- The current LED framework's aid/donor approach to tourism development sees project participants as accepting and this determines the "top-down" approach to poverty reduction such that their economic empowerment hangs in the balance.

- The legacy of minimal basic education and business management skills among the project participants inevitably presents a first hurdle when seeking to operate entrepreneurial cultural tourism home-stays.

\section{Proposed action}

- The aid/donor approach should be designed and implemented to enhance participants' capacities to promote self-leadership and ownership of the development process.

- It is important to enforce institutional arrangements that allow the women operators to bear the costs, thus promoting responsibility and entrepreneurial steering. Additionally, it will foster greater cooperation, organization and collaboration (synergy) among project participants and with other tourism businesses and networks.

- An integrated approach to tourism planning and training that includes support from tourism sector, government, and academic institutions would be beneficial to project participants. 
- BEE and LED goals have to be communicated, understood and recognized by project participants, and not only by the government and the business sector, as is seemingly the case now.

Figure 8.1: Black Economic Empowerment Entrepreneurial Model

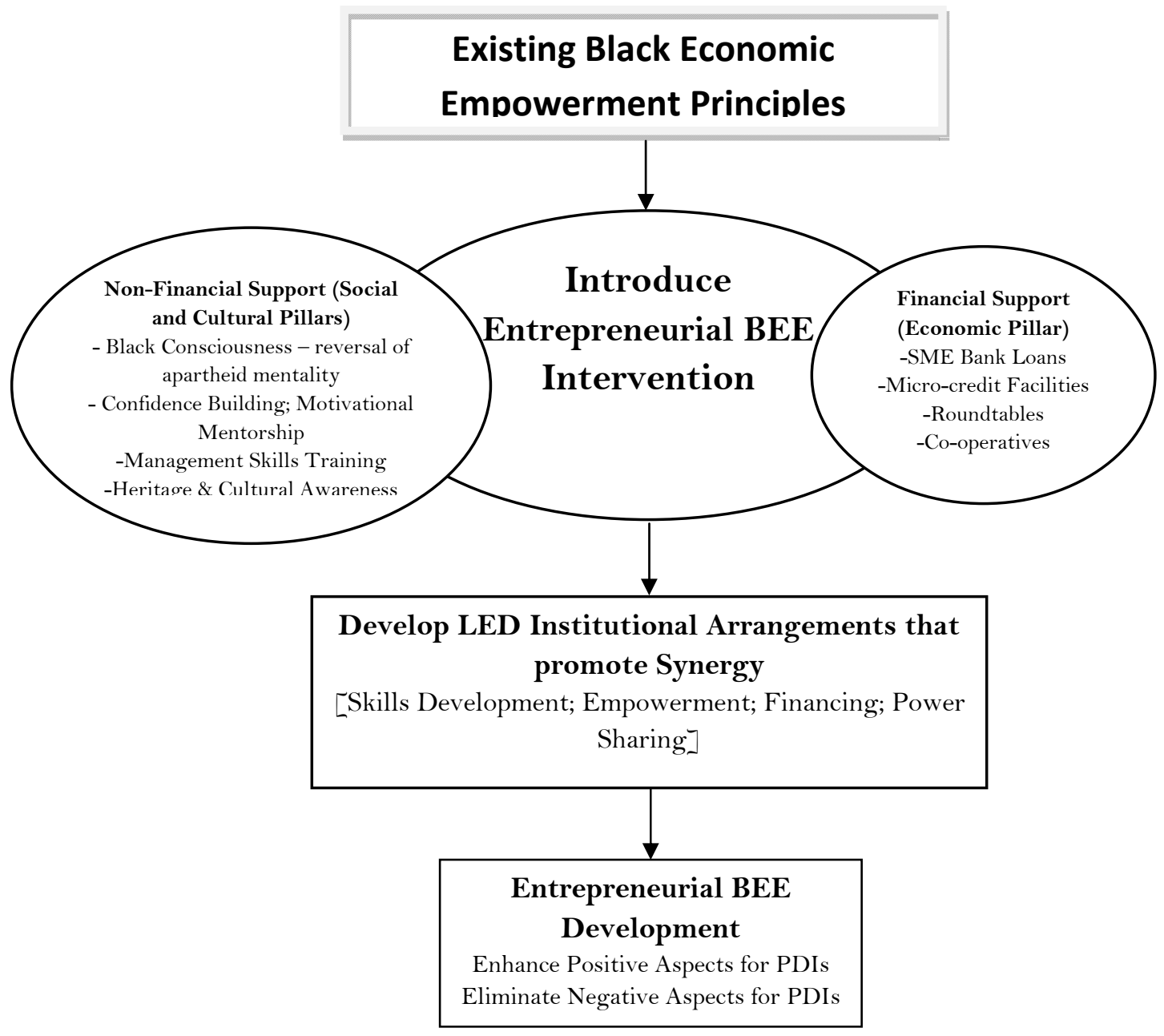

Indeed, BEE has had some economic impact in the country, the goals are commendable, however more has to be done in order to realize meaningful success. The study has shown that the aid/donor financing approach to tourism LED is less effective than the entrepreneurially driven operations as shown in Chapter 4. Undeniably, this may appear to be a more cumbersome and less appealing approach, but without a detailed intervention the goal of attaining BEE in South Africa through LED initiatives that promote entrepreneurship within the black population remains 
remote. BEE is a necessary first step in addressing the legacy of black poverty in South Africa; however, the delivery is somewhat problematic and still needs significant attention. There is need to focus not only on the economic goals, but the social and psychological pillars of empowerment need to be considered for true BEE to be attained see (Figure 8.1). There is need for diversified forms of financing that promote financial responsibility and independence in project participants.

\subsubsection{Emotional intelligence and conscientisation}

At the project level the Kwam eMakana case study showed that LED tourism developments have the potential to address women's social-economic and cultural needs relevant to their empowerment. A necessary enabling condition for project development is the presence of complementary capabilities within the LED landscape. This is to say local level LED institutions have to have capabilities to review and approve projects and to create enabling environments for entrepreneurial economic empowerment. The project participants have to extend their capacities and offer more cultural products and experiences. The possible role Apartheid played and continues to play in shaping the development consciousness and communal values needs to be taken into account when designing projects targeted at promoting LED. The situation is further complicated by the top-down approach in decision making which does not equip the women to establish a strong social interdependent environment. It is therefore important for sustainable tourism planners to consider community differences including historical contexts if BEE to achieve entrepreneurial economic empowerment. The overarching framework of this study, frames the process of conscientisation as a necessary pre-requisite to successful BEE. The study also shows the processes of conscientisation that are already occurring within the project framework as detailed in Table 8.1 below. The strength of LED framework as a tool towards poverty reduction is linked to how:

- LED tourism ventures have the ability to incorporate less educated and historically disadvantaged women through encouragement of cultural-based (natural resources - assets the already possess) and less capital intensive businesses.

- LED tourism home-stay projects have the potential to improve the entrepreneurial empowerment of the women through improved participation, transparency, and accountability.

\section{Proposed actions}

- LED tourism including community-based tourism developments should continue to be encouraged, but planned from a heritage-sensitive perspective to consider historical contexts so that they promote equality and provide sustainable benefits. 
- Promote networking capabilities with other sectors so the home-stays do not remain dependent on the government support thus curtailing the capacity needed for entrepreneurial steering.

Table 8.1: The process of Conscientisation in Kwam eMakana

\begin{tabular}{|c|c|c|c|c|}
\hline & Prise de conscience & Dialogue & 'True words' & Transformation \\
\hline $\begin{array}{l}\text { Applied to } \\
\text { Entrepreneurship } \\
\text { through LED }\end{array}$ & $\begin{array}{l}\text { Experience } \\
\text { marginalization or } \\
\text { suppression with } \\
\text { regard to LED } \\
\text { entrepreneurial } \\
\text { initiatives }\end{array}$ & $\begin{array}{l}\text { Reflecting with others } \\
\text { upon suppressed } \\
\text { initiatives. Framing or } \\
\text { naming liberating } \\
\text { discourse of LED and } \\
\text { entrepreneurship }\end{array}$ & $\begin{array}{l}\text { Using liberating } \\
\text { discourse. Take action } \\
\text { against } \\
\text { marginalization and } \\
\text { suppression }\end{array}$ & $\begin{array}{l}\text { Mobilization, } \\
\text { awareness of } \\
\text { 'entrepreneurial' } \\
\text { potential. Co- } \\
\text { ordination. } \\
\text { Organizing } \\
\text { collective action }\end{array}$ \\
\hline $\begin{array}{l}\text { Applied to Kwam } \\
\text { eMakana tourism } \\
\text { home-stays }\end{array}$ & $\begin{array}{l}\text { Historical context has } \\
\text { been seen to decrease } \\
\text { education and } \\
\text { management skills in } \\
\text { the project participants } \\
\text { which in turn } \\
\text { suppresses the self- } \\
\text { confidence }\end{array}$ & $\begin{array}{l}\text { Aid/donor approach to } \\
\text { LED. The project } \\
\text { implementation and } \\
\text { operational trajectory } \\
\text { has caused } \\
\text { dissatisfaction among } \\
\text { the women and they } \\
\text { have voiced their } \\
\text { concerns on perceived } \\
\text { notions of } \\
\text { suppression. }\end{array}$ & $\begin{array}{l}\text { Dual roles - home } \\
\text { and enterprise } \\
\text { illuminates the notion } \\
\text { of personal space } \\
\text { simultaneously utilized } \\
\text { for commercial gains. } \\
\text { The display and } \\
\text { commodification of } \\
\text { culture. Advancement } \\
\text { in Emancipative } \\
\text { Beliefs }\end{array}$ & $\begin{array}{l}\text { Increased use of } \\
\text { Indigenous } \\
\text { Knowledge which } \\
\text { will boost self- } \\
\text { confidence and } \\
\text { the Capabilities of } \\
\text { the women } \\
\text { operators }\end{array}$ \\
\hline
\end{tabular}

The role of confidence building is integral to the raising of self-esteem of the women of Kwam. Lack of confidence and self-belief could explain why these women are not so active in the management of the project at their disposal. Poverty reduction requires a shift to "expand the capabilities of people" (Sen, 1984: 497). In conclusion, government actions may prove more effective if they to focus on building confidence to develop entrepreneurial activities, the issue of reduced self-confidence presents a starting point for a training program for the women.

\subsubsection{Contributions to academic knowledge}

Ultimately this study aims to contribute to the existing body of knowledge of LED and tourism development centered on the inclusion of previously disadvantaged communities. Some of the knowledge contributions that are essential to sustain the above mentioned aim are listed below:

A fuller understanding of why most of the poor in South Africa continue to remain poor and in some cases become even poorer in the face of government LED initiatives 
I apply the concept of conscientisation (see Chapter 2) to explain the pitfalls of LED at both local government and project levels. The South African LED framework does not take due consideration of the effects of the socio-spatial arrangements established by apartheid policy and how even today they still impact the socio-economic standing of every South African. I use the trauma of those disadvantaged by apartheid as a starting point in answering why most of the poor in South Africa continue to remain poor and in some cases become even poorer in the face of government LED initiatives. On the local government level I observed that all project officers were black South Africans, even though they have surpassed the poverty threshold they are not excluded from the trauma of apartheid. Most of them still live in the townships, indeed some have moved to more affluent areas, however, it remains that on a daily basis they are confronted by the stark realities of the socio-spatial arrangements of the country. In their employment capacity they are required to promote a space whose meaning and symbolism they have not yet come to terms with themselves. What does this space mean, what does it represent and how does it shape their social identity? This unresolved inner struggle surfaced when it emerged that most officials do not show up when they are booked into the home-stays during the festival period (see Chapter 7). In its official capacity DSRAC pledges support for the home-stays by way of booking the accommodation for its officers and artists attending the festival, however, when officers do not show up and money is still paid for occupancy to the home-stay operators, it illuminates deep trauma for both parties. What associations do the officers who do not show up hold with the township space? Owing to apartheid legislation prior to 1994 all black South Africans lived in the townships or the homelands. It is possible that one reason for the no-shows is connected to some traumatic issues for the officers. On the other hand the same action also plants feelings of insecurity in the home-stay operators, how can the people who introduced the project not be willing to experience it? In their own assessment they begin to question the viability of the project. This is a double blow because the home-stays have dual roles as home and enterprise. Undoubtedly, this dredges up the notions of rejection that were instilled by apartheid in the first place, hence during my day-visits the majority of the women were always quick to point out areas of improvement that they were intending to or already working on. They wanted me to know that their homes and home-stays are being improved, and comments like "my home-stay [in the same vein home] is not up to standard to receive international guests" (see Chapter 6) were common place. This trauma is also used to explain the low emotional competencies and confidence levels as shown in Chapter 6. The contribution that conscientisation theory makes is it recognizes that conscientisation is an ongoing process for all individuals of an oppressed society. It might be that a person who has 
not reached a certain level of conscientisation will not be able to not be able to carry out actions that would allow a fellow disempowered citizen to feel empowered. This theory shows that to attain BEE much more is required than just the economic dimensions of empowerment: it all starts with the psychology.

Insight into the degree to which these initiatives are more than just economic means and contribute to constructive social interdependence in other aspects of life (social and political),

In order to gain insight into the degree to which these initiatives are more than just economic means and contribute to constructive social interdependence in other aspects of life (social and political), I used the theories of social interdependence (Chapter 5) and capabilities (Chapter 6). I elected to apply the theory of social interdependence because it is the foundation of a variety of other important theories (integrative negotiation, trust, values, conflict resolution, positive power and distributive [social] justice) necessary to develop the knowledge, attitudes, and skills necessary to participate in the work force, entrepreneurial setups and in society. This goal is not possible without restructuring BEE and institutionalizing LED goals within the context of the theories. As currently conceptualized and organized, BEE and LED are unable to contribute to other social and political aspects in an empowering manner. The BEE and LED frameworks are more focused on economic goals but neglecting the other dimensions of empowerment curtails the sustainability of the economic goals. Another important implication of the social imperative is that PDIs must attain the knowledge, skills, competencies and capabilities necessary to interact with people who differ from them in significant ways (guests). These theories show that the women operators in this instance (and people in general) are socialized within families and in communities where they learn the values, perspectives, attitudes, and behaviors of their historic culture. Community culture enables people to survive. It also, however, restricts their freedom and their ability to make critical choices and to reform their society or promote progressive human values, even if it is for economic gain, hence you have societies that are more entrepreneurial than others as shown in Chapter 4.

A more balanced understanding of current power structures in place and how these impact the attainment of entrepreneurial economic empowerment.

I observed that the power structures in this project reinforce the top-down implementation and the results indicate that power has not shifted through to the 
project level. Power is still vested with the local government hence it is difficult to say that the project has seen to the empowerment of the women home-stay operators. As such there were no power relations observed among the women within the group. Moreover, the women operators' perceptions of the project and their desire to progress to a position where the project operates autonomously from DSRAC reflects their powerless position. This is related to whom they regard as responsible for reducing poverty. For example, most women operators held the view that the responsibility to address poverty is that of the government. This view ensures that power remains with the local government and is not transferred to the project level because project participants are not ready to take up the power.

\subsubsection{Areas for future research}

1. The transformation and promotion of entrepreneurship of the South African tourism sector are topical themes which have not been studied systematically. Therefore, they deserve more attention and should be similarly studied in all types of tourism enterprises.

2. The study focused on women tourism home-stay operators, it would be interesting if a similar analysis on a men-operated LED project in a different sector could be carried out, this would allow a comparison of issues studied here and could provide gendered insights on the operationalization of LED in South Africa. 


\section{References}

Abraham, A. (2006). The need for the integration of emotional intelligence skills in business education. Business Renaissance Quarterly, 1 (3), 65-79.

Addo, E. and Marshall, R. (2000). Ghana's non-traditional export sector: expectations, achievements and policy issues. Geoforum, 31 (3), pp. 355-370.

Aitchison, C. (2009). Gender and tourism discourses: Advancing the gender project in tourism studies. In: T. Jamal and M. Robinson (eds), The sage handbook of tourism studies. London: SAGE, pp. 631-644.

Aitchison, C. (2005). Feminist and gender perspectives in tourism studies: The social cultural nexus of critical and cultural theories. Tourist studies, 5 (3), pp. 207224.

Alkire, S. and Deneulin, S. (2009). The Human Development and Capability Approach. Sterling, VA: Earthscan.

Allen, G. and Brennan, F. (2004). Tourism in the new South Africa: Social responsibility and the tourist experience. New York: I.B. Tauris and Co Ltd.

Allport, G. (1954). Attitudes in the History of Social Psychology. In N. Warren and M. Jahod (1973) (eds.), Attitudes: Selected Readings, 2 Ed Edn, Harmondsworth, UK: Penguin.

Alsop, R. and Heinsohn, N. (2005). Measuring Empowerment in Practice: Structuring Analysis and Framing Indicators. Washington DC, World Bank Policy Research Working Paper 3510.

Altinay, L. and Paraskevas, A. (2008). Planning research in hospitality and tourism. Oxford: Elsevier Ltd.

Amin, A. and Thrift, N. (2000). What kind of economic theory for what kind of economic geography? Antipode, 32 (1) pp. 4-9.

Amir Y. (1976). The role of intergroup contact in change of prejudice and race relations. In Towards the Elimination of Racism, ed. PA Katz, pp. 245-280. New York: Pergamon.

Anand, P., Hunter, G., Carter, I., Dowding, K. and Hees, M. van (2009). The Development of Capability Indicators. Journal of Human Development and Capabilities, 10, pp. 125-52.

Andreasson, S. (2010). Africa's development impasse: rethinking the political economy of transformation. London: Zed Books.

Annells, M. (1996). Hermeneutic phenemenology: Philosophical perspectives and current use in research. Journal of Advanced Nursing, 23, pp. 705-713.

Anunobi, F. O. (2003). The role of women in economic and political development in contemporary Africa. The Negro Educational Review, 54 (3): 61-77.

Appadurai, A. (2004). The capacity to aspire. In: V. Rao and M. Walton (eds), Culture and Public Action. Stanford: Stanford University Press. 
Appadurai, A. (2002). Cultural Diversity: A Conceptual Platform. In: K. Stenou (ed.), UNESCO Universal Declaration on Cultural Diversity. UNESCO Publishing, Paris, pp. 9-16.

Appadurai, A. (2003). Modernity at Large. Cultural Dimensions of Globalization. Minneapolis: University of Minnesota Press.

Appadurai, A. (1986). Is Homo Hierarchicus. American Ethnologist, 13, pp. 745-761.

Ashley, C. and Mitchell, J. (2005). Can tourism accelerate pro-poor growth in Africa? London: Overseas Development Institute.

Ashley, C. and Roe, D. (2002). Making tourism work for the poor: Strategies and challenges in Southern Africa. Development Southern Africa, 19, pp. 61-82.

Ashley, C., Roe, D. and Goodwin, H. (2001). Pro-poor Tourism Strategies: Making Tourism Work for the Poor: A review of experience. Pro-poor Research Report, 1, Overseas Development Institute, London.

Ashworth, G.J. (2003). Heritage identity and places: For tourists and host communities. In: S. Singh; D.J. Timothy and R.K. Dowling (eds). Tourism in Destination Communities. Wallingford: CABI.

Ashworth, G.J. (2004). Tourism and the heritage of atrocity: Managing the heritage of South African apartheid for entertainment. In T.V. Singh (eds). Tourism Seeks New Horizons. Basingstoke: CABI.

Ashworth, G.J. and Hartmann, R. (2005). The management of horror and human tragedy. In

Ashworth, G., and Hartmann, R. (Eds.), Horror and Human Tragedy Revisited: The Management of Sites of Atrocities for Tourism pp. 253-262. New York: Cognizant Communications Corporation.

Askjellerud, S. (2003). The tourist: A messenger of peace? Annals of Tourism Research. 30 (3), pp. $741-744$.

Ateljevic, I. (2000). Circuits of tourism: stepping beyond a production-consumption dichotomy. Tourism Geographies, 2 (4), pp. 369-88.

Baaijens, S. and Nijkamp, P. (2000). Meta-analytic methods for comparative and exploratory policy research: An application to the assessment of regional tourist multipliers. Journal of Policy Modeling 22 (7), pp. 821-858.

Bandura, A. (2002). Social cognitive theory in cultural context. Applied Psychology: An International Review, 51, pp. 269-290.

Barnes, T. J. and Sheppard, E. (2000). Introduction: The art of economic geography. In:

E. Sheppard and T. J. Barnes (eds), A companion to economic geography.

Oxford: Blackwell, pp.1-3.

Baskin, J. (1995). Local economic development - tourism: good or bad? In Small, medium and micro enterprises tourism. Working Paper No. 21, pp. 103-120. Johannesburg: Land and Agriculture Policy Centre. 
Becker, H. (1963). Outsiders, studies in the sociology of deviance. New York, NY: Free Press.

BEECom [Black Economic Empowerment Commission] (2001). BEECom Report. Johannesburg: Skotaville Press.

Belasco, W.J. (1987). Ethnic fast foods: the corporate melting pot. Food Foodways, 2, pp. 1-30.

Bennell, P. (1999). Learning to change: Skills development among the economically vulnerable and socially excluded in developing countries. Employment and Training Papers, 43, International Labour Organisation, http://www.ilo.org/public/English/employment/strat/publ/etp43.html

Berglund, K. and Johansson, A.W. (2007). The entrepreneurship discourse - outlined from diverse constructions of entrepreneurship on the academic scene. Journal of Enterprising Communities: People and Places in the Global Economy, 1 (1), pp. 77-102.

Berger, P.L. and Luckmann, T. (1991). The Social Construction of Reality (London: Anchor Books).

Berta-Avila, M. (2003). The Process of Conscientization: Xicanas/Xicanos Experiences in Claiming Authentic Voice. Journal of Hispanic Higher Education, 2, pp. 117.

Bhavnani, K. (1994). Tracing the Contours: Feminist Research and Feminist Objectivity. In: Afshar, H. and Maynard, M. (eds), The Dynamics of 'Race' and Gender: Some Feminist Interventions. London: Taylor and Francis Ltd.

Bianchi, R. (2002). Towards the political economy of global tourism. In: R. Sharpley and D. Telfer (eds), Tourism and development concepts and issues. Clevedon: Channel View Publications, pp. 265-299.

Biko, S. (1978). I write what I like. Randburg: Ravan Press.

Binns, T. and Nel, E. (2002a). Supporting local economic development in postapartheid South Africa. Local Economy, 17, pp. 8-24.

Binns, T. and Nel, E. (2002b). Tourism as a local development strategy in South Africa. Geographical Journal, 168, pp. 235-247.

Binns, T. and Nel, E. (2000). Rural self-reliance strategies in South Africa: community initiatives and external support in the former black homelands. Journal of Rural Studies, 16, pp. 367-377.

Binns, T. and Nel, E. (1999). Beyond the development impasse: local economic development and community self-reliance in South Africa. Journal of Modern African Studies, 37, pp. 389-408.

Bisk, L. (2002). Formal entrepreneurial mentoring: the efficacy of third party managed programs. Career Development International, 7, pp. 262-270.

Blanchflower, D. and Oswald, A. (1990). What makes an entrepreneur? Journal of Labor Economics 16, pp. 26-60.

Boonabaana, B. (2010). Women's tradition bargains and community tourism benefits: Experiences of a Ugandan rural context. Paper presented at the international 
conference on sustainable tourism development, November 15-19, Nelspruit, South Africa, ISBN: 978-0-620-46397-3.

Bourke, L., Butcher, S., Chisonga, N., Jumani, C., Davies, F. and Thorn, J. (not dated.). Fieldwork stories: Negotiating positionality, power and purpose. Feminist Africa, 13, pp. 95-105. Retrieved [04.12.2010] from http://www.feministafrica.org/uploads/File/Issue 13/fa13 profile bourke et al.pdf

Boyle, M. (1997). Civic boosterism in the politics of local economic development -'institutional positions' and 'strategic orientations' in the consumption of hallmark events. Environment and Planning, 29, pp. 1975-1997.

Briedehann, J. and Wickens, E. (2004). Rural tourism - Meeting the challenges of the new South Africa. International Journal of Tourism Research, 6 (3), pp. 189203.

Britton, S. (1996). Tourism, dependency and development. In: Apostolopoulos, Y.,Livaldi, S. \& Yinnakis, A. (eds.) The Sociology of tourism: Theoretical and empirical investigations, 155-172. Routledge, London.

Britton, S.G. (1982). The Political Economy of Tourism in the Third World. Annals of Tourism Research, 9, pp. 331-358.

Brodnig, G. and Mayer-Schonbergerz, V. (2000). Bridging the gap: The role of spatial information technologies in the intergration of traditional environmental knowledge and western science. The Electronic Journal on Information Systems in Developing Countries.

Brohman, J. (1996). New directions in tourism for third world development. Annals of Tourism Research 23 (1), pp. 48-70.

Brown, D.O. (1998). In search of an appropriate from of tourism for Africa: Lessons from the past and suggestions for the future. Tourism Management, 19 (3), pp. 237-245.

Bruner, E. M. (2004). Culture on Tour: Ethnographies of Travel. Chicago: The University of Chicago Press.

Buhalis, D. and Costa, C. (eds.) (2006). Tourism management dynamics. Trends, management and tools. Amsterdam: Elsevier Butterworth Heinemann.

Burr, V. (1995). An Introduction to Social Constructionism. London: Routledge.

Burt, R. S. (2000). The network entrepreneur. In: Swedberg, R. (ed.), Entrepreneurship The Social Science View. New York: Oxford University Press, pp. 281-307.

Butler, R.W. (2006). The Tourism Area Life Cycle: Applications and Modifications. Bristol, UK: Multilingual Matters.

Butler, R.W. (1980). The Concept of a Tourism Area Cycle of Evolution: Implications for Management Resources. The Canadian Geographer, 24 (1), pp. 5-16.

Carbonara, N. (2002). New models of inter-firm networks within industrial districts, Entrepreneurship \& Regional Development, 14, pp. 229-246. 
Calinescu, M. (1987). Five faces of modernity. Durham, NC.: Duke University Press. Chambers, R. (1995). Paradigm shifts and the practice of participatory research perspective. In: N. Nelson and S. Wright (eds), Power and Participatory Development: Theory and Practice. London: ITDG Publishing, pp. 19-30.

Chell, E. and Baines, S. (2000). Networking, entrepreneurship and microbusiness behavior. Entrepreneurship \& Regional Development, 12, pp. 195-215.

Chirkov, V., Ryan, R.M., Kim Y. and Kaplan, U. (2003). Differentiating autonomy from individualism and independence: A self-determination theory perspective on internalization of cultural orientations and well-being. Journal of Personality and Social Psychology, 84, pp. 97-110.

Christopher, J.C. (1999). Situating psychological well-being: Exploring the cultural roots of its theory and research. Journal of Counselling and Development, 77, pp. 141-52.

Clark, M., Riley, M., Wilkie, E. and Wood, R.C. (1999). Researching and writing dissertations in hospitality and tourism. London: International Thomson Business Press.

Cohen, E. (1988). Authenticity and Commoditization in Tourism, Annals of Tourism Research, 15, pp. 371-386.

Cohen, E. (1992). Pilgrimage and tourism: convergence and divergence. In: Alan Morinis (ed.), Sacred journeys: the anthropology of pilgrimage. Westport: Greenwood.

Cole, S. (2007). Beyond authenticity and commodification. Annals of Tourism Research, 34 (2), pp. 943-60.

Coleman, P. T. and Tjosvold, D. (2000). Positive power: Mapping the dimensions of constructive power relations.

Conklin Frederking, L. (2004). A cross-national study of culture, organization and entrepreneurship in three neighbourhoods. Entrepreneurship \& Regional Development, 16, pp. 197-215.

Commission of the European Communities (2003). Green Paper on Entrepreneurship in Europe. Brussels: European Commission.

Cook, S.W. (1978). Interpersonal and attitudinal outcomes in cooperating interracial groups. Journal of Research and Development Education. 12, pp. 97-113.

Cooper, C. and FitzGerald, E.V.K. (1989). Development studies revisited: Twenty-five years of the Journal of Development Studies. London: Cass.

Corbridge, S. (1986). Capitalist world development: A critique of radical development geography. London: MacMillan.

Crang, P. (1997). Performing the tourism product. In: C.Rojek and J. Urry (eds), Touring Cultures: Transformations of Travel and Theory. London: Routledge, pp. 13754.

Creswell, J. (1994). Research Design - Qualitative and Quantitative Approaches, London: SAGE Publications. 
Crotty, M. (1996). Phenomenology and nursing research. Melbourne, Australia: Churchill Livingstone.

Cusack, I. (2000). African Cuisines: Recipes for Nation Building? Journal of African Cultural Studies, 13 (2), pp. 207-255.

Dahles, H. and Bras, K. (1999). Entrepreneurs in romance: Tourism in Indonesia. Annals of Tourism Research, 26, pp. 267-293.

Dakhli, M. and de Clercq, D. (2004). Human capital, social capital, and innovation: a multi-country study. Entrepreneurship \& Regional Development, 16, pp. 107128.

Dana, L.P. and Dana, T.E. (2005). Expanding the scope of methodologies used in entrepreneurship research. International Journal of Entrepreneurship and Small Business, 2 (1), pp. 79-88.

Dann, G.M.S and Seaton, A.V. (eds) (2003). Slavery, contested heritage and more than a tourism Haworth New York /London.

Dann, G.M.S. (2002). Tourism and development. In: Desai, V. and Potter, R.B. (eds), The companion to development studies Arnold. London, pp. 236-240.

Darder, A. (1991). Culture and power in the classroom: A critical foundation for bicultural education. Westport, CT: Bergin and Garvey.

Darder, A. (1995). Bicultural identity and the development of voice: Twin issues in the struggle for cultural and linguistic democracy. In: J. Frederickson (ed.), Reclaiming our voices: Bilingual education, critical pedagogy \& praxis. Ontario: California Association for Bilingual Education, pp. 35-52.

Davidsson, P. (1995). Culture, structure and regional levels of entrepreneurship. Entrepreneurship \& Regional Development, 7, pp. 41-62.

Decrop, A. (1999). Triangulation in qualitative tourism research. Tourism Management, 20 (1), pp. 157-161.

De Kadt, E. (1979). Tourism - Passport to Development? Perspectives on the Social and Cultural Effects of Tourism in Developing Countries, Oxford University Press, Oxford.

Demaziere, C. and Wilson, P.A. (1996). Local economic development in Europe and the Americas, London: Mansell.

Dennett, G. Connell, J. (1988). Acculturation and health in the highlands of Papua New Guinea: dissent on diversity, diets, and development. Current. Anthropology. 29 (2), pp. 273-99.

Department of Environmental Affairs and Tourism. [DEAT] (2009). Opening Address made by Minister van Schalkwyk at the Local Government and Tourism Conference. Cape Town. January 2009.

Department of Environmental Affairs and Tourism. [DEAT] (2006). A Framework for Sustainable Development in South Africa. (Draft for Public Comment). 15 September 2006. Retrieved [19.04.2007] from www.deat.gov.za. 
Department of Environmental Affairs and Tourism [DEAT] (2005). Tourism BEE charter and scorecard. A user's guide. Department of Environmental Affairs and Tourism \& Tourism Business Council of South Africa, Pretoria.

Department of Environmental Affairs and Tourism [DEAT] (2000). Unblocking delivery on tourism strategy by Government departments. Pretoria: Government Printers of South Africa.

Department of Environmental Affairs and Tourism [DEAT] (1998). Tourism in GEAR Development Strategy 1999-2000. Pretoria: Government Printers of South Africa.

Department of Environmental Affairs and Tourism [DEAT] (1996). White Paper: The development and promotion of tourism in South Africa. Pretoria: Government Printers of South Africa.

Department of Trade and Industry [DTI] (2004a). Broad-based black economic empowerment framework: Principles and definitions. Pretoria: Government Printers of South Africa.

Department of Trade and Industry [DTI] (2004b). The role of equity ownership in broadbased economic empowerment. Pretoria: Government Printers of South Africa.

Department of Trade and Industry [DTI] (2003). South Africa's economic transformation: A strategy for broad-based economic empowerment. Pretoria: Government Printers of South Africa.

Deutsch, M. (2000). Cooperation and competition. In M.Deutsch\& P. Coleman (Eds.), Handbook of conflict resolution: Theory and practice (pp. 21-40). San Francisco: Jossey-Bass.

Deutsch, M. (1985). Distributive justice: A social psychological perspective. New Haven, CT: Yale University Press.

Deutsch, M. (1962). Cooperation and trust: Some theoretical notes. In M.R. Jones (Ed.), Nebraska symposium on motivation. Lincoln, NE: University of Nebraska Press.

De Villiers, R. (2005). The battle of black economic empowerment business: Innovation or entrepreneurship. February Issue, Entrepreneur South Africa.

Diener, E. and Suh, E. (2000). Culture and Subjective Well-Being, Cambridge, MA: MIT Press.

Dieke, P.U.C. (2003). 'The Relevance of NGOs in Tourism Development: Some Critical Reflections and Research Agenda'. Invited paper delivered to the 2nd International Symposium on 'Tourism \& Sustainability', themed Global Frameworks and Local Realities: Social \& Cultural Identities in Making and Consuming Tourism, organized by the Centre for Tourism Policy Studies, University of Brighton, UK, 11-12th September.

Doyal, L. and Gough I. (1991). A Theory of Human Need, Basingstoke: MacMillan. Edwards J. A. and Coit J. C. L. (1996). Mines and quarries: industrial heritage tourism. Annals of Tourism Research, 23, pp. 341-363. 
Dlamini, C.D. (1997). The Relationship between Human Rights and Education. In: De Groof, J. and Malherbe, E.F.J. (eds), Human Rights in South African Education. Leuven: Acco, pp. 39-52.

Dube, E. (1985). The Relationship between Racism and Education in South Africa. Harvard Educational Law Review, pp. 86-100.

Dulewicz, V. and Higgs, M. (2003). Leadership at the top: The need for emotional intelligence in organizations. The International Journal of Organizational Analysis, 11 (3), pp. 193-210.

du Rand, G. E., Heath, E., and Alberts, N. (not dated). The Role of Local and Regional Food in Destination Marketing: A South African Situation Analysis, Retrieved [12.11.2011] from http://137.215.9.22/bitstream/handle/2263/6080/DuRand_Role(2003).pdf?se quence $=1$

Easterly, W.R. (2006). White man's burden: why the west's efforts to aid the rest have done so much ill and so little good. New York: Penguin.

Edwards, J.A. and Coit, J.C.L. (1996). Mines and quarries: industrial heritage tourism. Annals of Tourism Research, 23, pp. 341-363.

Elliott, G., Mitchell, B., Wiltshire, B., Manan, I.A. and Wismer, S. (2001). Coastal management community participation in marine protected area management Wakatobi National Park, Sulawesi Indonesia. Coastal Management, 29, pp. 295-316.

Elmont, S. (1995). Tourism and food service. Two sides of the same coin. Cornell Hotel and Restaurant Administration Quarterly, February, 57-63.

Evans, D.S. and Leighton, L.S. (1990). Small business formation by unemployed and employed workers. Small Business Economics, 2, pp. 319-330.

Fabrizio, C., Snowdon, P. and Prasad, N. (2000). Change in Continuity: Concepts and Tools for a Cultural Approach to Development. Paris: UNESCO Publishing.

Finlay, L. (2008). A dance between the reduction and reflexivity: explicating the "phenomenological psychological attitude". Journal of Phenomenological Psychology, 39, pp. 1-32.

Finnis, J. (1980). Natural Law and Natural Rights. Oxford: Clarendon Press.

Fontyn, Y, 2008. New Gold. Financial Mail http://free.financialmail.co.za/report08/satourism08/ asat.htm [Online] Accessed 22 November 2008.

Forsyth, F. (2000). Women's enterprise and business development - lessons from targeted women's programmes in Glasgow. Local Economy, 15 (1), pp. 18-31.

Fouche, F. (1993). Phenomenological theory of human science. In: J. Snyman (ed.), Conceptions of Social Inquiry. Pretoria: Human Science Research Council, pp. 87-112. 
Freire, P. (1998). Pedagogy of freedom: Ethics, democracy, and civic courage. Lanham, M.D.: Rowman and Littlefield.

Freire, P. (1973). Education for Critical Consciousness. New York: Continuum.

Freire, P. (1972). Pedagogy of the Oppressed. Harmondsworth: Penguin.

Friedman, J. (1992). Empowerment: The Politics of an Alternative Development, Oxford: Blackwell.

Frietag, T.G. (1994). Enclave tourism development: For whom the benefits toll? Annals of Tourism, 1, pp. 538-554.

Gadamer, H.G. (1975). Truth and Method. London: Sheed and Ward. [Second revised edition originally published in German 1965].

Gasper, D. (2007). What is the capability approach? Its core, rationale, partners and dangers. Journal of Socio-Economics, 36, pp. 335-359.

Gawe, S. and Meli, F. (1990). The missing past in South Africa, In Stone, P. and Mackenzie, R. (eds) The excluded past: archaeology in education, London: Unwin Hyman, pp. 98-108.

Geertz, C. (1984). From the native's point of view: On the nature of anthropological understanding. In: R. Schweder and R. LeVine (eds), Culture Theory: Essays on Mind, Self and Emotion. Cambridge: Cambridge University Press, pp. 123-136.

Geertz, C. (1973). The Interpretation of Cultures. New York: Basic books.

Gergen, K. (1999). An Invitation to Social Construction. London: SAGE Publications.

Gibson, H. J. (2001). Gender in tourism: Theoretical perspectives. In: Y. Apostolopoulos, S. Sonmez and D.J. Timothy (eds), Women as producers and consumers of tourism in developing countries. Westport: Praeger Publishers, pp.19-43.

Giddens, A. (1984). The Constitution of Society, Oxford: Blackwell.

Giorgi, A. (1994). A phenomenological perspective on certain qualitative research methods. Journal of Phenomenological Psychology, 25, pp. 190-220.

Goleman, D. (1995). Emotional Intelligence: Why it can matter more that IQ. London: Bloomsbury Publishing.

Goleman, D. (2001). Emotional intelligence: Issues in paradigm building. In: C. Cherniss and D. Goleman (eds), The Emotionally Intelligent Workplace. San Francisco: Jossey-Bass, pp. 13-26.

Goodson, L. and Phillimore, J. (2004). The inquiry paradigm. In: J. Phillimore and L. Goodson (eds), Qualitative research in tourism: Ontologies, epistemologies and methodologies. London: Routledge.

Goody J. (1998). The globalisation of Chinese food. In Food and Love: a Cultural History of East and West, pp. 161-71. London: Verso.

Gosovic, B. (2000). Global intellectual hegemony and the international development agenda. Oxford: Blackwell Publishers. 
Goudie, S.C., Khan, F. and Kilian, D. (1999). Transforming tourism: black empowerment, heritage and identity beyond apartheid. South African Geographical Journal, 81, pp. 21-33.

Greene, F.J. and Storey, D.J. (2004). An assessment of a venture creation programme: the case of Shell Live WIRE. Entrepreneurship \& Regional Development, 16, pp. 145-159.

Greve, A. (1995). Networks and entrepreneurship - an analysis of social relations, occupational background, and use of contacts during the establishment process. Scandinavian Journal of Management, 11, pp. 1-24.

Hall, C.M. (2009). Sharing space with visitors: The servicescape of the commercial exurban home. In: P. Lynch, A. McIntosh and H. Tucker (eds), The commercial home. London: Routledge, pp. 60-72.

Hall, M. (2008). Tourism planning. Policies, processes and relationships. $2^{\text {nd }}$ edition. Harlow: Pearson Education Limited.

Hall, C.M. (2004). Reflexivity and tourism research: Situating myself and/with others. In: J. Phillimore and L. Goodson (eds), Qualitative research in tourism: Ontologies, epistemologies and methodologies. London: Routledge, pp. 137155.

Hall, T. and Hubhard, P. (1996). The entrepreneurial city: new urban politics, new urban geographies. Progress in Human Geography, 20, pp. 153-74.

Hamilton, R. (2007). Feminist theories. In: N. Cook (ed.), Gender relations in perspective: Essential readings. Toronto: Canadian Scholars' press Inc., pp. 4960.

Hangala, L. (2007). A businessman's perspective on black economic empowerment. In An eclectic review of Namibia's black economic empowerment landscape, IPPR Research Report 10, Windhoek: Institute for Public Policy Research.

Hawkesworth, M. (2007). Truth and Truths in Feminist Knowledge Production. In: S.N. Hesse-Biber (ed.), Handbook of Feminist Research: theory and Praxis. Thousand Oaks CA: SAGE Publications, pp. 469-491.

Healy, R. (1994). Tourist Merchandise as a Means of Generating Local Benefits from Ecotourism. Journal of Sustainable Tourism, 2 (3), pp. 137-151.

Hellriegel, D., Jackson, S.E., Slocum, J., Staude, G., Amos, T., Klopper, H.B., Louw, L. and Oosthuizen, T. (2009). Management. Oxford: University Press.

Heidegger, M. (1927/1962). Being and Time. Oxford: Blackwell.

Henderson, H. (1999). Beyond Globalisation: Shaping a Sustainable Global Economy. Connecticut: Kumarian Press, pp. 21-60.

Henderson, J.C. (2002). Tourism and Politics in the Korean Peninsula, Journal of Tourism Studies, 13 (2), pp. 16-27.

Hjalmarsson, D. and Johansson, A. W. (2003). Public advisory services - theory and practice, Entrepreneurship \& Regional Development, 15, pp. 83-98. 
Hjorth, D. and Johannisson, B. (2003). Conceptualising the opening phase of regional development as the enactment of a 'collective identity'. Concepts and Transformation, 8, pp. 69-92.

Higgins-Desbiolles, F. (2006). More than an "industry": The forgotten power of tourism as a social force. Tourism Management 27, pp. 1192-1208.

Higgins-Desbiolles, F. (2005). Reconciliation Tourism: Challenging the Constraints of Economic Rationalism. In: C. Ryan and M. Aicken (eds), Indigenous Tourism: the Commodification and Management of Culture. Oxford: Pergamon.

Higgins-Desbiolles, F (2010). The elusiveness of sustainability in tourism: The cultureideology of consumerism and its implications. Journal of Tourism \& Hospitality Research, 10 (2), pp. 116-129.

Hine T. (1995). The Total Package: the Secret History and Hidden Meanings of Boxes, Bottles, Cans, and Other Persuasive Containers. Boston: Back Bay.

Hooks, B. (1989). Talking back: Thinking feminist, thinking Black. Boston: South End. Hycner, R.H. (1999). Some guidelines for the phenomenological analysis of interview data. In: A. Bryman and R.G. Burgess (eds), Qualitative Research. London: SAGE, pp. 143-164.

Ibrahim, S. and Alkire, S. (2007). Agency and empowerment: a proposal for internationally comparable indicators. Oxford Development Studies, 35, pp. 379-403.

Inglehart, R. and Welzel, C. (2005). Modernization, Cultural Change and Democracy. NY: Cambridge University Press.

Janis, J. (2010). Challenges in post-apartheid transformation of the tourism sector in Namibia. Paper presented at the international conference on sustainable tourism development, November 15-19, Nelspruit, South Africa, ISBN: 978-0620-46397-3.

Jauch, H. (2007). A labour perspective on black economic empowerment. In An eclectic review of Namibia's black economic empowerment landscape. IPPR Research Report 10. Windhoek: Institute for Public Policy Research.

Jauch, H., Edwards, L. and Cupido, B. (2009). A rich country with poor people: Inequality in Namibia. Windhoek: Labour Resource and Research Institute.

Jensen, $\varnothing$. (2009). The activation of local service suppliers by incoming tour operators in a "developing" destination - the case of Madagascar. Current Issues in Tourism, 12 (2), pp. 133-163.

Jensen, $\varnothing$. (2010). Social meditation in remote developing world tourism locations - the significance of social ties between local guides and host communities in sustainable tourism development. Journal of Sustainable Tourism, 18 (5), pp. 615-633. 
Johannisson, B. (1995). Paradigms and entrepreneurial networks - some methodological challenges. Entrepreneurship \& Regional Development, 7, pp. 215-231.

Johannisson, B. and Nilsson, A. (1989). Community entrepreneurship - leadership for local economic development. Entrepreneurship \& Regional Development, 1, pp. 1-19

Johnson, D. W., Johnson, R. (2005). New developments in social interdependence theory. Genetic, Social and General Psychology Monographs, 131 (4), pp. 285360.

Johnson D.W., and Johnson, R. (2000). Cooperative learning, values, and culturally plural classrooms. In M. Leicester, C. Modgill \& S. Modgil (Eds). Values, the classroom, and cultural diversity (pp. 15-28). London: Cassell PLC.

Johnson D.W., and Johnson, R. (1999). Learning together and alone: Cooperative, competitive and individualistic learning ( $5^{\text {th }}$ ed.). Boston: Allyn \& Bacon.

Johnson D.W., and Johnson, R. (1989). Cooperation and competition: Theory and research. Edina, MN: Interaction Book Company.

Johnson, M. (1992). Lore: Capturing traditional environmental knowledge. Ottawa: Dene Cultural Institute.

Johnstone, H. and Lionais, D. (2004). Depleted communities and community business entrepreneurship: Revaluing space through place. Entrepreneurship \& Regional Development, 16, pp. 217-233.

Kaplan, L. (2004). Skills development in tourism: South Africa's tourism-led development strategy. GeoJournal, 60, pp. 217-227.

Kerr, N. and Bruun, S. (1983). The dispensability of member effort and group motivation losses) Free-rider effects. Journal of Personality and Social Psychology, 44, pp. 78-94.

Khamouna, M. and Zeiger, J. (1995). Peace through Tourism. Parks and Recreation, 30 (9), pp. 80-86.

Kim, H. S. (2007). The politics of border crossings: Black, postcolonial, and transnational feminist perspectives. In: S.N. Hesse-Biber (ed.), Handbook of feminist research: Theory and practice. Thousand Oaks: SAGE Publications, pp. 107-122.

Kim, J.C., Watts, C.H., Hargreaves, J.R., Ndhlovu, L.X., Phetla, G., Morison, L.A., Busza, J., Porter, J.D.H., Pronyk, P. (2007). Understanding the impact of a microfinance-based intervention on women's empowerment and reduction of intimate partner violence in South Africa. America Journal of Public Health, 97, pp. 1794-1802.

Kinnaird, V. and Hall, D. (1996). Understanding tourism processes: A gender aware framework. Tourism management, 17 (2), pp. 95-102. 
Kirshenblatt-Gimblett, B. (1998). Destination Culture: Tourism, Museums, and Heritage. Berkeley, Los Angeles, London: University of California Press.

Kößler, R. and Melber, H. (2001). Political culture and civil society: on the state of the Namibian state. In: I. Diener and O. Graefe (eds), Contemporary Namibia: The first landmarks of a post-apartheid society. Windhoek: Gamsberg Macmillan Publishers, pp. 147-160.

Korten, D. (1995). When Corporations Rule the World. Connecticut and San Francisco: Kumarian Press and Berrett-Koehler.

Koutra, C. (2007). Corporate Social Responsibility: An Application in Tourism Development in Ghana. Journal of Global Management Research, 3 (2), pp. 2532.

Koch, T. (1995). Interpretive approaches in nursing research: The influence of Husserl and Heidegger. Journal of Advanced Nursing, 21, pp. 827-836.

Kvale, S. (1996). InterViews: An introduction to qualitative research. Thousand Oaks, CA: Sage.

Kwaramba, H.M. (2011). Case 2 Kwam eMakana Tourism Home-stays, Eastern Cape Province, South Africa,. In UNWTO/UNIFEM Global Report on Women in Tourism 2010. ISBN: 978-92-844-1373-7 (UNWTO), ISBN: 978-1-936291-36-6 (UN Women).

Kwaramba, H.M., Lovett, J.C., Louw, L. and Chipumuro, J. (2011). Emotional confidence levels and success of tourism development for poverty reduction: The South African Kwam eMakana home-stay project, Tourism Management, doi:10.1016/j.tourman.2011.09.010 [in Press].

Laclau, E. and Mouffe, C. (1985). Hegemony and socialist strategy. Towards a radical democratic politics. London: Verso.

Lalu, A. (2004). The pillars of black economic empowerment framework, Black Business Quarterly, 7 (2), pp. 59-60.

Landy, F.J. (2005). Some historical and scientific issues related to research on emotional intelligence. Journal of Organizational Behavior, 26, pp. 411-424.

Lapeyre, R. (2009). Revenue sharing in community-private sector lodges in Namibia: a bargaining model. Tourism Economics 15 (3), pp. 653-669.

Lash, S. and Urry, J. (1994). Economies of signs and space. London: SAGE Publications.

Latour, B. (2004). A dialogue on actor-network theory with a (somewhat) Socratic Professor. In: Avgerou, C., Ciborra, C. and Land, F.F. (eds), The Social Study of ICT. Oxford: Oxford University Press, pp. 62-76.

Laukkanen, M. and Niittykangas, H. (2003). Local developers as virtual entrepreneurs do difficult surroundings need initiating interventions? Entrepreneurship \& Regional Development, 15, pp. 309-331.

Laverty, S. (2003). Hermeneutic Phenomenology and Phenomenology: A Comparison of Historical and Methodological Considerations, International Journal of 
Qualitative Methods, 2(3), Retrieved [22.12.2009] from http://www.ualberta.ca/ iiqm/backissues/2 3final/pdf/laverty.pdf .

Leach, H.M. (1999). Food processing technology: its role in inhibiting or promoting change in staple foods. In The Prehistory of Food, (ed). C Gosden, J Hather, pp. 129-38. London: Routledge

Lediga, C. (2006). Empowerment needs entrepreneurship too. Sunday Times: (Business times). 19 November 2006.

Lee, J. (2001). Entrepreneurship and business development among African Americans, Koreans, and Jews: exploring some structural differences. In: N.H.R. CorderoGuzma (ed.), Migration, transnationalization, and race in a changing New York. Philadelphia: Temple University Press, pp. 258-278.

Lefebvre, H. (1991). The Production of Space. London, New York: Blackwell Publishing. Leistner, G.M.E. (1983). Decolonising the mind - the answer to Africa's development needs? Africa Insight?, 13 (3), pp. 17.

Lincoln, Y. and Guba, E. (1985). Naturalistic inquiry. Thousand Oaks CA: SAGE Publications.

Lipietz, A. (1993). The local and the global: Regional individuality or inter regionalism? Transactions of the Institute of British Geographers, 18 (1), pp. 8-18.

Lockwood, W.G., Lockwood, Y.R. (2000). Continuity and adaptation in Arab American foodways.In Arab Detroit: From Margin to Mainstream, ed. N Abraham, A Shryock, pp. 515-59. Detroit: Wayne State University Press.

Lofland, J. and Lofland, L.H. (1995). Typological Systems: Analyzing Social Settings. $3^{\text {rd }}$ edition. Belmont, CA: Wadsworth.

Lubbe, B.A. (2003). Tourism management in Southern Africa. Cape Town: Maskew Miller Longman (Pty) Ltd:

Maathai, W. M. (2006). Unbowed: One woman's story. London: William Heinemann.

Macedo, D. (1998). Foreword. In: P. Freire, Pedagogy of freedom: Ethics, democracy, and civic courage (pp. xi-xxxii). Lanham, MD: Rowman \& Littlefield.

MacDonald, H.S. (2001). National Tourism and Cuisine Forum: Recipes For Success. Ottawa: Canadian Tourism Commission.

MacLeod, D. (2006). Cultural commodification and tourism: a very special relationship, Tourism, Culture and Communication, 6, pp. 71-84.

Madhok, S. (2005). Autonomy, political literacy and the 'social woman': Towards a politics of inclusion. In: C. Bates and S. Basu (eds), Rethinking Indian Political Institutions. London: Anthem Press, pp. 151-169.

Magi, L.M. (2010). Tourism small micro medium enterprises development and delivery through the black economic empowerment initiatives: A struggle for sustainability. Paper presented at the international conference on sustainable 
tourism development, November 15-19, Nelspruit, South Africa, ISBN: 978-0620-46397-3.

Magi, L.M. and Nzama, A.T. (2009). Tourism Strategies and Local Community Responses around the World Heritage Sites in KwaZulu-Natal. South African Geographical Journal, 91 (2), pp. 94 -102.

Mahony, K. and Zyl, J. van (2002). The impacts of tourism investment on rural communities: three case studies in South Africa. Development Southern Africa, 19, pp. 83-104.

Makkink, W. (2009). Makana Annual Tourism Report. Grahamstown: Makana Tourism. Manyara, G. and Jones, E. (2007). Community-based tourism enterprises development in Kenya: an exploration of their potential as avenues of poverty reduction. Journal of Sustainable Tourism, 15 (6), pp. 628-644.

Markus, H.R. and Kitayama, S. (1991). Culture and the self: Implications for cognition, emotion, and motivation. Psychological Review, 98, pp. 224-253.

Massey, D. (1992). Politics and space/time. New Left Review, 196, pp. 65-84.

Matinga, M.N. (2010). "We grow up with it": An Ethnographic study of the experiences, perceptions and responses to the health impacts of energy acquisition and use in rural South Africa. PhD Thesis. Enschede: University of Twente.

Max-Neef, M. 1991. Human-scale development: Conception, application and further reflection. New York: Apex Press.

Mayer, J.D. and Salovey, P. (1990). Emotional Intelligence. Imagination, Cognition and Personality, 9, pp. 185-211.

Mbaiwa, J.E. (2005). Community-based tourism and the marginalized communities in Botswana: the case of the Basarwa in the Okavango Delta. In: Ryan, C. and Aicken, M. (eds), Indigenous tourism, the commodification and management of culture. Elsevier: Oxford, pp. 87-109.

Mbeki, M. (2009). Architects of poverty: Why African capitalism needs changing. Johannesburg: Picador Africa.

Mbembe, A. (2004). Aesthetics of Superfluity - Public Culture, Public Culture, 16(3), pp. 373-405.

McGraw, L., Zvonkovic, A. and Walker, A. (2000). Studying postmodern families: A feminist analysis of ethical tensions in work and family research. Journal of Marriage and the Family, 62 (1), pp. 68-78.

McEachern, C. (2001). Mapping the memories: politics, place and identity in the district six museum. In Zegeye, A. (ed) Social identities in the new South Africa, Cape Town: Kwela books, pp. 223-47.

McIntosh, R.W., Goeldner, C.R. and Ritchie, J.R.B. (1995). Tourism: Principles, Practices, Philosophies, 7th edn. New York: Wiley.

McLaren, P. (1989). Critical pedagogy: An overview. White Plains, NY: Longman.

Mennell, S. (1985). All Manners of Food: Eating and Taste in England and France from the Middle Ages to the Present. Oxford: Blackwell. 
Merleau-Ponty, M. (1968). The visible and the invisible. Evanston, IL: Northwestern University Press

Meyer, D. (2004). Tourism Routes and Gateways: Key Issues for the Development of Tourism Routes and Gateways and Their Potential for Pro-Poor Tourism, Overseas Development Institute, London.

Miles, M.B. and Huberman, A.M. (1984). Qualitative Data Analysis. A Sourcebook of New Methods. Beverly Hills (CA): SAGE Publications, Inc.

Minang, P.A. (2007). Implementing global environmental policy at local level: Community carbon forestry perspectives in Cameroon. PhD Thesis, Enschede: International Institute for Geo-information Science and Earth Observation.

Mitchella, R E. and Reid, D.G. (2001). Community integration: island tourism in Peru. Annals of Tourism Research, 28, pp. 113-139.

Mkandawire, T. and Soludo, C.C. (1998). Our continent, our future: African perspectives on structural adjustment. Africa World Press.

Mønsted, M. (1993). Regional network processes: networks for the service sector or development of entrepreneurs? In: Karlsson, C., Johannisson, B. and Storey, D. (eds), Small Business Dynamics. London: Routledge, pp. 204-223.

Moser, O.N. (2009). Ordinary families, extraordinary lives; Assets and poverty reduction in Guayaquil, 1978-2004. Washington DC: Brookings Inst Pr.

Moser, C. (1991). Gender Planning and Development. London: Routledge.

Moustakas, C. (1994). Phenomenological Research Methods. Thousand Oaks, CA: SAGE Publications.

Mowforth, M. and Munt, I. (1998). Tourism and Sustainability. London: Routledge. Moyo, D. (2009). Dead aid: Why aid is not working and how there is a better way for Africa. New York: Farrar, Straus and Giroux.

Munhall, P. (1989). Philosophical ponderings on qualitative research methods in nursing. Nursing Science Quarterly, 2(1), 20-28.

Murphy, D. (1997). South from the Limpopo. London: Murray.

Murphy, P.E. (1985). Tourism: A Community Approach. New York and London: Methuen.

Nagar, R. (2002). "Footloose researchers, traveling theories and the politics of transnational feminist praxis", Gender, Place and Culture, 9 (2), pp.179-86.

Nash, D. (1989). Tourism as a Form of Imperialism. In: V. Smith (ed.) Hosts and Guests. 2nd edition. Philadelphia: University of Pennsylvania Press, pp. 37-52.

Nash, J. (1951). Non-Cooperative Games. Annals of Mathematics, 54 (2), pp. 286-295.

Nederveen Pieterse, J. (2001). Development theory deconstructions/reconstructions. London: SAGE Publications Ltd.

Nel, E. (2001). Local economic development: a review and assessment of its current status in South Africa. Urban Studies, 38, pp. 1003-1024. 
Nel, E. and Binns, T. (2001). Initiating 'developmental local government' in South Africa: evolving local economic development policy. Regional Studies, 35, pp. 355-62.

Nel, E. (1999). Regional and local economic development in South Africa: the experience of the Eastern Cape. Ashgate: Aldershot.

Neuman, W. L. (2000). Social research methods: Qualitative and quantitative approaches. 4th edition. Boston: Allyn and Bacon.

Ngugi, W.T. (1981). Writers in Politics. London: Heinemann.

Nisan, N., Roughgarden, T., Tardos, E. and Vazirani, V.V. (2007). Algorithmic game theory. Cambridge New York: University Press.

Noble, M., Ratcliffe, A. and Wright, G. (2004). Conceptualizing, defining and measuring poverty in South Africa: An argument for a consensual approach. Oxford: University of Oxford.

North, D., Smallbone, D. and Vickers, I. (2001). Public sector support for innovating SMEs. Small Business Economics, 16, pp. 303-317.

Nussbaum, M.C. (2000). Women and Human Development: The Capabilities Approach. Cambridge: Cambridge University Press.

Obama, B. (2004). Dreams from My Father: A Story of Race and Inheritance. New York: Crown,

Okin, S.M. (2003). Poverty, well-being, and gender: what counts, who's heard? Philosophy \& Public Affairs, 31 (3), pp. 280-316.

Okpukpara, B. (2009). Microfinance paper wrap-up: Strategies for effective loan delivery to small scale enterprises in rural Nigeria. Journal of Development and Agricultural Economics, 1 (2), pp. 41-48.

Olutola, A.A. and Mofokeng, J.T. (2010). Beyond the hype of 2010 World Cup: Safety and security of tourists in South Africa, Paper presented at the international conference on sustainable tourism development, November 15-19, Nelspruit, South Africa. ISBN: 978-0-620-46397-3.

Ondicho, T.G. (2000). International tourism in Kenya: Development, problems and challenges, Eastern Africa Social Science Review, 15 (2), pp. 49-70.

Pan African Research and Innovation Services [PARIS], (2010). A framework to benchmark tourism GDP in South Africa: What is the role of tourism in the economy and what drives tourism in South Africa? [Retrieved on 11. 09.2011] from http://www.southafrica.net/sat/action/media/downloadFile?media fileid=295 $\underline{71 .}$

Patton, M. (1985). Qualitative Evaluation and Research Methods. $2^{\text {nd }}$ edition. Thousand Oaks, CA: SAGE Publications. 
Pereira, A. (2004). State entrepreneurship and regional development: Singapore's industrial parks in Batam and Suzhou. Entrepreneurship \& Regional Development, 16, pp. 129-144.

Perret, S., Carstens, J., Randela, R. and Moyo, S. (2000). Activity systems and livelihoods in the Eastern Cape Province rural areas (Transkei): Household typologies as socio-economic contributions to a LandCare project. University of Pretoria/CIRAD, working paper, $28^{\text {th }}$ October 2000.

Pettigrew, T.F. (1997). The affective component of prejudice: empirical support for the new view. In Racial Attitudes in the 1990s: Continuity and Change, ed. S.A. Tuch, J.K. Martin, pp. 76-90. Westport, CT: Praeger.

Pleumarom, A. (1994). The political economy of tourism. The Ecologist, 24 (4), pp. 1429.

Picard, D. and Robinson, M. (2005). Remaking Worlds: Festivals, Tourism and Change. Clevedon: Channel View.

Pizam, A. (1996). Does tourism promote peace and understanding between unfriendly nations? In: A Pizam and Y. Mansfield (eds), Tourism, crime and international security issues. London: Wiley.

Polkinghorne, D.E. (1983). Methodology for the human sciences: Systems of inquiry. Albany: State University of New York Press.

Polkinghorne, D.E. (1992). A postmodern epistemology of practice. In S. Kvale (Ed.), Psychology and postmodernism (pp. 146-165). London: Sage.

Poria, Y. (2001). The show must not go on. Journal of Tourism and Hospitality Research, 3 (2): 115-119.

Prasad, P. (2005). Crafting qualitative research: Working in the post-positivist traditions. Armonk, New York: M.E Shape, Inc.

Preister, K. (1989). The theory and management of tourism impacts. Tourism Recreation Research, 14 (1), pp. 15-22.

Pro Poor Tourism Partnership (2005). Pro poor tourism. Retrieved [22.07.2008] from http://www.propoortourism.org.uk/index.html .

Ramphele, M. (2008). Laying ghosts to rest: Dilemmas of the transformation in South Africa. Cape Town: Tafelberg.

Ramutsindela, M. (2007). Transfrontier Conservation in Africa: At the Confluence of Capital, Politics and Nature. Nosworthy Way and Massachusetts: CABI.

Rea, M.A. (2003). Furusato away from home. Annals of Tourism Research, 27 (3), pp. 638-660.

Rehn, A. and Taalas, S. (2004). 'Znakomsva I Svyazi' - Blat, the Soviet Union, and mundane Entrepreneurship. Entrepreneurship and Regional Development, 16, pp. 235-250.

Ringer, G. (1998). 'Introduction'. In: Ringer, G. (ed.), Destinations: Cultural landscapes of tourism, pp. 1-16. London: Routledge. 
Rivett-Carnac, K. (2009). Local economic development, tourism and land use choices. Development Planning Division Working Paper Series No.4, Midrand: DBSA

Roberts, P. (2003). Pedagogy, neoliberalism and postmodernity: reflections on Freire's later work. Educational Philosophy and Theory, 35, pp. 451-465.

Robinson, J. (2004). Squaring the circle? Some thoughts on the idea of sustainable development.

Ecological Economics 48: 4, 369-384.

Robinson, M. and Picard, D. (2006). Tourism, Culture and Sustainable Development. Paris: UNESCO Publishing.

Roe, D., Ashley, C., Page, S. and Meyer, D. (2004). Tourism and the Poor: Analysing and Interpreting Tourism Statistics from a Poverty Perspective, PPT Working Paper No. 16.

Rogerson, C. M. (1997). Local economic development and post-apartheid reconstruction in South Africa. Singapore Journal of Tropical Geography, 18, pp. 175-95.

Rogerson, C.M. (1999). Place marketing for local economic development in South Africa. The South African Geographical Journal, 81, pp. 32-43.

Rogerson, C.M. (2002). Tourism, small enterprise development and empowerment in post-apartheid South Africa. Johannesburg: University of the Witwatersrand, WITS.

Rogerson, C.M. (2004). Transforming the South African tourism industry: The emerging black-owned bed and breakfast economy. GeoJournal, 60, pp. 273-281.

Rogerson, C.M. (2006). Pro-Poor local economic development in South Africa: The role of pro-poor tourism. Local Environment, 11 (1), pp. 37-60.

Rogerson, C.M. (2007). Tourism routes as vehicles for local economic development in South Africa: The example of the Magaliesberg Meander. Urban Forum, 18, pp. 49-68.

Roomi, M. A. and Parrot, G. (2008). Barriers to development and progression of women entrepreneurs in Pakistan. The Journal of Entrepreneurship, 17 (1), pp. 59-72.

Rozin, P. (1999). Preadaptation and the puzzles and properties of pleasure. In: D. Kahneman, E. Diener and N. Schwarz (eds), Well-being: The Foundations of Hedonic Psychology. New York: Russell Sage Foundation, pp. 109-133.

Republic of South Africa (1996). The Constitution of the Republic of South Africa, Act No. 108 of 1996, Pretoria: Government of South Africa.

Ryan, R.M. and Deci, E.L. (2001). On happiness and human potentials: A review of research on hedonic and eudaimonic web-being. Annual Review of Psychology, 52, pp. 141-166.

Saxenian, A. (1999). Silicon Valley's new immigrant entrepreneurs. San Francisco: Public Policy Institute of California. 
Scheyvens, R. (2002). Tourism for development: Empowering communities. Essex: Pearson Education.

Scott, W. E., and Cherrington, D. J. (1974). Effects of compet itive, cooperative, and individualistic reinforcement contingencies. Journal of Personality and Social Psychology, 30: 748-758.-

Sen, A. (2002). Rationality and Freedom. Cambridge, MA: Belknap Press.

Sen, A.K. (1999). Development as Freedom. New York: Knopf Press.

Sen, A.K. (1993). Capability and well-being. In: M. Nussbaum and A. Sen (eds), The Quality of Life. Oxford: Clarendon Press, pp. 30-53.

Sen, A.K (1992). Inequality Reconsidered. Cambridge, MA: Harvard University Press.

Sen, A.K. (1984). Resources, Value and Development. Oxford: Basil Blackwell.

Sen, A.K. (1985). Commodities and Capabilities. Amsterdam: Elsevier.

Sharpley, R. (2002). Tourism management: rural tourism and the challenge of tourism diversification: the case of Cyprus. Tourism Management, 23, pp. 233-244.

Sharpley, R. (2009). Tourism development and the environment: Beyond sustainability? London: Earthscan.

Shah, K. and Gupta, V. (2000). Tourism, the Poor and Other Stakeholders: The Experience of Asia, Overseas Development Institute, London.

Simmons, C. and Parsons, R. (1983). Empowerment for role alternative in adolescence. Adolescence, 18(69): 193-200.

Sinclair, T.M. (1997). Gender, Work and Tourism. London: Routledge.

Sinclair, T.M. (1998). Tourism and economic development: A Survey. Journal of Development Studies, 34, pp. 1-51.

Skinner, B. F. (1968). The technology of teaching. New York: Appleton-Century-Crofts, Inc.

Smith, J.A. (2004). Reflecting on the development of interpretative phenomenological analysis and its contribution to qualitative research in psychology. Qualitative Research in Psychology, 1(1), 39-54.

Smith, V. (1977). Hosts and Guests. An Anthropology of Tourism. Philadelphia: University of Philadelphia Press.

Snowball, J. and Hamer, N. 2008. Tourism as a pillar of Makana Local Economic Development Plan, Report on Current state of the Tourism Industry, Makana Research Group, ISER. Rhodes University Retrieved [22.12.2011] from http://www.ru.ac.za/media/rhodesuniversity/content/iser/documents/Makan a\%20Tourism\%20Report.pdf

Spykes, P. (2002). South African tourism industry empowerment and transformation annual review. Cape Town: Letsema and Infonomics.

Sofield, T.H.B. (2003). Empowerment for Sustainable Tourism Development. Oxford: Pergamon

South African Tourism, (2007). Annual Tourism Report 2007. Johannesburg. Retrieved [22.01.2008] from http://www.southafrica.net. 
Southall, R. (2007). Strategies to promote broad based economic empowerment in Namibia. In Broad-based economic empowerment: Experience from other developing countries. 9th Annual Symposium Publication, pp. 87-108. Windhoek: Bank of Namibia.

Squire, S.J. (1994). Accounting for cultural meanings: the interface between geography and tourism studies and tourism studies re-examined. Progress in Human Geography, 18, pp. 1-16.

Stenou K. (2004). UNESCO and the issue of Cultural Diversity: Review and Strategy, 1946-2004. Paris: UNESCO Publishing.

Steyaert, C. and Katz, J. (2004). Reclaiming the space of entrepreneurship in society: geographical, discursive and social dimensions. Entrepreneurship \& Regional Development, 16, pp. 179-196

Stone, P. (2008). Consuming dark tourism: A thanatological perspective. Annals of Tourism Research. 35 (2), pp. 574-595.

Storey, D. (1994). Understanding the small business sector. New York: Routledge.

Strauss, A. and Corbin, J. (1990). Basics of Qualitative Research: Grounded theory procedures and techniques. Newbury Park (CA): SAGE Publications

Storper, M. (1990). Industrialization and the regional question in the world: Lessons of post imperialism; prospects of post-fordism. International Journal of Urban and Regional Research, 14 (3), pp. 423-444.

Stuart, T. and Sorenson, O. (2003). The geography of opportunity: Spatial heterogeneity in founding rates and the performance of biotechnology firms. Research Policy, 32, pp. 229-253.

Tata, J. and Prasad, S. (2008). Social capital, collaborative exchange and microenterprise performance: The role of gender. International Journal of Entrepreneurship and Small Business, 5 (3/4), pp. 373-385.

Taylor, P. V. (1993). The Texts of Paulo Freire. Buckingham: Open University Press.

Taylor, J. (2001). Authenticity and sincerity in tourism, Annals of Tourism Research, 28, pp. 7-26.

Telfer, D. and Sharpley, R. (eds) (2008). Tourism and development in the developing world. Abingdon: Routledge.

The Presidency, (2007). Accelerated and Shared Growth Initiative of South Africa 2006 Annual Report. Pretoria. Retrieved [12.03.2008] from http://www.thepresidency.gov.za/docs/AsgiSA2006.pdf.

Timothy, D. (1998). Cooperative tourism planning in a developing destination. Journal of Sustainable Tourism, 6 (1), pp. 52-68.

Timothy, D.J. and Boyd, S.W. (2003). Heritage Tourism. Harlow: Prentice-Hall.

Todaro, M.P. (1994). Economic Development. ( $5^{\text {th }}$ edition). UK: Longman Group. 
Tomljenovic, R. and Faulkner, B. (2000). Tourism and World Peace: A Conundrum for the Twenty-first Century, in B. Faulkner; G.Moscardo; E.Laws (Eds.) Tourism in the Twenty-first Century, London: Continuum.

Tosun, C. (2006). Expected nature of community participation in tourism development. Tourism Management, 27 (3), pp. 493-504.

Tosun, C., and Timothy, D. J. (2003). Arguments for Community Participation in the Tourism Development Process. The Journal of Tourism Studies, 14 (2), pp. 2-15.

Tosun, C. (2000). Limits to Community participation in the tourism development process in developing countries. Tourism Management, 21 (6), pp. 613-623.

Tosun, C. (2006). Expected nature of community participation in tourism development. Tourism Management, 27 (3), pp. 493-504.

Trainer, T. (2002). Development, charity and poverty. The appropriate development perspective. International Journal of Social Economics. 29, (1/2), pp. 54-71.

Tripathi, N. and Bhattarya, S. (2004). Integrating indegenous knowledge and GIS participatory natural science resource management: State-of-the-Practice. Electronic Journal on Information Systems in Developing Countries, 17, (3), pp. 1-13.

Tropp, L. R. and Pettigrew, T. F. (2005a). Relationships between intergroup contact and prejudice among minority and majority status groups. Psychological Science, 16, pp. 951-957.

Tropp, L. R., and Pettigrew, T. F. (2005b). Differential relationships between intergroup contact and affective and cognitive indicators of prejudice. Personality and Social Psychology Bulletin, 31, pp. 1145-1158.

Tsheola, J. (2002). Basic Needs in the Northern Province and South Africa's globalization agenda. African Development Review, 14 (1), pp. 48-74.

Tong, R. (2009). Feminist thought: A more comprehensive introduction. ( $3^{\text {rd }}$ edition). Colorado: West View Press.

Tucker, H. (2007). Undoing shame: Tourism and women's work in Turkey. Journal of Tourism and Cultural change, 5 (2), pp. 87-105.

Tunbridge, J.E. and Ashworth, G.J. (1996). Dissonant heritage: the management of the past as a resource in conflict, London: Wiley.

Turok, B. (eds), (2008). Wealth Doesn't Trickle Down: the case for a Developmental State in South Africa. New Agenda: South African Journal of Social and Economic Policy. Cape Town.

Tuyezere, A.P. (2007). Gender and development: The role of religion and culture. Kampala: Fountain Publishers Limited.

Uchida, Y., Norasakkunit V. and Shinobu, K. (2004). Cultural constructions of happiness: Theory and empirical evidence. Journal of Happiness Studies, 5, pp. 223-239.

United Nations Millennium Development Goals, [MDGs]. Millennium Development Goals. Retrieved [14.12.2008] from http://www.un.org/millenniumgoals. 
UNWTO/UNIFEM (2011). Global Report on Women in Tourism 2010. ISBN: 978-92-8441373-7 (UNWTO), ISBN: 978-1-936291-36-6 (UN Women).

United Nations World Tourism Organization [UNWTO] (2009). World Tourism Barometer 7: 1, January 2009. UNWTO, Madrid. Retrieved [27.9.2009] http://www.unwto.org/facts/eng/pdf/barometer/UNWTO Barom09_1_en_ex cerpt.pdf.

United Nations World Tourism Organization [UNWTO] (2005). United Nations World Tourism Barometer, January, 3, (1), Madrid: UNWTO

United Nations World Tourism Organization [UNWTO] (2002). Enhancing the economic benefits of tourism for local communities and poverty reduction. Madrid: UNWTO.

Urry, J. (2002). The Tourist gaze. ( $2^{\text {nd }}$ edition). London: SAGE Publications.

Visser, G. and Rogerson, C.M. (2004). Researching the South African tourism and development nexus. GeoJournal, 60, pp. 201-215.

Wahab, S. and Pigram, J.J. (eds) (1997). Tourism, development and growth: the challenge of sustainability. London: Routledge.

Wang, N. (1999). Rethinking authenticity in tourism experience. Annals of Tourism Research, 26, pp. 349-70.

Welzel, C. (2006). Democratization as an emancipative process: the neglected role of mass motivations. European Journal of Political Research, 45 (4), pp. 871-96.

Welzel, C. and Inglehart, R. (2008). Democratization as human empowerment. Journal of Democracy, 18, pp. 126-140.

Wendt, S. (2008). Christianity and domestic violence: Feminist post-structural perspectives. Journal of Women and Social Work, 23 (2), pp. 144-115.

Wertz, F. (2005). Phenomenological research methods for counselling psychology. Journal of Counselling Psychology, 52 (2), pp. 167-177.

Wilce, J. (1998). Eloquence in Trouble: The Poetics and Politics of Complaint in Bangladesh. Oxford: Oxford University Press.

Wilk, R.R. (1999). 'Real Belizean food': building local identity in the transnational Caribbean. Am. Anthropology. 101 (2), pp. 244-55.

Wood, M.E. (1996). Issues of Class and Culture: An Interview with Aijaz Ahmad. Monthly Review, 48 (5), pp. 10-28.

Yanow, D. and Schwartz-Shea, P. (eds) (2006). Interpretation and method: Empirical research methods and the interpretive turn. Armonk, NY: M.E. Sharpe. 
Yu, L., and Chung, M. H. (2001). Tourism as a catalytic force for low-politics activities between politically divided countries: The cases of South/North Korea and Taiwan/China, New Political Science, 23 (4), pp. 537-545.

Zaaijer, M. and Sara, L. M. (1993). Local economic development as an instrument for urban poverty alleviation: a case from Lima, Peru. Third World Planning Review, 15, pp. 127-42.

Zeithamal, V.A. and Bitner, M.J. (2000). Services Marketing. New York: McGraw- Hill. 


\section{Summary}

Over the past few years Africa's economy has declined in per capita income in most countries and the level of poverty has risen significantly. For most governments restoring and sustaining rapid economic growth in order to generate wealth and economic expansion is a priority. To address the poverty crisis tourism has emerged as a popular strategy; however the sector's accrued benefits to the poor have been a topic of debate. In light of the socio-economic benefits that tourism can generate for the well-being of countries, the importance of exploring the possibilities of using various types of tourism as a potential option for poverty reduction has gained prominence. Against this background the emphasis of the South African government has been on incorporating the poor so they can benefit from tourism. The postapartheid government's development policies in South Africa are committed to a longterm process of structural transformation that will create a politically and economically independent state with a high level of human welfare. The initial chapter lays out the conceptual foundations of this research in terms of problem formulation and structuring, research questions and methods, and the country and site-specific context of the analysis. This involves an institutional framework evaluation of the Eastern Cape local economic development (LED) objectives in the Makana Municipality (local government level). At the project level an analysis of the Kwam eMakana home-stay pilot project is carried out and a comparative investigation on entrepreneurially run home-stays in Port Elizabeth is conducted to evaluate the effectiveness of government LED tourism initiatives as tools for attaining women economic entrepreneurial empowerment under the aegis of black economic empowerment (BEE).

In Chapter 2, the thesis presents the possible contribution of a critical pedagogic approach to an evaluation of black South African women's inclusion in the township tourism economy through cultural tourism home-stays. The author's connection to the tourism study area is explained, and descriptions of important episodes are provided illuminating the impact of the trauma of apartheid in the townships. The chapter then links the ideas of Freire (1978) to the concept of discourse, and uses the pedagogic approach to interpret township tourism as a potential conscientisation agent. The study utilizes a pedagogical approach to elucidate the workings of township tourism development and LED through three interrelated discourses which are relevant in the South African context. These are: space, conscientisation and inequality; tourism and 
LED; and tourism and poverty reduction. From a conscientisation point of view, it is important that prevailing socio-spatial arrangements are addressed in the planning of township tourism development. The chapter charts how poverty diminishes people and their potential to work for their collective advancement. Poverty in the townships is seen to have numerous manifestations including: low and unreliable income; poor health; low levels of education and literacy; insecurity and lack of access to justice; disempowerment; and isolation from the mainstream of socio-economic development.

In Chapter 3 the philosophical and methodological foundations of the study are presented, this necessitates an overview of the wider philosophy of social science research. This leads into the acceptance of the interpretive approach with hermeneutical considerations and a discussion of its validity ensues. It seeks to challenge the reader to think beyond the traditional notion of tourism and stresses the importance of emic and situated approaches to research. The discussion emphasises that everyday life cannot be separated either from tourism operators (hosts), tourists (guests) or from researchers who act as culturally situated story-tellers. Township tourism is presented as a phenomenon that can tell us about the place - a proposal which summons a theoretical shift as to what LED tourism is and does and what it can be and it can do. The role of tourism as a discipline and research orientation provides a conceptual framework. The importance of reflexivity is raised together with the relevant significance of positionality (situating myself) as researcher. The study utilizes different data collection methods at the local government level and an extensive analysis of secondary data sources and semi-structured methods used. At the project level a combination of observations (day and overnight visits), semi-structured interviews, questionnaire survey and discussion sessions were applied.

The study in Chapter 4 challenges the classic structure of government-led conceptual frameworks which fund top-down projects. It presents the first set of empirical findings of this study. The chapter proposes an approach to women economic empowerment anchored in developing and encouraging a truly entrepreneurial approach to wealth creation as an avenue to achieving BEE. Major attention is paid to how the national development objectives are understood and conceptualized by the representatives of BEE at local government and project levels and the ways in which they relate to the practical needs of project participants. Through local policy knowledge the study explores various opportunities, challenges and constraints related to the promotion of government LED tourism cultural home-stays in attaining 
women entrepreneurial economic empowerment. Additionally, a comparison with entrepreneurially women run tourism home-stays is presented. Findings show that government is clearly serious about doing something about economic development and wealth creation for the previously marginalized population, which, in many ways sets the country apart from other African countries. The lesson derived here is that government must be incentivized to implement the right policies. Sometimes this might mean government stays out of the way, thus enabling entrepreneurship and innovation from the citizenry. It concludes that to achieve $B E E$, more emphasis must be placed on an agenda that promotes prosperity and progressive human values.

The study then focuses on the economic contributions of tourism at local and project levels in Chapter 5. It analyses how formal and informal institutional arrangements of LED impact the women assuming ownership of the project. The chapter refers to a model derived from economic game theory to inform the argument that social interdependence can enhance the sustainability of LED women tourism home-stay initiatives. The chapter shows how foundations for a broad, sustained attack on poverty, and the creation of a more equitable society must be strengthened. At the same time, government, working together with the community (in this case the women tourism home-stay operators in townships) must take a number of targeted short term measures to directly address some critical causes and manifestations of poverty. In the light of these findings it is obvious that aspects of social interdependence in the LED women home-stay operators affect the tourism-LED nexus.

The research identifies and addresses some problematic aspects of research on the role of tourism for poverty reduction. Chapter 6 reviews some of the discourses on small medium micro enterprises (SMMEs) that combine tourism, development and poverty reduction. The chapter presents a debate on how the past structures continue to impact the development consciousness of women LED tourism home-stay participants in South Africa. It employs empowerment and Sen's capabilities approach to poverty reduction and empirical evidence explains how the women operators' competencies impact their performance and bargaining with the LED tourism initiative to attain entrepreneurial economic empowerment. This chapter shows that the tourism-LED nexus in South Africa involves highly topical issues related to tourism planning, power relations, community participation and capabilities. South Africa offers a particularly interesting context for the study of these issues due to its colonial 
legacy, vast tourism potential, LED and tourism policies and BEE approaches to tourism development.

The assessment of cultural commoditization in Chapter 7 highlights the possibilities and consequences of cultural misconception, and presents explanations in the role of culture as a natural resource in tourism. The discussion includes the potential of poor communities rich in intangible resources such as culture, which are often located near famous tourist sites. The debate maintains that if well combined and integrated into tourism products, these resources, intangible and tangible, can become a powerful tool for poverty reduction. The concepts of indigenous knowledge and emancipative beliefs are used to explain the relationship between hosts and guests. The study contests more traditional ways of perceiving the workings of cultural tourism, and on a more general level, social action and cultural expressions. This opens new possibilities and offers great potential for new understandings. The findings indicate that in the government initiated cultural township tourism home-stays, the LED policy objectives appear complex and ambiguous thus curtailing their achievement. Furthermore, they involve multiple meanings and interpretations which reflect the diversity of the South African socio-cultural and economic terrain, and restrictions on the capacity of tourism, to address the set LED objectives.

In Chapter 8, the study concludes that, in order to promote women entrepreneurial empowerment and reduce poverty, the government should not only target inclusion of the previously marginalized population into the tourism economy. It is also important to pay attention to how the development consciousness of the previously marginalized population is connected to past trauma and structures that the country was exposed to. The poor must be provided with the means to help themselves through income earning opportunities, access to means of production, and the provision of affordable, basic services. This will not be achieved through temporary relief programmes but through a deliberate and long term policy to increase equity of opportunity and to ensure that all members of society can participate fully in the socio-economic development of the country. The current LED trajectory presents a necessary first step in attaining $\mathrm{BEE}$, however, it is important that development programs in tourism are implemented against strong economic cases and not as social appeasement projects, as this approach is seldom sustainable. The reasons for government's promotion of tourism as an LED option are primarily economic. As an economic field, tourism is based on business principles such that considerations of visitor numbers and 
expenditures, export output, capital investment, income and employment are equally important. It is, therefore, necessary to devise multi-dimensional policies and interventions that will provide a permanent solution to the poverty crisis facing the country. 


\section{Summary in Dutch}

In de afgelopen paar jaar is in de meeste Afrikaanse landen het inkomen per hoofd van de bevolking gedaald en is het armoedeniveau aanzienlijk gestegen. Voor de meeste regeringen vormen herstel en continuering van economische groei een prioriteit, omdat er dankzij deze groei welvaart en economische expansie kan worden gegenereerd. Om de armoedecrisis het hoofd te bieden, heeft het toerisme opgang gemaakt als populair strategisch middel - maar in welke mate de armen profiteren van de groei van deze sector is een onderwerp van discussie. Gezien de sociaaleconomische voordelen die het toerisme kan opleveren voor het welvaartsniveau van een land, wordt er steeds meer gekeken naar verschillende soorten toerisme die kunnen worden aangewend om armoede terug te dringen. Tegen deze achtergrond poogt de Zuid-Afrikaanse regering nadrukkelijk de armen bij het toerisme te betrekken, zodat ook zij hiervan kunnen profiteren. Het ontwikkelingsbeleid van de post-apartheid regering in Zuid-Afrika is gericht op een langetermijnproces van structurele transformatie dat moet leiden tot een politiek en economisch onafhankelijke staat met een hoog welvaartsniveau. In het eerste hoofdstuk wordt de conceptuele basis van dit onderzoek behandeld: de probleemstelling en structurering, de onderzoeksvragen en -methoden, en de specifieke context (land en locatie) van de analyse. Hiertoe wordt het institutionele kader van de doelstellingen van de 'local economic development' (LED) van de Oostkaap in de gemeente Makana (lokaal overheidsniveau) geëvalueerd. Op projectniveau wordt er een analyse van het Kwam eMakana homestay-pilotproject uitgevoerd. Ook wordt er een vergelijkend onderzoek uitgevoerd naar zogeheten 'homestays' in Port Elizabeth die worden geleid als kleine ondernemingen. Aan de hand hiervan wordt geëvalueerd hoe effectief deze LED-overheidsinitiatieven in de toerismesector zijn als instrument om vrouwen uit te laten groeien tot financieel zelfstandige ondernemers onder de zogeheten 'Black Economic Empowerment' (BEE) wetgeving.

In hoofdstuk 2 wordt een kritische pedagogische aanpak gepresenteerd die een bijdrage kan leveren aan de evaluatie van een project waarbij zwarte Zuid-Afrikaanse vrouwen via homestays in het kader van cultureel toerisme betrokken worden bij de economie van het townshiptoerisme. De relatie van de auteur met het onderzoeksterrein, het toerisme, wordt uitgelegd en er worden belangrijke gebeurtenissen beschreven om de impact te tonen die het trauma van de apartheid op de townships heeft gehad. Vervolgens worden de ideeën van Freire (1978) gekoppeld 
aan het onderzoeksgebied en wordt er een pedagogische aanpak gebruikt om het townshiptoerisme te interpreteren als potentieel bewustmakingsinstrument. Bij het onderzoek wordt een pedagogische benadering gevolgd om de werking van de ontwikkeling van townshiptoerisme en LED te verduidelijken. Dit gebeurt aan de hand van drie onderling gerelateerde onderwerpen die relevant zijn in de context van ZuidAfrika, te weten: 1) ruimte, bewustmaking en ongelijkheid, 2) toerisme en LED, 3) toerisme en armoedebestrijding. Vanuit het perspectief van bewustmaking is het belangrijk dat de heersende sociaal-ruimtelijke ordening aan de orde komt bij de planning van de ontwikkeling van townshiptoerisme. In dit hoofdstuk wordt uiteengezet hoe armoede een ondermijnend effect heeft op mensen en hun vermogen om te werken aan gezamenlijke vooruitgang. Armoede in de townships komt tot uiting op velerlei manieren, zoals: laag en geen vast inkomen; slechte gezondheid; laag opleidings- en alfabetiseringsniveau; onveiligheid en geen toegang tot het rechtssysteem; gebrek aan zelfredzaamheid en uitsluiting van de algemene sociaaleconomische ontwikkeling.

In hoofdstuk 3 worden de filosofische en methodologische grondslagen van het onderzoek gepresenteerd, waarbij tevens de bredere filosofie achter sociaalwetenschappelijk onderzoek aan bod komt. Dit leidt vervolgens tot het accepteren van de interpretatieve aanpak met hermeneutische overwegingen, waarna de validiteit van deze methode besproken wordt. In dit hoofdstuk wordt getracht de lezer uit te dagen om buiten de traditionele opvattingen over toerisme te denken en wordt het belang van emische en gesitueerde benaderingen voor het onderzoek benadrukt. Hierbij is het belangrijk om te beseffen dat voor alle betrokkenen geldt dat het dagelijks leven niet gescheiden kan worden van hun rol in het onderzoek als toerisme-ondernemer (gastvrouwen), als toerist (gasten) of als onderzoeker die optreedt als cultureel gesitueerde verhalenverteller. Townshiptoerisme wordt gepresenteerd als een fenomeen dat ons iets kan vertellen over de plaats - een opvatting die vraagt om een theoretische verschuiving ten aanzien van wat LEDtoerisme is en doet en wat het kan zijn en kan doen. De rol van het toerisme als discipline en onderzoeksrichting levert een conceptueel kader op. Het belang van reflexiviteit komt samen met het relevante belang van mijn positionaliteit als onderzoeker ('hoe situeer ik mezelf') aan de orde. Er wordt ten behoeve van het onderzoek gebruik gemaakt van verschillende methoden voor het verzamelen van gegevens op het niveau van de lokale overheid. Daarnaast is er sprake van een uitgebreide analyse van de gehanteerde secundaire gegevensbronnen en semigestructureerde methoden. Op projectniveau werd een combinatie van 
waarnemingen (bezoeken overdag en 's avonds), semigestructureerde interviews, vragenlijsten en discussiesessies gehanteerd.

In hoofdstuk 4 zet het onderzoek vraagtekens bij de klassieke structuur van door de overheid geleide conceptuele kaders die top-down projecten financieren. In dit hoofdstuk wordt tevens de eerste reeks empirische bevindingen van dit onderzoek gepresenteerd. Ook wordt er een aanpak voor het bevorderen van financiële zelfstandigheid van vrouwen voorgesteld; hierbij wordt echt ondernemerschap ontwikkeld en gestimuleerd, met als doel welvaart te creëren en zodoende BEE te bewerkstelligen. Er wordt veel aandacht besteed aan de manier waarop de nationale ontwikkelingsdoelstellingen worden opgevat en geconceptualiseerd door BEEvertegenwoordigers op lokaal overheidsniveau en projectniveau. Ook wordt er gekeken naar de manier waarop zij omgaan met de praktische behoeften van de deelnemers aan het project. Aan de hand van kennis van het lokale beleid worden diverse mogelijkheden, uitdagingen en beperkingen met betrekking tot het promoten van culturele homestays onderzocht. Deze culturele homestays zijn door de overheid in het kader van LED-toerisme opgezet en hebben tot doel de financiële zelfstandigheid van vrouwen te bevorderen. Daarnaast wordt de vergelijking gemaakt met toeristische homestays die door vrouwen als kleine zelfstandige worden gerund. De onderzoeksuitkomsten wijzen uit dat de overheid serieus van plan is om iets te doen aan economische ontwikkeling en welvaartsbevordering voor gemarginaliseerde bevolkingsgroepen, waarmee Zuid-Afrika zich duidelijk onderscheidt van andere Afrikaanse landen. De les die hieruit getrokken kan worden, is dat de overheid geprikkeld moet worden om de juiste beleidslijnen te implementeren. Soms kan dit betekenen dat de overheid zich juist niet met een project bemoeit, waardoor er volop ruimte is voor ondernemerschap en innovaties van de kant van de burgers zelf. Tot slot wordt er vastgesteld dat, wil de overheid daadwerkelijk BEE realiseren, er meer nadruk moet worden gelegd op een agenda die welvaart en progressieve menselijke waarden stimuleert.

Het onderzoek richt zich in hoofdstuk 5 vervolgens op de economische bijdragen die het toerisme levert op lokaal niveau en op projectniveau. Er wordt geanalyseerd hoe formele en informele institutionele LED-regelingen invloed hebben op de mate waarin vrouwen het project naar zich toe trekken. In dit hoofdstuk wordt verwezen naar een model dat is afgeleid van economische speltheorie. Aan de hand hiervan wordt betoogd dat sociale interdependentie de slaagkans van deze homestay-initiatieven voor vrouwen in het kader van LED-toerisme kan bevorderen. Er wordt eveneens aangetoond dat er een meer solide basis nodig is om armoede grondig te bestrijden en 
om een meer gelijkwaardige maatschappij te creëren. Tegelijkertijd moet de overheid samenwerken met de gemeenschap (in dit geval de vrouwen die toeristische homestays runnen in de townships) en een aantal gerichte kortetermijnmaatregelen nemen waarmee enkele cruciale oorzaken en symptomen van armoede kunnen worden aangepakt. In het licht van deze bevindingen is het logisch dat aspecten van sociale interdependentie (onder de vrouwen die homestays runnen) invloed hebben op het verband tussen lokale economische ontwikkelingen en het toerisme.

Het onderzoek brengt enkele problematische aspecten naar voren met betrekking tot de rol die het toerisme speelt bij armoedebestrijding. In hoofdstuk 6 worden micro-, kleine en middelgrote ondernemingen (Engels acroniem: 'SMME') bekeken die toerisme, ontwikkeling en armoedebestrijding combineren. Tevens wordt besproken in welke mate de oude structuren nog altijd van invloed zijn op het bewustzijn en zelfvertrouwen van de vrouwen die deelnemen aan LED-projecten voor toeristische homestays in Zuid-Afrika. Hierbij komen zelfverwezenlijking en Sens 'capabilities approach' voor armoedebestrijding aan de orde. Met behulp van empirisch bewijs wordt verklaard hoe de competenties van deze vrouwen hun prestaties beïnvloeden en welke gevolgen dit heeft voor hun onderhandelingspositie als deelnemer aan dit initiatief in het kader van LED-toerisme (dat bedoeld is om hen te leren als ondernemer op eigen benen te staan). In dit hoofdstuk wordt aangetoond dat er bij het verband tussen toerisme en LED in Zuid-Afrika bijzonder actuele onderwerpen spelen op het gebied van toerismeplanning, machtsrelaties, gemeenschapsparticipatie en ontplooiingsmogelijkheden. Vanwege het koloniale verleden, het gigantische toeristische potentieel, het LED- en toerismebeleid en BEE-benaderingen voor de ontwikkeling van het toerisme biedt Zuid-Afrika een enorm interessante context om deze onderwerpen te onderzoeken.

De culturele comodificatie die in hoofdstuk 7 aan de orde komt, belicht de mogelijkheden en gevolgen van culturele misvattingen en biedt verklaringen voor de rol van cultuur als een natuurlijke hulpbron in het toerisme. De discussie gaat ook over het potentieel van arme gemeenschappen die rijk zijn aan niet-tastbare hulpbronnen (zoals cultuur) en vaak gelegen zijn in de buurt van toeristische trekpleisters. Er wordt beweerd dat, mits deze tastbare en niet-tastbare hulpbronnen goed gecombineerd en geïntegreerd worden in toeristische producten, ze uit kunnen groeien tot een krachtig instrument voor armoedebestrijding. De concepten inheemse kennis en emancipatorische opvattingen worden gebruikt om de relaties tussen gastvrouwen en gasten te verklaren. Het onderzoek zet vraagtekens bij de meer traditionele zienswijzen op de werking van cultureel toerisme en, in algemenere zin, sociale actie 
en culturele uitingen. Dit opent nieuwe mogelijkheden en biedt een enorm potentieel voor nieuwe inzichten. Het onderzoek wijst uit dat de LED-beleidsdoelstellingen voor de door de overheid in het kader van cultureel toerisme geïnitieerde homestays complex en ambigu lijken, waardoor het bereiken van deze doelstellingen bemoeilijkt wordt. Bovendien spelen hierbij meerdere betekenissen en interpretaties een rol; een afspiegeling van de diversiteit van het Zuid-Afrikaanse sociaal-culturele en economische landschap. Daarnaast zijn er beperkingen aan de capaciteit van de toerismesector om de gestelde LED-doelstellingen te verwezenlijken.

In hoofdstuk 8 wordt erop gewezen dat de overheid zich er niet alleen op dient te richten om de gemarginaliseerde bevolking simpelweg te betrekken bij de toerismeeconomie, als zij ondernemerschap onder vrouwen wil bevorderen en armoede terug wil dringen. Het is eveneens belangrijk aandacht te schenken aan de manier waarop het bewustzijn van deze bevolkingsgroep ten aanzien van de eigen ontwikkeling in verband staat met de oude trauma's en structuren waaraan het land vroeger was blootgesteld. De armen moeten middelen geboden worden om zichzelf te redden; wat ze nodig hebben zijn mogelijkheden om geld te verdienen, toegang tot productiemiddelen en betaalbare basisvoorzieningen. Dit zal niet worden bereikt door middel van tijdelijke hulpprogramma's maar wel dankzij een weloverwogen langetermijnbeleid dat gelijke kansen bevordert en door ervoor te zorgen dat alle leden van de maatschappij zonder belemmeringen kunnen bijdragen aan de sociaaleconomische ontwikkeling van het land. Het huidige LED-traject vertegenwoordigt een noodzakelijke eerste stap richting het realiseren van BEE. Het is echter belangrijk dat ontwikkelingsprogramma's in het toerisme worden geïmplementeerd op een gezonde financiële basis en niet als sociale 'zoethoudertjes', aangezien een dergelijke aanpak zelden langdurig resultaat oplevert. De redenen waarom de overheid toerisme promoot als LED-optie liggen voornamelijk op economisch vlak. Het toerisme is een economische sector die gebaseerd is op zakelijke principes. Dit betekent dat bezoekersaantallen en uitgaven, exportopbrengsten, kapitaalinvesteringen, inkomens en werkgelegenheid van cruciaal belang zijn. Het is derhalve noodzakelijk om veelzijdige beleidslijnen en interventiemethodes te ontwikkelen die een permanente oplossing kunnen bieden voor de armoedecrisis waar het land mee worstelt. 


\section{Appendix 1: Home-stay facilities}

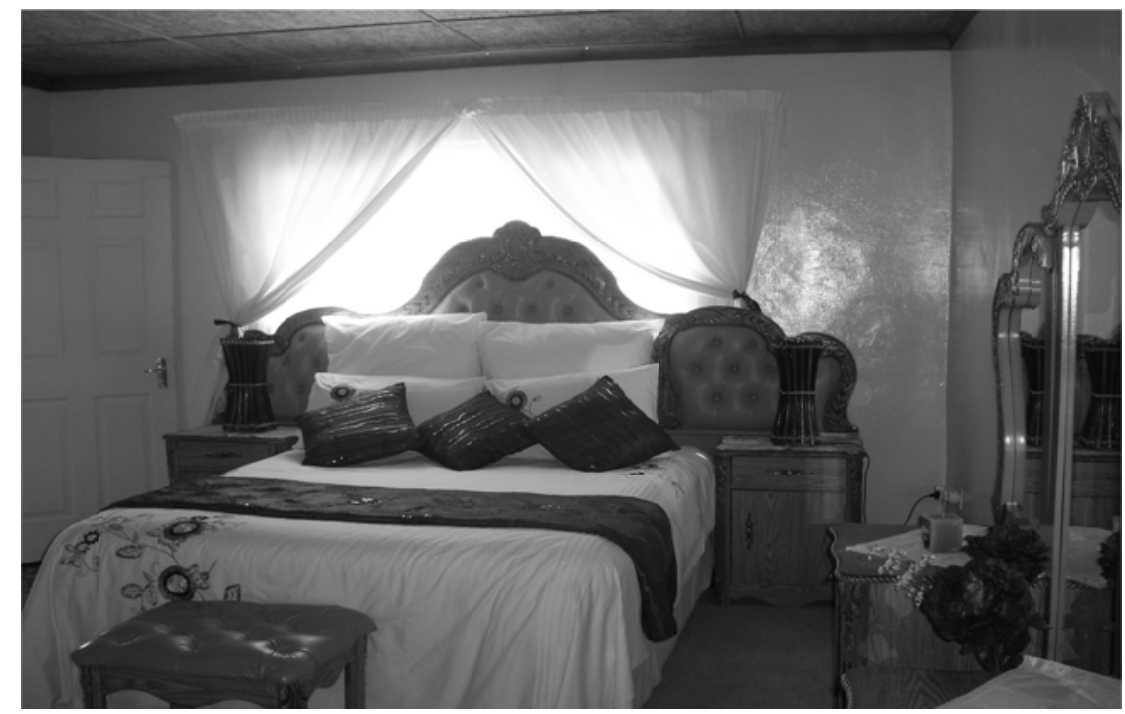

Bedroom at KL home-stay

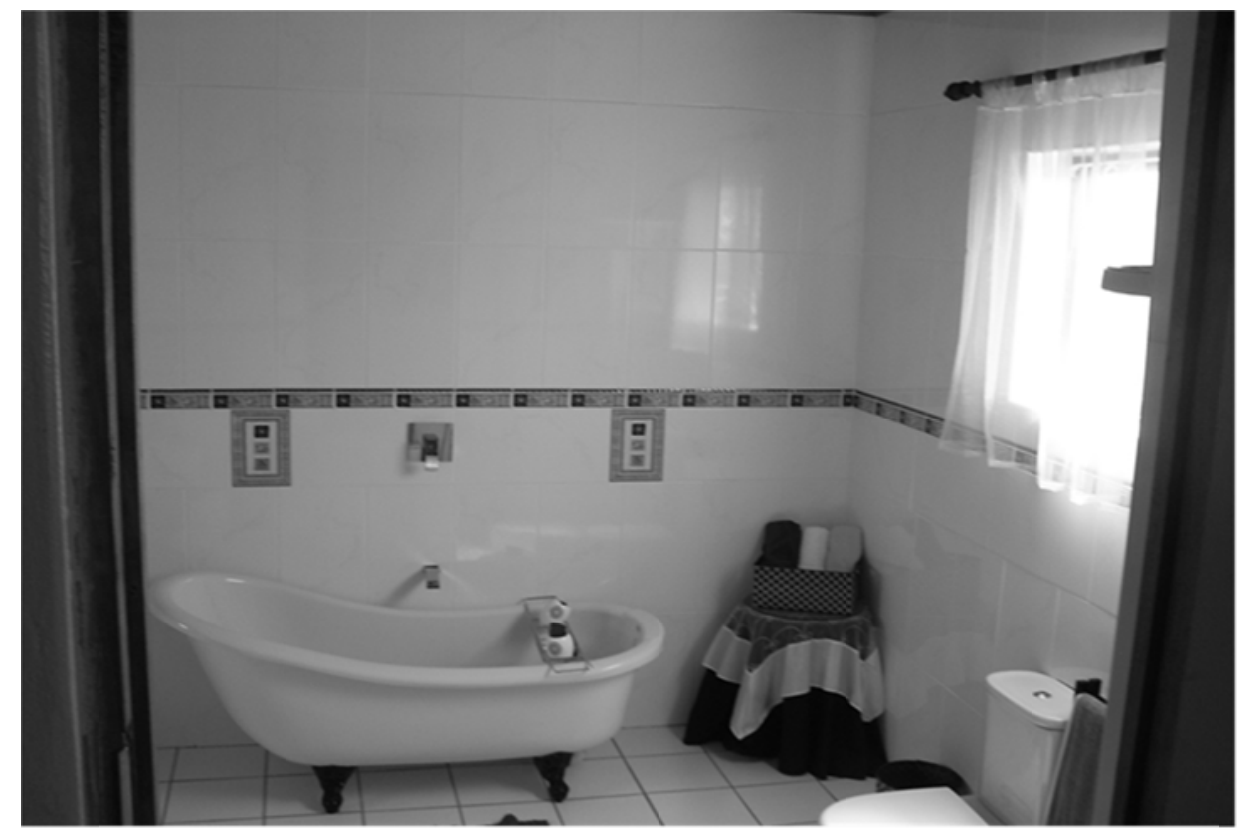

Bathroom at KL home-stay 


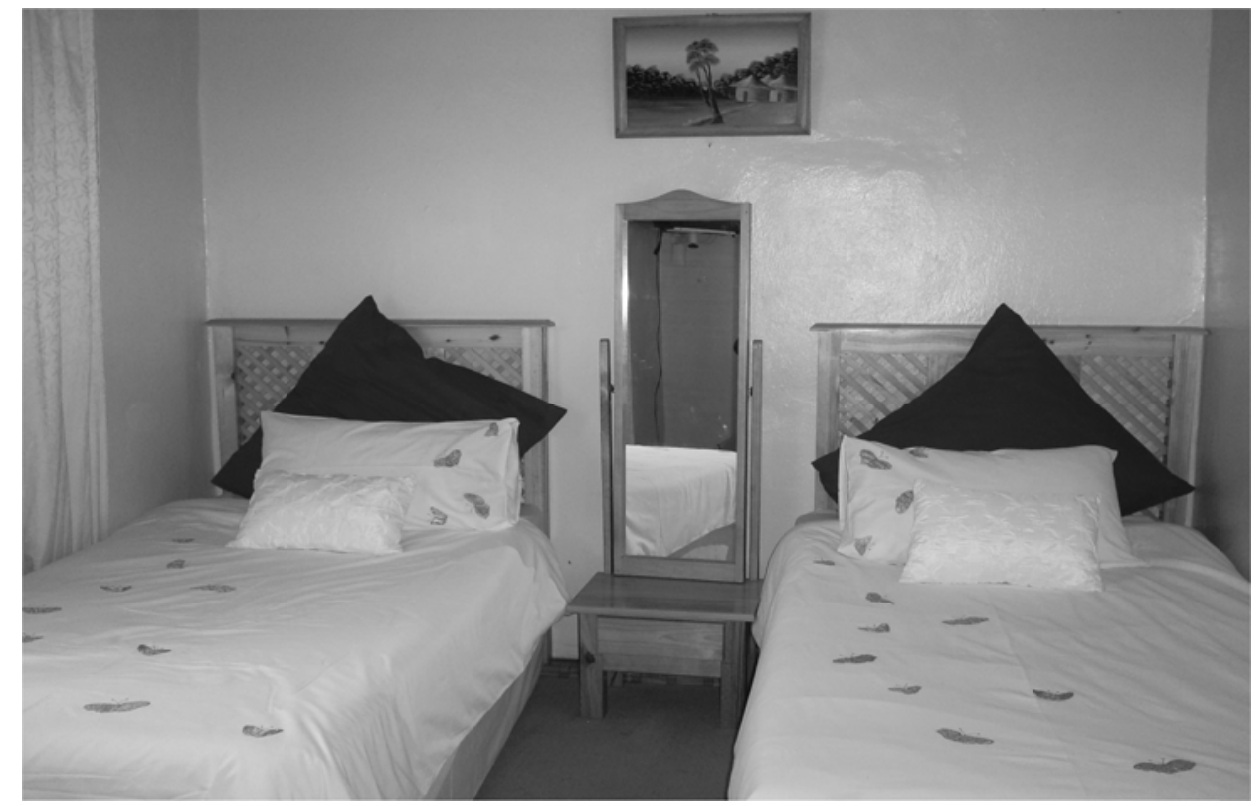

Bedroom at KK home-stay

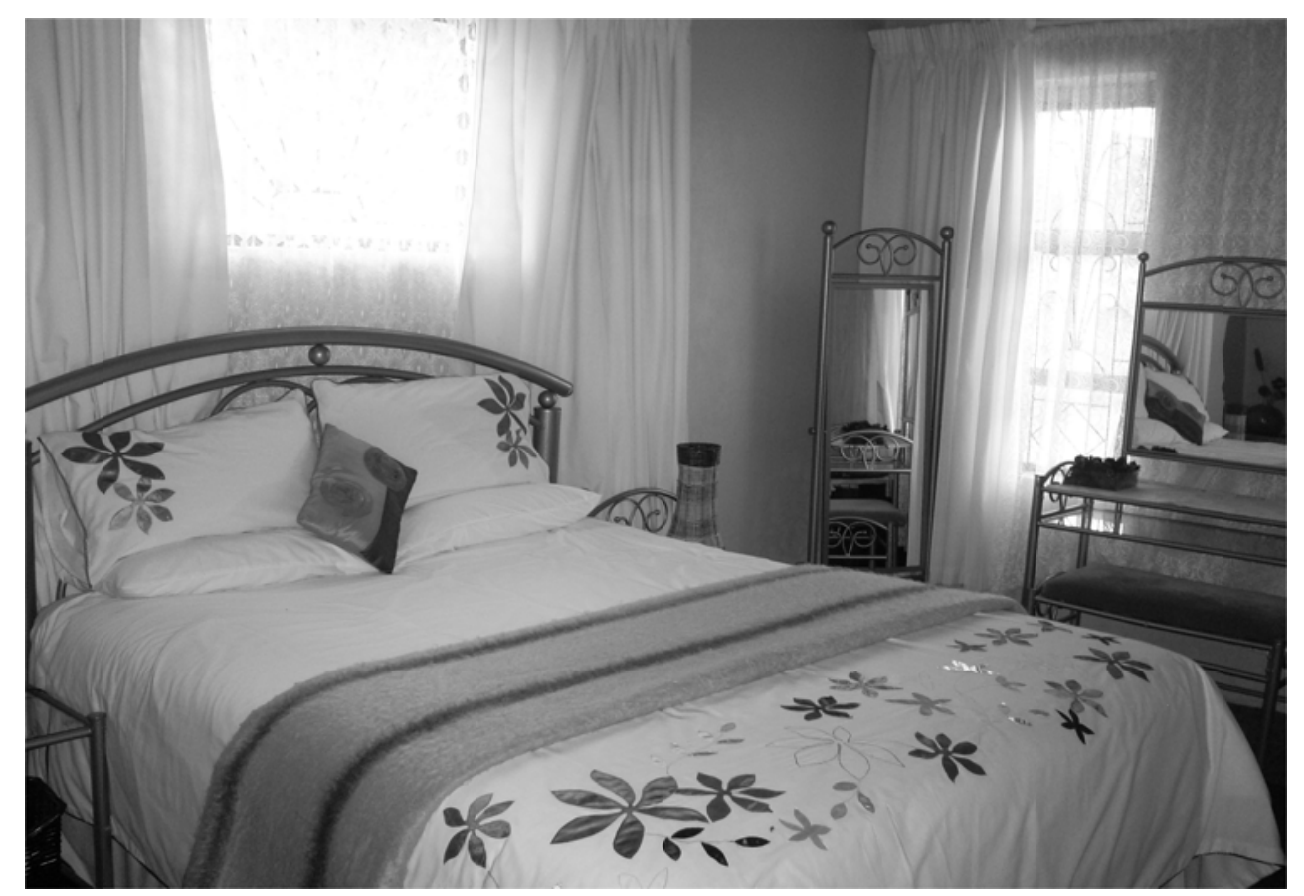

Bedroom at KL home-stay 


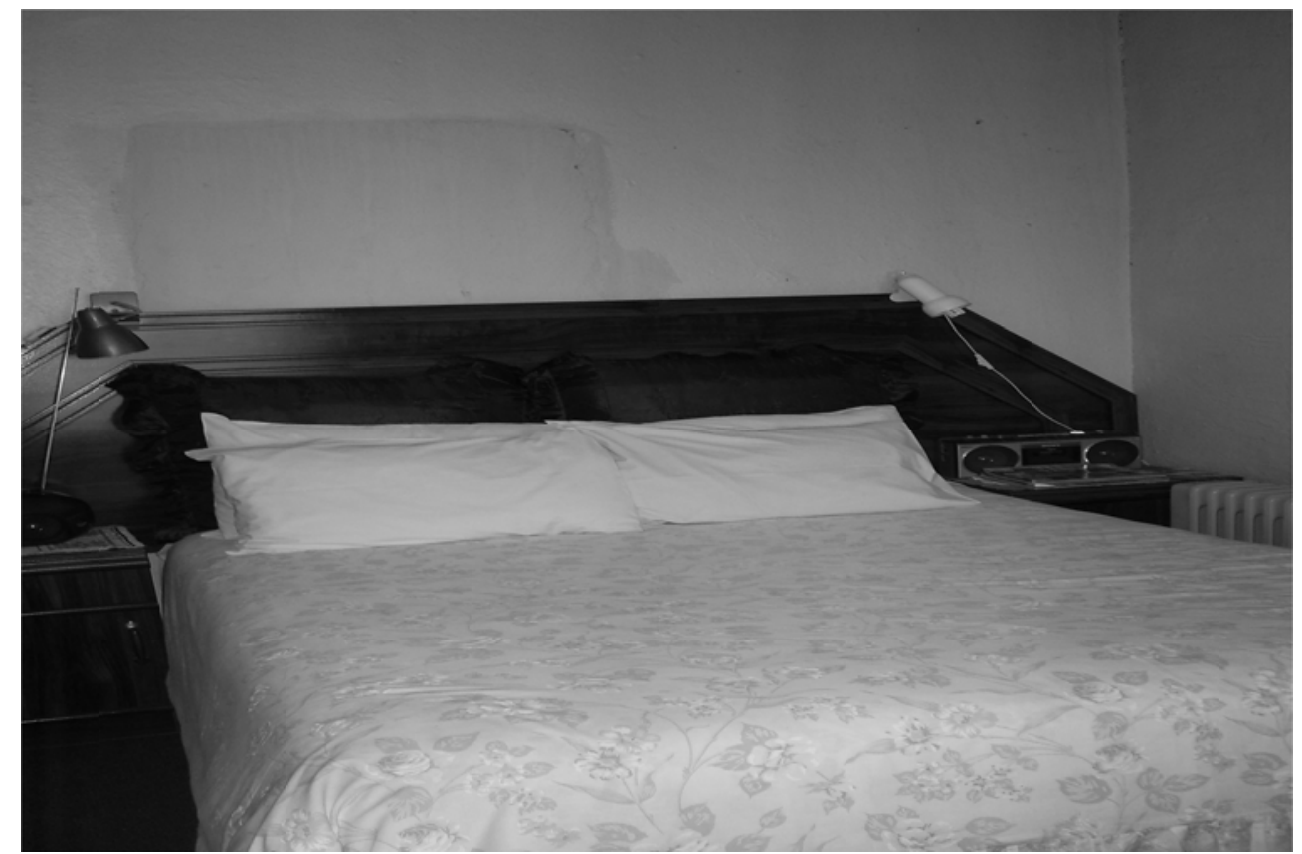

Bedroom at KE home-stay

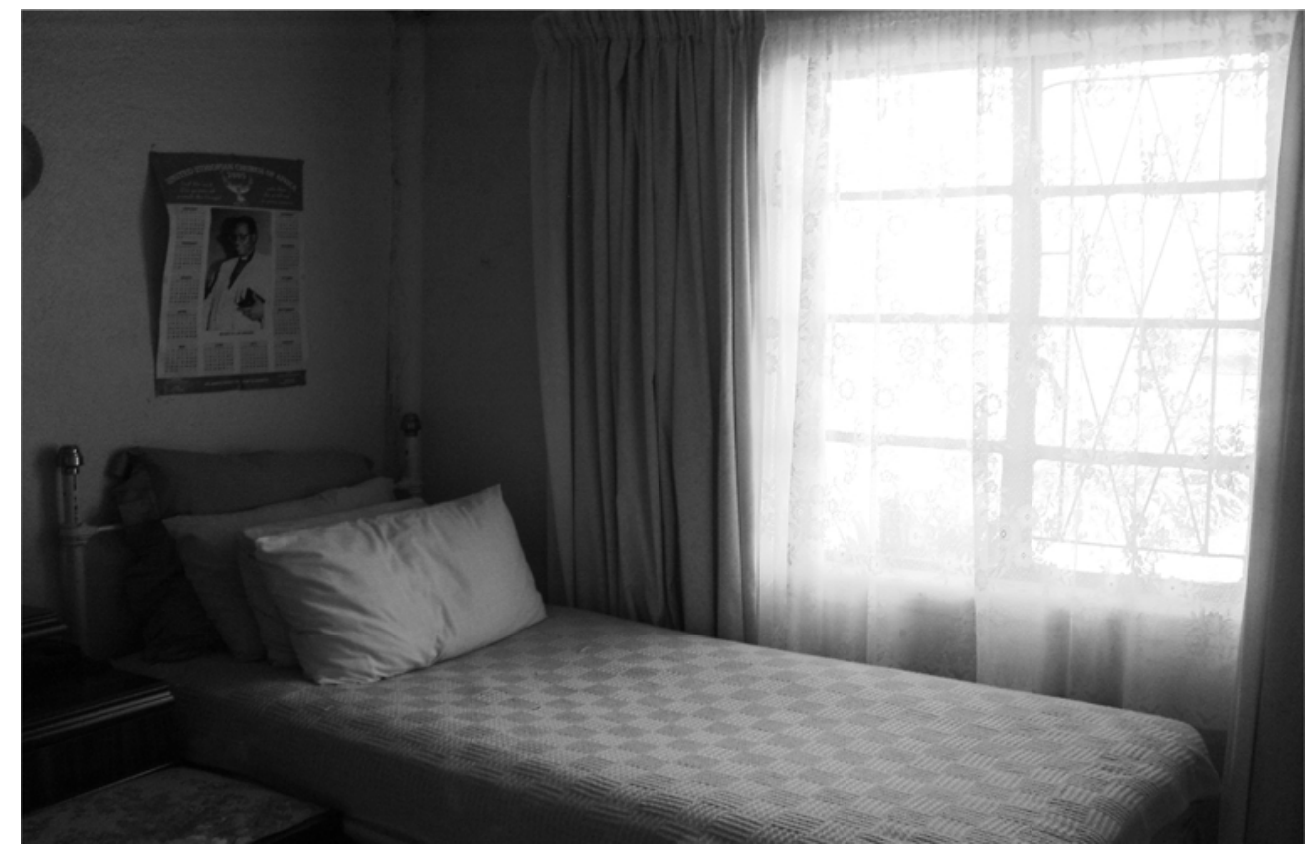

Bedroom at KE home-stay 


\section{Appendix 2: Economic Theory}

Using game theory from economics and applied mathematics [1,2], we will show that though Autonomy seems to give LED a jump initially, it is not sustainable in the long run. In fact we will show that with Autonomy, the women will eventually return to state of no profit (and thus folding their hands and waiting for the government to do it for them). On the other hand, the communal life of these women if properly directed and inspired will lead to a more sustainable LED. We now define the following words and notations:

$N \quad$ set of all the women in "mention the community name"

$i \quad$ index for women in $N$

$c_{i} \quad$ cost of operation for woman $i \in N$

$p_{i}^{t} \quad$ profit made by woman $i$ at time $t$

$K_{i}^{t} \quad$ cost of a rental home of woman $i$ at time $t ; K_{i}^{t}=c_{i}+p_{i}^{t}$

$L E D^{t}$ LED at time $t ; L E D^{t}=\sum_{i=1}^{N} p_{i}^{t}$

Autonomy (AT) in this setting will mean where each woman $i \in N$ tries to maximize her own profit $p_{i}^{t}$ at any point in time $t$. In fact Autonomy brings in competition among these women. In other words, we can say that Autonomy leads to profit maximization game among these women.

Social Interdependence (ID) in this setting will mean a communal life among the women where they direct their objective to improve the welfare (profit) of members, which in turn improves LED. It will be seen as a grand coalition of all the women where they all come together and agree to pursue a common interest as opposed to competition in the Autonomy case.

LED in this setting will represent the economic development of this community which of course depends on how well these women successfully carry out their business plans. It is natural to assume that their business plan (whether AT or ID) is to maximize the profit they make.

Claim 1: A setting with $100 \%$ Autonomy will lead to a zero LED in the long run.

Proof: We will assume that LED is a measure of profit level in the businesses undertaken by these women. We again define the following: one-shot price setting to mean a situation where each woman ${ }^{1}$ sets the price of her rental home without the knowledge of the price set by other women. It is intuitive to assume that one-shot price setting is the initial price setting among these women. Then, because each

\footnotetext{
${ }^{1}$ we will use "woman" and "player" interchangeably
} 
woman is selfish, and knowing that people will prefer a cheaper accommodation with the same facilities, she will now make a move setting a price that is lowest among other women of the same commodity. Since each of the women will behave in the same way, it means that in turns, these women will keep reducing their profit until each has zero profit. Of course, no player will set a price that is beyond the operational cost $c_{i}$. In what follows, we will assume that these women have identical rental facilities (i.e. $c_{i}$ is the same for all $i$ ) or at least the same cost for a unit of facility. Mathematically, we have the following:

At $t=1$, we have that

$$
\begin{aligned}
& K_{i}^{1}=c_{i}+p_{i}^{1} \quad \forall i \in N \\
& \left.\therefore L E D^{1}=\sum_{i=1}^{N} p_{i}^{1}>0 \quad \text { (it is intuitive to assume that } p_{i}^{1}>0 \quad \forall i \in N\right)
\end{aligned}
$$

Now, to attract guests, an arbitrary player (woman) $j$ will set the cost of her rental home such that she has the cheapest home in town, i.e.

$$
\begin{gathered}
\qquad K_{j}^{2}=c_{j}+p_{j}^{2} \quad \text { such that } 0<p_{j}^{2}<p_{i}^{1} \quad \forall i \in N \backslash j \\
\text { implies that } L E D^{2}=\sum_{i=1}^{N} p_{i}^{2}<\sum_{i=1}^{N} p_{i}^{1} \\
\therefore L E D^{2}<L E D^{1}
\end{gathered}
$$

Here we take the time step $t$ to represent the moves of the players. So, $p_{i}^{2}$ represents the profit set by player $i$ in her second move (turn). In the same way (in the next time step $t=3$ ), an arbitrary player $k$ will set the cost of her rental home such that she has the cheapest home in town, i.e.

$$
\begin{aligned}
& K_{k}^{3}=c_{k}+p_{k}^{3} \quad \text { such that } 0<p_{k}^{3}<p_{i}^{2} \quad \forall i \in N \backslash k \\
& =c_{k}+p_{k}^{3} \quad \text { such that } 0<p_{k}^{3}<p_{j}^{2} \quad \text { where } \mathrm{j} \text { is the last player in } t=2
\end{aligned}
$$

$$
\therefore L E D^{3}<L E D^{2}
$$

Observe from the second line above that the lowest profit from the previous round of play $(t=2)$ must be the profit set by the last player in that round (in this case, player $j$ ). Owing to the competitive nature of the game, this chain of event continues as time $t$ increases. It holds in general that $p_{i}^{t}<p_{i}^{t-1}$ and $L E D^{t}<L E D^{t-1}$ for any time step $t$, Thus, in the long run $(I r), p_{i}^{t=l r}=0$, implying that $K_{i}^{t=l r}=c_{i} \forall i \in N$, where $t=I r$ means time in the long run. Therefore, at $t=I r$, the $L E D^{t=l r}=0$. If we take $I r=1$ year, 
it means that the total profit made by a woman in the 2 nd year is zero. At $t=I r$, observe that no player will be interest in the business again since no one makes any profit out of it, thus we are back to situation with no LED. Thus, we conclude that Autonomy (and hence competition) leads to non-sustainable LED.

Claim 2: A setting with $100 \%$ Inter-dependency will lead to a more sustainable and fast growing LED.

Proof: Now we assume that the women come together with a sole aim of maximizing the profit they make from all the rental homes. They will set up a committee that will be in charge of price setting and allocation of the homes to guests. They will set a flat price for all commodities of the same facility, in this way, guests have no preference for homes of the same commodity. The women will have to agree on a profit allocation rule (which may depend on the number of rental home that each woman has) prior to the coalition. The allocation rule looks at the total profit made and not the facility allocated. Thus with certainty, every woman is guaranteed of profit above zero at the end of every year provided that at least one home is rented out that year. Given that at least $50 \%$ of the homes are rented out each year, then the LED at any point in time is maintained above a certain level. This is not the case with Autonomy, even with $100 \%$ rental possibility, the LED for Autonomy will still drop to zero in the long run. Again, note that part of profit made from these facilities can be used to start off other businesses, thus increasing their income which in turn improves LED. In this case, $L E D^{t} \geq L E D^{t-1}$ for any time step $t$. The women can always adjust the rental prices without fear that it may not be hired since there are no other competitors in the community. In this way, we can say that the ID leads to a growing and more sustainable LED if the women stay in their usual communal way of life, but more business oriented.

One may argue that a player can leave this grand coalition and be better off (i.e. make more profit) controlling her own rental home. In what follows, we claim that in the long run, no player will be better off outside the grand coalition $N$.

Claim 3: No woman will be better off being Autonomous. In other words, no player is better off leaving the communal grand coalition ID.

Proof: Suppose a player $k$ will be better off leaving the grand coalition $N$, then it means that when she pulls out of $N$, she will set the price of her home to be at least slightly less than that set by the coalition $N$ for the same commodity. We suppose that the profit she makes in this home will be greater than the profit coalition $N$ allocates to her. But then, the coalition $N$ without $k(N \backslash k)$ acting as one Autonomous entity, will in turn set a price that is less than that set by player $k$ for the same commodity. As in the 
proof of claim 1, the price setting game will continue until the profit for this commodity is zero. Now, players in $N \backslash k$ will still make profit on other commodities, thus, guaranteeing each woman a non-zero profit after profit allocation. On the other hand, player $k$ gains nothing both from the coalition $N \backslash k$ which she is not part of and from her home which she now rents for the operational cost. See then that this woman will be back to the communal grand coalition ID where she can guarantee herself at least a profit greater than zero. This claim can be interpreted as having a percentage of the women practicing AT and other ID. As a result of claim 3, we give the following corollary:

Corollary: LED will grow sustainably only if there is $100 \%$ Inter-dependency among the women.

Proof: Follows from claim 1, 2 and 3.

Diagrammatic representation of the relationship between LED, AT and ID over time $t$.

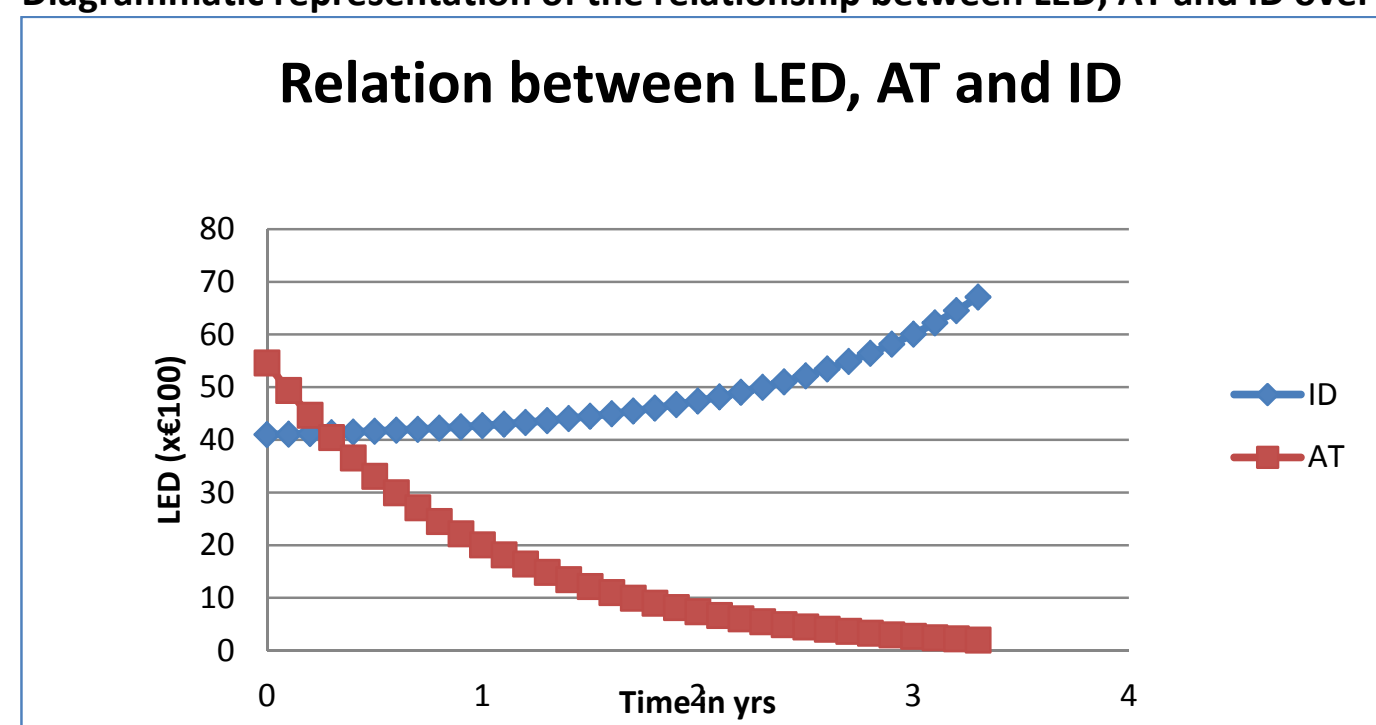

Observe that as $t$ increases, the LED for AT tends to zero very fast while that of ID increases steadily. 


\section{References}

[1] J. Nash. Non-Cooperative Games. Annals of Mathematics, 54(2):286-295, 1951.

[2] Noam. Nisan, Tim Roughgarden, Eva Tardos, and Vijay V. Vazirani. Algorithmic game theory.

Cambridge University Press, New York, USA, July 2007. 


\section{Appendix 3: Summary of the differences between traditional and modern Xhosa food}

\author{
XHOSA CUISINE \\ FOOD \\ TRADITIONAL STARCH \\ Sorghum \\ Maize (corn, mealies) \\ Umngqusho (hominy corn with beans and \\ spices) \\ MEAT \\ Own livestock and hunting wild animals \\ Small intake (2 - 3 times a year and on special \\ occasions) \\ Cattle seen a means of communication with \\ forefathers \\ Cattle regarded as a status symbol of wealth
}

\author{
VEGETABLES \\ Gathered wild and home-grown vegetables \\ Unique indigenous vegetables \\ Limited variety \\ Totally seasonal \\ Only traditionally cooked vegetables consumed
}

FRUIT

Wild fruit the only source

Variety and quantity strictly seasonal

\section{INSECTS}

Significant dietary component

\section{MILK}

Fermented milk (Amasi) in general use

\author{
MODERN STARCH \\ Maize (corn, mealies) \\ Rice \\ Bread \\ Pasta \\ Potatoes
}

MEAT

Sources are purchase from a butchery, from own livestock or occasionally from the wild

Meat eaten on a weekly basis

Cattle as well as other material possessions and money seen as indicators of wealth

Cattle still used as a communication medium with ancestors although this no longer appears to be general practice

\section{VEGETABLES}

Obtained from shops, the wild or home-grown

Vegetables for sale often not obtainable

Larger selection

Characteristically seasonal although alternate sources are available, for example, processed

Vegetables used in Western styled dishes such as French Salad

FRUIT

Fruit comes from the wild, own cultivation and from shops

Availability depends on seasonal production, supplemented by purchases from shops and markets.

\section{INSECTS}

Although still eaten in small quantities, other protein sources have replaced insects as a major nutritional element

MILK

Nowadays fresh milk preferred rather than Amasi.

Powdered milk also used 


\section{BEVERAGES}

Traditional beer drinking follows strict rules and conventions

Water also consumed

\section{CONVENIENCE FOOD}

Convenience food not available. Food was only procured from the wild or through subsistence production

\section{MEALS PER DAY \\ Two \\ Late morning and early evening \\ EFFECT OF THE SEASONS \\ Important impact on availability}

WEEKSDAYS, SATURDAYS AND SUNDAYS

Eating habits do not differ on different days of the week

\section{BEVERAGES}

Traditional beer is still drunk although not as much as in the past

Intake of commercial alcoholic beverages is on the increase especially among women

Fruit juice and aerated cold drinks also popular

\section{CONVENIENCE FOOD}

Nowadays the Xhosa make use of a wide range of convenience foods such as canned food, cold meats, cooked meals and sandwiches

Convenience food purchased in shops and at markets

\section{MEALS PER DAY \\ Three \\ Breakfast, lunch and supper \\ EFFECT OF THE SEASONS \\ Seasonal change has an effect but purchases can compensate for shortages}

\section{WEEKSDAYS, SATURDAYS AND SUNDAYS}

Work commitments and cultural beliefs influence eating patterns on different days of the week 


\section{Appendix 4: Research Instrument A}

\section{Questionnaire}

We would like to take this opportunity to thank you for your time and effort in agreeing to participate in this research. This study aims to analyze the ways in which Kwam eMakana tourism home-stays have and continue to contribute to local economic development. Recommendations will be derived from this data on how to further develop and improve the initiative.

\section{Section A}

1. Please select your age group below

$\square 21-30 \quad \square 31-40 \quad \square 41-50 \quad \square 51-60 \quad \square 61-70$

$\square$ Other [please

specify]......

2. What is your racial background?

$\square$ Native African $\quad \square$ Colored $\quad \square$ Indian $\square$ Asian $\quad \square$ White

$\square$ Other [please

specify]

3. What is your marital status?

$\square$ Single $\quad \square$ Married $\quad \square$ Separated $\quad \square$ Divorced $\quad \square$ Widowed

4. Are you the bread winner in your home?

$\square$ Yes

$\square$ No

5. What is your highest educational qualification?

$\square$ Grade $7 \quad \square$ Grade $10 \quad \square$ Matric $\square$ Certificate $\square$ Diploma $\square$ Degree

$\square$ Other [please specify]

6. How many children do you have?

$\square 1 \quad \square 2 \quad \square 3 \quad \square 4 \quad \square 5$

$\square$ Other [please specify]

7. How many dependants do you have that live with you in your home?

$\square 1 \quad \square 2 \quad \square 3 \quad \square 4 \quad \square 5$

$\square$ Other [please specify].

8. Please indicate if currently you are 
$\square$ Employed full-time $\quad \square$ Employed part-time $\quad \square$ Self-employed
$\square$ Unemployed $\quad \square$ Pension $\quad \square$ Retired

9. Prior to 1994 what was your occupation?

$\square$ Domestic worker $\quad \square$ Shop Assistant $\quad \square$ Factory worker $\quad \square$ School teacher

Housewife

$\square$ Other [please specify]

\section{Section B}

10. How long have you been operating your KWAM eMakana home-stay?

$\square 1 \quad \square 2 \quad \square 3 \quad \square 4 \quad \square 5$

$\square$ Other [please specify].

11. How many bedrooms do you have for guests in your KWAM eMakana home-stay?

$\square 1 \quad \square 2 \quad \square 3 \quad \square 4 \quad \square 5$

$\square$ Other [please specify]

12. What is the maximum number of guests that you can have in your KWAM eMakana home-stay?

$\square 2 \quad \square 3 \quad \square 4 \quad \square 5 \quad \square 6 \quad \square 7 \quad \square 8$

$\square$ Other [please specify].

13. Do you employ people to help you with the domestic work in your KWAM eMakana home-stay?

$\square$ Yes $\square$ No

If you answered No please proceed straight to Question 16

14. If yes to Question 13 how many people do you employ?

$\square 1 \quad \square 2 \quad \square 3 \quad \square 4 \quad \square 5$

$\square$ Other [please specify]

15. What type of contract do you have for your employees?

$\square$ Employed full-time $\quad \square$ Employed part-time $\quad \square \mathrm{Ad} \mathrm{Hoc}$ 
16. If yes to Question 13 how much do you pay your employees per day?

$\square 20$ Rand $\quad \square 50$ Rand $\quad \square 80$ Rand $\quad \square 100$ Rand

$\square$ Other [please specify]

17. Do your family members help you with the general work of the KWAM eMakana home-stay?

$\square$ Yes $\square$ No

If you answered No please proceed straight to Question 19

18. If yes to Question 16 how many family members help you with the cleaning and preparation of the KWAM eMakana home-stay?

$\square 1 \quad \square 2 \quad \square 3 \quad \square 4 \quad \square 5$

Other [please specify]

19. Since the opening of your KWAM eMakana home-stay are you able to pay your utility bills and/or accounts on time as a result of the additional income you receive? $\square$ Yes $\quad \square$ No

20. What home improvements have you been able to make as a result of the additional income you receive from the KWAM eMakana home-stay?

$\square$ Washing Machine $\quad \square$ Stove $\quad \square$ Fridge $\quad \square$ Lounge Suite $\quad \square$ Bedroom Suite

$\square$ Other [please specify]

21. As a result of the income you receive from your KWAM eMakana home-stay have you made any structural changes to your home?

$\square$ Yes $\quad \square$ No

If you answered No please proceed straight to Question 23

22. If yes to Question 20 please indicate if it is a

$\square 1$ room extension $\quad \square 2$ room extension $\quad \square 3$ room extension $\quad \square 4$ room extension $\square$ Other [please specify]. 
23. As a result of the additional income you receive from your KWAM eMakana homestay do you have more savings in the bank?

$\square$ Yes

$\square$ No

24. As a result of the additional income you receive from your KWAM eMakana homestay do you have more financial investments?

$\square$ Yes $\quad \square$ No

25. After opening your KWAM eMakana home-stay have you been able to start another income generating projects?

$\square$ Yes $\quad \square$ No

If you answered No please proceed straight to Question 27

26. What type of income generating projects have you opened?

$\square$ Catering $\quad \square$ Sewing $\quad \square$ Spaza/Kiosk

$\square$ Other [please specify].

27. What other opportunities has your KWAM eMakana home-stay brought you?

\section{Section C}

28. When is the busiest period your KWAM eMakana home-stay?

$\square$ Grahamstown Festival $\quad \square$ Christmas Festival Period $\quad \square$ Easter Period

$\square$ Other [please specify]

29. Would you like to have more guests visit your KWAM eMakana home-stay throughout the year?

$\square$ Yes $\quad \square$ No 
30. How do the guests that visit you know of your KWAM eMakana home-stay? $\square$ Grahamstown Tourism Office $\square$ Friends \& Family $\square$ Word of Mouth $\quad \square$ Local Church

$\square$ Other [Please specify]

31. Have you made any promotional material for your KWAM eMakana home-stay? $\square$ Yes $\square$ No

If you answered No please proceed straight to Question 33

32. If yes, please select from the options listed $\square$ Posters $\quad \square$ Flyers $\quad \square$ Business Cards

$\square$ Other [please specify].

33. Do you think you are doing enough to attract guests to your KWAM eMakana home-stay?

$\square$ Yes $\quad \square$ No

34. Is the government helping you to get guests for your KWAM eMakana home-stay? $\square$ Yes $\square$ No

35. Do you think the government could do more to help you get more people KWAM eMakana home-stay?

$\square$ Yes $\quad \square$ No 
Section D

\begin{tabular}{|c|c|c|c|c|}
\hline & 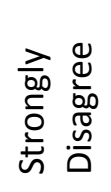 & 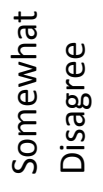 & 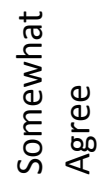 & 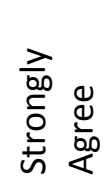 \\
\hline $\begin{array}{l}\text { 36. I know when to speak about my personal problems to } \\
\text { others. }\end{array}$ & 1 & 2 & 3 & 4 \\
\hline $\begin{array}{l}\text { 37. When I am faced with obstacles, I remember times I faced } \\
\text { similar obstacles and overcame them. }\end{array}$ & 1 & 2 & 3 & 4 \\
\hline 38. I expect that I will do well on most things. & 1 & 2 & 3 & 4 \\
\hline 39. Other people find it easy to confide in me. & 1 & 2 & 3 & 4 \\
\hline $\begin{array}{l}\text { 40. I find it easy to understand the non-verbal messages of } \\
\text { other people. }\end{array}$ & 1 & 2 & 3 & 4 \\
\hline $\begin{array}{l}\text { 41. Some of the major events of my life have led me to re- } \\
\text { evaluate what is important and not important. }\end{array}$ & 1 & 2 & 3 & 4 \\
\hline 42. When my mood changes, I see new possibilities. & 1 & 2 & 3 & 4 \\
\hline 43. Emotions are one of the things that make life worth living. & 1 & 2 & 3 & 4 \\
\hline 44. I am aware of my emotions as I experience them. & 1 & 2 & 3 & 4 \\
\hline 45. I expect good things to happen. & 1 & 2 & 3 & 4 \\
\hline 46. I like to share my emotions with people. & 1 & 2 & 3 & 4 \\
\hline $\begin{array}{l}\text { 47. When I experience a positive emotion, I know how to } \\
\text { make it last. }\end{array}$ & 1 & 2 & 3 & 4 \\
\hline 48. I arrange events others enjoy. & 1 & 2 & 3 & 4 \\
\hline 49. I seek out activities that make me happy. & 1 & 2 & 3 & 4 \\
\hline 50. I am aware of the non-verbal messages I send to others. & 1 & 2 & 3 & 4 \\
\hline $\begin{array}{l}\text { 51. I present myself in a way that makes a good impression on } \\
\text { others. }\end{array}$ & 1 & 2 & 3 & 4 \\
\hline $\begin{array}{l}\text { 52. When I am in a positive mood, solving problems is easy } \\
\text { for me. }\end{array}$ & 1 & 2 & 3 & 4 \\
\hline $\begin{array}{l}\text { 53. By looking at facial expressions, I can recognize the } \\
\text { emotions that others are feeling. }\end{array}$ & 1 & 2 & 3 & 4 \\
\hline 54. I know why my emotions change. & 1 & 2 & 3 & 4 \\
\hline $\begin{array}{l}\text { 55. When I am in a positive mood, I am able to come up with } \\
\text { new ideas. }\end{array}$ & 1 & 2 & 3 & 4 \\
\hline 56. I have control over my emotions. & 1 & 2 & 3 & 4 \\
\hline 57. I easily recognize my emotions as I experience them & 1 & 2 & 3 & 4 \\
\hline $\begin{array}{l}58 \text { I motivate myself by imagining a good outcome to the } \\
\text { tasks I do }\end{array}$ & 1 & 2 & 3 & 4 \\
\hline $\begin{array}{l}\text { 59. I compliment others when they have done something } \\
\text { well. }\end{array}$ & 1 & 2 & 3 & 4 \\
\hline 60. I am aware of the non-verbal messages other people send & 1 & 2 & 3 & 4 \\
\hline $\begin{array}{l}\text { 61. When another person tells me about an important event } \\
\text { in their life, I almost feel as though I have experienced } \\
\text { this event myself. }\end{array}$ & 1 & 2 & 3 & 4 \\
\hline
\end{tabular}




\begin{tabular}{|l|c|c|c|c|}
\hline $\begin{array}{l}\text { 62. When I feel a change in emotions, I tend to come up with } \\
\text { new ideas. }\end{array}$ & 1 & 2 & 3 & 4 \\
\hline $\begin{array}{l}\text { 63. When I am faced with a challenge, I usually rise to the } \\
\text { occasion. }\end{array}$ & 1 & 2 & 3 & 4 \\
\hline $\begin{array}{l}\text { 64. I know what other people are feeling just by looking at } \\
\text { them }\end{array}$ & 1 & 2 & 3 & 4 \\
\hline 65. I help other people feel better when they are down. & 1 & 2 & 3 & 4 \\
\hline $\begin{array}{l}\text { 66. I use good moods to help myself keep trying in the face of } \\
\text { obstacles. }\end{array}$ & 1 & 2 & 3 & 4 \\
\hline $\begin{array}{l}\text { 67. I can tell how people are feeling by listening to the tone of } \\
\text { their voices. }\end{array}$ & 1 & 2 & 3 & 4 \\
\hline
\end{tabular}




\title{
Appendix 5: Research Instrument - Observations 1
}

\author{
Home-stay Day Visit
}

\begin{tabular}{|l|l|}
\hline \multicolumn{1}{l}{ Date: } \\
Time: \\
Location:
\end{tabular}




\section{Appendix 6: Research Instrument - Observations 2}

Home-stay Overnight Stay

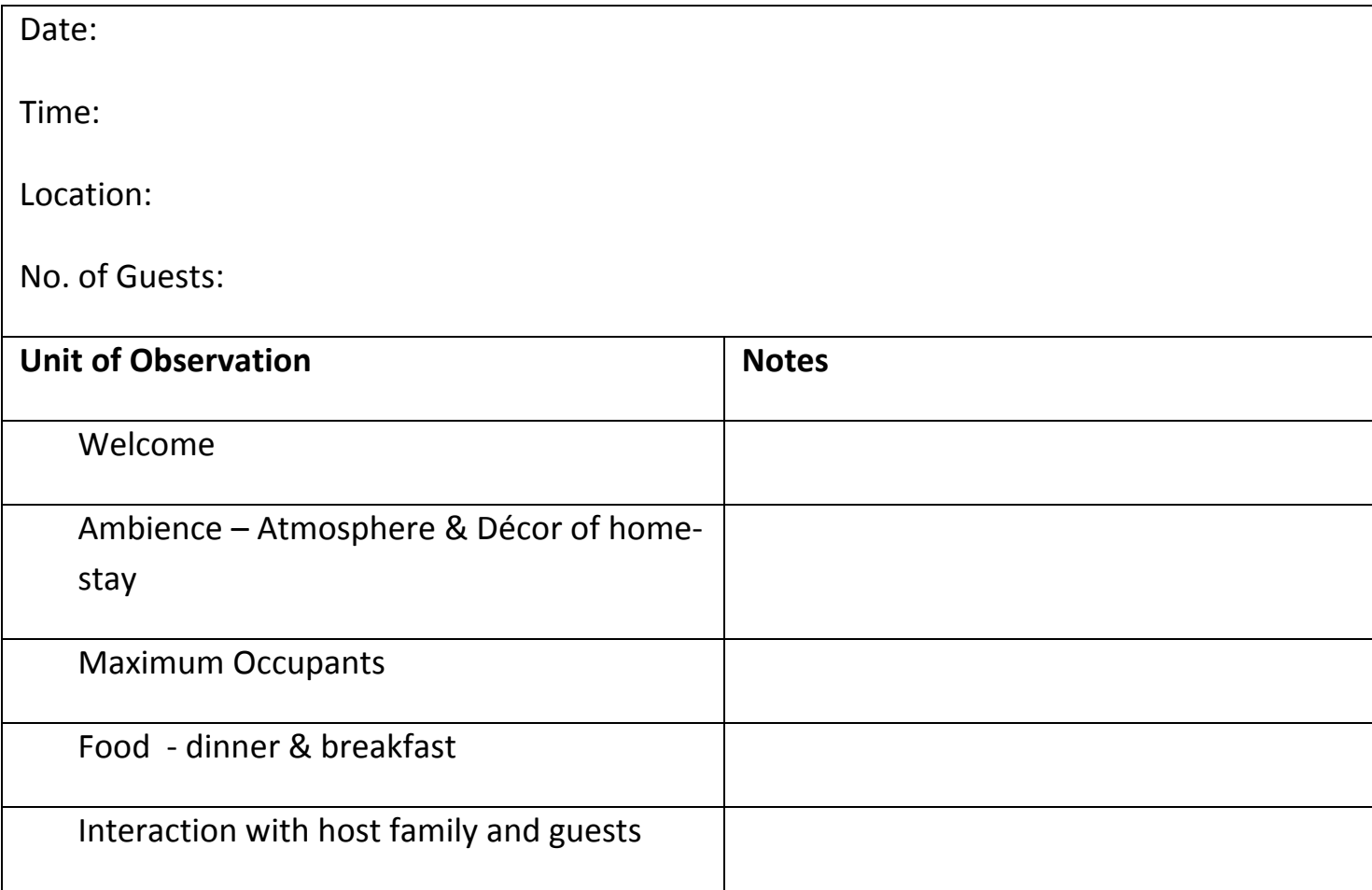




\section{Appendix 7: Research Instrument}

\section{Semi-structured Interview Schedule}

Place: Easter Cape, South Africa

Date: October - December 2009

Key Informants: Cross Section of Experts

Local Government Level Analysis;

Black Economic Empowerment

Local Economic Development

Entrepreneurship

Project Level Analysis;

Women operators role in Kwam eMakana

Challenges of leadership in Kwam eMakana and 


\title{
Appendix 8: Research Instrument - Discussion Session
}

\author{
Discussion Session Schedule
}

Place: Nduna Library; Joza Township

Date: $2^{\text {nd }}$ December 2009

Participants: Kwam eMakana women operators

\section{Project Level Analysis}

1) the experiences instrumental in the participants' role in the government LED initiative;

2) the participants' involvement in the development of their home-stays;

3) the participants' perceptions of their needs with regard to the future of the initiative and

4) the women operators' interpretation of the future of Kwam. 


\section{About the author}

Hazel M. Kwaramba holds a Higher Diploma from the International Hotel Management Institute (IMI), Switzerland and a Bachelor of Arts (Honours) degree in Hospitality Management with Tourism from the Manchester Metropolitan University, United Kingdom. She subsequently went on to complete a Master of Arts degree in Tourism, Planning and Development from the same university. Hazel is currently an associate with Biofil Technologies which specializes in promoting environmental protection and development. In 2010, she was included in the experts directory of the Africa Round Table on Sustainable Consumption and Production (ARSCP). She has also worked in the tourism industry in Geneva, in Manchester she worked as a research assistant at Manchester Metropolitan University. Hazel has published several papers on the tourism-poverty reduction nexus. 